\author{
UNIVERSIDADE DE SÃO PAULO \\ ESCOLA DE ENGENHARIA DE SÃO CARLOS \\ DEPARTAMENTO DE ENGENHARIA DE ESTRUTURAS \\ MESTRADO EM ENGENHARIA DE ESTRUTURAS
}

GEOVANNE VIANA NOGUEIRA

Formulação de elemento finito posicional para modelagem numérica de pórticos planos constituídos por compósitos laminados: uma abordagem não linear geométrica baseada na teoria Layerwise 



\section{Formulação de elemento finito posicional para modelagem numérica de pórticos planos constituídos por compósitos laminados: uma abordagem não linear geométrica baseada na teoria Layerwise}

\section{VERSÃO CORRIGIDA}

A versão original encontra-se na Escola de Engenharia de São Carlos

Dissertação apresentada ao Departamento de Engenharia de Estruturas da Escola de Engenharia de São Carlos, Universidade de São Paulo, para a obtenção do título de Mestre em Engenharia de Estruturas.

Área de Concentração: Engenharia de Estruturas

Orientador: Prof. Dr. Rodrigo Ribeiro Paccola 
AUTORIZO A REPRODUÇÃO TOTAL OU PARCIAL DESTE TRABALHO, POR QUALQUER MEIO CONVENCIONAL OU ELETRÔNICO, PARA FINS DE ESTUDO E PESQUISA, DESDE QUE CITADA A FONTE.

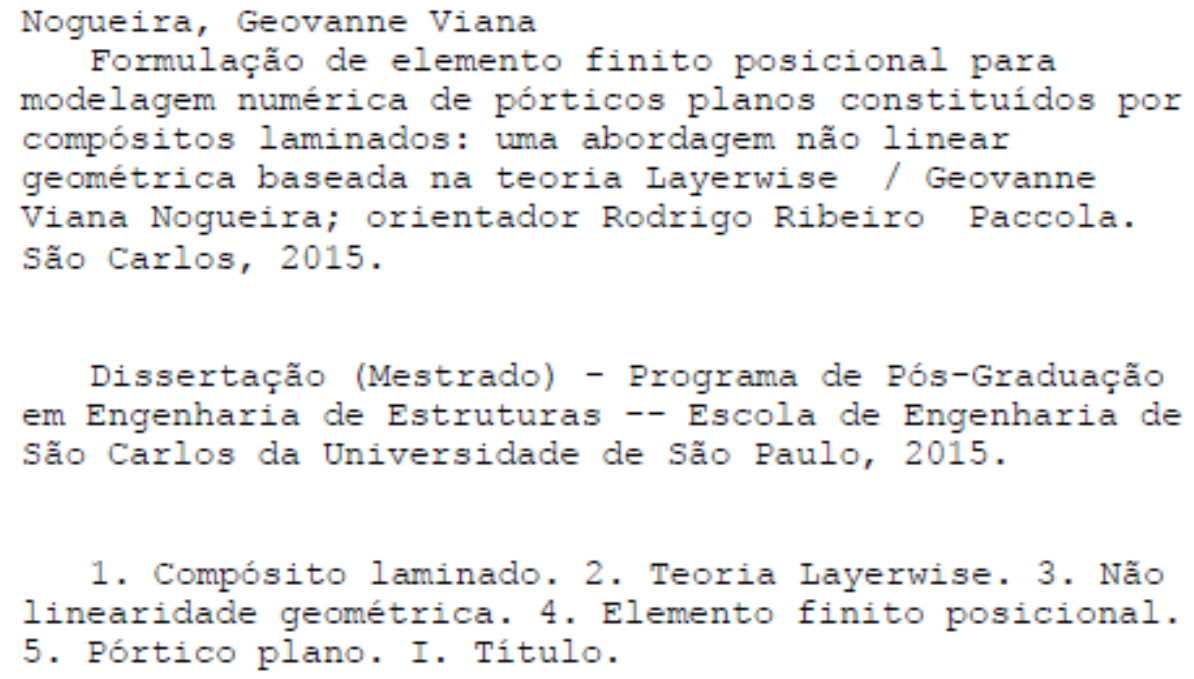




\section{FOLHA DE JULGAMENTO}

Candidato: Engenheiro GEOVANNE VIANA NOGUEIRA.

Título da dissertação: "Formulação de elemento finito posicional para modelagem numérica de pórticos planos constituídos por compósitos laminados: uma abordagem não linear geométrica baseada na teoria LAYERWISE"

Data da defesa: 30/04/2015

Comissāo Julgadora:

Prof. Dr. Rodrigo Ribeiro Paccola (Orientador)

(Escola de Engenharia de São Carlos/EESC)

Prof. Titular Humberto Breves Coda

(Escola de Engenharia de São Carlos/EESC)

Prof. Dr. Rodrigo Bresciani Canto

(Universidade Federal de São Carlos/UFSCar)
Resultado:

APROVADO

Aprovado

APROVADO

Coordenador do Programa de Pós-Graduação em Engenharia Civil (Engenharia de Estruturas):

Prof. Titular Humberto Breves Coda

Presidente da Comissāo de Pós-Graduação:

Prof. Associado Paulo César Lima Segantine 

Dedico este trabalho aos meus queridos pais, Geová e Sonha, às minhas irmãs, Glacyanne, Leidyanne, Leilyanne, Lilyanne e Lidianne, e a minha noiva Rafaelly. 



\section{AGRADECIMENTOS}

Em primeiro lugar, agradeço à Deus por ter me abençoado e dado força não só para elaborar este trabalho, mas também para superar todos os desafios encontrados ao longo do mestrado.

À minha família, por toda a compreensão, apoio irrestrito e carinho.

Faço um especial agradecimento aos professores Rodrigo Ribeiro Paccola e Humberto Breves Coda, por todo o conhecimento e experiência repassados, por terem me guiado no desenvolvimento deste trabalho e também pela amizade, parceria e paciência.

A todos os colegas, pelos momentos de conversa agradáveis que muito ajudaram a reduzir a tensão. Em especial, agradeço aos amigos Arthur Álax, Caio Cezar e Matheus Fernandes.

Ao Departamento de Engenharia de Estruturas da Escola de Engenharia de São Carlos, pela oportunidade de realização do curso de mestrado.

À CAPES, pela concessão da bolsa de mestrado e pelo apoio financeiro para a realização desta pesquisa. 



\section{RESUMO}

NOGUEIRA, G. V. Formulação de elemento finito posicional para modelagem numérica de pórticos planos constituídos por compósitos laminados: uma abordagem não linear geométrica baseada na teoria Layemvise. Dissertação (Mestrado em Engenharia de Estruturas) Departamento de Engenharia de Estruturas, Escola de Engenharia de São Carlos, Universidade de São Paulo, São Carlos, 2015.

A análise de compósitos laminados apresenta grandes desafios, pois, diferentemente dos materiais isotrópicos homogêneos, os compósitos laminados são constituídos de materiais heterogêneos e anisotrópicos. Além disso, as distribuições de tensões interlaminares obtidas com as formulações convencionais são descontínuas e imprecisas. Sua melhoria, portanto, é imprescindível para buscar e modelar critérios de falha relacionados às estruturas formadas por compósitos laminados. Diante disso, este trabalho se concentrou no desenvolvimento e implementação computacional de um elemento finito posicional de pórtico plano laminado cuja cinemática é descrita ao longo da espessura do laminado de acordo com a teoria Layerwise. A formulação do elemento considera a não linearidade geométrica, originada pela ocorrência de grandes deslocamentos e rotações, e admite deformações moderadas, em função da lei constitutiva de Saint-Venant-Kirchhoff. O desenvolvimento deste trabalho se iniciou com uma preparação teórica sobre mecânica dos sólidos deformáveis e métodos numéricos para que fossem adquiridos os subsídios teóricos necessários ao desenvolvimento de códigos computacionais, à interpretação dos resultados e à tomada de decisões quando das análises numéricas. A formulação desenvolvida é Lagrangiana total com emprego do método dos elementos finitos baseado em posições. Inicialmente o elemento finito posicional de pórtico plano homogêneo é proposto, uma vez que sua cinemática possibilita uma expansão natural para o caso laminado. Os graus de liberdade são compostos por posições nodais e por vetores generalizados que representam o giro e a variação na altura da seção transversal. A eficiência do elemento é constatada através de análises realizadas em problemas de pórtico sujeitos a grandes deslocamentos e rotações. Os resultados obtidos apresentaram excelente concordância com soluções numéricas e analíticas disponíveis na literatura. Uma expansão natural da cinemática é empregada na formulação do elemento laminado. Os graus de liberdade do elemento são as posições nodais e as componentes de vetores generalizados associados às seções transversais de cada lâmina. Dessa forma, as lâminas têm liberdade para variação de espessura e giro independente das demais, mas com as posições compatibilizadas nas interfaces. Os resultados de análises numéricas realizadas em vários exemplos demonstram a eficiência da formulação proposta, pois as distribuições de deslocamentos e tensões ao longo da espessura do laminado apresentaram excelente concordância com as obtidas a partir de análises numéricas utilizando um elemento finito bidimensional em uma discretização bastante refinada. Os exemplos analisados contemplam problemas com seção laminada fina ou espessa.

Palavras-chave: Compósito laminado. Teoria Layerwise. Não linearidade geométrica. Elemento finito posicional. Pórtico plano. 



\section{ABSTRACT}

NOGUEIRA, G. V. Positional finite element formulation for numerical modeling of frames made of laminated composites: a geometric nonlinear approach based on Layerwise theory. Dissertação (Mestrado em Engenharia de Estruturas) - Departamento de Engenharia de Estruturas, Escola de Engenharia de São Carlos, Universidade de São Paulo, São Carlos, 2015.

The analysis of laminated composites presents challenges because, unlike homogeneous isotropic materials, the laminated composites are made up of heterogeneous and anisotropic materials. Moreover, the distribution of interlaminar stresses obtained with conventional formulations are discontinuous and inaccurate. His improvement is therefore essential to check and modeling failure criteria related to structures formed by laminates. Thus, this work focused on developing and computational implementation of a positional finite element of laminated plane frame whose kinematics is described throughout the thickness of the laminate according to Layerwise theory. The formulation element considers the geometric nonlinearity, caused by the occurrence of large displacements and rotations, and admits moderate deformation, in the constitutive law function of Saint-Venant-Kirchhoff. The development of this work began with a theoretical preparation on mechanics of deformable solids and numerical methods for the acquired of the theoretical support needed for the development of computational codes, interpretation of results and decision-making when of the numerical analyzes. The developed formulation is total Lagrangian with use of the finite element method based on positions. Initially the positional finite element of homogeneous plane frame is proposed, since their kinematic enables a natural expansion for the laminate case. The degrees of freedom are composed of nodal positions and generalized vectors representing the spin and the variation in the height of the cross section. The efficiency of the element is verified through analyzes performed in frame problems subject to large displacements and rotations. The results showed excellent agreement with numerical and analytical solutions available in the literature. A natural expansion of the kinematics is used in the formulation of the laminate element. The degrees of freedom of the element are the nodal positions and components of the generalized vectors associated to cross-sections of each lamina. Thus, the laminas are free for the thickness variation and for independent spin, but with the positions matched in the interfaces. The results of numerical analysis performed in various examples show the effectiveness of the proposed formulation, since the distributions of displacements and stresses through the thickness of the laminate agreed well with those obtained from numerical analysis using a discretization with two-dimensional finite elements in a very refined. The examples discussed include problems with thin or thick laminated section.

Keywords: Composite laminate. Layerwise theory. Geometric nonlinearity. Positional finite element. Plane frame. 



\section{LISTA DE FIGURAS}

Figura 1 - Deslocamentos e tensões transversais ao longo de uma seção homogênea e laminada 28

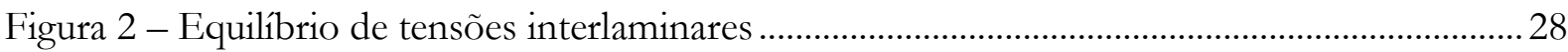

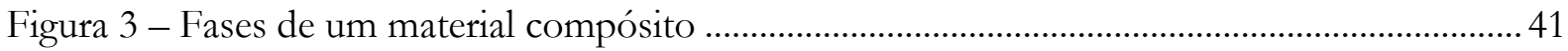

Figura 4 - Classificação dos compósitos em função do tipo de reforço (adaptado) ......................... 42

Figura 5 - Nomenclatura do esquema de laminação........................................................................... 45

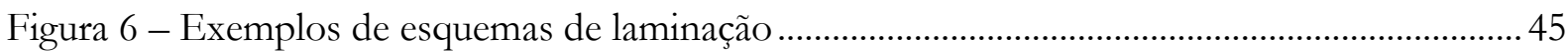

Figura 7 - ${ }^{*}$ Compósito do tipo sanduíche: (A) painel, (B) faces e (C) núcleo em forma de colmeia

Figura 8 - Níveis de análise em estruturas formadas por materiais compósitos

Figura 9 - Cinemática das teorias CLT, FSDT e HSDT (esq.) e deformações e tensões das teorias

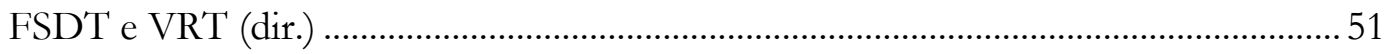

Figura 10 - Interpolação linear dos deslocamentos na teoria Layerwise ............................................. 52

Figura 11 - Deslocamentos no plano das lâminas ao longo da espessura segundo as teorias ESL e Layerwise. 53

Figura 12 - Configurações importantes para identificação das descrições Lagrangianas .77

Figura 13 - Configurações na descrição Lagrangiana total................................................................... 77

Figura 14 - Configurações na descrição Lagrangiana atualizada ......................................................... 78

Figura 15 - Configurações na descrição corrotacional.................................................................... 79

Figura 16 - Funções de mapeamento das configurações inicial e atual.............................................. 81

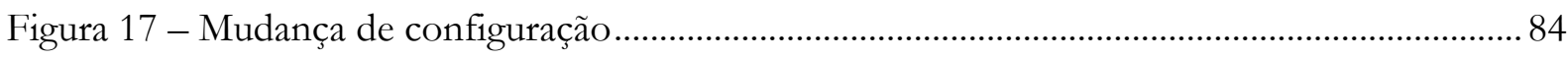

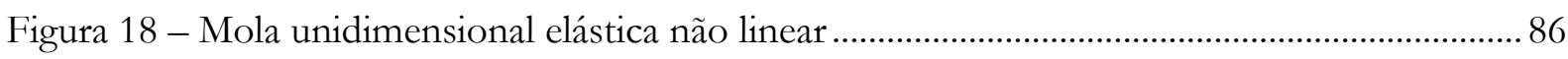

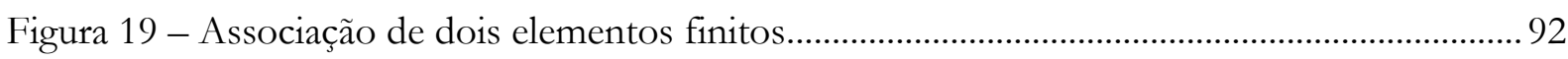

Figura 20 - Fluxograma básico do método de Newton-Raphson.................................................... 99

Figura 21 - Mapeamento posicional do elemento de pórtico plano homogêneo ............................. 102

Figura 22 - Mapeamento posicional de um ponto qualquer na configuração inicial ..................... 103

Figura 23 - Mapeamento posicional de um ponto qualquer na configuração atual .......................105

Figura 24 - Carga distribuída e forças nodais equivalentes ............................................................... 107

Figura 25 - Binários correspondentes ao momento concentrado ......................................................109

Figura 26 - Associação de dois elementos finitos de pórtico plano homogêneo .............................112

Figura 27 - Modelo de acoplamento entre elementos .......................................................................115

Figura 28 - Exemplos de possibilidades para ligação entre elementos............................................116 
Figura 29 - Identificação das rotações de um vetor generalizado nodal.......................................... 117

Figura 30 - Geometria, carregamento e parâmetros elásticos do Exemplo 4.1 ............................... 124

Figura 31 - Trajetória de equilíbrio para a viga com força concentrada ........................................125

Figura 32 - Trajetória de equilíbrio para a viga com momento concentrado.................................. 126

Figura 33 - Trajetória de equilíbrio para a viga com força distribuída ..............................................126

Figura 34 - Configurações deslocadas das vigas em balanço para alguns incrementos de carga ........

Figura 35 - Geometria, carregamento e parâmetros elásticos do Exemplo 4.2 ………………....... 129

Figura 36 - Trajetória de equilíbrio para o quadro em forma de losango...................................... 131

Figura 37 - Trajetória de equilíbrio para o quadro em forma de quadrado......................................132

Figura 38 - Trajetória de equilíbrio para o arco achatado senoidal .................................................. 132

Figura 39 - Configurações atuais dos quadros e do arco para alguns incrementos de carga ou

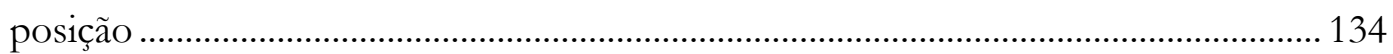

Figura 40 - Geometria, carregamento e parâmetros elásticos do Exemplo 4.3 ………………….... 136

Figura 41 - Trajetórias de equilíbrio para o pórtico com apoios simples (superior). Trecho inicial (inferior).

Figura 42 - Trajetórias de equilíbrio para o pórtico com apoios simples com uma rigidez elástica à rotação (superior). Trecho inicial (inferior).

Figura 43 - Trajetórias de equilíbrio para o pórtico com apoios engastados (superior). Trecho inicial (inferior).

Figura 44 - Mapeamento posicional do elemento de pórtico plano laminado 144

Figura 45 - Mapeamento posicional de um ponto qualquer da Lâmina de Referência na configuração inicial

Figura 46 - Mapeamento posicional de um ponto qualquer na configuração inicial de uma lâmina inferior à Lâmina de Referência. 146

Figura 47 - Mapeamento posicional de um ponto qualquer na configuração inicial de uma lâmina superior à Lâmina de Referência.

Figura 48 - Modelo de acoplamento entre elementos laminados ................................................. 166

Figura 49 - Sistemas de referência local e global no elemento laminado........................................ 169

Figura 50 - Geometria, carregamento e parâmetros elásticos para o problema do Exemplo 5.1 .......

Figura 51 - Resultados do Exemplo 5.1 para uma discretização com 4 elementos cúbicos e variação do número de lâminas (Caso $\operatorname{com} S=10)$. 
Figura 52 - Resultados do Exemplo 5.1: Deslocamento na direção 1 (u) para seção a 2,5 m do apoio esquerdo.

Figura 53 - Resultados do Exemplo 5.1: Tensão axial S11 para seção localizada no meio do vão.

Figura 54 - Resultados do Exemplo 5.1: Tensão axial S22 para seção localizada no meio do vão.

Figura 55 - Resultados do Exemplo 5.1: Tensão de cisalhamento S12 para seção a 2,5 m do apoio esquerdo.

Figura 56 - Resultados do Exemplo 5.1: Mapa de cores para os deslocamentos e tensões na viga $\operatorname{com} S=10$.

Figura 57 - Geometria, carregamento e parâmetros elásticos do problema: Exemplo 5.2

Figura 58 - Malhas de elementos finitos empregadas no Exemplo 5.2 para o caso $\operatorname{com} S=2$

Figura 59 - Resultados do Exemplo 5.2: Deslocamento na direção 1 (u) para seção a 2,5 m do apoio esquerdo.

Figura 60 - Resultados do Exemplo 5.2: Tensão axial S11 para seção localizada no meio do vão.

Figura 61 - Resultados do Exemplo 5.2: Tensão axial S22 para seção localizada no meio do vão.

Figura 62 - Resultados do Exemplo 5.2: Tensão de cisalhamento S12 para seção a 2,5 m do apoio esquerdo.

Figura 63 - Resultados do Exemplo 5.2: Mapa de cores para os deslocamentos e tensões na viga $\operatorname{com} S=2$. 192

Figura 64 - Geometria, carregamento e parâmetros elásticos do Exemplo 5.3 193

Figura 65 - Malhas de elementos finitos empregadas no Exemplo 5.3 para o Modelo ABA......194

Figura 66 - Resultados do Exemplo 5.3: Deslocamento na direção 1 (u) para seção a 2,5 m do apoio esquerdo.

Figura 67 - Resultados do Exemplo 5.3: Tensão axial S11 para seção a 2,5 m do apoio esquerdo.

Figura 68 - Resultados do Exemplo 5.3: Tensão axial S22 para seção a 2,5 m do apoio esquerdo.

Figura 69 - Resultados do Exemplo 5.3: Tensão de cisalhamento S12 para seção a 2,5 m do apoio esquerdo. 
Figura 70 - Resultados do Exemplo 5.3: Mapa de cores para os deslocamentos e tensões do

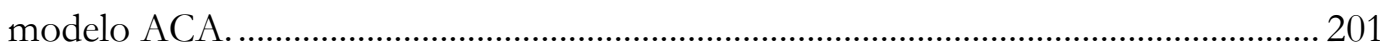

Figura 71 - Geometria, carregamento e parâmetros elásticos do Exemplo 5.4 …...........................203

Figura 72 - Trajetórias de equilíbrio para o pórtico com ligações semirrígidas analisado com o elemento laminado (superior). Trecho inicial (inferior)................................................... 204

Figura 73 - Resultados do Exemplo 5.4: Configurações atuais no último passo de carga........... 206

Figura 74 - Geometria, carregamento e parâmetros elásticos dos pórticos laminados. ................207

Figura 75 - Distribuição de deslocamentos longitudinais $u(\mathrm{~m})$ para algumas seções transversais do pórtico com cinco pavimentos. Resultados para o último incremento de carga.........

Figura 76 - Deslocamentos globais do pórtico com cinco pavimentos. Resultados para o último incremento de carga.

Figura 77 - Distribuição de deslocamentos longitudinais $u(\mathrm{~m})$ para algumas seções transversais do pórtico com um pavimento. Resultados para o último incremento de carga......209

Figura 78 - Deslocamentos globais do pórtico com um pavimento. Resultados para o último incremento de carga.

Figura 79 - Trajetórias de equilíbrio referente ao deslocamento horizontal $u$ (m) do nó superior esquerdo. 


\section{LISTA DE TABELAS}

Tabela 1 - Compósitos com fibras: materiais constituintes mais comuns ......................................... 44

Tabela 2 - Avaliação da quantidade de pontos de Gauss necessária para as integrações numéricas do elemento de pórtico plano laminado no Exemplo 5.1 ............................................. 174 



\section{LISTA DE SÍMBOLOS}

$\begin{array}{ll}\mathbf{f}^{0} & \text { função de mapeamento posicional da configuração inicial } \\ \mathbf{f}^{1} & \text { função de mapeamento posicional da configuração atual } \\ \left(\xi_{1}, \xi_{2}\right) & \text { sistema de coordenadas adimensionais } \\ \mathbf{f} & \text { função mudança de configuração } \\ \mathbf{u} & \text { função deslocamento } \\ \mathbf{x} & \text { vetor posição da configuração inicial } \\ \mathbf{y} & \text { vetor posição da configuração atual } \\ \mathbf{A} & \text { gradiente da função mudança de configuração }\end{array}$

$\mathbf{A}^{0} \quad$ gradiente da função de mapeamento posicional da configuração inicial

$\mathbf{A}^{1} \quad$ gradiente da função de mapeamento posicional da configuração atual

$x_{1} \quad$ posição da configuração inicial na direção 1

$x_{2} \quad$ posição da configuração inicial na direção 2

$y_{1} \quad$ posição da configuração atual na direção 1

$y_{2} \quad$ posição da configuração atual na direção 2

C tensor alongamento à direita de Cauchy-Green

$C_{i j} \quad$ tensor alongamento à direita de Cauchy-Green, em notação indicial

E tensor deformação de Green

$E_{i j} \quad$ tensor deformação de Green, em notação indicial

S

tensor tensão de Piola-Kirchhoff de segunda espécie

$S_{i j} \quad$ tensor tensão de Piola-Kirchhoff de segunda espécie, em notação indicial

I tensor identidade

$\varepsilon \quad$ tensor deformação linear

$u_{e} \quad$ energia específica de deformação

E módulo de elasticidade longitudinal

$v \quad$ coeficiente de Poisson

G módulo de elasticidade transversal

$\mathrm{V}_{0} \quad$ volume inicial

b largura da seção transversal 


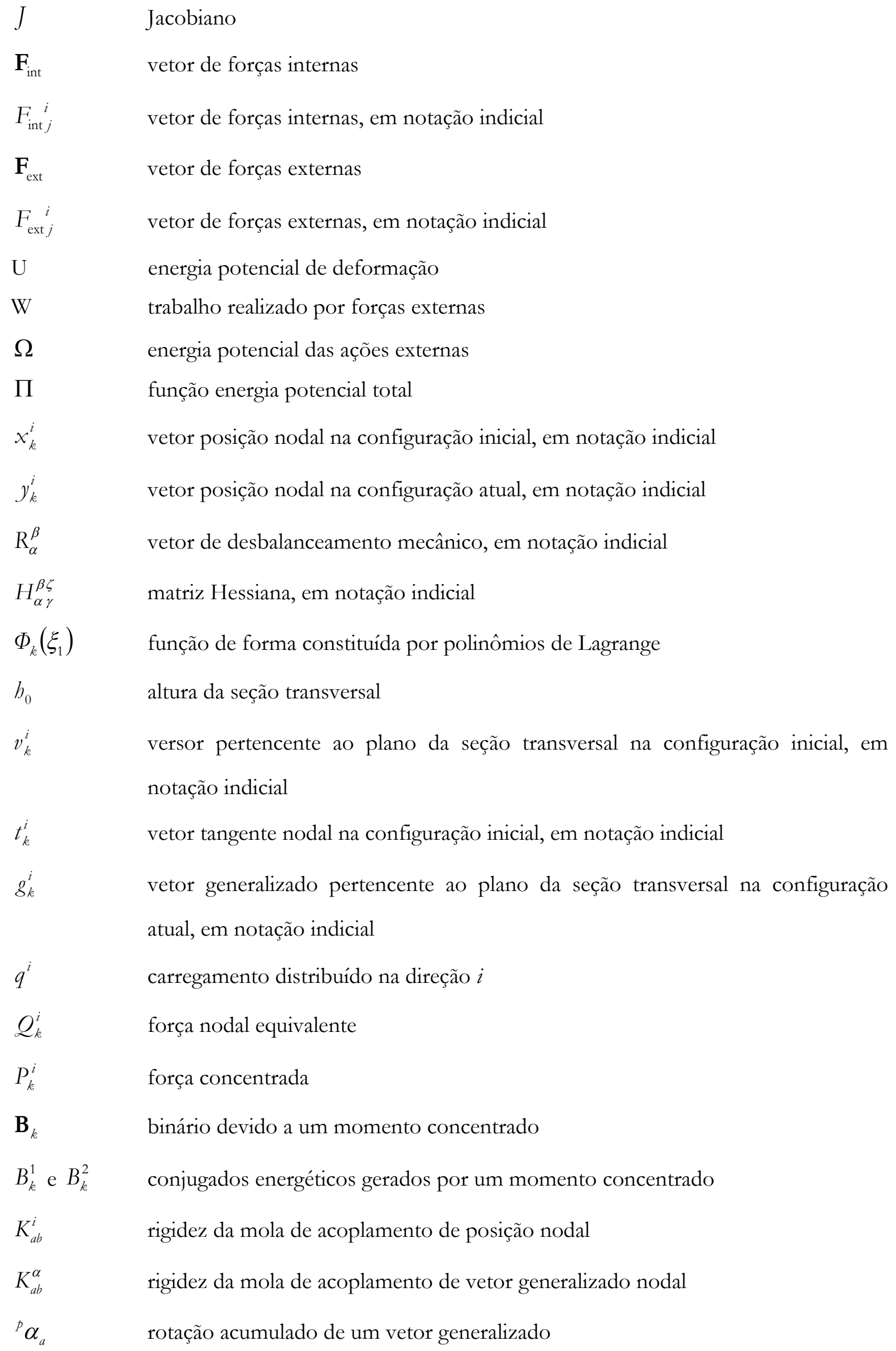




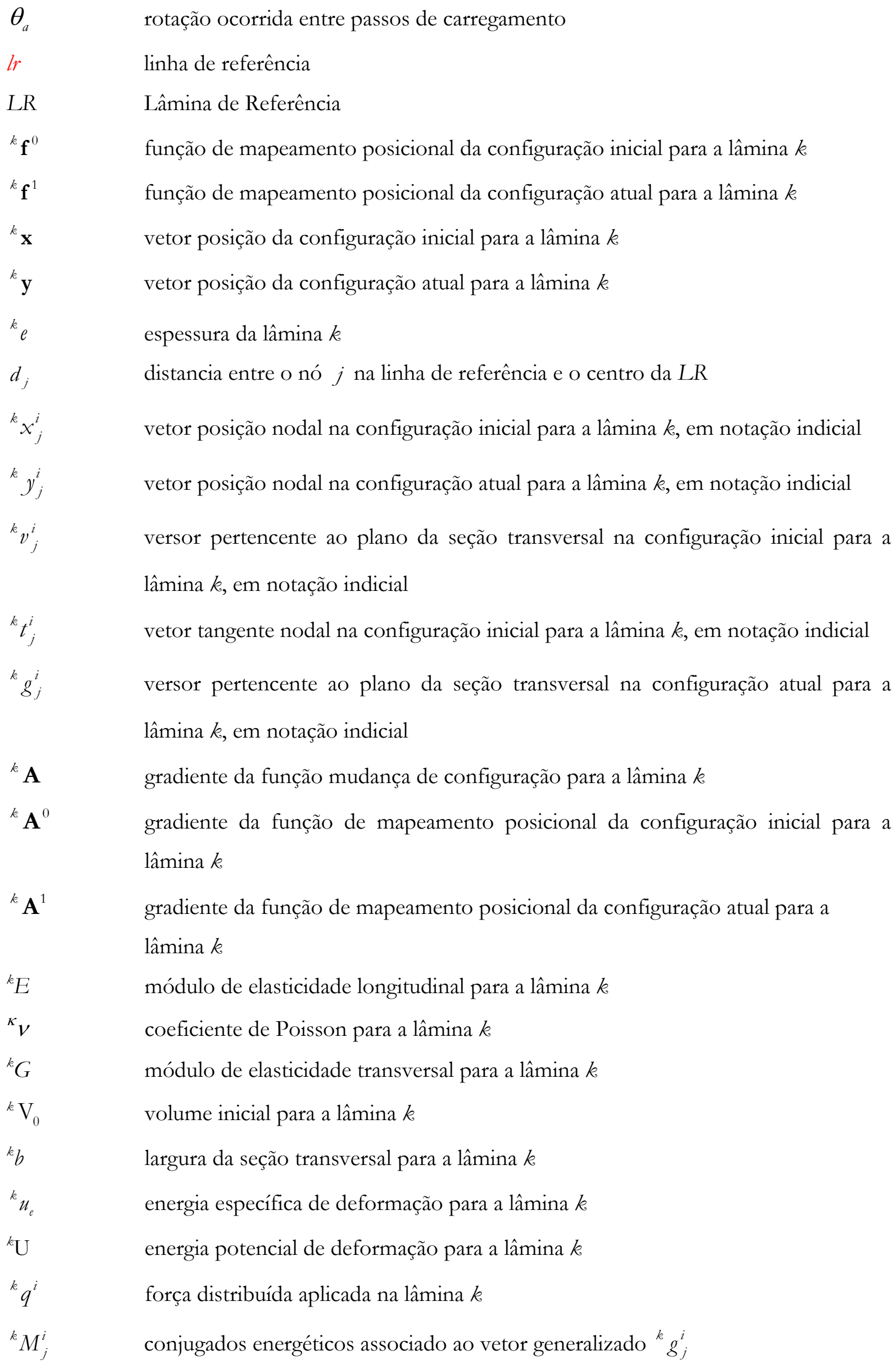


$M_{n} \quad$ momento concentrado aplicado na seção nodal $n$

${ }^{k} M_{n} \quad$ parcela de momento atribuída a lâmina k

kJacobiano associado à lâmina k

${ }^{k} K_{a b}^{\alpha} \quad$ rigidez da mola de acoplamento de vetor generalizado nodal para a lâmina $k$

${ }^{k} \mathbf{E} \quad$ tensor deformação de Green para a lâmina k

${ }^{k} \mathbf{S} \quad$ tensor tensão de Piola-Kirchhoff de segunda espécie para a lâmina k

${ }^{k} \mathbf{T} \quad$ tensor tensão de Cauchy para a lâmina k

$\mathbf{R}$ matriz de rotação do sistema de referência global para o local 


\section{SUMÁRIO}

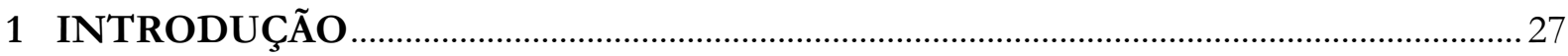

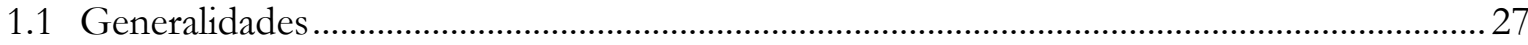

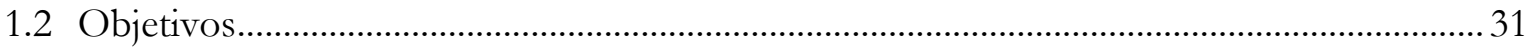

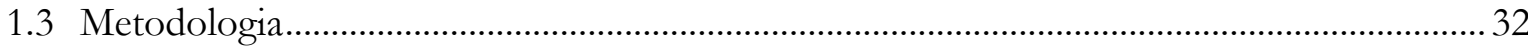

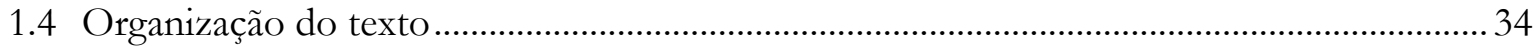

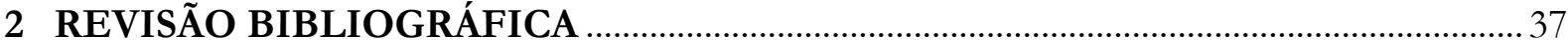

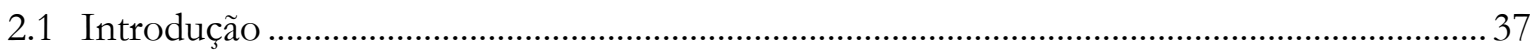

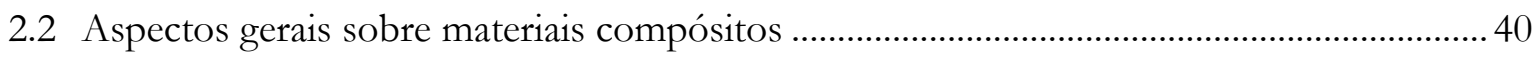

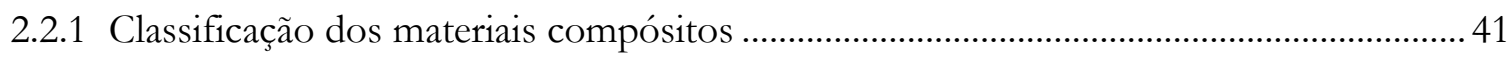

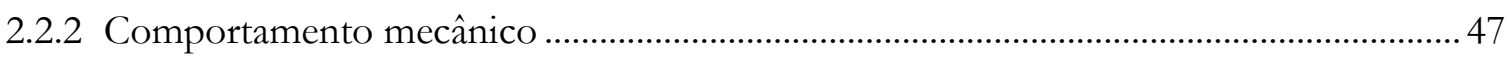

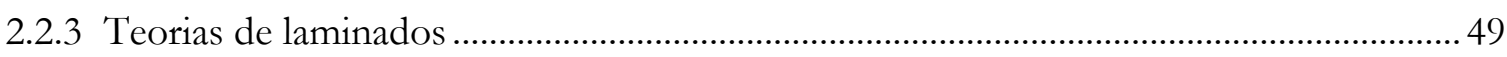

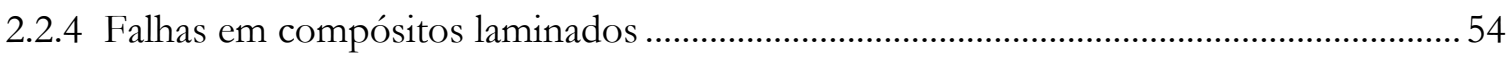

2.3 Formulações para análise de estruturas constituídas por compósitos laminados ................56

3 MÉTODO DOS ELEMENTOS FINITOS POSICIONAL APLICADO A MODELOS

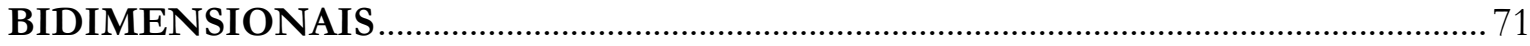

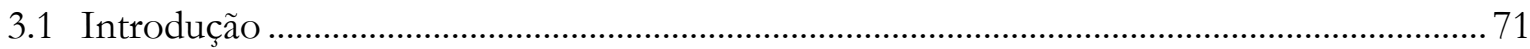

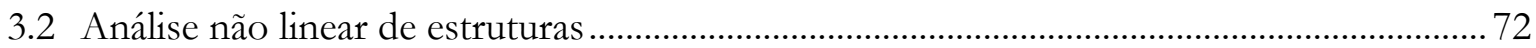

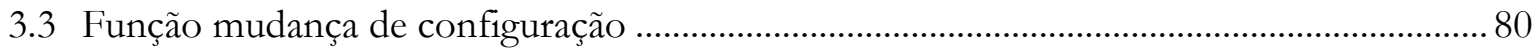

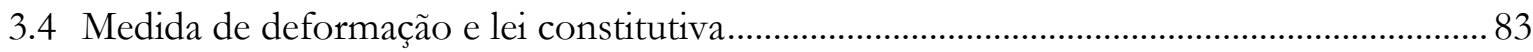

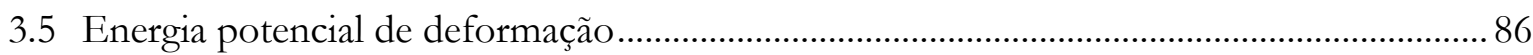

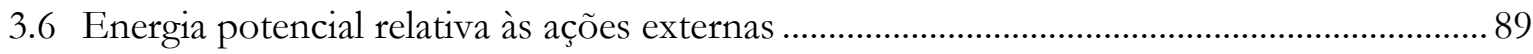

3.7 Energia potencial total e equações de equilíbrio .......................................................................... 91

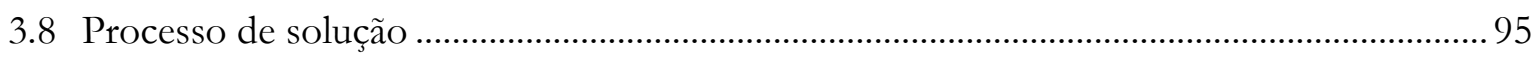

4 ELEMENTO FINITO DE PÓRTICO PLANO HOMOGÊNEO ................................. 101

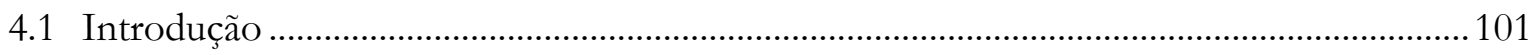

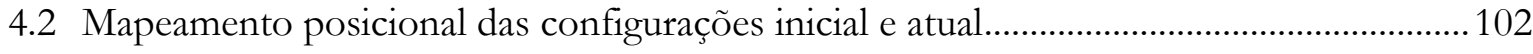

4.3 Particularidades do elemento de pórtico plano homogêneo.....................................................105

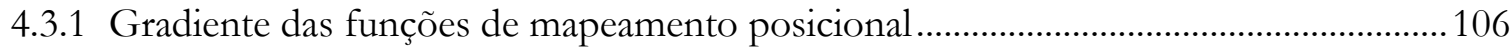

4.3.2 Energia potencial de deformação ……………………………………………………........ 106

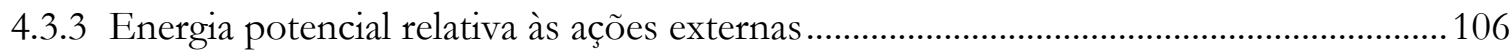

4.3.4 Energia potencial total e equações de equilíbrio..................................................................... 110

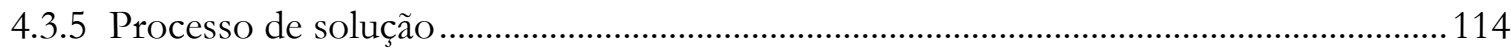


4.3.6 Ligações entre elementos não colineares.

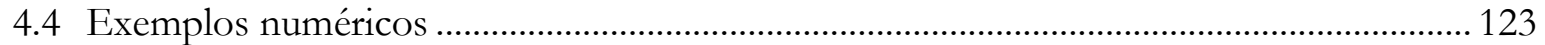

4.4.1 Exemplo 4.1: Viga em balanço solicitada por ações externas variadas ...........................124

4.4.2 Exemplo 4.2: Pórticos planos com diferentes geometrias e condições de contorno.128

4.4.3 Exemplo 4.3: Pórtico com ligações semirrígidas................................................................... 134

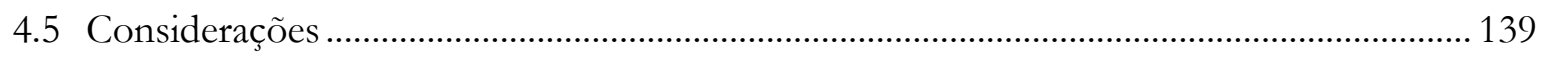

5 ELEMENTO FINITO DE PÓRTICO PLANO LAMINADO …................................. 141

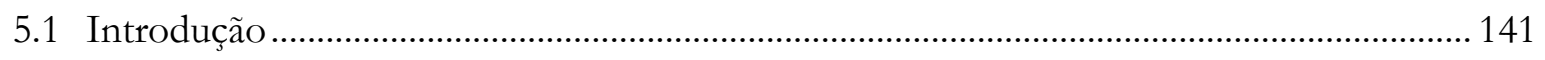

5.2 Mapeamento posicional das configurações inicial e atual .................................................. 143

5.3 Particularidades do elemento finito de pórtico plano laminado............................................ 150

5.3.1 Gradiente das funções de mapeamento posicional............................................................ 150

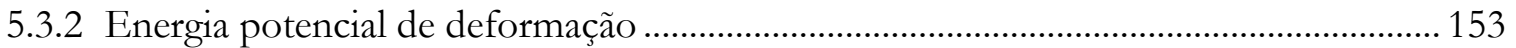

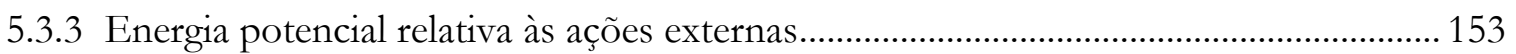

5.3.4 Energia potencial total e equações de equilíbrio ………………………………………....... 159

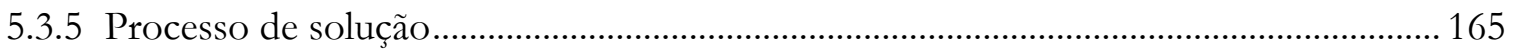

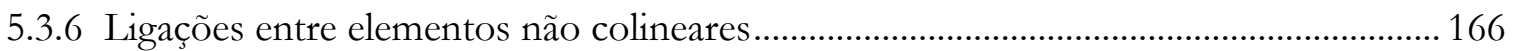

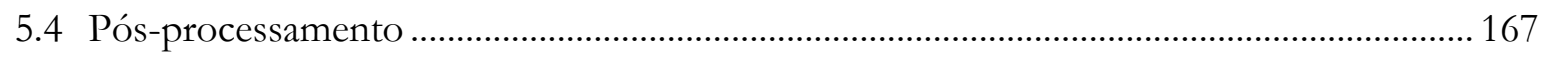

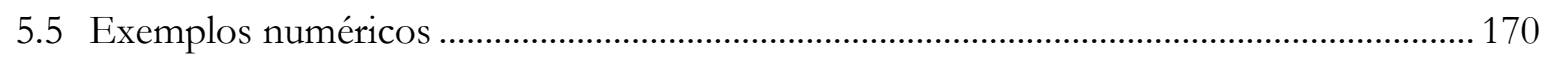

5.5.1 Exemplo 5.1: Viga homogênea biapoiada com força distribuída ................................... 171

5.5.2 Exemplo 5.2: Viga sanduíche biapoiada com força distribuída ...................................... 183

5.5.3 Exemplo 5.3: Viga sanduíche biapoiada com força concentrada ..................................... 193

5.5.4 Exemplo 5.4: Pórtico homogêneo com ligações semirrígidas........................................... 202

5.5.5 Exemplo 5.5: Pórticos laminados .......................................................................................... 206

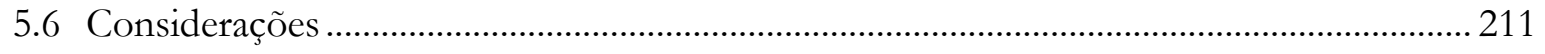

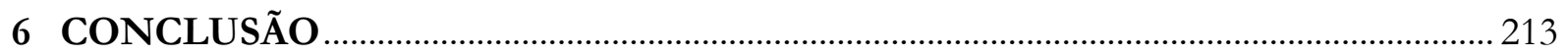

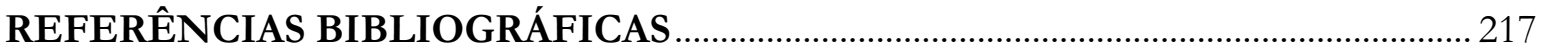




\section{CAPÍTULO 1}

\section{INTRODUÇÃO}

\subsection{Generalidades}

De acordo com Carrera (2002), qualquer teoria para análise de compósitos laminados, bem como um elemento finito desenvolvido com essa teoria, deve considerar os seguintes aspectos complexos de uma estrutura laminada: anisotropia no plano do laminado, heterogeneidade transversal, efeito Zig-Zag e continuidade interlaminar.

A anisotropia no plano do laminado surge quando as propriedades físicas e mecânicas se modificam conforme a direção considerada no plano. Laminados constituídos por compósitos de fibras apresentam elevada resistência e rigidez ao longo das fibras, mas essas propriedades são menores na direção transversal, pois praticamente só há a influência da matriz do compósito. Isso leva, segundo Carrera (2002), a uma elevada flexibilidade na direção transversal, tanto em relação ao cisalhamento como em relação às tensões axiais.

De acordo com Jones (1999) e Reddy (2004a), uma consequência mais relevante da anisotropia no plano das lâminas diz respeito ao acoplamento entre as deformações normais e cisalhantes que aumenta muito as dificuldades nos procedimentos de solução de estruturas laminadas. Jones (1999) e Reddy (2004a) também relatam que essa anisotropia pode produzir um acoplamento adicional entre as deformações contidas no plano e fora dele, levando à ocorrência de grandes deslocamentos mesmo para baixos níveis de carregamento.

A heterogeneidade transversal representa a mudança das propriedades físicas e mecânicas ao longo da espessura devido aos materiais diferentes empregados em cada lâmina. Nas interfaces, essa heterogeneidade produz descontinuidade da primeira derivada do campo de deslocamento em relação à coordenada ₹ (ou 3), localizada ao longo da espessura do laminado. Este comportamento é conhecido por efeito Zig-Zag como pode ser observado na Figura 1 para o caso de uma estrutura composta por três lâminas (CARRERA, 2002). 
Deslocamentos

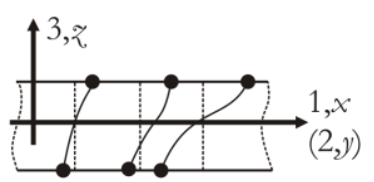

Seção Homogênea

$(\bullet$ Interface)
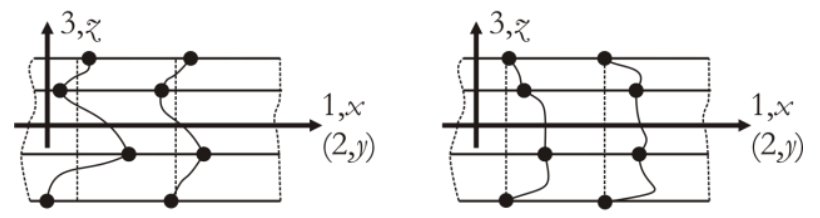

Seção Laminada

Figura 1 - Deslocamentos e tensões transversais ao longo de uma seção homogênea e laminada Fonte: Carrera (2002).

Segundo Reddy (2004a), a continuidade interlaminar surge do equilíbrio de forças entre as diversas lâminas do compósito (Figura 2), fazendo com que as tensões transversais sejam contínuas. Essa condição de continuidade leva a uma descontinuidade das deformações interlaminares desde que os materiais de lâminas adjacentes sejam distintos.

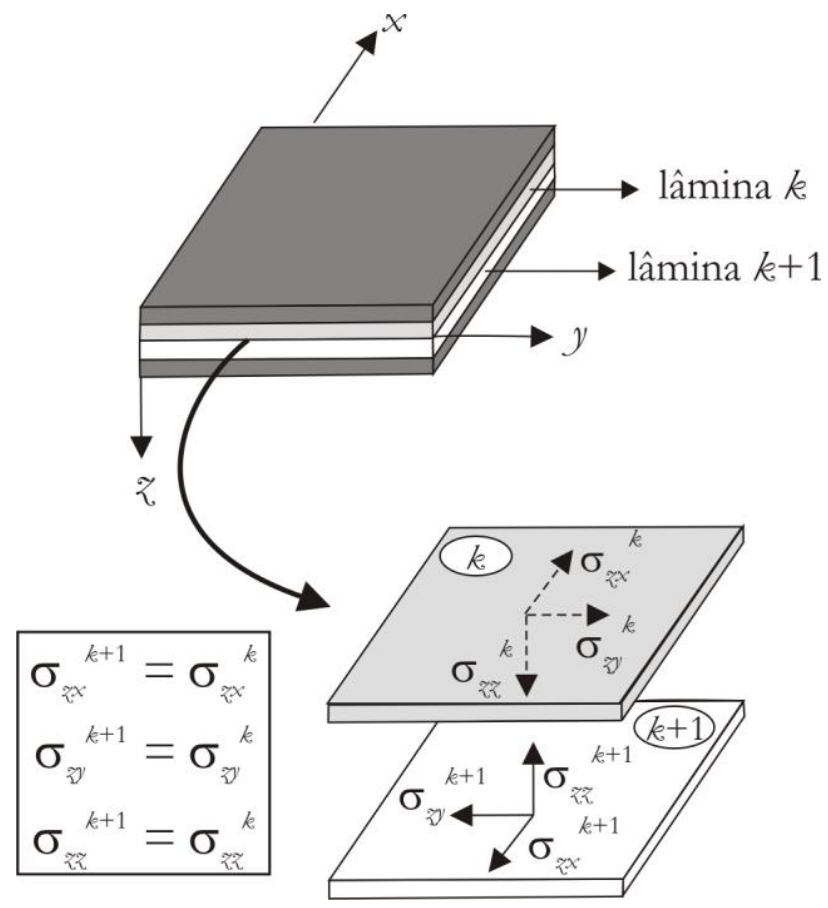

Figura 2 - Equilíbrio de tensões interlaminares

Fonte: Reddy (2004a).

Carrera (2002) denomina o efeito Zig-Zag e a continuidade interlaminar como condições de classe $C^{0}\left(C_{z}^{0}-\right.$ Requeriments). Ele também alerta que o atendimento a essas 
condições é imprescindível para o desenvolvimento de qualquer teoria adequada à análise de estruturas formadas por compósitos laminados.

Quando o objetivo da análise de estruturas laminadas de espessura fina a moderada é a obtenção de respostas globais como deslocamentos, cargas críticas de flambagem e frequências de vibração, por exemplo, as teorias de camada única equivalente (Equivalent Single Layer - ESL), que analisam o laminado considerando uma camada única com propriedades mecânicas equivalentes, fornecem aceitável precisão nos resultados. No entanto, essas teorias apresentam aplicação limitada quando se trabalha com laminados espessos ou quando há a necessidade de uma avaliação no nível das lâminas e de suas interfaces para identificar o processo de falha do compósito como, por exemplo, por delaminação ou deslizamento. Essa limitação ocorre porque as teorias ESL não são capazes de representar com precisão a distribuição das tensões ao longo da espessura e nas interfaces do compósito laminado (REDDY, 2004a).

Como visto anteriormente, devido à continuidade interlaminar, à anisotropia no plano das lâminas e à heterogeneidade transversal, as distribuições de tensões são contínuas e as deformações são descontínuas nas interfaces do laminado. As teorias ESL representam esse comportamento justamente de forma contrária, pois, ao tratar o laminado como uma única lâmina equivalente, as deformações obtidas ficam contínuas e as tensões descontínuas.

Assim, teorias que diferenciam as lâminas são mais adequadas, pois viabilizam o atendimento às condições de classe $C^{0}$ (CARRERA, 2002). Uma teoria bastante conhecida é a Layerwise cujas hipóteses cinemáticas consideram campos de deslocamentos independentes em cada lâmina, mas compatibilizados nas interfaces (REDDY, 2004a). Essas hipóteses geram uma distribuição de deformações transversais descontínuas nas interfaces, tornando possível a representação de tensões mais realistas principalmente para o caso de laminados espessos.

Outras questões importantes sobre os laminados dizem respeito aos efeitos não lineares. Os materiais compósitos laminados são leves e possuem elevada resistência e rigidez específicas. Assim, há uma tendência em se ter estruturas esbeltas e sujeitas a grandes deslocamentos e rotações. Como consequência, a análise do equilíbrio na configuração indeformada não é mais aceitável, tornando-se imprescindível o emprego de formulações que realizem a análise na configuração deformada da estrutura (não linearidade geométrica).

A hipótese de um comportamento linear para a relação tensão-deformação é bastante aceita e amplamente usada na engenharia, pois os materiais compósitos são fortemente lineares longe da situação de ruptura, com linearidade geralmente superior a dos metais (MENDONÇA, 2005). No entanto, quando o objetivo da análise é identificar a falha do material, os efeitos da não linearidade física podem ser importantes para a identificação realista desse fenômeno. 
Diante de tudo que foi discutido, conclui-se que a análise de compósitos laminados apresenta grandes desafios, pois as distribuições das tensões nas formulações convencionais são descontínuas e imprecisas e sua melhoria é imprescindível para definir eficientes critérios de falha relacionados às estruturas compósitas laminadas. Portanto, justifica-se o emprego de uma teoria discreta por lâminas além da consideração de efeitos não lineares, visto que a busca por uma formulação numérica que consiga representar de forma realista as distribuições de tensões ao longo da espessura e nas interfaces de um laminado deve considerar também a presença desses efeitos.

Neste trabalho, a formulação desenvolvida segue uma cinemática semelhante à adotada pela teoria de laminados Layerwise e utiliza o método dos elementos finitos posicional (CODA; PACCOLA, 2007; CODA, 2009; CODA; PACCOLA, 2011; PASCON; CODA, 2013; SAMPAIO, 2014) para a análise de pórticos planos laminados considerando a não linearidade geométrica. Dessa forma, espera-se obter uma distribuição de tensões mais realista ao longo da espessura e nas interfaces. A não linearidade física não é considerada, ficando como proposta para trabalhos futuros.

O método dos elementos finitos posicional é uma formulação de elementos finitos que trabalha com graus de liberdade em posição no lugar dos tradicionais deslocamentos. A formulação posicional possui como características relevantes o emprego de uma descrição Lagrangiana total e da medida de deformação de Green-Lagrange cujo conjugado energético é o tensor de tensões de Piola-Kirchhoff de segunda espécie. Essa medida de deformação é objetiva e adequada para representação de problemas sujeitos a grandes deslocamentos e rotações. O emprego da formulação posicional também é justificado porque seu desenvolvimento faz parte de uma importante linha de pesquisa do Grupo de Mecânica Computacional (GMEC) pertencente ao Departamento de Estruturas da Escola de Engenharia de São Carlos - USP.

Uma solução possível para a análise de pórticos laminados seria o emprego de elementos finitos bidimensionais comumente chamados como elementos de chapa. No entanto, a discretização das lâminas com esse elemento pode provocar o mau condicionamento matricial do sistema de equações de equilíbrio no modelo discreto. Isso ocorre em virtude da presença de lâminas finas e longas, mesmo em laminados espessos, e devido à variação brusca e significativa nas propriedades elásticas de uma lâmina para outra. Assim, o refinamento da discretização é necessário para evitar a presença de elementos muito distorcidos que provocam esse mau condicionamento, mas a quantidade de graus de liberdade e, consequentemente, o custo computacional podem se tornar inviáveis por conta da maior quantidade de elementos. 
Nos Itens 2.2.3 e 2.3, apresenta-se descrição sobre as teorias de laminados, com ênfase na teoria Layerwise. Identifica-se uma importante abordagem em deslocamentos da teoria Layerwise encontrada no trabalho de Reddy (2004a) que consiste em representar o campo de deslocamentos através de uma combinação linear do produto de polinômios unidimensionais de interpolação ao longo da espessura com polinômios de interpolação bidimensionais no plano do laminado.

O desenvolvimento de um elemento finito para análise de pórticos planos laminados com cinemática correspondente a da teoria Layerwise de Reddy (2004a) podem não ser eficientes, pois os elementos finitos utilizados para representar as lâminas se tornam semelhantes aos elementos finitos bidimensionais Lagrangianos. Portanto, são sujeitos aos problemas de mau condicionamento discutidos anteriormente.

Assim, a proposta de um elemento finito com características dos modelos de pórtico, mas com a possibilidade de giro independente e variação de espessura para a seção das lâminas se torna interessante, pois é esperado que a análise de problemas com pequena ou moderada espessura, como no caso de barras de pórtico homogêneas e laminadas, e de problemas com seção transversal espessa laminada ou não, como no caso de vigas paredes e vigas sanduíche, não fique sujeita ao problema de mau condicionamento matricial. Com isso, torna-se possível o emprego de uma quantidade menor de elementos finitos, mas com uma qualidade equivalente dos resultados em deslocamentos e em tensões se comparado aos obtidos com os elementos de chapa através de uma análise que utilize uma discretização bastante refinada.

\subsection{Objetivos}

Diante das questões acima, o objetivo principal deste trabalho é desenvolver um elemento finito de pórtico plano laminado baseado na formulação posicional cuja cinemática possibilite giros independentes e variação de espessura das lâminas em uma extensão da teoria Layerwise.

Pretende-se, assim, obter um elemento capaz de realizar análises não lineares geométricas em estruturas de pórticos planos constituídos por materiais compósitos laminados com seção transversal fina ou espessa. Dessa forma, espera-se que os resultados de distribuições de deformações e tensões sejam mais realistas ao longo da espessura e interfaces, visando futuras modelagens do processo de falha do laminado por delaminação ou deslizamento.

Em função desse objetivo, os seguintes objetivos específicos são definidos: 
a) desenvolver a formulação matemática do elemento finito de pórtico plano homogêneo com graus de liberdade compostos por posições nodais e por vetores generalizados que representam o giro e a variação na altura da seção transversal;

b) expandir a formulação desse elemento para considerar uma seção transversal composta por várias lâminas de materiais diferentes, com independência de giro e variação de espessura, em uma extensão da teoria Layerwise;

c) avaliar a eficiência do elemento de pórtico plano laminado em relação aos elementos finitos bidimensionais, comumente chamados como elementos de chapa;

d) realizar análises em casos de interesse.

\subsection{Metodologia}

O desenvolvimento deste trabalho se iniciou com uma preparação teórica no estudo da mecânica dos sólidos deformáveis, dos métodos numéricos e da análise não linear de estruturas para a aquisição dos subsídios teóricos que possibilitassem o desenvolvimento de códigos computacionais, a interpretação dos resultados e a tomada de decisões quando das análises numéricas. Essa preparação teórica foi obtida cursando diversas disciplinas oferecidas no Departamento de Engenharia de Estruturas - SET, na Escola de Engenharia de São Carlos USP.

Realizou-se também uma revisão bibliográfica dividida em duas partes. A primeira parte se concentrou em uma fundamentação teórica sobre materiais compósitos em geral e sobre as diversas teorias empregadas para análise de estruturas constituídas por compósitos laminados. A segunda parte da revisão foi voltada ao estudo das diversas formulações disponíveis para a realização de análises não lineares em estruturas.

A conclusão das disciplinas da fase de preparação teórica forneceu os subsídios necessários para o desenvolvimento e implementação computacional do elemento de pórtico plano homogêneo, mas ainda sem a possibilidade de acoplamento entre barras com direções diferentes. Análises numéricas em problemas de vigas foram feitas para verificar a formulação do elemento e as implementações realizadas.

O elemento de pórtico plano homogêneo possui graus de liberdade constituídos por posições e vetores generalizados nodais. A função de mapeamento posicional empregada é semelhante à proposta por Coda e Paccola (2011) para análise de pórticos tridimensionais não 
laminados. Essa cinemática corresponde a uma cinemática de Reissner-Timoshenko e, portanto, não inclui a possibilidade de giros independentes para laminados.

Inicialmente, o elemento finito posicional de pórtico plano homogêneo foi desenvolvido, uma vez que sua cinemática possibilita uma expansão natural para o caso laminado. Esse elemento é semelhante ao elemento de pórtico laminado constituído por uma única lâmina. Dessa forma, os resultados de análises em problemas homogêneos forneceram uma avaliação prévia da eficiência da cinemática proposta.

A adaptação dessa formulação para laminados é baseada na teoria Layerwise com a possibilidade de giros independentes e variação da espessura das lâminas. Entretanto, as formulações baseadas nesta teoria são utilizadas em geral para análise de problemas lineares, nos quais a superposição de giros é possível. $\mathrm{Na}$ proposta desta pesquisa, um procedimento semelhante a do elemento de pórtico plano homogêneo foi seguido para considerar a análise não linear geométrica.

A formulação matemática do elemento de pórtico plano laminado foi desenvolvida, seguida por sua implementação computacional em linguagem de programação FORTRAN. Com isso, análises numéricas foram realizadas em exemplos de vigas homogêneas e laminadas. Os resultados obtidos foram comparados a soluções analíticas e numéricas quando disponíveis e principalmente aos resultados obtidos a partir de análises com elementos finitos bidimensionais em diferentes níveis de discretização. O software utilizado para essas análises foi o Ansys ${ }^{\circledR}$, pois é um software que facilita a modelagem numérica dos problemas e cujos resultados obtidos com as análises são bastante confiáveis. Outros softwares também poderiam ser empregados desde que esses dois aspectos fossem garantidos.

Com a verificação do elemento finito laminado, a formulação do acoplamento entre elementos foi desenvolvida e implementada em ambos os programas, possibilitando a existência de ligações rígidas, articuladas e semirrígidas. Após isso, análises numéricas em exemplos de pórticos planos homogêneos encontrados na literatura e em exemplos propostos de pórticos planos laminados foram realizadas.

Os desenvolvimentos matemáticos necessários foram realizados manualmente e utilizando-se eventualmente os recursos de softwares de manipulação simbólica disponíveis. A programação da formulação foi feita em linguagem FORTRAN visando futuras generalizações para elementos finitos de casca, consideração de não linearidade física e paralelização do código com o propósito de permitir aplicações gerais.

Por fim, o fechamento da pesquisa ocorreu com a redação do presente texto e sua subsequente apresentação. 


\subsection{Organização do texto}

A organização dos diversos tópicos deste trabalho é descrita neste item a fim de esclarecer a sequência lógica utilizada e apresentar os conteúdos que compõem cada capítulo deste trabalho.

Uma revisão bibliográfica contendo os aspectos gerais dos materiais compósitos é apresentada na primeira parte do Capítulo 2. São abordadas questões relativas ao conceito de material compósito e à classificação dos diversos tipos existentes. Atenção maior foi despendida para os compósitos laminados. Os níveis de abordagens existentes na avaliação do comportamento mecânico de estruturas constituídas por esses materiais são identificadas, o que permitiu a localização da formulação desenvolvida neste trabalho.

Um resumo das principais teorias para análise de laminados, englobando suas hipóteses e limitações, também é apresentado. Por fim, um item aborda o assunto de falhas em compósitos laminados, sendo dada ênfase aos principais aspectos que precisam ser considerados em uma análise mais realista visando à identificação precisa desse fenômeno. Neste item, são apresentados também os critérios de falha existentes.

Todo o conteúdo desta primeira parte da revisão bibliográfica foi escrito para fornecer uma visão geral sobre os materiais compósitos ao leitor que não possua uma formação acadêmica básica nessa área da engenharia. Muito do que está escrito neste item foi extraído de literaturas bastante conhecidas da Engenharia de Materiais, tais como os livros de Jones (1999), Reddy (2004a), Vinson e Sierakowski (2004), Mendonça (2005), Daniel e Ishai (2006), entre outros.

A segunda parte da revisão bibliográfica apresentada no Capítulo 2 busca identificar e caracterizar as principais teorias existentes para análise de compósitos laminados tanto em regime linear como em não linear. São discutidas as hipóteses, aplicações e limitações de cada teoria. O intuito desse capítulo é localizar a formulação do elemento finito laminado desenvolvido neste trabalho em relação às demais formulações existentes. A maior parte do conteúdo foi extraída de artigos científicos tais como o de Ghugal e Shimpi (2001, 2002), Carrera (2002), Kreja (2011), Lo et al. (2011), entre outros.

O Capítulo 2, portanto, delimita este trabalho dentro do campo de conhecimento relativo aos materiais compósitos. Feito isso, os próximos capítulos do texto descrevem as formulações dos elementos finitos desenvolvidos.

Inicia-se, no Capítulo 3, com uma apresentação da formulação matemática peculiar aos elementos finitos posicionais aplicados a problemas que permitem uma simplificação ao 
Capítulo 1 - Introdução

domínio bidimensional. No primeiro item deste capítulo, há a revisão bibliográfica sobre as principais formulações destinadas à análise não linear de estruturas. A formulação posicional é identificada dentro das formulações com descrição Lagrangiana total como pode ser observado no item referente à definição da função mudança de configuração. A medida de deformação e a lei constitutiva adotada são apresentadas em seguida. Como a formulação posicional é desenvolvida por meio de uma abordagem energética, as parcelas que compõem a energia potencial total do problema são identificadas. O capítulo é concluído com a descrição do processo de solução empregado para resolver o sistema de equações não linear, que é baseado no método de Newton-Raphson. Como se verá, o conjunto de operações matemáticas apresentado no Capítulo 3 é independente do tipo de elemento desenvolvido.

Dessa forma, os Capítulos 4 e 5 foram organizados com a mesma sequência lógica que consiste em descrever inicialmente a cinemática adotada através das funções de mapeamento posicional das configurações inicial e atual seguida pela apresentação dos aspectos particulares de cada elemento finito desenvolvido. Esses aspectos são relacionados principalmente à determinação dos termos que compõem os diversos vetores e matrizes da formulação posicional, identificados no Capítulo 3. No penúltimo item, são apresentados os resultados obtidos em análises numéricas de exemplos. Esses resultados são comparados a outros analíticos e numéricos disponíveis na literatura ou obtidos em análises realizadas no Ansys ${ }^{\circledR}$. As considerações referentes à verificação da formulação constam no final de cada capítulo.

Finalmente, conclusões e sugestões para a continuação desta pesquisa estão descritas no Capítulo 6. 



\section{CAPÍTULO 2}

\section{REVISÃO BIBLIOGRÁFICA}

\subsection{Introdução}

Muitos avanços tecnológicos relevantes em diversas áreas do conhecimento somente se tornaram possíveis em virtude do desenvolvimento e utilização dos materiais compósitos. Apesar da aplicação desses materiais estar sempre referida à tecnologia de ponta, a origem dessa importante classe de materiais se remete aos chamados compósitos naturais presentes nas madeiras, nos ossos e nos tecidos musculares (HULL; CLYNE, 1996). Historicamente, o emprego dos compósitos é muito antigo. Por exemplo, palhas eram usadas pelos Israelitas para aumentar a resistência de tijolos e os Egípcios já trabalhavam com madeira laminada para melhorar o desempenho mecânico, aumentar a resistência às expansões térmicas e reduzir a absorção de umidade (JONES, 1999). Nas aplicações modernas, os primeiros empregos dos materiais compósitos surgiram na construção de veículos espaciais durante a última metade do século passado (CARRERA, 2002).

Os compósitos podem ser projetados para apresentar inúmeras propriedades vantajosas frente aos materiais que constituem as estruturas monolíticas tradicionais. Dentre elas podem ser listadas, por exemplo: maior resistência e rigidez, menor densidade, maior tempo para ocorrer fadiga, maior resistência ao desgaste e à corrosão, maior estabilidade dimensional relacionada a ações térmicas e higroscópicas, entre outras.

Segundo Daniel e Ishai (2006), esse desempenho superior somente é possível porque os materiais constituintes dos compósitos possuem características que aumentam as possibilidades para o desenvolvimento de uma configuração ótima do material em função das restrições de uma aplicação específica. As principais propriedades que os compósitos apresentam e que garantem um ganho de desempenho são: elevada resistência específica (relação entre resistência e densidade), elevada rigidez específica (relação entre rigidez e densidade) e propriedades anisotrópicas e heterogêneas. 
As aplicações dos materiais compósitos vão desde objetos simples como o botão de uma camisa até objetos extremamente complexos como um ônibus espacial. $\mathrm{O}$ uso inclui aplicações nas áreas aeroespacial, aeronáutica, naval, de energia, de infraestrutura e construção civil, militar, biomédica e de produtos esportivos.

$\mathrm{Na}$ área aeroespacial, os materiais precisam ter uma grande estabilidade dimensional, pois são expostos a condições ambientais severas. Assim, materiais compósitos com coeficientes de expansão térmica e higroscópica próximos de zero são projetados e empregados nas estruturas dos ônibus e instalações espaciais, em antenas, em espelhos e em instrumentos ópticos (DANIEL; ISHAI, 2006).

Nas aplicações em aeronaves militares e em aviação civil, é desejável que os materiais apresentem alta rigidez, alta resistência e baixa densidade. Dessa forma, o emprego de materiais compósitos cresceu de forma significativa nas últimas décadas. Como exemplo, pode-se citar o Airbus A380 que é o maior avião comercial do mundo e utiliza uma grande quantidade de compósitos: formado por $22 \%$ de plásticos reforçados com fibras de carbono, vidro e quartzo e 3\% de laminado sanduíche com faces constituídas por lâminas de alumínio ou de laminado polimérico com fibras de carbono e núcleo composto por fibras de vidro em uma matriz de epóxi. Outro exemplo é o avião militar B-2 que é feito quase inteiramente por compósitos como o constituído de carbono com epóxi (VINSON; SIERAKOWSKI, 2004; DANIEL; ISHAI, 2006).

O uso de materiais compósitos em automóveis, ônibus, caminhões e veículos sobre trilhos se deve a leveza e resistência desses materiais que são empregados de diversas formas como em: portas, capôs, para-choques, isolantes térmicos, blindagem, revestimentos internos, tetos, carenagens, entre outras. Os compósitos são usados, por exemplo: na substituição de peças metálicas por peças mais leves, como nas molas feitas de fibras de vidro com epóxi; nos assentos de trens e metrôs, fabricados com resinas termofixas autoextinguíveis; em partes da carenagem, que utilizam painéis sanduíches; na utilização de SMC (compósito de resina termofixa e fibras de reforço) em carenagens de automóveis para redução de peso; em blindagens feitas a partir de compósitos de alto desempenho, como o compósito de resinas termofixas com fibras de aramida; entre outras (ABMACO, 2008; VINSON; SIERAKOWSKI, 2004; DANIEL; ISHAI, 2006).

A indústria náutica é uma das principais usuárias de compósitos no mundo e se aproveita das vantagens desses materiais, tais como: isolamento térmico, menor custo de fabricação, baixa necessidade de manutenção, maior resistência à corrosão e menor peso. Muito usado na construção de barcos são os painéis sanduíche híbridos que são formados por faces espessas de um laminado polimérico reforçado com fibras de vidro e carbono e um núcleo 
preenchido com espuma de PVC. Esse material é usado, por exemplo, no navio suíço Corvette YS - 2000. Nas embarcações menores como lanchas, barcos de pesca e catamarãs, o casco é totalmente fabricado com resinas reforçadas com fibra de vidro (ABMACO, 2008; VINSON; SIERAKOWSKI, 2004; DANIEL; ISHAI, 2006).

$\mathrm{Na}$ indústria de energia, o emprego de materiais compósitos ocorre, por exemplo, nas pás de turbinas eólicas e em risers de perfuração de poços de petróleo em alto mar. As pás são produzidas com resinas de poliéster ou de epóxi reforçadas com tecidos e mantas de fibras de vidro e de carbono (ABMACO, 2008; DANIEL; ISHAI, 2006). O uso de risers de material compósito é uma excelente alternativa aos risers de aço, pois são mais leves, mais resistentes à fadiga, mais resistentes à corrosão e melhores isolantes térmicos. Para confecção dos risers, são utilizadas estruturas híbridas compostas de fibra de carbono e fibra de vidro numa matriz de epóxi (SOUSA; PINA FILHO; DUTRA, 2007).

Os materiais compósitos (carbono com epóxi ou carbono com polisulfona, por exemplo), também, podem ser encontrados em produtos da área biomédica como próteses, membros artificiais, cadeiras de rodas, muletas e em produtos esportivos, que necessitam de materiais leves e resistentes, como raquetes, tacos de golfe, varas de pesca, skis, pranchas e bicicletas. As bicicletas profissionais, por exemplo, podem ser fabricadas com resinas termofixas reforçadas com fibra de carbono, apresentando elevada rigidez e leveza.

$\mathrm{Na}$ construção civil, as aplicações de materiais compósitos são bastante extensas. Os principais produtos são: caixas d'água, telhas, mármores sintéticos, coberturas, mobiliários urbanos, entre outras (ABMACO, 2008). Em infraestrutura, a quantidade de aplicações também é extensa como, por exemplo: tubulações de água e esgoto, tanques, pisos e perfis pultrudados em geral. Nessa área, o uso de materiais compósitos tem crescido principalmente em recuperações e reforços de pontes, na substituição de tabuleiros e de estais (VINSON; SIERAKOWSKI, 2004). No Brasil, a construção civil e a área de infraestrutura lideram a demanda por materiais compósitos, sendo responsável por 40\% do consumo segundo dados de 2008 fornecidos pela ABMACO.

Os setores da construção civil e de infraestrutura são também os principais consumidores do concreto simples e do concreto armado que são os materiais compósitos mais empregados no mundo. O concreto simples é um compósito formado a partir de partículas inertes, representadas pelos agregados de origem pétrea, com uma matriz a base de cimento Portland. Suas aplicações são para fins não estruturais como em alguns elementos pré-moldados e para estruturas cujas tensões de tração permanecem baixas como em barragens, pavimentos e blocos de fundação. 
O concreto simples resiste bem a esforços de compressão, mas possui baixa resistência a esforços de tração. Assim, para aumentar a resistência à tração, barras de aço são inseridas em uma disposição predefinida, formando o concreto armado. Este é vastamente empregado para fins estruturais como na construção de estruturas de edifícios e de pontes.

Como pode ser visto, o uso de materiais compósitos ocorre em diversas áreas tanto em aplicações não estruturais como em estruturais. Isso se deve a viabilização de um projeto otimizado e eficiente para o material e, consequentemente, para a estrutura.

A seguir, são abordados os aspectos gerais sobre os materiais compósitos como: definição, classificação, tipos de constituintes, comportamento mecânico, tipos de análises estruturais possíveis e formas de falhas. Esses aspectos contribuem para a justificativa e contextualização da formulação numérica apresentada neste trabalho, bem como, fornecem uma visão geral sobre os materiais compósitos e mais especificamente sobre os compósitos laminados.

\subsection{Aspectos gerais sobre materiais compósitos}

Um material é denominado compósito quando dois ou mais materiais são combinados em uma escala macroscópica para formar um terceiro material que apresenta propriedades superiores a dos seus componentes individualmente (JONES, 1999; REDDY, 2004a; VINSON; SIERAKOWSKI, 2004). Quando essa combinação se dá em uma escala microscópica, como nas ligas metálicas, o material formado não é considerado compósito.

Basicamente podem ser identificadas três fases em um compósito, a matriz, o reforço e a zona de transição (Figura 3). Dependendo da aplicação do compósito, a função dessas fases pode variar. Em compósitos de baixo a médio desempenho, a matriz é o principal elemento resistente e o reforço contribui para a rigidez. Já em compósitos de elevado desempenho, o reforço determina a rigidez e a resistência do material, enquanto a matriz tem a função de proteger o reforço de danos superficiais e de agentes agressivos ambientais, manter o espaçamento e orientação e transmitir as tensões entre os elementos de reforço. A zona de transição tem importante influência nos mecanismos de falha e sobre o comportamento tensãodeformação do material (DANIEL; ISHAI, 2006).

$\mathrm{Na}$ sequência deste item, uma classificação para os diferentes tipos de materiais compósitos é apresentada, sendo identificado o grupo ao qual pertencem os laminados. Os níveis de abordagens existentes para determinar o comportamento mecânico dos compósitos são descritos e a formulação desenvolvida neste trabalho é enquadrada nesses níveis. Por fim, as teorias para análise de compósitos laminados e os principais critérios de falha existentes são 
apresentados. O objetivo é identificar os fatores relevantes que precisam ser considerados em qualquer formulação cuja proposta seja a determinação mais precisa da distribuição de tensões com vistas à identificação do processo de falha de um compósito laminado.

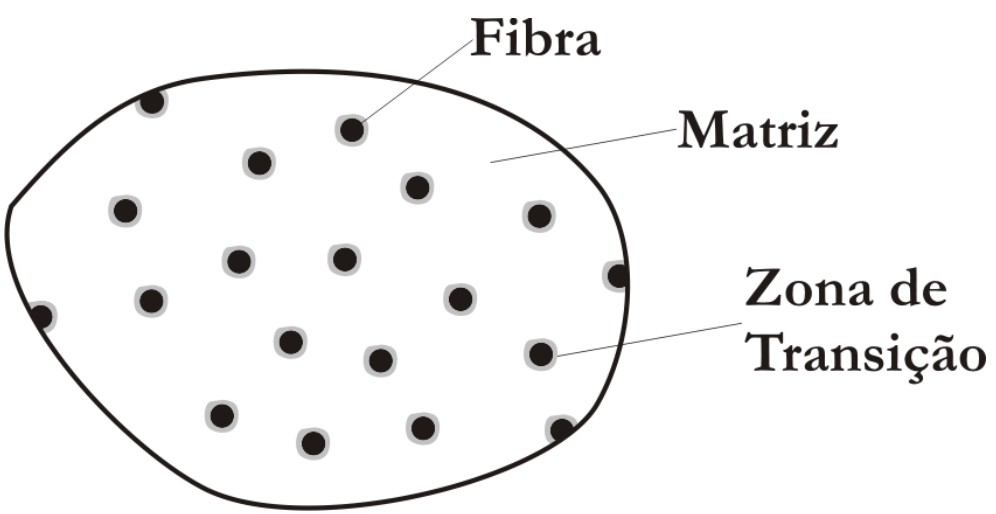

Figura 3 - Fases de um material compósito

Fonte: Daniel e Ishai (2006).

\subsubsection{Classificação dos materiais compósitos}

Reddy (2004a) classifica os materiais compósitos em compósitos de partículas, compósitos de fibras e compósitos laminados. Além dessas três, Jones (1999) inclui uma quarta classificação correspondente a um grupo de compósitos formados pela combinação dos três tipos anteriores, os compósitos híbridos. Outra divisão que pode ser encontrada em Levy Neto e Pardini (2006) se refere à divisão em compósitos naturais e sintéticos. Esses autores propõem o diagrama de classificação ilustrado na Figura 4, definido em função dos tipos e arranjos dos reforços.

Obviamente qualquer classificação que se pretenda fazer não será geral o suficiente para englobar a grande quantidade de combinações possíveis dos materiais compósitos. Essas combinações surgem em virtude da flexibilidade que esses materiais possuem para o desenvolvimento de propriedades ótimas diante de um conjunto de solicitações específicas. Dessa forma, foram incluídas na classificação hierárquica de Levy Neto e Pardini (2006) (Figura 4) algumas modificações (destacadas na cor vermelha) para indicar outras combinações possíveis e encontradas na Engenharia Civil. Algumas dessas combinações e seus compósitos resultantes estão convenientemente identificados nos tópicos seguintes. 


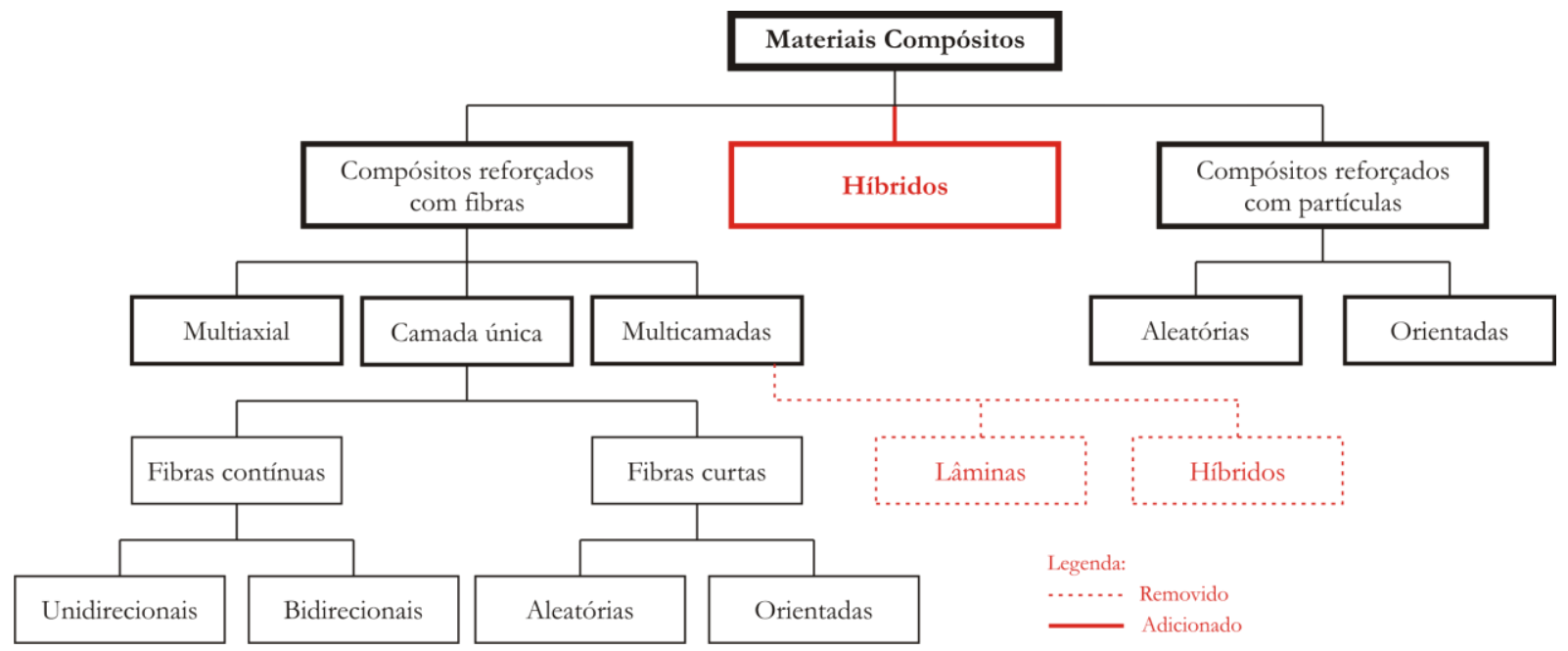

Figura 4 - Classificação dos compósitos em função do tipo de reforço (adaptado)

Fonte: Levy Neto e Pardini (2006).

a) Compósitos de partículas

Os compósitos de partículas são formados por um ou mais tipos e formas de partículas suspensas em uma matriz de outro material. Na maioria dos casos, a distribuição das partículas é aleatória podendo considerar o material homogêneo e isotrópico em uma escala macroscópica. Ao todo, são possíveis quatro combinações para os compósitos de partículas.

A composição mais comum ocorre entre partículas e matriz não metálicas. $O$ compósito mais famoso dessa categoria é o concreto simples, formado por uma matriz cimentícia (cerâmica) reforçada com partículas de origem pétrea. Outros exemplos são: vidro reforçado com flocos de mica, polímeros frágeis reforçados com partículas de borracha, cerâmica reforçada com partículas de cerâmica e um nano compósito entre polímero e argila. Neste último exemplo, as partículas são orientadas levando a um comportamento anisotrópico (DANIEL; ISHAI, 2006).

Podem ser combinadas também partículas metálicas em matriz não metálica. Exemplos dessa categoria são: compósito composto por partículas de alumínio dispersas em borracha de poliuretano que é empregado em propelentes de foguetes; solda fria que é constituída de um pó metálico suspenso em uma resina e compósito de cobre com epóxi que aumenta a condutividade elétrica. A inclusão de partículas metálicas em plásticos aumenta a condutividade térmica, reduz o desgaste e diminui o coeficiente de expansão térmico (JONES, 1999).

Outra categoria de compósitos com partículas pode ser obtida entre partículas e matrizes metálicas. Nesse tipo de material compósito, as partículas não estão dissolvidas na matriz e isso o diferencia das ligas metálicas. O compósito comum dessa categoria é formado pela 
adição de partículas de chumbo em ligas de cobre ou aço para melhorar a usinagem. Outro exemplo envolve o processo chamado sinterização líquida, que consiste na adição de partículas de metais frágeis em matrizes metálicas dúcteis formando um compósito dúctil e com elevadas propriedades térmicas (JONES, 1999).

Por fim, podem ser combinadas partículas não metálicas em matrizes metálicas. $\mathrm{O}$ compósito mais comum é formado por partículas cerâmicas de óxidos ou carbetos suspensas em matriz metálica. Esses compósitos são utilizados em aplicações nas quais é importante haver elevada rigidez, elevada resistência à corrosão, à abrasão e, também, em aplicações sujeitas a elevadas temperaturas (JONES, 1999).

b) Compósitos de fibras

Os compósitos de fibras são constituídos por fibras (material de reforço) inseridas em uma matriz. Basicamente podem ser identificadas duas classificações: os compósitos com fibras descontínuas e os compósitos com fibras contínuas. O primeiro tipo é formado por fibras curtas ou por whiskers, que são fibras muito curtas e com diâmetro da mesma ordem de grandeza do cristal constituinte. Apesar do pequeno comprimento, essas fibras apresentam uma alta razão de aspecto (razão comprimento por diâmetro). Na matriz, as fibras curtas podem ser dispostas de forma aleatória ou orientadas em uma direção específica. O segundo tipo são os compósitos com fibras longas (da mesma ordem de grandeza dos elementos estruturais) que podem ser do tipo unidirecional e do tipo bidirecional com fibras cruzadas ou formando um tecido. Esses compósitos são muito mais eficientes estruturalmente do que os compósitos formados por fibras curtas (DANIEL; ISHAI, 2006; LEVY NETO; PARDINI, 2006; VINSON; SIERAKOWSKI, 2004).

Os compósitos de fibras também podem ser classificados em relação aos materiais constituintes. Essa classificação é definida em função do tipo de matriz, podendo ser polimérica, metálica, cerâmica ou de carbono. Os compósitos de matriz polimérica são constituídos por polímeros termofixos ou termoplásticos e fibras de vidro, carbono, aramida ou boro. Sua aplicação se restringe a baixas temperaturas. Os compósitos de matriz metálica são constituídos por metais ou ligas metálicas e, em geral, fibras não metálicas de boro, carbono ou cerâmica. Os compósitos de matriz cerâmica tem sua aplicação destinada principalmente a ambientes sujeitos a elevadas temperaturas e suas fibras são constituídas por materiais cerâmicos como carbeto ou nitreto de silício e alumina. Os compósitos de carbono são formados por matriz de carbono ou grafite e reforço com fibras ou tecidos de grafite. São compósitos de elevada rigidez e resistência 
(DANIEL; ISHAI, 2006). Os tipos de materiais mais comuns que formam os compósitos de fibras estão apresentados na Tabela 1 .

Tabela 1 - Compósitos com fibras: materiais constituintes mais comuns

\begin{tabular}{lll}
\hline Tipo de matriz & Fibra & Matriz \\
\hline Polímero & $\begin{array}{l}\text { vidro E, vidro S, carbono } \\
\text { (grafite), aramida (Kevlar), } \\
\text { boro }\end{array}$ & $\begin{array}{l}\text { epóxi, fenólica, poliimida } \\
\text { bismaleimida, poliéster, } \\
\text { poli-éter-éter-cetona, } \\
\text { poliamidas, polipropileno }\end{array}$ \\
Metal & $\begin{array}{l}\text { boro, carbono (grafite), } \\
\text { carbeto de silício, alumina }\end{array}$ & $\begin{array}{l}\text { alumínio, magnésio, cobre, } \\
\text { titânio, aço, tungstênio, berílio }\end{array}$ \\
Cerâmica & $\begin{array}{l}\text { carbeto de silício, alumina, } \\
\text { nitreto de silício }\end{array}$ & $\begin{array}{l}\text { carbeto de silício, alumina, } \\
\text { nitreto de silício, cerâmica vítrea }\end{array}$ \\
Carbono & carbono & carbono \\
\hline
\end{tabular}

Fonte: Daniel e Ishai (2006).

c) Compósitos laminados

Os compósitos laminados são formados pelo empilhamento e união de lâminas de materiais diferentes. A união das lâminas é realizada de maneira tal que garanta o trabalho solidário entre elas. Assim, as propriedades dos materiais constituintes de cada lâmina são combinadas e formam um material com melhores propriedades tais como maior resistência, maior rigidez, menor peso, maior resistência à corrosão e ao desgaste, entre outras.

Em um laminado, as lâminas são a unidade básica e podem ser constituídas por materiais compósitos como os reforçados com fibras. Estes são os mais empregados quando há necessidade de elevado desempenho mecânico (JONES, 1999; REDDY, 2004a).

O compósito laminado é produzido segundo um esquema de laminação pré-definido em função das propriedades desejadas para o material e isso constitui a principal proposta de um laminado (JONES, 1999). Desta forma, podem-se ter direções principais do material em termos de resistência e rigidez orientadas ao longo das direções mais solicitadas (caminho das cargas).

O esquema de laminação possui como possibilidades a variação do número, da espessura, da sequência, das propriedades mecânicas e da orientação das fibras de cada lâmina. Assim, os compósitos podem ser fabricados de maneira a obter projetos altamente otimizados em cada situação específica (TEÓFILO et al., 2008).

A nomenclatura empregada para especificar o esquema de laminação é do tipo $\left[t_{1}, \alpha_{1} / t_{2}, \alpha_{2} / \ldots t_{n-1}, \alpha_{n-1} / t_{n}, \alpha_{n}\right]$, na qual $\left[t_{1}, t_{2}, \ldots t_{n-1}, t_{n}\right]$ e $\left[\alpha_{1}, \alpha_{2} \ldots \alpha_{n-1}, \alpha_{n}\right]$ representam a espessura das lâminas e o ângulo de orientação das fibras nas lâminas, respectivamente 
Capítulo 2 - Revisão Bibliográfica

(BELO, 2006). A sequência de numeração das lâminas é realizada seguindo a direção positiva do eixo $x_{3}$ e o ângulo de inclinação das fibras obedece ao sentido positivo da rotação no sistema de referência adotado (regra da mão direita), como pode ser visto na Figura 5.

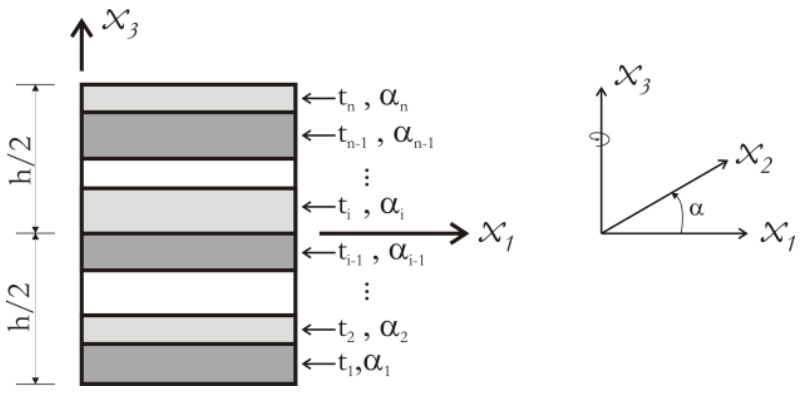

Figura 5 - Nomenclatura do esquema de laminação

Fonte: Belo (2006).

O ângulo de inclinação das fibras nas lâminas pode variar de $-90^{\circ}$ a $90^{\circ}$. O esquema de laminação é denominado cruzado (cross-ply) quando essa inclinação for sempre $0^{\circ}$ ou $90^{\circ}$ e é denominado angular (angle-ply) quando as fibras apresentarem outras inclinações. Mais uma observação importante com relação ao esquema de laminação se refere à distribuição das lâminas em relação à superfície média do laminado que pode ser simétrica, antissimétrica ou assimétrica. A Figura 6 contém exemplos de esquemas de laminação com suas denominações específicas.

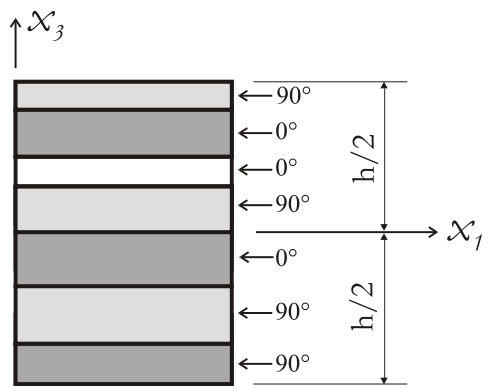

a) Laminado cruzado assimétrico

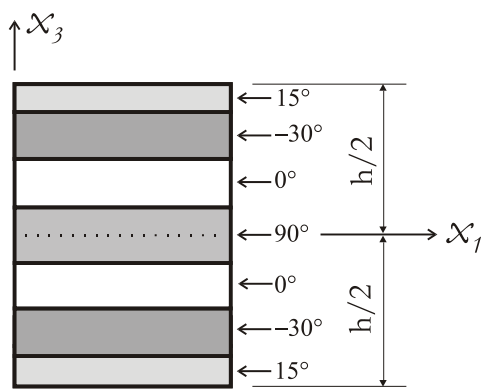

d) Laminado simétrico angular

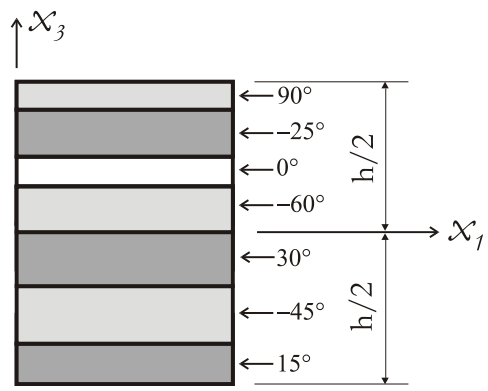

b) Laminado angular assimétrico

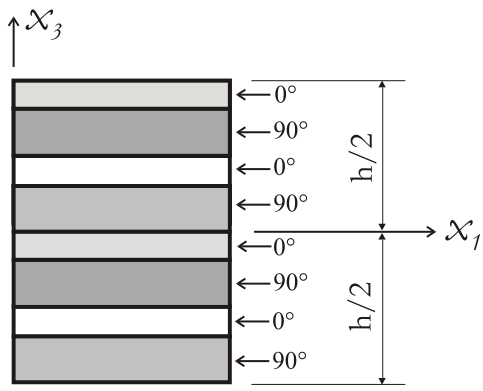

e) Laminado antissimétrico cruzado

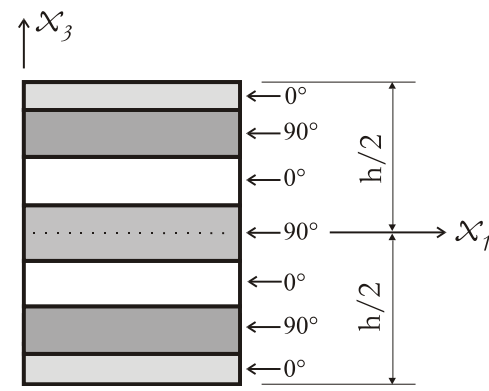

c) Laminado simétrico cruzado

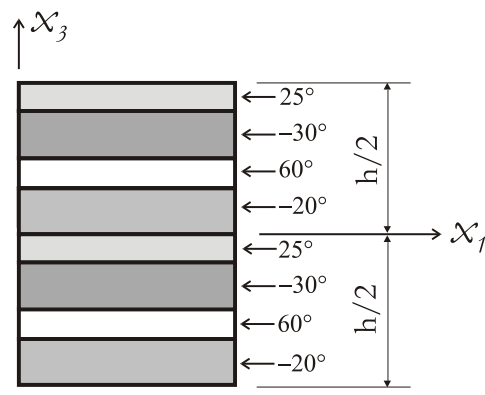

f) Laminado antissimétrico angular

Figura 6 - Exemplos de esquemas de laminação

Fonte: Belo (2006). 
d) Compósitos híbridos

Segundo Jones (1999), os compósitos híbridos são materiais formados a partir da combinação de materiais pertencentes às outras três categorias de compósitos (de partículas, de fibras e laminados). Daniel e Ishai (2006) afirmam que a combinação de diferentes tipos de fibra em uma mesma lâmina pode ser vantajosa em alguns casos. Dessa forma, os autores classificam os compósitos híbridos em três tipos: de intracamada, de intercamadas e de intracamada/intercamadas.

Um exemplo claro de compósito híbrido é o concreto armado. Esse material é constituído por concreto simples, que pode ser classificado como um compósito de partículas, e por barras de aço, que representam as fibras. Então, o concreto armado pode ser classificado como um compósito de partículas e de fibras.

Outras possibilidades identificadas para um compósito híbrido são a utilização de fibras ou matrizes diferentes em um compósito laminado e a combinação de lâminas de compósitos diferentes. Neste último caso, podem ser identificados, por exemplo, a combinação de lâminas metálicas com lâminas de compósitos, estruturas de concreto armado reforçadas com fibras de carbono, estruturas compósitas tipo sanduíche, entre outras.

Os denominados compósitos sanduíche são um importante tipo de compósitos híbridos formados a partir de duas finas lâminas de um material rígido localizado nas faces e um núcleo central leve, espesso e de baixa resistência (Figura 7). Esse laminado apresenta elevada rigidez à flexão e baixa densidade.

Os principais componentes responsáveis pela resistência do compósito sanduíche são as faces e o material da interface de ligação. A função das faces é a de suportar tensões axiais de compressão, de tração e tensões de cisalhamento coplanares geradas por esforço de flexão. $\mathrm{O}$ material da interface de ligação absorve tensões axiais e cisalhantes interlaminares. O núcleo tem a função de manter o afastamento das faces, garantindo um alto momento de inércia (MENDONÇA, 2005).

$\mathrm{Na}$ constituição de um compósito sanduíche, o núcleo pode ser preenchido com espumas de plásticos expandidos, madeiras, plásticos, corrugados e colmeias. Os corrugados e colmeias são comuns em embalagens, em portas e em divisórias e os materiais usados podem ser papel, papelão, algodão, tecidos impregnados e lâminas de alumínio ou aço. Nas faces, as lâminas finas são, em geral, constituídas por laminados de polímeros termofixos ou termoplásticos reforçados com fibras de vidro ou de carbono. Folhas de metal são também comumente empregadas. A ligação entre o núcleo e as lâminas das faces é realizada com adesivos ou com 
componentes metálicos (MENDONÇA, 2005; LEVY NETO; PARDINI, 2006).

Os diversos modos possíveis de falha em um compósito sanduíche são escoamento ou ruptura das faces, cisalhamento do núcleo, flambagem global do painel, deflexão excessiva, enrugamento das faces, flambagem intracelular e esmagamento do núcleo (MENDONÇA, 2005).

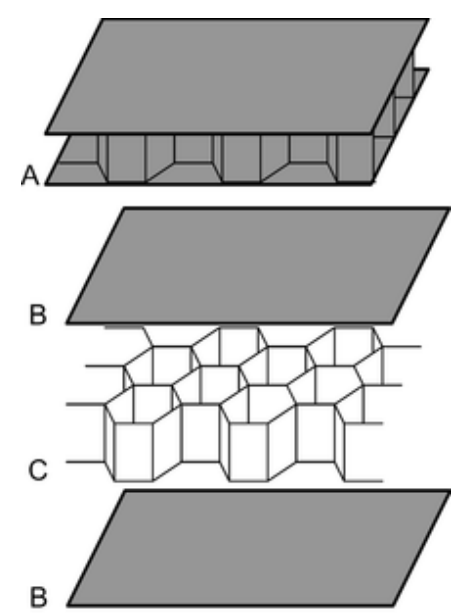

Figura 7 - ${ }^{*}$ Compósito do tipo sanduíche: (A) painel, (B) faces e (C) núcleo em forma de colmeia

\subsubsection{Comportamento mecânico}

Os materiais compósitos são frequentemente heterogêneos e ortotrópicos ou anisotrópicos. O material é heterogêneo quando há variação de suas propriedades de um ponto para outro e o material é anisotrópico quando essas propriedades dependem da direção considerada. A ortotropia ocorre se existem três planos de simetria perpendiculares entre si cuja interseção define os eixos principais do material. Todas essas características dependem da escala de observação. Quando essa escala decresce da dimensão macroscópica para a microscópica, um mesmo material pode ser considerado homogêneo ou heterogêneo, isotrópico, ortotrópico ou anisotrópico (DANIEL; ISHAI, 2006).

Em função das características heterogêneas e da escala do comportamento mecânico de interesse, a análise dos materiais compósitos pode ser dividida em duas abordagens: micromecânica e macromecânica. Segundo Jones (1999), na abordagem micromecânica, o estudo do comportamento mecânico do compósito ocorre no nível das interações entre os constituintes. Já na abordagem macromecânica, o estudo é realizado em uma escala macroscópica e assume-se um material homogêneo equivalente. A influência dos constituintes do compósito é considerada na forma de propriedades médias para o material como um todo. Um esquema das abordagens em um compósito é ilustrado na Figura 8. 


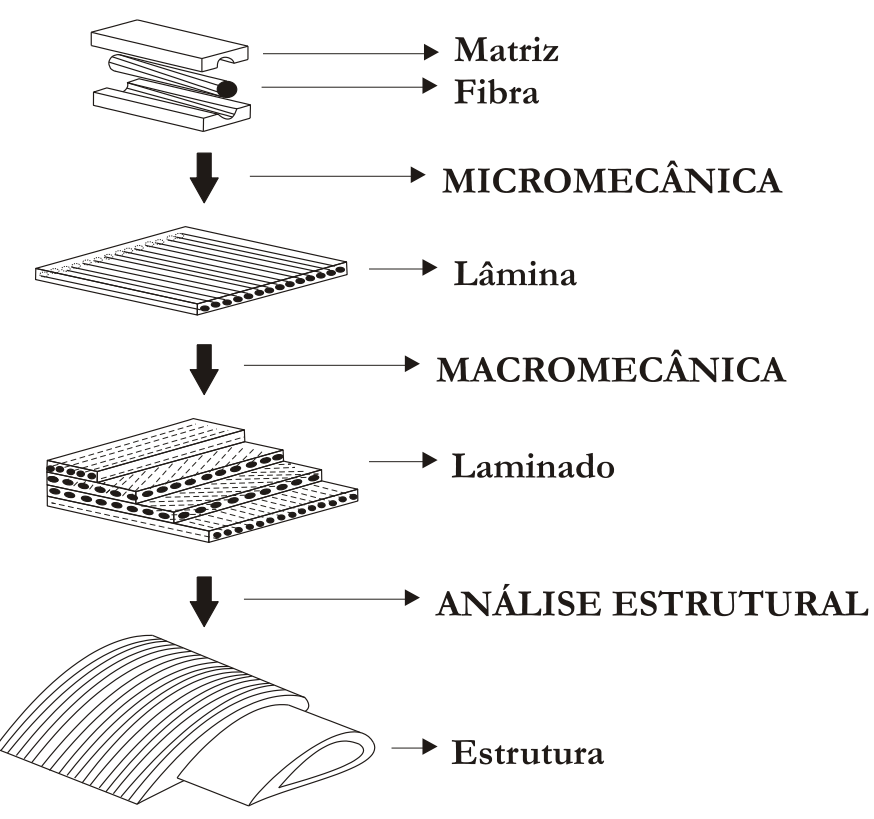

Figura 8 - Níveis de análise em estruturas formadas por materiais compósitos Fonte: Daniel e Ishai (2006).

De acordo com Daniel e Ishai (2006), a abordagem micromecânica é importante para o estudo dos mecanismos de resistência, dos mecanismos de falha (falha nas fibras, na matriz ou na zona de transição), da tenacidade à fratura e do tempo de ocorrência da fadiga. Além disso, a micromecânica permite estabelecer o comportamento médio no nível das lâminas a partir de seus constituintes. Já a abordagem macromecânica é recomendada para o estudo do comportamento global do laminado e da estrutura. Nessa abordagem, critérios de falha podem ser estabelecidos em termos de tensões e forças médias na lâmina.

A determinação do comportamento mecânico global da estrutura e das tensões ou forças médias no nível das lâminas, em uma abordagem macromecânica, pode ser obtida a partir do acoplamento das teorias de laminados com o método dos elementos finitos. Essas teorias levam em consideração as propriedades médias das lâminas e o esquema de laminação. Ainda dentro da macromecânica, as teorias de laminados trabalham basicamente considerando dois níveis de abordagem: uma na qual o laminado é analisado como uma única lâmina homogênea equivalente e outra na qual a análise considera uma discretização das lâminas.

Neste trabalho, as formulações desenvolvidas empregam esta última abordagem. Conforme discutido anteriormente no Capítulo 1, a discretização das lâminas permite representar o comportamento Zig-Zag para o campo de deslocamentos ao longo da seção transversal, possibilita a continuidade interlaminar das tensões transversais e considera a heterogeneidade transversal devido à mudança de material lâmina a lâmina. Esses aspectos são fundamentais para

\footnotetext{
${ }^{1}$ KOITER, W. T. A Consistent First Approximations in the General Theory of Thin Elastic Shells. In: First Symposium on the Theory of Thin Elastic Shells, 1959, Amsterdam. Proceedings ... Amsterdam: 1960. p.1223.
} 
Capítulo 2 - Revisão Bibliográfica

a obtenção de uma resposta em tensões mais precisa com vistas à verificação do processo de falha do laminado.

\subsubsection{Teorias de laminados}

Segundo Reddy (2004a), os principais modelos para análise de compósitos laminados podem ser divididos em:

a) Modelos baseados na teoria de camada única equivalente (Equivalente Single Layer ESL):

- Teoria clássica (Classical Laminated Theory - CLT);

- Teoria de primeira ordem em relação à deformação de cisalhamento (First order Shear Deformation Theory - FSDT);

- Teoria de alta ordem em relação à deformação de cisalhamento (High order Shear Deformation Theory - HSDT);

b) Modelos baseados em teorias tridimensionais:

- Teoria Layerwise;

- Teoria da elasticidade tridimensional;

c) Modelos baseados em teorias múltiplas.

Os modelos baseados na teoria ESL assumem um conjunto de hipóteses em relação ao campo de deslocamentos ou de tensões que transformam o problema tridimensional em um problema bidimensional (placas e cascas) ou unidimensional (barras). Já os modelos baseados em teorias tridimensionais analisam um compósito laminado tratando cada lâmina como um sólido tridimensional (REDDY, 2004a).

As teorias ESL transformam um compósito laminado heterogêneo em uma única lâmina estaticamente equivalente e composta por um material homogêneo cuja lei constitutiva é definida em função das leis constitutivas dos materiais que compõem o laminado.

Dentro das teorias ESL, a mais simples é a teoria clássica (CLT), pois é uma extensão das hipóteses de Euler-Bernoulli para o caso de barras, de Kirchhoff para o caso de placas e de Cauchy-Poisson-Kirchhoff-Love para o caso de cascas. Segundo essa teoria, seções planas e normais a uma superfície de referência permanecem planas e normais a essa superfície no estado deformado do laminado (JONES, 1999; REDDY, 2004a). Com esta hipótese, portanto, tanto as deformações normais ao plano do laminado como as deformações de cisalhamento transversais são desprezadas. 
Seguindo uma ordem crescente de complexidade dentro das teorias ESL, tem-se a teoria FSDT que considera para os compósitos laminados uma extensão das hipóteses de Reissner-Timoskenko para o caso de barras e de Reissner-Mindlin para o caso de placas. Segundo essa teoria, seções planas e normais a uma superfície de referência permanecem planas no estado deformado do laminado, mas não necessariamente normais a essa superfície de referência (CARRERA, 2002). Com esta hipótese, portanto, uma deformação transversal de cisalhamento constante é considerada, mas deformações normais continuam sendo desprezadas.

A teoria FSDT necessita de um fator de correção para o cisalhamento, pois, com a hipótese adotada, as deformações de cisalhamento permanecem constantes na seção transversal. Segundo Reddy (2004a), esse fator de correção é de difícil determinação e deve considerar não somente os parâmetros geométricos e de laminação, mas também as condições de contorno e de carregamento.

As teorias de alta ordem (HSDT) atendem as conhecidas recomendações de Koiter ${ }^{1}$ (1960 apud CARRERA, 2002, p. 99). Essas recomendações afirmam que qualquer refinamento das teorias de análise de compósitos laminados deve considerar de forma simultânea os efeitos das deformações normais e de cisalhamento transversais. Para isso, as teorias HSDT utilizam polinômios de alta ordem (grau maior ou igual a dois) para representar todas as componentes dos deslocamentos ao longo da espessura do laminado (REDDY, 2004a).

Uma teoria de alta ordem bastante conhecida é a chamada por Carrera (2002) de Teoria Vlasov-Reddy (VRT). Na VRT, a descrição do campo de deslocamentos apresenta uma expansão com um polinômio de terceira ordem ao longo da espessura e condições de contorno em forças são aplicadas para garantir o atendimento às tensões de cisalhamento transversais no topo e na base do laminado $\left(\sigma_{i 3}( \pm h / 2)=0\right)$. Segundo Reddy e Phan (1985), o atendimento das condições de contorno em forças na superfície do laminado leva a obtenção mais precisa das frequências de vibração e das cargas de flambagem de placas laminadas se comparado às teorias CLT e FSDT. Reddy (2004a) afirma que as teorias de terceira ordem produzem uma melhora na precisão dos resultados fornecidos por análises em compósitos laminados, mas com aumento no custo computacional e ainda sem garantir a continuidade interlaminar das tensões, pois, ao adotar um campo de deslocamentos único para todo o laminado, as deformações ficam contínuas nas interfaces, quando deveriam ser descontínuas.

A ilustração da Figura 9 permite fazer uma comparação entre as cinemáticas adotadas nas teorias CLT, FSDT, HSDT e entre os campos de deformações e de tensões obtidos com as teorias FSDT e VRT.

\footnotetext{
${ }_{1}^{1}$ KOITER, W. T. A Consistent First Approximations in the General Theory of Thin Elastic Shells. In: First Symposium on the Theory of Thin Elastic Shells, 1959, Amsterdam. Proceedings ... Amsterdam: 1960. p.1223.
} 


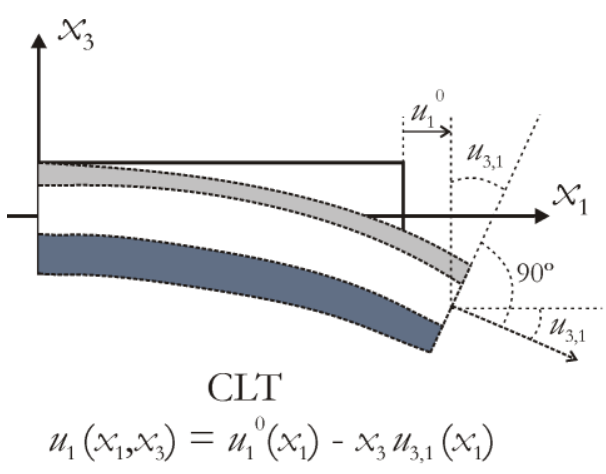

FSDT

(Cisalhamento)
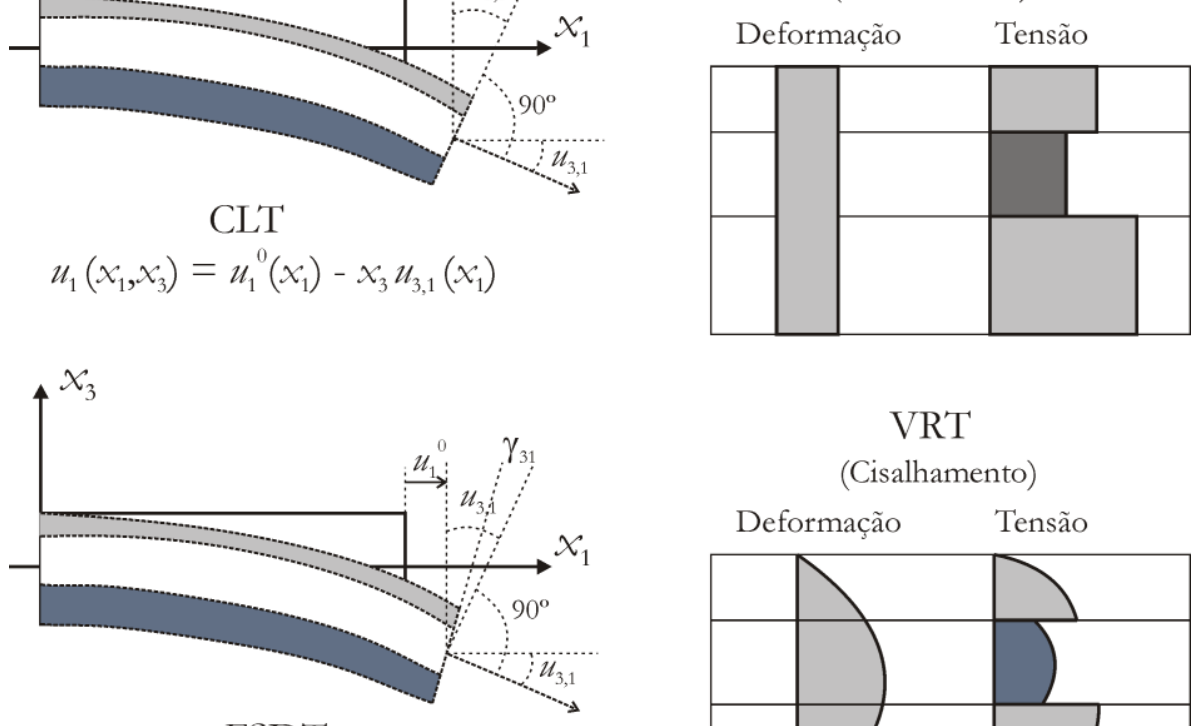

VRT

(Cisalhamento)

FSDT

$u_{1}\left(x_{1}, x_{3}\right)=u_{1}^{0}\left(x_{1}\right)-x_{3} \phi_{31}\left(x_{1}\right)$

$\phi_{31}\left(x_{1}\right)=u_{3,1}\left(x_{1}\right)-\gamma_{31}$
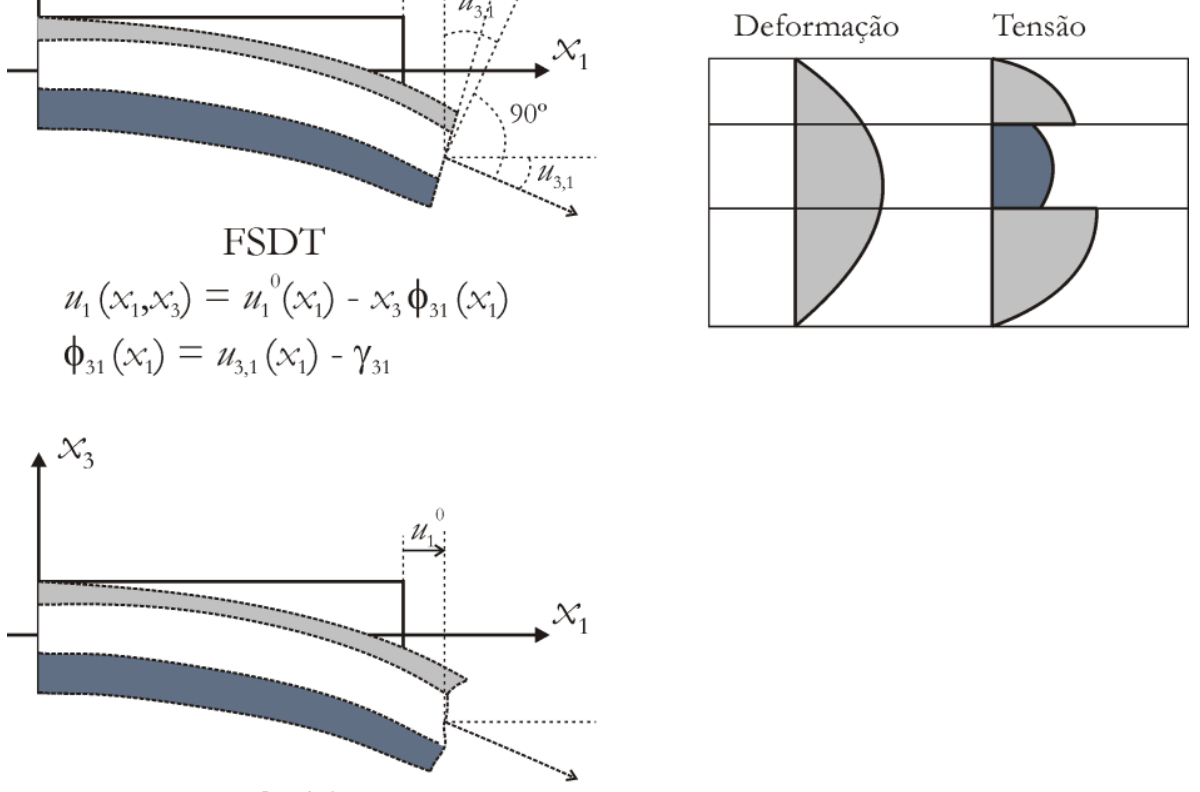

HSDT

$u_{1}\left(x_{1}, x_{3}\right)=u_{1}^{0}\left(x_{1}\right)+\left(x_{3}\right)^{i} u_{1}^{i}\left(x_{1}\right)$

$\operatorname{com} i=1, \ldots, N_{i}$

Figura 9 - Cinemática das teorias CLT, FSDT e HSDT (esq.) e deformações e tensões das teorias FSDT e VRT (dir.) Fonte: Carrera (2002).

Quando se está trabalhando com laminados espessos e quando é necessário determinar a distribuição de tensão e de deformação no nível das lâminas individualmente, principalmente próximo a descontinuidades de geometria e de material ou em regiões de aplicação de carga, os modelos baseados nas teorias de camada única equivalente apresentam resultados imprecisos. Nesses casos, formulações baseadas na teoria da elasticidade são mais adequadas, pois modelam o laminado como um sólido tridimensional. No entanto, essas formulações fornecem soluções analíticas lineares de aplicação restrita, às vezes muito complexas, e podem levar a um elevado custo computacional quando empregadas em conjunto com métodos numéricos como o método dos elementos finitos. 
Uma alternativa é o emprego de teorias de alta ordem associadas às lâminas individualmente. Segundo Carrera (2002), a forma natural de representar o efeito Zig-Zag que ocorre nos campos de deslocamentos de compósitos laminados é por meio da aplicação das teorias ESL (CLT, FSDT, VRT, HSDT) no nível das lâminas. Isto significa tratar cada lâmina de forma independente, o que constitui a abordagem da teoria Layerwise. De acordo com essa teoria, as equações de equilíbrio são estabelecidas para cada lâmina individualmente e condições de interface são introduzidas como restrição em termos de deslocamentos para garantir a compatibilidade entre lâminas adjacentes. (CARRERA, 2002; REDDY, 2004a).

Uma abordagem axiomática dessa teoria com variáveis em deslocamentos pode ser encontrada em Reddy (2004a). Nesta, o campo de deslocamentos para cada lâmina $I$ é representado ao longo da espessura através de uma combinação linear do produto entre polinômios de interpolação de Lagrange $F_{k}^{I}\left(x_{3}\right)$ e variáveis constituídas por funções $f_{k}^{I}\left(x_{1}, x_{2}\right)$ que definem os deslocamentos de todos os pontos localizados em um determinado plano $k$ contido na lâmina $I$. A quantidade de planos $k$ definidos na lâmina depende do grau do polinômio de interpolação empregado.

Na Figura 10, é ilustrado como a componente do deslocamento na direção de $x_{1}$ é aproximada ao longo da espessura do laminado para o caso de interpolação linear. A interpolação dos deslocamentos ao longo da espessura pode ser refinada através do emprego de mais subdivisões (refinamento $h$ ) ou com aumento do grau do polinômio interpolador (refinamento $p$ ).

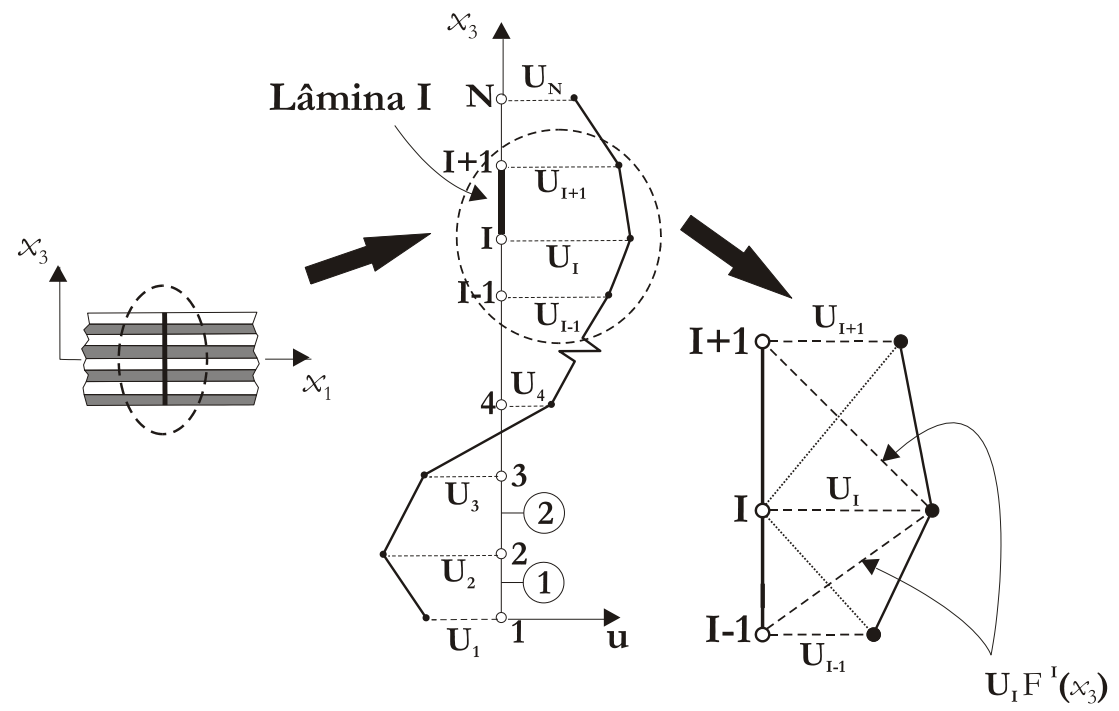

Figura 10 - Interpolação linear dos deslocamentos na teoria Layerwise Fonte: Reddy (2004a). 
A ilustração mostrada na Figura 11 permite comparar as diferenças obtidas com as formulações que empregam a teoria ESL e a teoria Layerwise na representação do campo de deslocamentos no plano das lâminas ao longo da espessura do laminado. Como pode ser observado, as lâminas apresentam giros independentes umas das outras nos campos de deslocamentos obtidos segundo a teoria Layerwise. Essas mesmas lâminas apresentam giros contínuos nas interfaces para os campos de deslocamentos obtidos segundo a teoria ESL. A ocorrência de giros independentes é um fenômeno presente nos compósitos laminados por conta da continuidade das tensões interlaminares, da anisotropia e da heterogeneidade entre lâminas adjacentes.

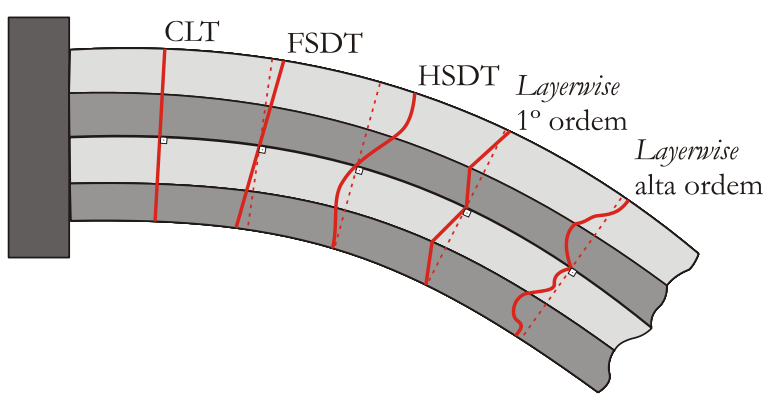

Figura 11 - Deslocamentos no plano das lâminas ao longo da espessura segundo as teorias ESL e Layerwise Fonte: Kreja (2011).

Por fim, as teorias múltiplas empregam diferentes modelos matemáticos (teoria ESL e teoria tridimensional) e diferentes níveis de discretização para modelagem de sub-regiões da estrutura. A combinação desses múltiplos modelos em uma análise global e local é realizada de forma simultânea ou de forma sequencial.

Quando realizada de forma simultânea, a estrutura é modelada, discretizada e analisada com emprego de diferentes modelos matemáticos e diferentes níveis de discretização: modelos baseados na teoria ESL são empregados nas regiões onde é suficiente uma análise global e modelos baseados na teoria Layerwise ou em elementos finitos tridimensionais são empregados onde é necessária uma análise local mais refinada.

Quando empregada de forma sequencial, uma análise global de toda a estrutura é realizada com emprego da teoria ESL e uma subsequente análise local em regiões críticas é realizada com a teoria Layerwise ou com elementos finitos tridimensionais. A grande vantagem dos modelos múltiplos é a possibilidade de analisar uma grande variedade de problemas em laminados com máxima eficiência e mínimo custo computacional (REDDY, 2004a). 


\subsubsection{Falhas em compósitos laminados}

Em um nível micromecânico, as falhas em um compósito laminado podem ocorrer no domínio da matriz, na forma de fissuras e esmagamento; no domínio do reforço (fibra), na forma de ruptura e flambagem; e no domínio das interfaces que pode ser entre as lâminas, entre a fibra e a matriz ou em uma falha originada de um defeito. A falha nas interfaces é caracterizada na forma de propagação de fissura, delaminação ou deslizamento. Quando a falha ocorre na lâmina, costuma-se identificá-la como intralaminar e se a falha ocorrer na interface entre as lâminas, a denominação adotada é de interlaminar (VINSON; SIERAKOWSKI, 2004).

Os critérios para definição de falha em um compósito laminado podem ser estabelecidos no nível dos constituintes das lâminas (critérios micromecânicos) ou no nível das lâminas e do laminado (critérios macromecânicos). Mesmo sendo precisa a detecção do início da falha em pontos críticos das lâminas, é difícil definir a resistência do laminado quando sujeito a um carregamento geral, pois o processo de falha em um laminado ocorre gradualmente em virtude da falha de uma lâmina causar a redistribuição de tensões entre as lâminas remanescentes. Assim, a definição de critérios macromecânicos é preferível em relação aos critérios micromecânicos (DANIEL; ISHAI, 2006).

Como as lâminas são em geral anisotrópicas, a determinação da resistência destas depende da definição completa do estado de tensão. Assim, os métodos de análise de laminados devem ser capazes de fornecer essa informação. Segundo Daniel e Ishai (2006), os critérios de falha para as lâminas podem ser classificados em três grupos:

a) Teorias não interativas: o critério de falha é definido simplesmente a partir da comparação das tensões ou das deformações com as tensões ou deformações últimas. Não há interação entre as diferentes componentes de tensão e deformação. Neste grupo, estão os critérios das tensões e das deformações máximas;

b) Teorias interativas: todas as tensões são consideradas no critério e a falha não é associada a um modo particular. Neste grupo estão os critérios de Tsai-Hill e de Tsai-Wu;

c) Teorias parcialmente interativas: critérios diferentes são estabelecidos para as fibras e para as matrizes e interfaces. Neste grupo, estão presentes os critérios de Hashin-Rotem e de Puck.

O processo de falha do laminado é muito mais complexo do que a falha das lâminas individualmente, pois muitos outros fatores influenciam na resistência do laminado, tais como: 
esquema de laminação, rigidez e resistência das diversas lâminas, processo de fabricação (produz tensões residuais), forma da falha (é mais provável haver danos dispersos em vez de danos localizados), entre outros. A resistência da lâmina é importante para a determinação do início e do progresso da falha no laminado (DANIEL; ISHAI, 2006).

Assim, os critérios de falha para os laminados podem ser divididos no critério da primeira lâmina com falha e no critério de falha última. No primeiro critério, considera-se que a lâmina trabalha da mesma forma tanto individualmente como em um laminado. A partir da análise do compósito laminado, o estado de tensão atuante nas lâminas é verificado com relação aos critérios de falha de lâminas individuais. Em geral, os resultados obtidos com esse critério são conservadores. No segundo critério, observa-se o fato da falha em um laminado ocorrer por meio de um processo de dano progressivo. Como isso é muito mais complexo para determinar, não há uma definição bem estabelecida sobre o que caracteriza a falha última. Alguns critérios estabelecem a falha quando se atinge a carga máxima suportada, outros definem uma deformação limite, outros ainda definem a falha a partir do processo de degradação da rigidez. Por conta dessa incerteza, os laminados projetados com esse critério utilizam maiores coeficientes de segurança do que os projetados com o critério da primeira lâmina com falha (DANIEL; ISHAI, 2006).

Logo, para a determinação precisa da resistência última de um laminado, é necessário obter o estado de tensões tridimensionais atuante nas lâminas e em suas interfaces. Também é necessário conhecer as propriedades relativas à tenacidade das lâminas e à resistência das interfaces. Vale ressaltar que a separação (delaminação) e o deslizamento das lâminas são um importante modo de falha que ocorre comumente em bordas livres e em regiões de descontinuidade geométrica ou de carregamento (REDDY, 2004a).

Para a determinação de uma distribuição de tensões mais precisa nas lâminas e nas interfaces, é necessário o emprego de métodos de análise de laminados mais refinados como os baseados na teoria da elasticidade tridimensional ou na teoria Layerwise. Portanto, neste trabalho, a cinemática adotada para o desenvolvimento do elemento finito laminado permite a rotação independente da seção transversal das lâminas e a variação da espessura destas, em uma extensão da teoria Layerwise.

As principais diferenças da cinemática proposta em relação à da teoria Layerwise são o emprego de posições no lugar de deslocamentos como graus de liberdade e o caráter de pórtico do elemento. 


\subsection{Formulações para análise de estruturas constituídas por compósitos laminados}

Neste item, uma revisão bibliográfica dos trabalhos que tratam sobre análise de estruturas constituídas por compósitos laminados é apresentada. Nesta revisão, pretende-se identificar e descrever sucintamente como a teoria Layerwise vem sendo empregada nas formulações destinadas à análise linear e não linear de estruturas constituídas por compósitos laminados. No fim da revisão, a formulação proposta neste trabalho é delimitada dentre as formulações existentes para análise compósitos laminados que empregam a teoria Layerwise como base para seu desenvolvimento.

Como os compósitos laminados são aplicados principalmente em estruturas de placas e cascas, a quase totalidade dos trabalhos identificados nesta revisão bibliográfica se destina ao estudo desses tipos de estruturas. Apesar disso, as formulações desenvolvidas nos trabalhos relacionados à análise de placas laminadas podem ser diretamente aplicadas aos pórticos planos laminados, bastando desconsiderar uma das dimensões no plano da placa.

Nas teorias ESL, o laminado é representado por uma única lâmina equivalente cujas propriedades são obtidas através de uma média ponderada das propriedades mecânicas de cada lâmina que compõe o laminado ou por meio de técnicas de homogeneização (KREJA, 2011). As variáveis (deslocamentos, tensões ou deslocamentos e tensões) podem ser aproximadas ao longo da espessura de todo o laminado segundo uma descrição axiomática com funções do tipo (REDDY, 2004a):

$$
f\left(x_{1}, x_{2}, x_{3}\right)=f_{i}\left(x_{1}, x_{2}\right) F_{i}\left(x_{3}\right), \quad i=1 \ldots N
$$

na qual $f\left(x_{1}, x_{2}, x_{3}\right)$ é a função assumida para representar a variável do problema em todo o laminado, $f_{i}\left(x_{1}, x_{2}\right)$ são as funções que descrevem a variável do problema no domínio bidimensional e $F_{i}\left(x_{3}\right)$ são as funções que realizam a expansão dessa variável ao longo da espessura do laminado.

Como apresentado no capítulo anterior, as teorias ESL podem ser classificadas basicamente em três tipos: a teoria clássica CLT (Classical Lamination Theory), a teoria de primeira ordem FSDT (First order Shear Deformation Theory) e a teoria de alta ordem HSDT (High order Shear Deformation Theory). Uma ampla revisão bibliográfica sobre as formulações que empregaram essas teorias bem como suas hipóteses básicas podem ser encontradas em Reddy (1993), Ghugal e Shimpi (2001, 2002), Carrera (2002), Reddy (2004a), Kreja (2011) e Lo et al. (2011). As hipóteses básicas dessas teorias são descritas de forma sucinta em seguida. 
A teoria CLT se baseia na hipótese de que seções planas e normais a uma superfície de referência permanecem planas e normais a essa superfície no estado deformado do laminado. O modelo utilizado na descrição do campo de deslocamentos $u\left(x_{1}, x_{2}, x_{3}\right)$ para o caso de placas, por exemplo, é dado por (CARRERA, 2002):

$$
\begin{aligned}
& u_{i}\left(x_{1}, x_{2}, x_{3}\right)=u_{i}^{0}\left(x_{1}, x_{2}\right)-x_{3} u_{3, i}\left(x_{1}, x_{2}\right), \text { com } i=1 \text { e } 2 \\
& u_{3}\left(x_{1}, x_{2}, x_{3}\right)=u_{3}^{0}\left(x_{1}, x_{2}\right) .
\end{aligned}
$$

com $u_{1}$ e $u_{2}$ indicando deslocamentos em direções contidas do plano e $u_{3}$, na espessura.

A teoria FSDT considera a hipótese de que seções planas e normais a uma superfície de referência permanecem planas no estado deformado do laminado, mas não necessariamente normais a essa superfície de referência. O modelo utilizado na descrição do campo de deslocamentos $(u)$ para o caso de placas, por exemplo, é dado por (CARRERA, 2002):

$$
\begin{aligned}
& u_{i}\left(x_{1}, x_{2}, x_{3}\right)=u_{i}^{0}\left(x_{1}, x_{2}\right)-x_{3} \phi_{3 i}\left(x_{1}, x_{2}\right), \text { com } i=1 \text { e } 2 \\
& u_{3}\left(x_{1}, x_{2}, x_{3}\right)=u_{3}^{0}\left(x_{1}, x_{2}\right),
\end{aligned}
$$

$\operatorname{com} \phi_{3 i}\left(x_{1}, x_{2}\right)=u_{3, i}\left(x_{1}, x_{2}\right)-\gamma_{3 i}\left(x_{1}, x_{2}\right)$ e $\gamma_{3 i}\left(x_{1}, x_{2}\right)$ sendo a deformação de cisalhamento.

As teorias de alta ordem (HSDT) surgiram para representar melhor a distribuição das tensões de cisalhamento transversais e para considerar as tensões axiais transversais. De acordo com essas teorias, a descrição do campo de deslocamentos para o caso de placas, por exemplo, é dado por (CARRERA, 2002):

$$
u_{i}\left(x_{1}, x_{2}, x_{3}\right)=u_{i}^{0}+\left(x_{3}\right) u_{i}^{1}+\left(x_{3}\right)^{2} u_{i}^{2}+\ldots+\left(x_{3}\right)^{N_{i}} u_{i}^{N_{i}}, \quad \text { com } i=1,2 \text { e } 3,
$$

sendo $u_{i}^{j}\left(x_{1}, x_{2}\right), \operatorname{com} j=0, \ldots, N_{i}$, os coeficientes do polinômio e $N_{i}$ a ordem de expansão do campo de deslocamento na direção $i$.

Conforme discutido anteriormente, as distribuições de tensões axiais e de cisalhamento transversais devem ser contínuas nas interfaces de um laminado devido ao equilíbrio de forças e os deslocamentos devem ser compatíveis desde que não haja falha do material. Por conta disso e da mudança de propriedades do material de uma lâmina para outra, é necessário haver uma descontinuidade das deformações transversais nas interfaces das lâminas, gerando deslocamentos no plano do laminado com um comportamento Zig-Zag ao longo da espessura.

Esse comportamento Zig-Zag é bem pronunciando em laminados espessos e quando há uma variação brusca das constantes elásticas do material das lâminas. Isso pode ser constatado nas soluções analíticas obtidas a partir da teoria da elasticidade tridimensional encontradas em 
Pagano (1969, 1970), Pagano e Hatfield (1972), Noor (1973) e Piskunov, Sipetov e Tuimetov (1990), para o caso de flexão de placas laminadas, e em Ren (1987b) e Varadan e Bhaskar (1991), para o caso de flexão de cascas cilíndricas.

Uma cinemática mais correta para o campo de deslocamentos em laminados espessos pode ser obtida com a teoria Layerwise, pois o comportamento Zig-Zag dos deslocamentos no plano do laminado é representado. Ao contrário dos modelos ESL, nos quais, ao longo da espessura do laminado, o campo de deslocamentos é de classe $C^{1}$ e, portanto, produz continuidade de deformações e descontinuidade de tensões nas interfaces, a cinemática adotada na teoria Layerwise permite representar um campo de deslocamentos de classe $C^{0}$. Isso gera um campo de deformações descontínuo nas interfaces das lâminas e torna possível a continuidade das tensões interlaminares. Reddy (2004a) afirma que a teoria Layerwise é bem aceita quando é necessária uma representação mais precisa das distribuições de tensões para, por exemplo, identificar o início da falha nas lâminas e interfaces, bem como, seu progresso ao longo do laminado como um todo.

A ideia essencial da teoria Layerwise é representar as variáveis do problema (deslocamentos, tensões ou deslocamentos e tensões) através de funções independentes em cada lâmina. Para os casos de placas e cascas, nos quais essa teoria é mais aplicada, as variáveis do problema são assumidas, por exemplo, como funções do tipo:

$$
f^{(k)}\left(x_{1}, x_{2}, x_{3}\right)=f_{i}^{(k)}\left(x_{1}, x_{2}\right) F_{i}^{(k)}\left(x_{3}\right), \quad i=1 \ldots N
$$

na qual $f^{(k)}\left(x_{1}, x_{2}, x_{3}\right)$ é a função assumida para representar a variável do problema na lâmina $(k), f_{i}^{(k)}\left(x_{1}, x_{2}\right)$ são as funções bidimensionais que descrevem a variável do problema no domínio de planos $i$ contidos na lâmina, $F_{i}^{(k)}\left(x_{3}\right)$ são as funções que realizam a expansão dessa variável ao longo da espessura da lâmina e $N$ é o número de nós distribuídos ao longo da espessura da lâmina. As condições de compatibilidade em deslocamentos e de continuidade das tensões transversais interlaminares podem ser satisfeitas com a imposição de restrições nas interfaces (CARRERA, 2002).

Segundo Reddy (2004a), a teoria Layerwise baseada em deslocamentos pode ser classificada em parcial e completa. Na teoria Layerwise parcial, a componente do campo de deslocamentos na direção transversal - $u_{3}\left(x_{1}, x_{2}\right)$ - é considerada constante ao longo da espessura e a expansão discreta por lâminas ocorre apenas para as componentes do campo de deslocamentos nas direções contidas no plano das lâminas $-u_{1}\left(x_{1}, x_{2}, x_{3}\right)$ e $u_{2}\left(x_{1}, x_{2}, x_{3}\right)$. Já na teoria Layerwise completa, a expansão discreta por lâminas ocorre para as três componentes 
do campo de deslocamentos - $u_{1}\left(x_{1}, x_{2}, x_{3}\right), u_{2}\left(x_{1}, x_{2}, x_{3}\right)$ e $u_{3}\left(x_{1}, x_{2}, x_{3}\right)$. Consequentemente, as tensões de cisalhamento transversais são consideradas tanto na teoria parcial como na completa, mas as tensões axiais transversais são desprezadas na teoria parcial e consideradas somente na teoria completa.

Outra divisão interessante foi proposta por Ghugal e Shimpi (2002) para classificar as teorias Layerwise aplicadas a placas. Essa divisão, entretanto, pode ser estendida para as teorias Layerwise aplicadas a outras estruturas laminadas como vigas e cascas. Segundo esses autores, o número de incógnitas das teorias Layerwise pode depender ou não do número de lâminas que compõe o laminado. Dessa forma, têm-se as teorias Layerwise dependentes e as teorias Layerwise independentes.

Diante dessas duas classificações para as teorias Layerwise, os trabalhos consultados nesta revisão bibliográfica serão apresentados e ordenados nas seguintes categorias: teoria Layerwise parcial dependente, teoria Layerwise parcial independente, teoria Layerwise completa dependente e teoria Layerwise completa independente.

Alguns trabalhos que empregam a teoria Layerwise parcial dependente do número de lâminas são encontrados em Srinivas (1973), Reddy ${ }^{2}$ (1987 apud REDDY, 2004a) e Barbero, Reddy e Teply (1990). Srinivas (1973) apresentou uma formulação layerwise parcial para análises estáticas e dinâmicas de placas laminadas. De acordo com essa formulação, os deslocamentos no plano do laminado são aproximados a partir de uma expansão layerwise linear. Já o deslocamento transversal é assumido constante na espessura. Uma generalização da teoria layerwise parcial para representação do campo de deslocamentos foi apresentada por Reddy ${ }^{2}(1987$ apud REDDY, 2004a) para análise de placas laminadas. Barbero, Reddy e Teply (1990) estenderam a ideia para cascas laminadas cilíndricas. A teoria é baseada na interpolação do campo de deslocamentos em cada lâmina. $\mathrm{Na}$ proposta dos autores, a representação dos deslocamentos na espessura é realizada através de elementos finitos Lagrangianos unidimensionais que se mostraram bastante convenientes, pois qualquer grau de aproximação é facilmente empregado. Os resultados de deslocamentos, tensões e frequências naturais obtidos se aproximaram bem de soluções analíticas tridimensionais.

Os modelos baseados na teoria Layerwise parcial são mais realistas do que os modelos de camada única equivalente (ESL), pois consideram o comportamento Zig-Zag para o campo de deslocamentos no plano das lâminas e, consequentemente, produzem um campo de deformações de cisalhamento transversal descontínuo na espessura. Uma limitação da teoria parcial está associada à desconsideração de uma variação do deslocamento transversal ao longo da espessura do laminado, desprezando, assim, as tensões axiais transversais. Dessa forma, não é possível 
satisfazer as condições de contorno na base e no topo do laminado com tensões normais aplicadas e não se obtém uma distribuição de tensões realista na região de bordos livres sujeitos a tensões de cisalhamento transversais. Os modelos baseados na teoria Layerwise parcial fornecem resultados imprecisos em regiões descontínuas como aberturas, bordos livres e frentes de delaminação. Isso se deve à desconsideração das tensões axiais transversais que são significativas nessas regiões. Uma alternativa para contornar essa limitação é realizar uma expansão layerwise, também, para o deslocamento transversal, o que constitui a proposta da teoria Layerwise completa (REDDY, 2004a).

Formulações que empregam a teoria Layerwise completa e possuem a quantidade de variáveis dependentes do número de lâminas podem ser encontradas nos trabalhos de Epstein e Huttelmaier (1983), Huttelmaier e Epstein (1985), Cho, Striz e Bert (1990), Cho, Bert e Striz (1991), Lee e Liu (1992), Gaudenzi (1992), Gaudenzi, Barboni e Mannini (1995), Negishi e Hirashima (1997), Zhu e Lam (1998) e Reddy (2004a).

As formulações de Epstein e Huttelmaier (1983) e de Huttelmaier e Epstein (1985) apresentam características semelhantes à formulação desenvolvida no presente trabalho. Empregando um mapeamento vetorial, Epstein e Huttelmaier (1983) e Huttelmaier e Epstein (1985) apresentaram uma formulação baseada no método dos elementos finitos para análise de placas e cascas laminadas, respectivamente. $\mathrm{Na}$ proposta, um elemento finito bidimensional quadrangular isoparamétrico com quatro nós fica localizado em uma superfície de referência e o mapeamento na espessura é realizado ao longo de cada um de seus nós. Todo esse mapeamento é realizado a partir de um sistema de referência adimensional. Para isso, são empregados vetores posição $\mathbf{r}$ que localizam os nós do elemento na superfície de referência e vetores diretores $\mathbf{d}_{I}$ que, em conjunto com uma coordenada adimensional $q_{I}$, mapeiam todos os pontos na espessura de cada lâmina $I$. Os graus de liberdade do elemento são constituídos por vetores $\mathbf{u}$ e $\mathbf{e}_{I}$ que representam o deslocamento de um nó do elemento e variação do vetor diretor $\mathbf{d}_{I}$ nodal, respectivamente. Dessa forma, consideram-se tanto as tensões de cisalhamento transversais como as tensões axiais transversais. A determinação de $\mathbf{u}$ e $\mathbf{e}_{I}$ é realizada aplicando o Princípio dos Trabalhos Virtuais (PTV). A formulação emprega uma cinemática semelhante à expansão layerwise de primeira ordem, pois as seções de cada lâmina apresentam giros constantes ao longo da espessura e independentes, permanecendo retas, mas não necessariamente normais à superfície de referência. Esta formulação teve origem no trabalho de Epstein e Glockner (1977) para análise não linear de cascas laminadas. 
As formulações de Epstein e Glockner (1977), Epstein e Huttelmaier (1983) e Huttelmaier e Epstein (1985) são um dos poucos trabalhos encontrados com esse apelo vetorial para representar a cinemática de um laminado. Todos os demais trabalhos consultados utilizam funções matemáticas que representam os campos de deslocamentos e/ou de tensões.

Nesse sentido, Cho, Striz e Bert (1990) e Cho, Bert e Striz (1991) assumiram um campo de deslocamentos de alta ordem para os três deslocamentos e apresentaram uma solução analítica para o problema de flexão cilíndrica com carregamento senoidal e para a vibração em placas laminadas simplesmente apoiadas. Nessa solução, os deslocamentos no plano e o deslocamento transversal de cada lâmina são aproximados por funções de terceira e segunda ordem na coordenada ao longo da espessura, respectivamente. Na proposta de Lee e Liu (1992), para análise de vigas laminadas, polinômios cúbicos de Hermite foram empregados para a interpolação independente dos deslocamentos longitudinal e transversal ao longo da espessura. A fim de garantir a descontinuidade de deformações transversais, giros distintos nas lâminas adjacentes a uma interface são admitidos.

Através de uma expansão do campo de deslocamentos na direção da espessura utilizando série de potências de alta ordem, Gaudenzi (1992) propôs uma formulação geral para análise de placas laminadas. Casos particulares de modelos Zig-Zag e modelos de camada única podem ser obtidos a partir dessa formulação geral. Gaudenzi, Barboni e Mannini (1995) estenderam essa proposta para uma formulação baseada no método dos elementos finitos. Negishi e Hirashima (1997) também utilizaram uma expansão com série de potências para desenvolver uma formulação geral que utiliza o princípio de Hamilton e relaxamento das condições de compatibilidade dos deslocamentos nas interfaces para a análise estática e dinâmica de compósitos laminados sujeitos ao deslizamento.

Uma alternativa ao uso de funções de Hermite é o emprego de funções de interpolação do tipo spline. Essa ideia foi utilizada por Zhu e Lam (1998) para a determinação de tensões locais em compósitos laminados. Uma distribuição de tensões precisa foi obtida com o emprego de funções spline cúbicas para a interpolação do campo de deslocamentos de cada lâmina na espessura e com a imposição de condições de compatibilidade e continuidade de tensões transversais nas interfaces. O método de solução de Rayleigh-Ritz também foi empregado.

Em busca de uma generalização da teoria Layerwise, Reddy (2004a) apresentou uma formulação baseada no método dos elementos finitos que é desenvolvida a partir da composição entre elementos bidimensionais, responsáveis pela interpolação dos deslocamentos no plano da lâmina, e elementos unidimensionais Lagrangianos para a interpolação, com qualquer grau de 
aproximação, dos deslocamentos ao longo da espessura. Dessa forma, teorias Layerwise completas de baixa a alta ordem podem ser desenvolvidas facilmente.

Os elementos desenvolvidos com essa generalização se assemelham aos elementos finitos 3D, no entanto, Reddy (2004a) afirma que os elementos layerwise possuem algumas vantagens, tais como: manutenção de uma estrutura de dados do tipo $2 \mathrm{D}$ semelhante à estrutura de dados das teorias ESL, levando a uma redução do volume de dados de entrada se comparado aos elementos 3D, e maior flexibilidade com relação ao refinamento da malha no plano do laminado e na direção transversal, pois é possível realizá-lo independentemente um do outro. Nos elementos finitos 3D, não há essa independência, uma vez que é necessária a reformulação completa do elemento.

A estrutura de dados 2D permite uma formulação mais eficiente para a matriz de rigidez do elemento, pois as integrações de volume podem ser realizadas por meio de integrações numéricas separadas com relação à coordenada ao longo da espessura e com relação às coordenadas no plano. Uma única integração ao longo da espessura pode ser utilizada para todos os pontos de Gauss nas integrações no plano. Essas integrações separadas reduzem significativamente a quantidade de operações matemáticas necessárias para o cálculo da matriz de rigidez do elemento layerwise se comparado às operações matemáticas para o cálculo da matriz de rigidez de um elemento finito 3D (REDDY, 2004a).

As teorias Layerwise dependentes podem se tornar limitadas quando o custo computacional passa a ser excessivo devido ao aumento do número de lâminas na composição de um laminado. Nesse sentido, as teorias Layerwise independentes são vantajosas, pois o número de incógnitas não aumenta com o número de lâminas. Além disso, outro aspecto importante a ser ressaltado está relacionado à continuidade interlaminar das tensões transversais. Muitas formulações baseadas nas teorias Layerwise dependentes satisfazem somente o comportamento Zig-Zag para o campo de deslocamentos enquanto a maior parte das formulações baseadas nas teorias Layerwise independentes satisfazem, também, a continuidade interlaminar das tensões transversais. Essa condição é utilizada justamente como uma restrição adicional para reduzir a quantidade de incógnitas, tornando a formulação independente do número de lâminas.

Dentre as teorias Layerwise independentes, as mais conhecidas e que tem recebido maior atenção dos pesquisadores são as chamadas por Sciuva (1986) de teorias Zig-Zag. Segundo Reddy (2004a), um campo de deslocamentos parcial adotado por essas teorias para aplicações estáticas assume uma forma do tipo: 


$$
\begin{aligned}
& u_{i}\left(x_{1}, x_{2}, x_{3}\right)=u_{i}^{0}\left(x_{1}, x_{2}\right)-x_{3} u_{3, i}^{0}\left(x_{1}, x_{2}\right)+f_{i j}\left(x_{3}\right) \phi_{j}\left(x_{1}, x_{2}\right) \operatorname{com} i, j=1 \text { e } 2 \\
& u_{3}\left(x_{1}, x_{2}, x_{3}\right)=u_{3}^{0}\left(x_{1}, x_{2}\right),
\end{aligned}
$$

sendo $f_{i j}\left(x_{3}\right)$ e $\phi_{j}\left(x_{1}, x_{2}\right)$ funções determinadas tais que os deslocamentos e as tensões transversais sejam contínuos nas interfaces das lâminas.

Uma excelente revisão bibliográfica sobre as teorias Zig-Zag é apresentada por Carrera (2002). Este autor cita três modelos principais que originaram essas teorias: o modelo Lekhnitskii-Ren, o modelo Ambartsumian-Whitney-Rath-Das e o modelo Reissner-MurakamiCarrera.

Segundo Carrera (2002), o modelo Lekhnitskii-Ren foi proposto por Lekhnitskii ${ }^{3}$ (1935 apud CARRERA, 2002) para vigas e foi estendido por Ren (1986a, 1986b, 1987a) para análise de placas laminadas ortotrópicas e anisotrópicas. A formulação de Ren (1986a, 1986b, 1987a) é baseada em tensões e uma expansão layerwise de segunda ordem ao longo da espessura foi adotada para as tensões de cisalhamento transversais, que satisfazem condições de continuidade nas interfaces. A partir da integração das relações deformação-deslocamento e da imposição de compatibilidade nas interfaces, uma expansão layerwise cúbica é determinada para representar os deslocamentos no plano do laminado.

Com relação ao modelo Ambartsumian-Whitney-Rath-Das, Carrera (2002) afirma ter sua origem devida aos trabalhos de Ambartsumian ${ }^{4}$ (1958a, 1958b, 1961, 1962, 1969 apud CARRERA, 2002) que foram estendidos para placas anisotrópicas por Whitney ${ }^{5}(1969$ apud CARRERA, 2002). Este último teve seu trabalho estendido para cascas laminadas por Rath e Das (1973) cuja formulação é baseada em tensões com uma expansão layerwise de segunda ordem ao longo da espessura para as tensões de cisalhamento transversais. Impondo a continuidade interlaminar dessas tensões e a partir da integração das relações deformação-deslocamento, um campo de deslocamentos layerwise de quarta ordem compatível nas interfaces foi determinado. $\mathrm{O}$ deslocamento transversal é considerado constante na seção.

Por fim, Carrera (2002) afirma que o modelo Reissner-Murakami-Carrera é originado a partir de uma abordagem variacional mista conhecida como Teorema Variacional Misto de

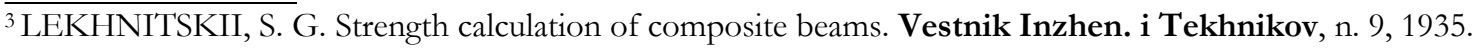

${ }^{4}$ AMBARTSUMIAN, S. A. On a theory of bending of anisotropic plates. Investiia Akad. Nauk SSSR, Ot. Tekh. Nauk., n. 4, 1958a.

${ }_{4}^{4}$ AMBARTSUMIAN, S. A. On a general theory of anisotropic shells. PMM, v. 22, n. 2, p. 226-237, 1958 b.

${ }^{4}$ AMBARTSUMIAN, S. A. Theory of anisotropic shells. Fizmatzig, Moskwa, 1961; Translated from Russian, NASA TTF-118, 1964.

${ }^{4}$ AMBARTSUMIAN, S. A. Contributions to the theory of anisotropic layered shells. Applied Mechanics Review, v. 15 , p. 245-249, 1962.

${ }^{4}$ AMBARTSUMIAN, S. A. Theory of anisotropic plates, Translated from Russian by T. Cheron and Edited by J.E. Ashton Tech. Pub. Co, 1969.

5 WHITNEY, J. M. The effects of transverse shear deformation on the bending of laminated plates. Journal of Composite Materials, v. 3, p. 534-547, 1969. 
Reissner (RMVT - Reissner's Mixed Variational Theorem). Nesse modelo, os deslocamentos e as tensões transversais são aproximados de forma independente por funções parciais (piecewise function) ou funções layerwise. Através da minimização do funcional de energia potencial total, as incógnitas são determinadas. Condições de compatibilidade e continuidade de tensões interlaminares são impostas no funcional de energia a partir de técnicas como a dos multiplicadores de Lagrange. Um exemplo de trabalho que empregou este modelo foi o de Toledano e Murakami (1987). Neste trabalho, uma função parcial (piecewise function) foi adotada para aproximar todos os deslocamentos. Essa função é constituída por polinômios de Legendre de primeiro, segundo e terceiro graus e por uma parcela Zig-Zag. Essa parcela Zig-Zag é composta por uma função que contém o termo $(-1)^{k}$ com $k$ sendo o número da lâmina. Independentemente, as tensões de cisalhamento transversais e a tensão normal transversal foram aproximadas em uma expansão layerwise utilizando polinômios de quarto e quinto graus, respectivamente.

Alguns trabalhos importantes para o desenvolvimento das técnicas de análise de compósitos laminados utilizaram formulações baseadas na teoria Layerwise parcial com independência do número de lâminas. Estas formulações podem ser classificadas como teorias Zig-Zag e foram propostas por Spilker (1980), Sciuva (1986), Owen e Li (1987a, 1987b), Lee et al. (1990, 1994), Soldatos (1992), Xavier, Lee e Chew (1993) e Xaxier, Chew e Lee (1995).

Spilker (1980) propôs uma formulação de elemento finito híbrido para análise de placas laminadas. O elemento proposto é desenvolvido a partir da adoção de uma expansão layerwise de alta ordem ao longo da espessura do laminado tanto para os deslocamentos quanto para as tensões. Condições de compatibilidade e equilíbrio são satisfeitas nas interfaces do laminado, assim como as condições de contorno em tensões nas faces superior e inferior.

No trabalho de Sciuva (1986) surgiu o nome teoria Zig-Zag. Problemas de flexão, amortecimento e flambagem em uma placa espessa quadrada, constituída por três laminas simétricas e simplesmente apoiadas foram analisados. Com o uso de funções de Heaviside, satisfazendo condições de equilíbrio e de compatibilidade nas interfaces das lâminas e empregando enriquecimento nas deformações, Sciuva (1986) propôs uma função linear parcial (piecewise function) para os deslocamentos no plano. O modelo adotado foi chamado de teoria ZigZag, pois o comportamento Zig-Zag dos deslocamentos ao longo da espessura foi representado.

Modificando uma proposta apresentada por Reddy ${ }^{2}(1987$ apud REDDY, 2004a), Owen e Li (1987a, 1987b) propuseram uma formulação de elementos finitos para análise de pro blemas estáticos, de vibração e de estabilidade em placas laminadas. A formulação apresenta os deslocamentos no plano do laminado representados ao longo da espessura por uma função linear 
parcial (piecewise function). Aplicando separadamente a primeira variação do funcional de energia em relação aos graus de liberdade dos nós contidos no corpo da lâmina e em relação aos graus de liberdade dos nós contidos na face superior da lâmina, as variáveis dos nós no corpo do elemento foram obtidas em função das variáveis pertencentes aos nós contidos na interface superior da lâmina. Owen e Li (1987a, 1987b) chamaram essa técnica de subestruturação (substrucuture). Por meio dela, a quantidade de variáveis da formulação ficou independente no número de lâminas.

Outros trabalhos com ideias diferentes que empregam uma expansão layervise de primeira ordem parcial e independente são o de He, Chou e Zhang (1993) e de Botello, Oñate e Canet (1999). Para reduzir e tornar a quantidade de variáveis independente do número de lâminas, He, Chou e Zhang (1993) adotaram uma hipótese de que as deformações de cisalhamento transversais de quaisquer duas lâminas são linearmente dependentes uma da outra e Botello, Oñate e Canet (1999) usaram técnicas de condensação durante a montagem da matriz de rigidez do elemento finito proposto.

Em vez de trabalhar, como nas formulações anteriores, com os deslocamentos no plano do laminado variando segundo uma função linear ao longo da espessura, Lee, Senthilnathan e Chow (1990) e Lee, Lin e Chow (1994) propuseram uma formulação mais precisa adotando uma variação cúbica para esses deslocamentos em cada lâmina. Empregando condições de compatibilidade e continuidade de tensões interlaminares, o comportamento Zig-Zag ao longo da espessura foi satisfeito e o número de incógnitas da formulação se tornou independente do número de lâminas e igual ao das formulações baseadas na teoria FSDT. Esses trabalhos se destinaram à análise de placas laminadas. Xavier, Lee e Chew (1993) e Xaxier, Chew e Lee (1995) estenderam a formulação para análise de cascas laminadas.

Muitas formulações são desenvolvidas considerando uma expansão layerwise parcial do campo de deslocamentos a partir de uma variação layerwise cúbica superposta com uma variação linear parcial (piecenvise function). Impondo compatibilidade de deslocamentos e continuidade das tensões transversais nas interfaces, a quantidade de variáveis do problema se torna independente do número de lâminas. Trabalhos já citados com essas características são os de Ren (1986a, 1986b, 1987a) e de Toledado e Murakami (1987). Outros trabalhos são os de Sciuva (1992) e Cho e Parmeter (1992), que superpuseram uma expansão layerwise de terceira ordem com funções de Heaviside, e de Icardi (1998), que adotou um campo de deslocamentos semelhante ao de Sciuva (1992) e de Cho e Parmeter (1992) para propor um elemento finito curvilíneo com oito nós para análise de placas laminadas.

Uma formulação geral de alta ordem foi apresentada por Soldatos (1992). Sua teoria é adequada para análises estáticas e dinâmicas de placas laminadas e baseia-se na adoção de um 
campo de deslocamentos expandido na espessura com emprego de séries de potências e funções de Heaviside. Com o uso de multiplicadores de Lagrange em conjunto com o princípio de Hamilton, as equações diferenciais do problema foram obtidas e suas soluções levaram a um campo de deslocamentos que satisfaz a compatibilidade dos deslocamentos e a continuidade das tensões de cisalhamento transversais nas interfaces das lâminas.

Em vez de adotar variações polinomiais ou em séries de potências ao longo da espessura como em muitos trabalhos, Karama et al. (1998) considerou uma expansão layerwise parcial do campo de deslocamentos empregando funções trigonométricas superpostas com funções lineares e funções de Heaviside. Esta última função garante o comportamento Zig-Zag do campo de deslocamentos que independe do número de lâminas.

Da mesma forma como na teoria Layerwise parcial, formulações independentes do número de lâminas são desenvolvidas para teorias Layerwise completas. As condições de continuidade das tensões transversais e de compatibilidade dos deslocamentos nas interfaces continuam constituindo as principais restrições utilizadas para tornar o número de incógnitas independente do número de lâminas. Além disso, as condições de contorno, também, são impostas e atendidas nessas formulações.

Muitas formulações da teoria Layerwise completa independente apresentam expansões de alta ordem. Moazzami e Sandhu (1993) propuseram uma formulação baseada em uma expansão de segunda ordem para os deslocamentos no plano e uma expansão linear para o deslocamento transversal. Já Wu e Kuo (1992) e Wu e Hsu (1993) adotaram uma expansão polinomial cúbica para os deslocamentos no plano e uma expansão polinomial quadrática para o deslocamento transversal. As condições de compatibilidade e continuidade de tensões nas interfaces foram introduzidas dentro do funcional de energia potencial total por meio de multiplicadores de Lagrange. Um trabalho baseado em tensões foi apresentado por He e Zhang $(1997,1999)$ que adotaram uma expansão cúbica para as tensões transversais. A fim de tornar a formulação independente do número de lâminas, além das condições de restrição citadas anteriormente, a hipótese de que as deformações de cisalhamento transversais de quaisquer duas lâminas são linearmente dependentes uma da outra foi adotada. A partir da integração das tensões transversais, uma variação cúbica na espessura foi determinada para a tensão transversal normal e para os campos de deslocamentos.

A maior parte dos trabalhos citados até aqui são dedicados à análise de estruturas formadas por compósitos laminados sujeitas a pequenos deslocamentos, pequenas deformações e constituídas por material elástico linear. Nesses casos, uma análise linear é suficiente para fornecer resultados satisfatórios. 
No entanto, como os compósitos laminados possuem elevadas resistência e rigidez específicas (relações resistência/densidade e rigidez/densidade, respectivamente), as estruturas são na sua grande maioria leves, esbeltas e suscetíveis a grandes deslocamentos. Outra característica relevante dos compósitos laminados é a anisotropia, que pode ser controlada com a mudança de orientação e sequência de empilhamento das lâminas. Isso permite a otimização das propriedades mecânicas do material, mas, como cada lâmina tende a trabalhar de forma independente, surgem concentrações de tensões nas interfaces para garantir a compatibilidade de deslocamentos. Essa anisotropia, também, leva a um complexo acoplamento entre as deformações no plano das lâminas e as deformações transversais às lâminas. Assim, devido a essas características, um comportamento não linear é observado tanto em estruturas sujeitas a pequenos deslocamentos como em estruturas sujeitas a grandes deslocamentos (GRUTTMANN et al., 1993; ĆETKOVIĆ, VUKSANOVIĆ, 2011).

Muitos trabalhos têm sido desenvolvidos considerando-se análises não lineares de estruturas formadas por compósitos laminados. A maior parte considera somente a não linearidade geométrica com a estrutura sujeita a pequenas ou grandes deformações e alguns dos problemas estudados são a detecção de falhas como a delaminação, análise do comportamento após a flambagem e análise de estruturas formadas por compósitos contendo materiais piezoelétricos.

Alguns trabalhos dedicados à análise não linear de placas laminadas são os de Barbero e Reddy (1991), Reddy Y. e Reddy J. (1992), Icardi (1994), Schmidt e Librescu (1994), Zinno e Barbero (1994), Reddy Y., Moorthy e Reddy J. (1995), Kam, Sher e Chao (1996), Sciuva, Icardi e Villani (1998), Reddy (2004a), Andrade, Awruch e Morsch (2007), Toudeshky, Hosseini e Mohammadi (2010), Ćetković e Vuksanović (2011), Choudhary e Tungikar (2011), Kishore, Singh e Pandit (2011), Kapoor e Kapania (2012). Para análise não linear de cascas laminadas, trabalhos relacionados são os de Epstein e Glockner (1977), Gruttmann et al. (1993), Chaudhuri e Hsia (1998), To e Liu (2001), Reddy (2004a), Kim e Chaudhuri (2005), Andrade, Awruch e Morsch (2007), Isoldi et al. (2008), Moreira, Sousa e Valente (2010). Por fim, até onde essa pesquisa bibliográfica se estendeu, somente o trabalho de Vo e Lee (2010) trata da análise não linear em barras (vigas) laminadas.

O procedimento numérico mais utilizado para o desenvolvimento de formulações adequadas à realização de análises não lineares em estruturas formadas por compósitos laminados é o método dos elementos finitos, pois este é uma ferramenta que facilita a manipulação numérica desses problemas e viabiliza a implementação computacional (CHAUDHURI, HSIA, 1998). Assim, Reddy (2004a) afirma que duas abordagens têm sido seguidas para o 
desenvolvimento de modelos com emprego do método dos elementos finitos para análise não linear de compósitos laminados. Essas abordagens dão origem aos elementos finitos laminados e aos elementos finitos contínuos.

Os elementos finitos laminados são obtidos com emprego das teorias de laminados ESL que reduzem o problema tridimensional para um problema bi ou unidimensional a partir de um conjunto de hipóteses cinemáticas e de homogeneização ao longo da espessura. As formulações não lineares que utilizam esses elementos são empregadas em análises de estruturas sujeitas a pequenas deformações e grandes deslocamentos. As deformações empregadas são as de von Kármán (REDDY, 2004a; ĆETKOVIĆ, VUKSANOVIĆ, 2011). O emprego dos elementos finitos laminados pode ser encontrado nos trabalhos de Reddy Y. e Reddy J. (1992), Kam, Sher e Chao (1996), Sciuva, Icardi e Villani (1998), Reddy (2004a), Isoldi et al. (2008), Vo e Lee (2010), Kishore, Singh e Pandit (2011), Kapoor e Kapania (2012) e Singh e Shukla (2012). As formulações propostas nesses trabalhos são adequadas quando o interesse está relacionado ao comportamento global de laminados com espessura fina ou moderada.

Como discutido nos itens anteriores, as formulações baseadas na teoria ESL não são capazes de representar o comportamento Zig-Zag dos deslocamentos no plano das lâminas e não conseguem satisfazer a continuidade de tensões interlaminares. Assim, quando é necessário avaliar aspectos locais como a distribuição de tensões ao longo da espessura para prever o início e o progresso da falha do laminado por delaminação, deslizamento ou fissuração, as teorias Layerwise são reconhecidas por fornecerem bons resultados para as distribuições de tensões e deslocamentos no nível das lâminas.

Nesse sentido, os elementos finitos contínuos são mais adequados, pois se baseiam em uma formulação contínua tridimensional, na qual hipóteses cinemáticas são introduzidas em uma aproximação também tridimensional. A essa abordagem pertencem os elementos obtidos a partir das teorias Layerwise e os elementos finitos tridimensionais. As formulações não lineares que utilizam esses elementos são empregadas em análises de estruturas sujeitas a pequenas ou grandes deformações e grandes deslocamentos. Consideram-se medidas de deformações não lineares completas ou as deformações de von Kármán (REDDY, 2004a; ĆETKOVIĆ, VUKSANOVIĆ, 2011). Formulações baseadas nos elementos finitos contínuos com emprego das teorias Layerwise podem ser encontradas em Epstein e Glockner (1977), Barbero e Reddy (1991), Icardi (1994), Schmidt e Librescu (1994), Reddy Y., Moorthy e Reddy J. (1995), Chaudhuri e Hsia (1998), To e Liu (2001), Kim e Chaudhuri (2005), Icardi (2007), Moreira, Sousa e Valente (2010), Toudeshky, Hosseini e Mohammadi (2010), Ćetković e Vuksanović (2011), Choudhary e Tungikar (2011), Eijo, Oñate e Oller (2014) e Yazdani, Ribeiro e Rodrigues (2014). 
Devido ao maior custo computacional, uma menor quantidade de trabalhos se baseia em elementos finitos contínuos com emprego de elementos finitos tridimensionais. Somente os trabalhos de Zinno e Barbero (1994) e de Andrade, Awruch e Morsch (2007) foram encontrados com essa formulação.

Diante de tudo que foi apresentado, a formulação desenvolvida neste trabalho apresenta uma cinemática semelhante a da teoria Layerwise completa com aproximação de primeira ordem para o campo de deslocamentos em cada lâmina.

Conforme é apresentado no capítulo referente ao elemento finito laminado, um vetor tangente à seção transversal de cada lâmina é empregado para representar o giro e a variação de espessura da lâmina. Com essa proposta, o comportamento Zig-Zag ao longo da espessura para os deslocamentos no plano do laminado é possível ser representado, mas a continuidade das tensões interlaminares não é satisfeita. A distribuição de tensão pode ser melhorada através do aumento da discretização na seção transversal, o que eleva o número de graus de liberdade, pois a cinemática proposta para o elemento finito laminado é dependente do número de lâminas.

Como discutido, a consideração das não linearidades é muito importante para a obtenção mais precisa de uma distribuição de deslocamentos, deformações e tensões no nível das lâminas. Assim, a presente proposta considera a não linearidade geométrica com a estrutura podendo apresentar grandes deslocamentos, grandes rotações e pequenas deformações. A formulação é Lagrangiana total com emprego do método dos elementos finitos baseado em posições. O material constituinte das lâminas se comporta de acordo com a lei constitutiva energética de Saint-Venant-Kirchhoff que relaciona as deformações de Green com o tensor de tensões de Piola-Kirchhoff de segunda espécie. Dentro das formulações voltadas a análise não linear de laminados, o elemento finito proposto nessa pesquisa pode ser enquadrado como um elemento finito contínuo.

Em relação às formulações encontradas na literatura que se baseiam na teoria Layerwise, a formulação deste trabalho se diferencia principalmente pelo caráter de elemento de pórtico. Assim, são evitados problemas de mau condicionamento matricial que podem surgir quando se emprega elementos finitos baseados na teoria Layerwise apresentada por Reddy (2004a) ou elementos finitos bidimensionais para analisar pórticos planos laminados constituídos por lâminas finas e com elevada variação nas propriedades dos materiais que constituem essas lâminas. 



\section{CAPÍTULO 3}

\section{MÉTODO DOS ELEMENTOS FINITOS POSICIONAL APLICADO A MODELOS BIDIMENSIONAIS}

\subsection{Introdução}

O método dos elementos finitos posicional apresenta como principal característica o emprego de graus de liberdade em posições, o que justifica o nome do método, em vez dos tradicionais graus de liberdade em deslocamentos.

Todo o desenvolvimento do método é realizado a partir da determinação de uma função mudança de configuração (f) que define a configuração atual, ou de equilíbrio, a partir de um domínio fixo e representado pela configuração inicial, $\mathbf{B}_{0} \stackrel{\mathbf{f}}{\longrightarrow} \mathbf{B} \operatorname{com} \mathbf{B}_{0}$ e $\mathbf{B} \in \mathfrak{R}^{2}$. Por empregar uma configuração de referência fixa e coincidente com a configuração inicial, a formulação posicional é caracterizada como Lagrangiana total.

A não linearidade geométrica é considerada de forma natural, pois não são impostas quaisquer simplificações relativas à ordem de grandeza dos deslocamentos e rotações sofridos pelo corpo na definição de $\mathbf{f}$. Isso se deve ao emprego da medida de deformação de Green que é uma medida de deformação objetiva e adequada para a solução de problemas envolvendo grandes deslocamentos e rotações. O conjugado energético da deformação de Green é o tensor de tensões de Piola-Kirchhoff de segunda espécie (OGDEN, 1984).

A solução aproximativa dos elementos finitos posicionais é representada por uma interpolação das posições nodais com emprego de polinômios de Lagrange. Para a determinação dessas posições nodais, o princípio da energia potencial total estacionária é utilizado. Ao impor a nulidade da primeira variação do funcional de energia potencial total, um sistema de equações não linear é obtido (OGDEN, 1984; CHOU; PAGANO, 1992; HOLZAPFEL, 2004; BONET; WOOD, 2008). A resolução desse sistema de equações é realizada por meio de uma estratégia baseada no método de Newton-Raphson (CRISFIELD, 1991). 
Capítulo 3 - Método dos elementos finitos posicional aplicado a modelos bidimensionais

O método dos elementos finitos posicional teve origem nos trabalhos de Bonet et al. (2000), Coda e Greco (2004), Greco et al. (2006) e Coda e Paccola (2007, 2008, 2011) que demonstram sua precisão e fácil entendimento. O desenvolvimento deste método faz parte de uma importante linha de pesquisa do Grupo de Mecânica Computacional (GMEC) pertencente ao Departamento de Engenharia de Estruturas da Escola de Engenharia de São Carlos.

O presente capítulo descreve a sequência de operações matemáticas necessárias ao desenvolvimento de elementos finitos posicionais aplicados a problemas bidimensionais. Essa sequência independe do tipo de elemento a ser desenvolvido. Inicia-se, no Item 3.2, com uma revisão sucinta sobre as diversas formulações existentes para a análise não linear de estruturas. $\mathrm{Na}$ sequência, Item 3.3, apresenta-se a maneira como a função mudança de configuração é definida a partir de posições. A medida de deformação e a lei constitutiva empregadas são descritas no Item 3.4. As diversas parcelas que compõem o funcional de energia potencial total são descritos nos Itens 3.5, 3.6 e 3.7. Por fim, a estratégia empregada para resolver o sistema de equações não lineares é apresentada no Item 3.8.

\subsection{Análise não linear de estruturas}

A análise de um problema estrutural é linear quando o modelo estrutural desenvolvido assume como hipóteses básicas: ocorrência de pequenos deslocamentos, material com comportamento elástico linear e condições de contorno constates durante a aplicação das solicitações externas.

Em um modelo discreto baseado em deslocamentos, o problema estrutural pode ser resolvido a partir da solução de um sistema de equações lineares de equilíbrio do tipo:

$$
\mathbf{K u}=\mathbf{F},
$$

no qual $\mathbf{K}$ é a matriz de rigidez da estrutura, u é o vetor contendo os graus de liberdade incógnitos do problema e $\mathbf{F}$ é o vetor de forças externas.

Devido às hipóteses adotadas nas análises lineares, a relação deformaçãodeslocamento é linear e a matriz constitutiva da relação tensão-deformação e as condições de contorno ficam constantes. Em consequência, $\mathbf{K}$ e $\mathbf{F}$ são independentes do deslocamento $\mathbf{u}$ e todas as integrais que surgem no modelo matemático podem ser avaliadas em relação à configuração inicial da estrutura (COOK et al., 2002). 
Capítulo 3 - Método dos elementos finitos posicional aplicado a modelos bidimensionais

Sempre que o problema estrutural puder ser modelado de forma realista adotando as hipóteses empregadas nos modelos lineares é preferível utilizá-las, pois as soluções são mais simples e com menor custo computacional se comparadas às soluções obtidas através de análises não lineares. Uma das razões para isso é a validade do princípio da superposição de efeitos.

Quando as hipóteses do problema linear não podem ser assumidas, a análise do problema estrutural passa a ser não linear. Nesse tipo de análise, o princípio da superposição de efeitos não é mais válido e para cada situação de carregamento é preciso empregar uma análise particular. Além disso, a história ou a sequência do carregamento devem ser consideradas. Segundo Reddy (2004b) e Bonet e Wood (2008), a análise não linear se torna imprescindível em alguns casos, tais como: (a) no projeto de estruturas de alto desempenho encontradas, por exemplo, nas indústrias aeroespacial, aeronáutica e nuclear e que empregam intensamente materiais compósitos; (b) no estudo do comportamento mecânico do corpo humano; (c) na avaliação da funcionalidade de estruturas que sofreram algum tipo de dano e falha; (d) na análise de estruturas em situação de estado limite último; (e) no estudo da estabilidade, entre outras.

A impossibilidade de atender a quaisquer das hipóteses básicas adotadas nos modelos lineares define os três tipos principais de análises não lineares existentes, que são: análise não linear geométrica, análise não linear física e problema de contato (CRISFIELD, 1991; BATHE, 1996; COOK et al., 2002; REDDY, 2004b; BONET; WOOD, 2008).

A análise não linear geométrica é aquela que considera o efeito de grandes deslocamentos sobre o comportamento da estrutura. A expressão não linearidade geométrica surge justamente em virtude da incorporação da mudança de geometria no modelo. Apesar de haver grandes deslocamentos, muitas estruturas podem ainda apresentar pequenas deformações. Assim, a análise não linear geométrica pode ser realizada com a consideração de pequenas ou de grandes deformações (PARENTE JR, 2012).

Nos problemas não lineares geométrico, não há limitações às mudanças de geometria. Isso aumenta as dificuldades para se realizar a análise estrutural porque as equações de equilíbrio devem ser escritas com relação à geometria deformada, que não é conhecida com antecedência. A configuração geométrica inicial ou indeformada só é uma configuração de equilíbrio quando não há ações externas sendo aplicadas à estrutura (COOK et al., 2002; BONET; WOOD, 2008).

A importância das análises não lineares geométricas tem crescido significativamente. Um dos motivos para isso é o desenvolvimento de materiais de alto desempenho, como os materiais compósitos, que tem possibilitado o projeto de estruturas mais eficientes e muitas vezes leves e esbeltas. Em consequência, a análise estrutural na condição indeformada não é mais 
Capítulo 3 - Método dos elementos finitos posicional aplicado a modelos bidimensionais

suficiente para fornecer resultados confiáveis sobre o comportamento da estrutura e, portanto, a incorporação de efeitos não lineares devidos à ocorrência de grandes deslocamentos se torna imprescindível.

Os modelos utilizados para representar o comportamento do material são chamados na literatura de modelos constitutivos e a relação matemática entre tensão e deformação de um determinado modelo é denominada lei constitutiva do material (BATHE, 1996; HOLZAPFEL, 2004; BONET; WOOD, 2008). Cada modelo constitutivo pode englobar diversas leis constitutivas, pois é possível haver diferentes materiais com um comportamento condizente às características de um determinado modelo constitutivo, mas com uma relação tensão-deformação específica.

Nas análises lineares, o material apresenta um comportamento de acordo com o modelo constitutivo elástico linear cuja relação tensão-deformação pode ser expressa pela lei constitutiva de Hooke. No entanto, em muitas situações, a análise precisa considerar um modelo mais realista para representar um comportamento não linear do material. Essa é outra fonte importante de não linearidade e, quando esse comportamento não linear do material é incorporado na análise, tem-se a chamada análise não linear física.

A terceira hipótese básica adotada nas análises lineares trata das condições de contorno do problema estrutural. $\mathrm{Na}$ prática, nem sempre essas condições são constantes, principalmente quando o problema envolve o contato entre dois ou mais corpos deformáveis como no caso da análise estrutural envolvendo a interação entre o solo e a estrutura.

Os problemas estruturais cujas condições de contorno não são constantes constituem os chamados problemas de contato. Esses problemas são outra importante fonte de não linearidade e surgem quando estruturas diferentes ou superfícies diferentes de uma única estrutura entram em contato, separam-se ou deslizam uma sobre as outras. As forças de contato, como, por exemplo, as forças de atrito, podem aumentar ou diminuir e devem ser determinadas para que se possa avaliar sua influência no comportamento da estrutura. Além disso, a localização e extensão do contato não são conhecidas com antecedência e também devem ser determinadas (COOK et al., 2002). A presença de condições de contorno dependentes do estado de deformação e tensão correntes do corpo introduz um comportamento não linear à estrutura cuja análise é bastante complexa. Outros exemplos desse tipo de problema são o contato entre pneus e pavimentos e os que envolvem rolamentos e juntas (BATHE, 1996).

O estudo dos problemas não lineares é complexo e existem poucas soluções analíticas. Em geral, essas soluções são restritas a casos de carregamento e estruturas simples. Soluções analíticas podem ser encontradas, por exemplo, para alguns casos sujeitos a não 
Capítulo 3 - Método dos elementos finitos posicional aplicado a modelos bidimensionais

linearidade geométrica como em problemas de vigas engastadas (BISSHOPP; DRUCKER, 1945; MATTIASSON, 1981) e em quadros articulados e rígidos (MAT'TIASSON, 1981). Algumas das dificuldades para a proposição de soluções analíticas estão relacionadas a não validade do princípio da superposição, ao fato de poder haver mais de uma condição de equilíbrio para um dado carregamento atuante e à necessidade de resolução de um sistema de equações não lineares.

Diante disso, as soluções numéricas são uma alternativa viável para a análise estrutural de problemas sujeitos a complexos efeitos não lineares, sendo o método dos elementos finitos, a técnica numérica predominantemente empregada (BONET; WOOD, 2008). Gadala e Oravas (1984) apresentam vasta revisão sobre as diversas formulações baseadas no método dos elementos finitos para a solução de problemas da mecânica do contínuo não linear. Outros trabalhos que ilustram as diferenças entre as diversas formulações existentes são os de Wong e Tin-Loi (1990), Crisfield (1991), Bathe (1996), Greco (2004), Felippa e Haugen (2005) e Felippa (2014).

Segundo Gadala e Oravas (1984), as formulações numéricas podem ser classificadas em quatro grupos denominados de descrição material, referencial, relativa e espacial. No entanto, uma classificação mais simples foi dada por Bonet e Wood (2008). Esses autores resumiram as formulações numéricas em apenas duas classificações: as descrições materiais ou Lagrangianas, que englobam as descrições material, referencial e relativa de Gadala e Oravas (1984), e as descrições espaciais ou Eulerianas.

As descrições materiais ou Lagrangianas se referem ao comportamento de uma partícula material do corpo e as grandezas físicas de interesse são representadas por meio de uma função $\mathbf{f}(\mathbf{X}, t)$, na qual as variáveis independentes são o tempo $t$ e a posição $\mathbf{X}$ ocupada pela partícula em relação a uma configuração de referência. Já as descrições espaciais ou Eulerianas se referem a uma posição do espaço e ao que acontece com o corpo naquela posição. As grandezas físicas de interesse são representadas através de uma função $\mathbf{f}(\mathbf{x}, t)$, na qual as variáveis independentes são o tempo $t$ e a posição $\mathbf{x}$ em relação à configuração espacial ou atual (BONET; WOOD, 2008).

Formulações com a descrição Euleriana são bastante empregadas nos problemas envolvendo fluidos, pois, em geral, o interesse é na condição do fluido em uma região fixa do espaço. Nos problemas envolvendo grandes deformações, essa descrição também é bastante encontrada uma vez que as malhas de elementos finitos não ficam sujeitas às distorções elevadas (FOUCARD et al., 2015). Exemplos de trabalhos com emprego de formulações Eulerianas aplicadas a problemas de fluidos são os de Hughes, Liu e Zimmermann (1981), Donea et al. 
Capítulo 3 - Método dos elementos finitos posicional aplicado a modelos bidimensionais

(2004) e Ritcher (2013) e aplicadas a problemas envolvendo grandes deformações são os de Gadala, Oravas e Dokainish (1983), Demarco e Dvorkin (2005) e Foucard et al. (2015).

Formulações do método dos elementos finitos baseadas na descrição Lagrangiana são as mais vastamente empregadas na análise de problemas não lineares da mecânica dos sólidos, pois o interesse maior se concentra na determinação do comportamento das partículas materiais que compõem o sólido (BONET; WOOD, 2008). Segundo Gadala e Oravas (1984) e Foucard et al. (2015), as principais vantagens desse tipo de descrição são a simplicidade na descrição de uma cinemática e o cálculo de grandezas físicas em relação a uma configuração de referência fixa e conhecida. As formulações Eulerianas empregadas para uma descrição material do sólido se tornam mais complexas, pois a configuração de referência é desconhecida a priori, levando a operações matemáticas mais complicadas (a variável posição $\mathbf{x}$ da configuração atual passa a ser uma função implícita do tempo $t$ ).

Outras vantagens apontadas, no caso da descrição Lagrangiana, são a implementação computacional mais simples, o menor custo e a facilidade de tratamento de condições de contorno, não sendo necessário o emprego de técnicas de rastreamento de interface. No entanto, desvantagens surgem quando o sólido sofre grandes deformações, devido às distorções de malha, e quando as condições de contorno são variáveis, como em problemas de contato e de propagação de fissuras. Para contornar essa limitação, algumas estratégias podem ser empregadas como a atualização da configuração de referência ou o emprego de técnicas de remalhamento (GADALA; ORAVAS, 1984; FOUCARD et al., 2015).

Segundo Crisfield (1991) e Bathe (1996), a descrição Lagrangiana utiliza duas abordagens distintas para a escolha da configuração de referência: a Lagrangiana total e a Lagrangiana atualizada. Felippa e Haugen (2005) também inclui a abordagem corrotacional como uma descrição Lagrangiana.

$\mathrm{Na}$ identificação da configuração de referência é importante distinguir mais duas configurações: a de base ou inicial e a atual ou corrente, conforme ilustra a Figura 12.

$\mathrm{Na}$ descrição Lagrangiana total, as configurações base e de referência se confundem e permanecem fixas durante todo o processo de solução (Figura 13). Segundo Gadala e Oravas (1984), essa descrição permite o desenvolvimento de formulações simples com relação às operações matemáticas envolvidas e implementações computacionais. Por empregar uma configuração de referência fixa, a representação de questões cinemáticas e de condições de contorno é realizada de maneira relativamente fácil. As principais limitações desse tipo de descrição estão relacionadas a resultados imprecisos e dificuldades de convergência do processo 
Capítulo 3 - Método dos elementos finitos posicional aplicado a modelos bidimensionais

de solução em problemas envolvendo grandes deformações devido às distorções significativas na malha de elementos finitos. Problemas de contato também são mais difíceis de serem resolvidos.

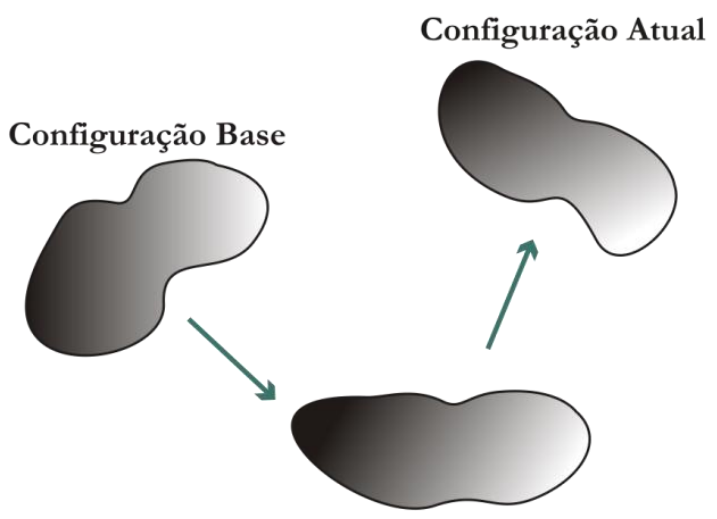

Configuração de Referência

Figura 12 - Configurações importantes para identificação das descrições Lagrangianas Fonte: Felippa e Haugen (2005).

Dessa forma, formulações baseadas na descrição Lagrangiana total são bastante convenientes para a solução de problemas não lineares sujeitos a grandes deslocamentos e rotações, mas com condições de contorno constantes e moderadas deformações. Formulações que trabalham com a descrição Lagrangiana total podem ser encontradas nos artigos de Mondkar e Powell (1977), Surana (1983), Schulz e Filippou (2001) e Coda e Paccola (2007, 2008, 2011).

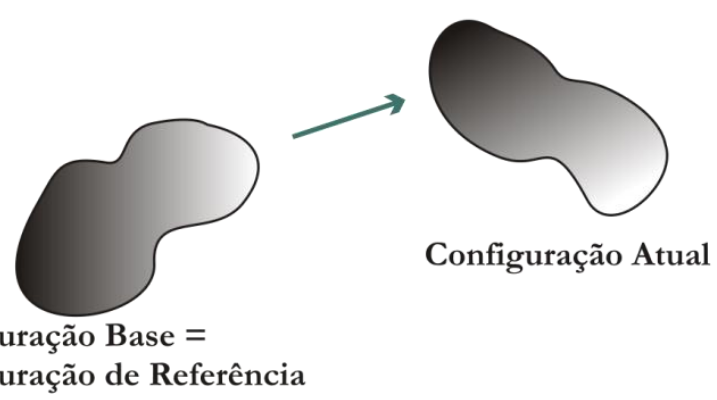

Figura 13 - Configurações na descrição Lagrangiana total Fonte: Felippa e Haugen (2005).

Uma alternativa às limitações da descrição Lagrangiana total é a descrição Lagrangiana atualizada, na qual a configuração base permanece fixa e a configuração de referência é continuamente atualizada durante o processo de solução (Figura 14). Nesse tipo de descrição, condições de contorno variáveis e grandes deformações podem ser mais facilmente tratadas. Além disso, a atualização da configuração de referência simplifica algumas expressões matemáticas da formulação como a da matriz de rigidez tangente (GADALA; ORAVAS, 1984). 
Capítulo 3 - Método dos elementos finitos posicional aplicado a modelos bidimensionais

Exemplos de trabalhos que utilizam formulações com descrição Lagrangiana atualizada podem ser encontradas nos artigos de Gadala, Dokainish e Oravas (1984) e Meek e Tan (1984) e Gattass e Abel (1987).

Uma variação dessa descrição é a chamada Lagrangiana parcialmente atualizada na qual a atualização ocorre somente a cada incremento de carga. Portanto, dentro de um mesmo incremento, a configuração de referência permanece fixa como na descrição Lagrangiana total. Segundo Wong e Tin-Loi (1990), isso reduz significativamente a quantidade de operações matemáticas envolvidas no processo de atualização da configuração de referência. Exemplos de trabalhos com a descrição Lagrangiana parcialmente atualizada podem ser encontrados nos artigos de Peterson e Petersson (1985) e de Wong e Tin-loi (1990).

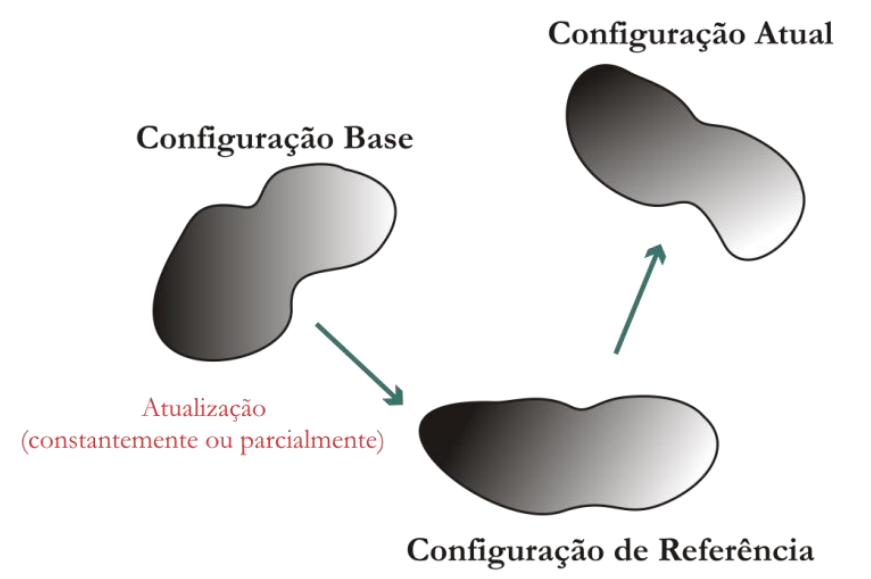

Figura 14 - Configurações na descrição Lagrangiana atualizada Fonte: Felippa e Haugen (2005).

Outra abordagem da descrição Lagrangiana é a corrotacional (FELIPPA; HAUGEN, 2005). Nessa abordagem, o movimento do sólido é separado em duas parcelas, a parcela devido ao movimento de corpo rígido e a parcela devido à deformação. Conforme ilustra a Figura 15, a configuração de referência é composta tanto pela configuração base como pela chamada configuração corrotacional. A configuração base é utilizada como referência para definir o movimento de corpo rígido e a corrotacional acompanha continuamente o sólido (ou o elemento finito) e é utilizada como referência para a determinação de deformações e tensões (CRISFIELD, 1991; FELIPPA, 2014).

As formulações corrotacionais permitem considerar grandes deslocamentos e rotações de uma forma simples e computacionalmente eficiente, além de simplificar a consideração da não linearidade física (PARENTE JR et al., 2014). As formulações corrotacionais, no entanto, se restringem a problemas com pequenas deformações, conforme alerta Felippa e Haugen (2005) e Felippa (2014). Isso se deve ao emprego de relações lineares 
Capítulo 3 - Método dos elementos finitos posicional aplicado a modelos bidimensionais

para a determinação das deformações entre a configuração atual e a configuração corrotacional. O emprego dessas relações lineares é viável, uma vez que o movimento de corpo rígido é explicitamente separado do movimento total do sólido. Dessa forma, é possível trabalhar com a medida de deformação linear de engenharia, mesmo sob o regime de grandes deslocamentos.

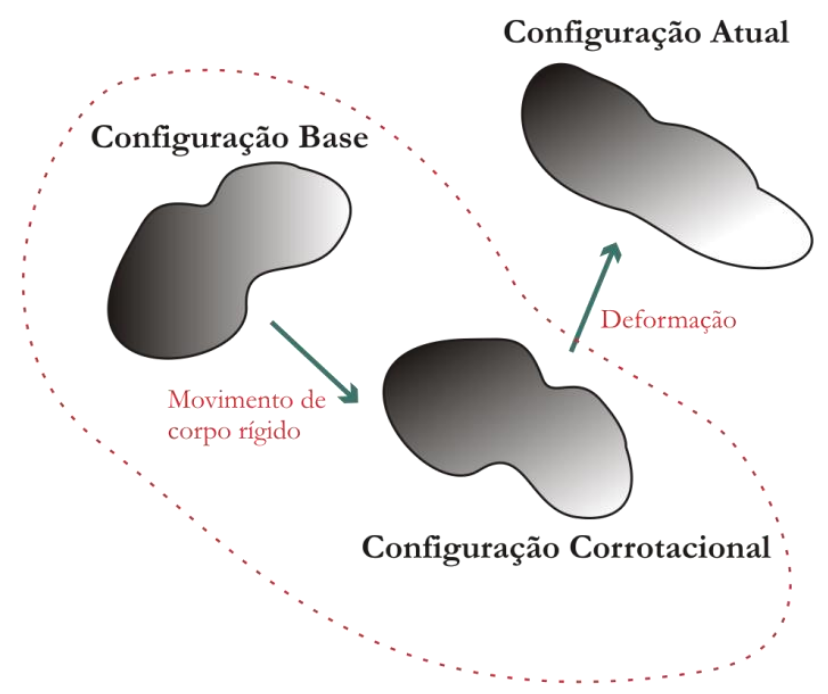

Configuração de Referência $=$ Base + Corrotacional

Figura 15 - Configurações na descrição corrotacional

Fonte: Felippa e Haugen (2005).

Exemplo de formulações corrotacionais podem ser encontrados em Crisfield (1990), Crisfield (1991), Ibrahimbegović (1995), Battini (2002), Yshii (2002), Monteiro (2004) e Parente Jr. et al. (2014).

A formulação desenvolvida neste trabalho adota uma descrição Lagrangiana total com emprego do método dos elementos finitos posicional. Como comentado anteriormente, essa formulação é chamada de posicional, uma vez que os parâmetros empregados não são os tradicionais deslocamentos e giros, mas posições e vetores generalizados nodais. Os vetores são empregados no mapeamento da seção transversal.

Os problemas tratados estão sujeitos a grandes deslocamentos e rotações, mas com deformações moderadas em função da lei constitutiva empregada. As condições de contorno são constantes e o material é representado por um modelo constitutivo Hiperelástico com a lei constitutiva de Saint-Venant-Kirchhoff que relaciona a medida de deformação de Green ao seu conjugado energético, o tensor de tensões de Piola-Kirchhoff de segunda espécie (OGDEN, 1984). De acordo com essa lei, o material apresenta comportamento elástico-linear, podendo ser isotrópico, ortotrópico ou anisotrópico, e a relação tensão-deformação é definida por uma função energia potencial de deformação específica. O emprego dessa lei constitutiva é o 
fator que restringe a aplicabilidade da formulação desenvolvida neste trabalho ao regime de deformações moderadas.

Aplicações e desenvolvimentos do método dos elementos finitos posicional podem ser encontrados na resolução de diversos problemas não lineares, tais como: análises não lineares geométricas de pórticos 2D e 3D, placas e cascas em pequenas deformações (CODA; PACCOLA, 2007; CODA, 2009; CODA; PACCOLA; SAMPAIO, 2013) e em grandes deformações (PASCON, 2012; PASCON; CODA, 2013), análises não lineares físicas e geométricas considerando materiais elastoplásticos, viscoelásticos e viscoplásticos (PACCOLA, 2004; VANALLI, 2004), problemas de contato envolvendo impacto (GRECO, 2004; CARRAZEDO; CODA, 2006), interação solo-estrutura (SILVA, 2014) e fluido-estrutura (SANCHES, 2011; SANCHES; CODA, 2014), análises não lineares dinâmicas (MACIEL; CODA, 2010; CODA; PACCOLA, 2011), análise de estruturas sujeitas a ações térmicas (CARRAZEDO, 2009; CARRAZEDO; CODA, 2010), análises não lineares geométricas de materiais compósitos reforçados com fibras e laminados (SAMPAIO, 2014; SAMPAIO; PACCOLA; CODA, 2015), entre outros. Os diversos trabalhos citados acima demostram a capacidade das formulações posicionais em analisar com eficiência e precisão os mais variados tipos de problemas não lineares. Todos esses trabalhos fazem parte de uma importante linha de pesquisa do Grupo de Mecânica Computacional (GMEC) pertencente ao Departamento de Estruturas da Escola de Engenharia de São Carlos - USP.

Feita essa revisão inicial sobre os problemas não lineares e sobre as principais estratégias para sua solução, prossegue-se com a descrição das operações matemáticas envolvidas no desenvolvimento da formulação posicional aplicada a problemas de estruturas representadas por modelos bidimensionais.

\subsection{Função mudança de configuração}

Para uma melhor compreensão deste item, é importante observar inicialmente a Figura 16 que contém uma ilustração dos mapeamentos empregados para descrever as configurações inicial $\mathbf{f}^{0}\left(\xi_{1}, \xi_{2}\right)$ e atual $\mathbf{f}^{1}\left(\xi_{1}, \xi_{2}\right)$ a partir de um sistema de coordenadas paramétrico adimensional. Também estão ilustrados a função mudança de configuração $\mathbf{f}(\mathbf{x})$ e o sistema de coordenadas global que define as posições em ambas as configurações. 
Capítulo 3 - Método dos elementos finitos posicional aplicado a modelos bidimensionais

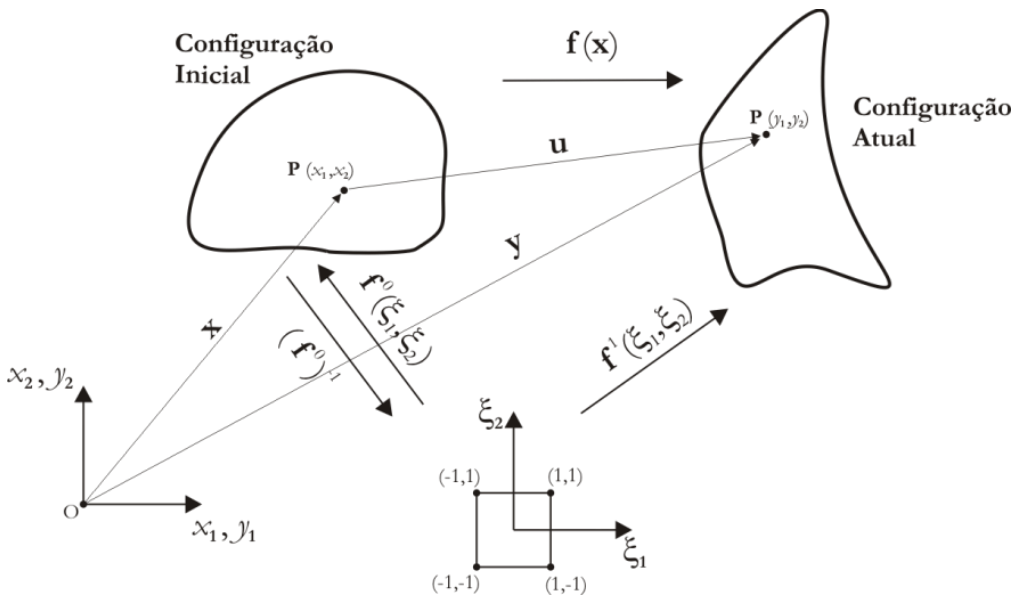

Figura 16 - Funções de mapeamento das configurações inicial e atual Fonte: Coda (2006).

Nas formulações de elementos finitos tradicionais baseados em deslocamentos, a $\mathbf{f}(\mathbf{x})$ é diretamente determinada com a obtenção dos graus de liberdade em deslocamentos do elemento, que são empregados para compor a solução aproximada para o campo de deslocamentos $\mathbf{u}(\mathbf{x})$. Como se observa na Figura 16, a $\mathbf{f}(\mathbf{x})$ representa uma função que fornece a posição y da configuração atual e cujo domínio é a configuração inicial. Assim, pode-se escrever $\mathbf{f}(\mathbf{x})$ como:

$$
\mathbf{f}(\mathbf{x})=\mathbf{y} \rightarrow \mathbf{f}(\mathbf{x})=\mathbf{u}(\mathbf{x})+\mathbf{x}
$$

No padrão empregado nas formulações de elementos finitos paramétricos, a $\mathbf{f}^{0}\left(\xi_{1}, \xi_{2}\right)$ é definida a partir de um sistema de coordenada paramétrico adimensional $\left(\xi_{1}, \xi_{2}\right)$ e representa o mapeamento das posições $\mathbf{x}$ na configuração inicial. Logo, tem-se que:

$$
\mathbf{x}=\mathbf{f}^{0}\left(\xi_{1}, \xi_{2}\right)
$$

Com a mudança de coordenadas, a $\mathbf{f}(\mathbf{x})$ fica definida por:

$$
\mathbf{f}(\mathbf{x})=\mathbf{u}(\mathbf{x}) \circ \mathbf{f}^{0}\left(\xi_{1}, \xi_{2}\right)+\mathbf{f}^{0}\left(\xi_{1}, \xi_{2}\right)
$$

Como afirmado anteriormente, não há graus de liberdade em deslocamentos na formulação posicional, pois se trabalha diretamente com as posições $\mathbf{y}$ ocupadas na configuração atual, não sendo possível, portanto, definir a $\mathbf{f}(\mathbf{x})$ conforme a Equação (10).

Apesar disso, uma solução aproximativa para o mapeamento da configuração atual $\mathbf{f}^{1}\left(\xi_{1}, \xi_{2}\right)$ a partir de um espaço adimensional pode ser determinado e, diferentemente das 
formulações paramétricas de elementos finitos baseados em deslocamentos, a definição da $\mathbf{f}(\mathbf{x})$ não envolve a solução aproximativa para o campo de deslocamentos $\mathbf{u}(\mathbf{x})$. Observando a Figura 16, verifica-se que a $\mathbf{f}(\mathbf{x})$ pode ser determinada através de uma composição de funções entre a $\mathbf{f}^{1}\left(\xi_{1}, \xi_{2}\right)$ e a inversa da $\mathbf{f}^{0}\left(\xi_{1}, \xi_{2}\right)$, conforme está representado na Equação (11).

$$
\mathbf{f}(\mathbf{x})=\mathbf{f}^{1}\left(\xi_{1}, \xi_{2}\right) \circ\left[\mathbf{f}^{0}\left(\xi_{1}, \xi_{2}\right)\right]^{-1}
$$

Como será mostrado nos itens posteriores, a função mudança de configuração e seu gradiente, $\mathbf{A}=\nabla \mathbf{f}$, são essenciais para a determinação das deformações e, consequentemente, das tensões e da energia específica de deformação. Nesse ponto do trabalho, é conveniente chamar atenção ao emprego da configuração inicial como a configuração de referência para a definição da função mudança de configuração $\mathbf{f}(\mathbf{x})$. Mostrando, portanto, que a formulação adota uma descrição do tipo Lagrangiana total.

Observando a composição de funções estabelecida na Equação (11), o Cálculo Diferencial estabelece que $\mathbf{A}$ é dado pelo produto entre o gradiente de $\mathbf{f}^{1}\left(\xi_{1}, \xi_{2}\right), \mathbf{A}^{1}=\nabla \mathbf{f}^{1}$, e a inversa do gradiente de $\mathbf{f}^{0}\left(\xi_{1}, \xi_{2}\right),\left[\mathbf{A}^{0}\right]^{-1}=\left[\nabla \mathbf{f}^{0}\right]^{-1}$. Assim, $\mathbf{A}$ pode ser expresso por:

$$
\mathbf{A}=\mathbf{A}^{1}\left(\xi_{1}, \xi_{2}\right) \cdot\left[\mathbf{A}^{0}\left(\xi_{1}, \xi_{2}\right)\right]^{-1}
$$

Os elementos que compõem $\mathbf{A}^{0}$ e $\mathbf{A}^{1}$ são obtidos a partir das expressões do mapeamento posicional adotado na definição do elemento finito. Esses mapeamentos estão apresentados nos capítulos seguintes para o elemento de pórtico plano homogêneo e para o elemento de pórtico plano laminado.

As funções do mapeamento posicional são funções vetoriais definidas do sistema de coordenadas bidimensional e adimensional $\left(\xi_{1}, \xi_{2}\right)$, variando no intervalo $[-1,1]$, para o sistema de coordenadas também bidimensional das posições inicial ou atual. Essas funções são representadas por:

$$
\mathbf{f}^{0}\left(\xi_{1}, \xi_{2}\right)=\left\{\begin{array}{l}
x_{1}\left(\xi_{1}, \xi_{2}\right) \\
x_{2}\left(\xi_{1}, \xi_{2}\right)
\end{array}\right\} \quad \mathbf{f}^{1}\left(\xi_{1}, \xi_{2}\right)=\left\{\begin{array}{l}
y_{1}\left(\xi_{1}, \xi_{2}\right) \\
y_{2}\left(\xi_{1}, \xi_{2}\right)
\end{array}\right\}
$$

na qual $x_{1}$ e $x_{2}$ são as posições da configuração inicial nas direções 1 e 2 , respectivamente. De forma análoga, referem-se $y_{1}$ e $y_{2}$ para a configuração atual. 
Observando a Equação (13), os gradientes $\mathbf{A}^{0}$ e $\mathbf{A}^{1}$ são definidos por matrizes de ordem dois, conforme as equações seguintes:

$$
\mathbf{A}^{0}\left(\xi_{1}, \xi_{2}\right)=\left[\begin{array}{ll}
\frac{\partial x_{1}}{\partial \xi_{1}} & \frac{\partial x_{1}}{\partial \xi_{2}} \\
\frac{\partial x_{2}}{\partial \xi_{1}} & \frac{\partial x_{2}}{\partial \xi_{2}}
\end{array}\right] \quad \mathbf{A}^{1}\left(\xi_{1}, \xi_{2}\right)=\left[\begin{array}{ll}
\frac{\partial y_{1}}{\partial \xi_{1}} & \frac{\partial y_{1}}{\partial \xi_{2}} \\
\frac{\partial y_{2}}{\partial \xi_{1}} & \frac{\partial y_{2}}{\partial \xi_{2}}
\end{array}\right],
$$

cujas componentes são particularizadas oportunamente após a definição dos mapeamentos posicionais dos elementos de pórtico plano homogêneo e laminado nos capítulos seguintes.

Estabelecido o significado das funções de mapeamento posicional, de mudança de configuração e seus respectivos gradientes, prossegue-se para a definição da medida de deformação empregada nas formulações deste trabalho, bem como, da lei constitutiva.

\subsection{Medida de deformação e lei constitutiva}

A medida de deformação empregada nas formulações aqui desenvolvidas é a de Green-Lagrange. Essa medida de deformação é objetiva, conveniente para o desenvolvimento de formulações com descrição Lagrangiana e adequada para o tratamento de problemas não lineares geométricos sujeitos a grandes deslocamentos e rotações (CRISFIELD, 1991; REDDY, 2004b).

A deformação de Green é derivada diretamente do gradiente da função mudança de configuração. Para defini-la, consideremos inicialmente dois pontos $P_{0}$ e $P_{1}$ separados de uma distância infinitesimal nas configurações inicial e atual (Figura 17). A posição relativa entre os pontos na configuração inicial é dada pelo vetor $d \mathbf{x}=\mathbf{x}_{P_{1}}-\mathbf{x}_{P_{0}}$. Após a deformação, a posição relativa passa a ser $d \mathbf{y}=\mathbf{y}_{P_{1}}-\mathbf{y}_{P_{0}}$. Aplicando a regra da cadeia, verifica-se a relação entre os vetores $d \mathbf{x}$ e $d \mathbf{y}$ estabelecida pelo gradiente da função mudança de configuração:

$$
\mathbf{y}_{P_{1}}=\mathbf{y}_{P_{0}}+\frac{\partial \mathbf{f}}{\partial \mathbf{x}} \cdot d \mathbf{x} \quad \rightarrow \quad d \mathbf{y}=\mathbf{A} \cdot d \mathbf{x} .
$$

Esse gradiente pode ser expresso em termos do vetor deslocamento do corpo. Partindo de $\mathbf{f}=\mathbf{u}+\mathbf{x}$ e aplicando a primeira derivada em relação à posição inicial, obtém-se (REDDY, 2004b):

$$
\frac{\partial \mathbf{f}}{\partial \mathbf{x}}=\frac{\partial \mathbf{u}}{\partial \mathbf{x}}+\frac{\partial \mathbf{x}}{\partial \mathbf{x}} \rightarrow \mathbf{A}=\nabla \mathbf{u}+\mathbf{I}
$$




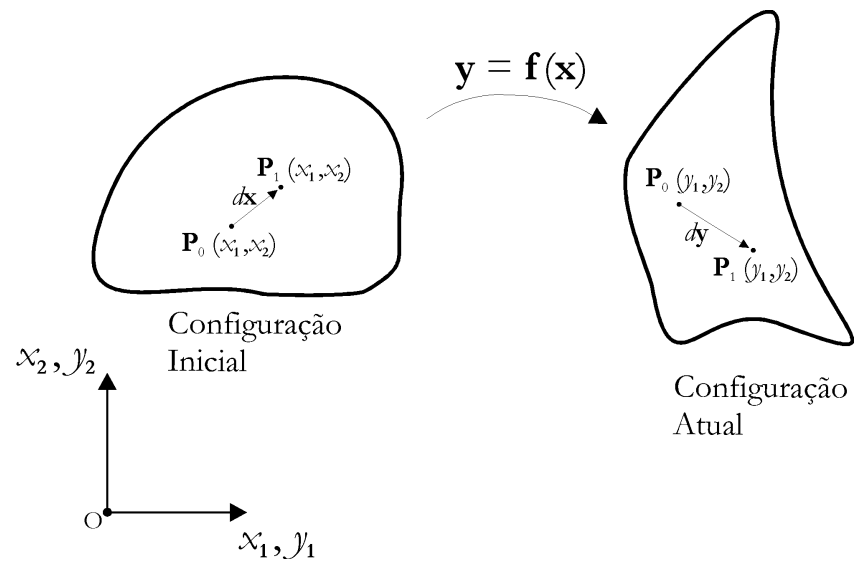

Figura 17 - Mudança de configuração

Fonte: Coda (2006).

De acordo com Reddy (2004b) e Ogden (1984), a deformação de Green pode ser deduzida a partir do cálculo das distâncias entre os pontos $P_{0}$ e $P_{1}$, nas configurações inicial e atual. Essas distâncias são obtidas com o produto escalar entre os vetores posições-relativa:

$$
(d x)^{2}=d \mathbf{x}^{t} \cdot d \mathbf{x} \quad(d y)^{2}=d \mathbf{y}^{t} \cdot d \mathbf{y} .
$$

Considerando as Equações (15) e (17), tem-se que:

$$
(d y)^{2}=d \mathbf{y}^{t} \cdot d \mathbf{y}=d \mathbf{x}^{t} \cdot \mathbf{A}^{t} \cdot \mathbf{A} \cdot d \mathbf{x}=d \mathbf{x}^{t} \cdot \mathbf{C} \cdot d \mathbf{x}
$$

sendo $\mathbf{C}=\mathbf{A}^{t} \cdot \mathbf{A}$ o tensor alongamento à direita de Cauchy-Green (OGDEN, 1984). Nas formulações posicionais, o gradiente da função mudança de configuração é definido conforme a Equação (12). Assim, C pode ser expresso por:

$$
\mathbf{C}=\mathbf{A}^{t} \cdot \mathbf{A}=\left(\mathbf{A}^{0}\right)^{-t} \cdot\left(\mathbf{A}^{1}\right)^{t} \cdot \mathbf{A}^{1} \cdot\left(\mathbf{A}^{0}\right)^{-1},
$$

na qual - $t$ representa a transposta da inversa.

A mudança no quadrado do comprimento de um infinitésimo ao passar da configuração inicial para atual pode ser relacionada ao comprimento original. Observando as Equações (17) e (18), temos que essa diferença é dada por:

$$
d y^{2}-d x^{2}=d \mathbf{x}^{t} \cdot \mathbf{C} \cdot d \mathbf{x}-d \mathbf{x}^{t} \cdot d \mathbf{x}=d \mathbf{x}^{t} \cdot(\mathbf{C}-\mathbf{I}) \cdot d \mathbf{x}=2 d \mathbf{x}^{t} \cdot\left[\frac{(\mathbf{C}-\mathbf{I})}{2}\right] \cdot d \mathbf{x},
$$

na qual o termo entre colchetes é denominado tensor de deformação de Green-Lagrange ou, como mais comumente chamado, tensor de deformação de Green (REDDY, 2004b). Portanto:

$$
d y^{2}-d x^{2}=2 d \mathbf{x}^{t} \cdot \mathbf{E} \cdot d \mathbf{x}, \operatorname{com} \mathbf{E}=\frac{1}{2}(\mathbf{C}-\mathbf{I})
$$


Capítulo 3 - Método dos elementos finitos posicional aplicado a modelos bidimensionais

Considerando a Equação (16), pode-se escrever o tensor de deformação de Green em função do vetor deslocamento como na Equação (22) e verificar que E é simétrico. Além disso, da Equação (21), observa-se que a diferença entre os quadrados das distâncias relativas nas configurações atual e inicial é nula, se e somente se, $\mathbf{E}$ for também nulo, mostrando a objetividade da medida de deformação (REDDY, 2004b).

$$
\mathbf{E}=\frac{1}{2}\left(\mathbf{A}^{t} \cdot \mathbf{A}-\mathbf{I}\right)=\frac{1}{2}\left[(\nabla \mathbf{u})^{t}+\nabla \mathbf{u}+(\nabla \mathbf{u})^{t} \cdot \nabla \mathbf{u}\right] .
$$

Nos problemas sujeitos a pequenos deslocamentos, o produto entre os gradientes dos vetores de deslocamentos tende a zero. Portanto, desprezando $(\nabla \mathbf{u})^{t} \cdot \nabla \mathbf{u}$ na Equação (22), a medida de deformação linear é recuperada, conforme Equação (23), e a formulação posicional descrita aqui se torna naturalmente restrita ao caso linear geométrico.

$$
\varepsilon=\frac{1}{2}\left[(\nabla \mathbf{u})^{t}+\nabla \mathbf{u}\right]
$$

O tensor de deformação de Green apresenta como conjugado energético o tensor de tensões de Piola-Kirchhoff de segunda espécie (OGDEN, 1984). A relação entre eles é definida pela lei constitutiva do material que, neste trabalho, apresenta como características: homogeneidade, isotropia e modelo hiperelástico representado pela lei constitutiva de Saint Venant-Kirchhoff.

Os materiais compósitos são fortemente lineares longe da situação de ruptura, com linearidade geralmente superior a dos metais. Assim, a hipótese de uma relação tensãodeformação com essa característica é bastante aceita e amplamente usada na engenharia (MENDONÇA, 2005).

A lei constitutiva de Saint-Venant-Kirchhoff é a mais simples dentre as leis para o modelo de material Hiperelástico, pois estabelece uma relação tensão-deformação linear que se confunde com a lei constitutiva de Hooke quando as deformações são pequenas. Essa lei é adequada para problemas sujeitos a grandes deslocamentos, mas com o material trabalhando no regime de deformações moderadas.

Em função das hipóteses cinemáticas assumidas para os elementos finitos desenvolvidos neste trabalho, os problemas analisados são restritos àqueles sob um estado plano de tensão. Em vista disso, a energia específica de deformação para a lei constitutiva de SaintVenant-Kirchhoff pode ser expressa por:

$$
u_{e}=\frac{1}{2} \frac{E}{1-v^{2}}\left[\left(E_{11}\right)^{2}+\left(E_{22}\right)^{2}+2 v E_{11} E_{22}+\frac{1-v}{2}\left(E_{12}+E_{21}\right)^{2}\right] \text {, }
$$


com E correspondendo ao módulo de elasticidade longitudinal, $v_{\mathrm{o}}$ coeficiente de Poisson . O módulo de elasticidade transversal $G$ se relaciona com $E$ e $v$ por:

$$
G=\frac{1}{2} \frac{E}{(1+v)} .
$$

A primeira derivada da energia específica de deformação em relação às deformações de Green $\mathbf{E}$ fornece as tensões de Piola-Kirchhoff de segunda espécie S. Observando a Equação (24), tem-se:

$$
\begin{aligned}
S_{11} & =\frac{E}{1-v^{2}}\left(E_{11}+v E_{22}\right) \\
S_{22} & =\frac{E}{1-v_{e}^{2}}\left(E_{22}+v E_{11}\right) \\
S_{12} & =G\left(E_{12}+E_{21}\right) \\
S_{21} & =G\left(E_{12}+E_{21}\right)
\end{aligned}
$$

Definidas a medida de deformação e a lei constitutiva a serem empregadas no desenvolvimento da formulação dos elementos finitos de pórtico plano homogêneo e laminado, é possível agora estabelecer as relações para determinar a função de energia potencial total. Para problemas estáticos, a energia potencial total é constituída pela energia potencial de deformação e pela energia potencial associada às ações externas.

\subsection{Energia potencial de deformação}

Antes de apresentar o procedimento para o cálculo da energia potencial de deformação, consideremos inicialmente o caso simples de uma mola unidimensional submetida à ação de uma força interna $F_{1}\left(u_{1}\right)$ e cujo diagrama força-deslocamento é elástico não linear (Figura 18). O objetivo desse exemplo simples é ilustrar a relação energeticamente conjugada entre força interna e posição da mesma forma que ocorre entre força interna e deslocamento.

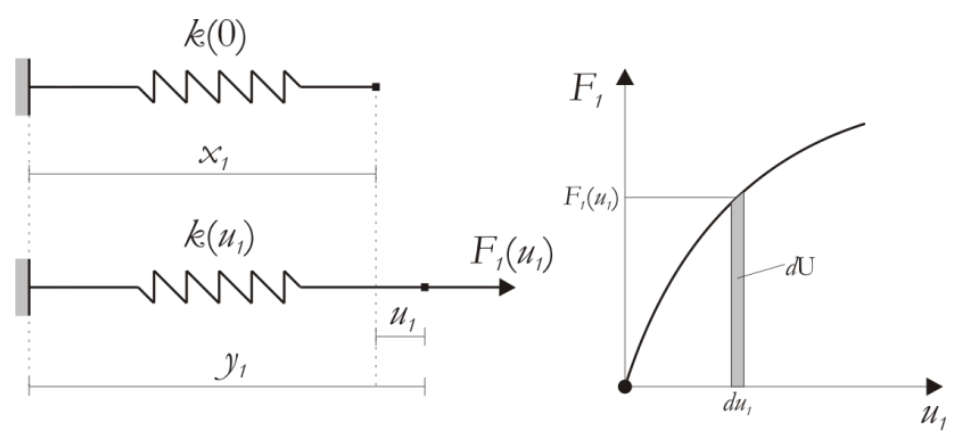

Figura 18 - Mola unidimensional elástica não linear Fonte: Coda (2006). 
Observando essa figura, verifica-se que a energia de deformação acumulada na mola é numericamente igual à área sob o gráfico força-deslocamento e é dada pela seguinte integral:

$$
\mathrm{U}=-\int_{0}^{u_{1}}\left[-F_{1}\left(u_{1}\right)\right] d u_{1}
$$

Se for realizada a derivada na Equação (27) em relação ao deslocamento $u_{1}$, obtemos a força aplicada na mola:

$$
\frac{d \mathrm{U}}{d u_{1}}=F_{1}\left(u_{1}\right) .
$$

Das Equações (27) e (28), conclui-se que $u_{1}$ e $F_{1}\left(u_{1}\right)$ são conjugados energéticos (CODA, 2006). Até aqui, tanto a energia de deformação da mola como a força aplicada estão estabelecidas como uma função do deslocamento sofrido pela extremidade livre. Para transformar a variável deslocamento na variável posição, basta observar que o deslocamento é dado pela diferença entre a posição atual $y_{1}$ e a posição inicial $x_{1}$ da extremidade da mola. Dessa diferença, estabelece-se também a relação diferencial entre $y_{1}$ e $u_{1}$ :

$$
u_{1}=y_{1}-x_{1} \rightarrow d u_{1}=d y_{1} .
$$

Aplicando a regra da cadeia na Equação (28) para modificar a variável da derivada, mostra-se que a posição atual e a força aplicada também são energeticamente conjugadas (CODA, 2006):

$$
F_{1}\left(u_{1}\right)=\frac{d \mathrm{U}}{d u_{1}}=\frac{d \mathrm{U}}{d y_{1}} \frac{d y_{1}}{d u_{1}} \rightarrow F_{1}\left(y_{1}\right)=\frac{d \mathrm{U}}{d y_{1}} \quad \text { e } \quad \mathrm{U}=-\int_{x_{1}}^{y_{1}}\left[-F_{1}\left(y_{1}\right)\right] d y_{1},
$$

na qual os limites de integração são dados pela posição $x_{1}$ da extremidade da mola na configuração inicial e a sua posição $y_{1}=x_{1}+u_{1}$ na configuração atual.

No caso bidimensional, essa ideia é expandida com a definição da função mudança de configuração f a partir das posições ocupadas pelo sólido na configuração atual, conforme apresentado no Item 3.3, e do cálculo da energia de deformação através da determinação de uma densidade de energia, chamada energia específica de deformação.

O modelo constitutivo considerado para o material é o hiperelástico. Para esse tipo de material, é válido o princípio da conservação da energia. Assim, a denominação energia potencial de deformação é adequada, pois só há dependência do estado de deformação atual, não importando a forma como ocorreu a mudança de configuração do sólido (CHOU; PAGANO, 1992). 
Para determinar a energia potencial de deformação, deve-se proceder a integração da energia específica, apresentada na Equação (24), em relação ao volume inicial do elemento, pois como já mencionado anteriormente, a formulação segue uma descrição Lagrangiana total. Assim, tem-se que:

$$
\mathrm{U}=\int_{\mathrm{V}_{0}} u_{e} d \mathrm{~V}_{0}
$$

Conforme apresentado no Item 3.3, as formulações posicionais adotam um sistema de referência paramétrico adimensional para descrever a função mudança de configuração e as funções de mapeamento posicional das configurações inicial e atual. Assim, os tensores deformação de Green E e alongamento à direita de Cauchy-Green C foram escritos, via Equações (11), (12), (13), (14), (19) e (21), como funções nas variáveis adimensionais $\left(\xi_{1}, \xi_{2}\right)$. Consequentemente, a energia específica de deformação fica, também, escrita em função dessas variáveis.

Dessa forma, a integral da energia específica no volume inicial $\left(V_{0}\right)$ na Equação (31) pode ser realizada em relação ao domínio adimensional por meio da seguinte mudança de variáveis:

$$
\mathrm{U}=b \int_{-1}^{1} \int_{-1}^{1} u_{e}\left(\xi_{1}, \xi_{2}\right) J\left(\xi_{1}, \xi_{2}\right) d \xi_{1} d \xi_{2}
$$

na qual $b$ é a largura de uma seção retangular ou largura média de uma seção trapezoidal e $J\left(\xi_{1}, \xi_{2}\right)$ é o Jacobiano da transformação do sistema de coordenadas da configuração inicial $\left(x_{1}, x_{2}\right)$ para o sistema de coordenadas da configuração de referência adimensional $\left(\xi_{1}, \xi_{2}\right)$. Esse Jacobiano é dado pelo determinante da matriz $\mathbf{A}^{0}$, ou seja, $J\left(\xi_{1}, \xi_{2}\right)=\frac{\partial x_{1}}{\partial \xi_{1}} \frac{\partial x_{2}}{\partial \xi_{2}}-\frac{\partial x_{1}}{\partial \xi_{2}} \frac{\partial x_{2}}{\partial \xi_{1}}$

Realizando uma série de operações matriciais para a obtenção da deformação de Green e substituindo na Equação (24), é possível chegar a uma função escalar para a energia específica de deformação. Essa função depende apenas das coordenadas adimensionais $\left(\xi_{1}, \xi_{2}\right)$ e das posições da configuração atual, pois as posições da configuração inicial e os parâmetros elásticos da lei constitutiva são conhecidos e constantes.

No entanto, a expressão matemática dessa função escalar é bastante extensa, dificultando sua integração analítica na Equação (32). Felizmente, é possível realizar a integração numericamente com o emprego, por exemplo, da quadratura de Gauss, que é utilizada neste trabalho. Logo, não há necessidade de obter uma expressão analítica para a função escalar energia 
específica de deformação, podendo-se trabalhar diretamente com os valores numéricos assumidos pelos gradientes $\mathbf{A}^{0}$ e $\mathbf{A}^{1}$, na determinação de $\mathbf{C}$ e $\mathbf{E}$. Esses valores numéricos dependem das coordenadas adimensionais dos pontos de Gauss e das posições da configuração atual, que assumem valores conhecidos durante a solução do problema não linear baseado em um processo iterativo de tentativa e correção. Assim, a integral na Equação (32) é determinada numericamente por:

$$
\left.\mathrm{U}=b u_{e}\left(\xi_{1 i g}, \xi_{2 j g}\right) J\left(\xi_{1 i g}, \xi_{2 j g}\right) w_{(i g)} w_{(j g}\right) \quad \text { com } i g=1, \ldots, n_{1} \text { e } j g=1, \ldots, n_{2},
$$

que representa um somatório dos produtos entre os valores numéricos assumidos por $u_{e}\left(\xi_{1}, \xi_{2}\right)$ e $J\left(\xi_{1}, \xi_{2}\right)$ em cada ponto de Gauss e os respectivos pesos de integração. Na Equação (33), $\xi_{1 i g}$ e $\xi_{2_{j g}}$ representam as coordenadas adimensionais dos pontos de Gauss, $w_{(i g)}$ e $w_{(j g}$ representam os pesos de integração e $n_{1}$ e $n_{2}$ são a quantidade de pontos distribuídos ao longo da direção longitudinal e transversal, respectivamente. Nos elementos desenvolvidos neste trabalho, essa integração numérica ocorre em domínios retangulares.

Para calcular a energia potencial de deformação, é necessário ainda determinar os termos que compõem os gradientes $\mathbf{A}^{0}$ e $\mathbf{A}^{1}$. Esses termos dependem da cinemática adotada no mapeamento posicional para os elementos finitos de pórtico plano homogêneo e laminado, cujas definições ocorrerão nos dois capítulos seguintes.

Analogamente ao caso simples da mola unidimensional (Equação (30) e Figura 18), a força interna pode ser obtida através da derivada da energia de deformação em relação à posição atual. Define-se um vetor de força interna em vez de uma única componente de força interna e a derivada é substituída pelo gradiente em relação ao vetor de posições atuais. Assim, tem-se que:

$$
\nabla \mathrm{U}(\mathbf{y})=\mathbf{F}_{\text {int }} \leftrightarrow \quad \mathbf{F}_{\text {int }}=\int_{\mathrm{V}_{0}} \nabla u_{e} d N_{0}=\int_{\mathrm{V}_{0}} \frac{\partial u_{e}}{\partial \mathbf{y}} d \mathrm{~N}_{0} .
$$

Com a definição da energia de deformação, resta somente descrever a segunda parcela da energia potencial total que é relativa às ações externas.

\subsection{Energia potencial relativa às ações externas}

As ações externas consideradas são constituídas por forças concentradas, forças distribuídas e momentos concentrados. Assume-se que todas as forças externas são conservativas, ou seja, o trabalho realizado depende apenas das posições inicial $\mathbf{x}$ e atual $\mathbf{y}$, não 
dependendo da trajetória realizada pela força durante o movimento. Assim, a integral de linha que define o trabalho realizado pela força externa $\mathbf{F}_{\text {ext }}$ ao longo de uma trajetória de deslocamento $C$ se transforma em uma integral nas posições ocupadas pela força na configuração atual e inicial:

$$
\mathrm{W}=\int_{C} \mathbf{F}_{\mathrm{ext}}(\mathbf{u}) \cdot d \mathbf{u} \quad \rightarrow \quad \mathrm{W}=\int_{\mathbf{x}}^{\mathbf{y}} \mathbf{F}_{\mathrm{ext}} \cdot d \mathbf{y},
$$

na qual a força, por ser conservativa, independe do deslocamento ou da posição e a integral não está relacionada à trajetória $C$, mas apenas às posições inicial $\mathbf{x}$ e atual $\mathbf{y}$. A mudança de coordenadas é possível considerando a relação entre deslocamento e posição atual:

$$
\mathbf{u}=\mathbf{y}-\mathbf{x} \quad \rightarrow \quad d \mathbf{u}=d \mathbf{y}
$$

Para forças conservativas, atribui-se uma energia potencial e sua relação com o trabalho é dada por:

$$
\Delta \Omega(\mathbf{u})=-\mathrm{W}
$$

Considerando a Equação (35) e a característica conservativa da força, tem-se que:

$$
\begin{aligned}
& \Delta \Omega(\mathbf{u})=\Omega(\mathbf{y})-\Omega(\mathbf{x}) \\
& \Omega(\mathbf{y})-\Omega(\mathbf{x})=-\int_{\mathbf{x}}^{\mathbf{y}} \mathbf{F}_{\mathrm{ext}} \cdot d \mathbf{y} \quad \leftrightarrow \quad \Omega(\mathbf{y})-\Omega(\mathbf{x})=-\left(\mathbf{F}_{\mathrm{ext}} \cdot \mathbf{y}-\mathbf{F}_{\mathrm{ext}} \cdot \mathbf{x}\right) .
\end{aligned}
$$

Do ponto de vista físico, apenas variações de energia potencial são relevantes. Assim, pode-se definir uma energia potencial nula na origem do sistema de referência global, tal que:

$$
\Omega(\mathbf{0})=0
$$

Considerando uma mudança na posição da força desde a origem em $\mathbf{x}=\mathbf{0}$ até a posição atual $\mathbf{y}$, determina-se a função energia potencial associada à força externa $\mathbf{F}_{\text {ext }}$ :

$$
\Omega(\mathbf{y})=-\mathbf{F}_{\mathrm{ext}} \cdot \mathbf{y} \quad \rightarrow \quad \Omega(\mathbf{y})=-\left(F_{\mathrm{ext}_{1}} y_{1}+F_{\mathrm{ext}_{2}} y_{2}\right)
$$

na qual a parcela da direita é restrita ao caso bidimensional, com $y_{1}$ e $y_{2}$ representando as posições atuais do ponto de aplicação da força nas direções globais 1 e 2, respectivamente.

O gradiente da energia potencial em relação ao vetor posição fornece o negativo da força aplicada: 


$$
\nabla \Omega(\mathbf{y})=-\mathbf{F}_{\mathrm{ext}}
$$

As Equações (40) e (41) acima mostram que, assim como o deslocamento, a posição também é energeticamente conjugada a força.

Para completar a definição da energia potencial associada às ações externas, resta determinar na Equação (40) o vetor posição y . Nos dois capítulos seguintes, estão definidos os elementos finitos posicionais de pórtico plano homogêneo e laminado. Para cada elemento, o vetor posição y é descrito por uma função que mapeia as posições no elemento a partir de uma interpolação das posições nodais $y_{k}^{i}$. Dessa forma, a energia potencial das ações externas fica escrita como um produto de forças nodais externas concentradas ou equivalentes e parâmetros nodais representados por posições e vetores generalizados. A Equação (40) passa a ser representada, então, por:

$$
\Omega(\mathbf{y})=-\mathbf{F}_{\mathrm{ext}} \cdot \mathbf{y}_{k} \leftrightarrow \Omega(\mathbf{y})=-F_{\mathrm{ext} k}^{i} y_{k}^{i},
$$

na qual $\mathbf{F}_{\text {ext }}$, ou $F_{\text {ext } k}^{i}$ em notação indicial, é o vetor de forças nodais externas ou equivalentes e $\mathbf{y}_{k}$, ou $y_{k}^{i}$, é o vetor posição nodal, com $i$ representando os graus de liberdade nodais e $k$ o nó.

Com isso, resume-se o cálculo da parcela de energia devida às ações externas simplesmente pelo negativo do produto entre a força externa e sua posição atual. Juntamente com a parcela da energia potencial de deformação, pode-se escrever a energia potencial total associada a problemas estáticos.

\subsection{Energia potencial total e equações de equilíbrio}

Como relatado anteriormente, a energia potencial total será composta pelas parcelas da energia de deformação mais o potencial das ações externas atuantes. Portanto, para um único elemento finito, a energia potencial é dada por:

$$
\stackrel{\mathrm{elm}}{\Pi}\left(y_{k}^{i}\right)=\stackrel{\mathrm{elm}}{\mathrm{U}}\left(y_{k}^{i}\right)+\stackrel{\mathrm{elm}}{\Omega}\left(y_{k}^{i}\right)
$$

sendo $\stackrel{\text { elm }}{\Pi}\left(y_{k}^{i}\right)$ a função energia potencial total, $\stackrel{\text { elm }}{U}\left(y_{k}^{i}\right)$ a energia potencial de deformação, dada pelas Equações (31), (32) e (33), $\stackrel{\mathrm{elm}}{\Omega}\left(y_{k}^{i}\right)$ a energia potencial das ações externas, dada pelas 
Equações (40) e (42), e $y_{k}^{i}$ é o vetor contendo as posições (graus de liberdade) nodais do elemento.

Em uma análise estrutural baseada no método dos elementos finitos, o contínuo é discretizado em vários elementos formando uma malha. Como a energia potencial é uma grandeza escalar, a energia potencial total da estrutura pode ser obtida simplesmente pela soma das contribuições de cada elemento individualmente.

Para a realização dessa soma, a incidência nodal deixa de ter uma referência local do elemento e passa a ter uma incidência global como está ilustrado na Figura 19 para o caso de dois elementos finitos constituídos por quatro nós cada.

O número do nó global ké utilizado como referência para a montagem dos diversos vetores e matrizes presentes no desenvolvimento da formulação. Na Figura 19, o vetor posição nodal $y_{k}^{i}$ está associado ao nó global k e os graus de liberdade deste nó estão representados pelo índice sobrescrito $i$, cuja quantidade depende do tipo de elemento finito representado. Os aspectos de montagem dos diversos vetores e matrizes, bem como, a identificação dos graus de liberdade serão detalhados nos capítulos seguintes referentes à descrição dos elementos finitos de pórtico plano homogêneo e laminado.

Após a soma das contribuições energéticas de cada elemento finito e considerando a Equação (42), referente à parcela do potencial externo, a energia potencial total da estrutura pode ser escrita como:

$$
\Pi\left(y_{k}^{i}\right)=\mathrm{U}\left(y_{k}^{i}\right)-F_{\mathrm{ext} k}^{i} y_{k}^{i}
$$

Nessa equação, o vetor de posições nodais $y_{k}^{i}$ é a solução do sistema de equações não lineares de equilíbrio, obtido a partir da condição de estacionariedade da energia potencial total $\Pi\left(y_{k}^{i}\right)$.
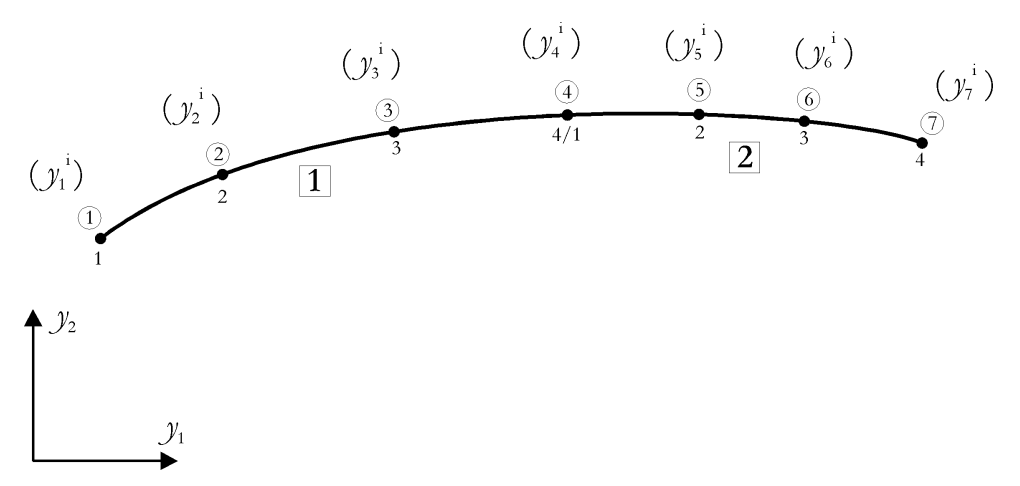

Figura 19 - Associação de dois elementos finitos Fonte: Coda (2006). 
Capítulo 3 - Método dos elementos finitos posicional aplicado a modelos bidimensionais

Através do princípio da energia potencial total estacionária é possível encontrar um sistema de equações cuja solução é constituída pelas posições de equilíbrio na configuração atual. De acordo com esse princípio, a energia potencial total assume valor estacionário quando a configuração deformada satisfaz as condições de equilíbrio e atende às condições de continuidade e de contorno (CHOU; PAGANO, 1992). Matematicamente, a estacionariedade é representada pela nulidade da primeira derivada da função de energia potencial total ou, de forma equivalente, pela nulidade de seu gradiente. $\mathrm{Na}$ formulação de elementos finitos posicional, esse gradiente é calculado em relação às posições nodais, ou seja:

$$
\nabla \prod\left(y_{k}^{i}\right)=0 \leftrightarrow \frac{\partial \prod\left(y_{k}^{i}\right)}{\partial y_{\alpha}^{\beta}}=0,
$$

na qual $\alpha$ representa os nós globais dos elementos e $\beta$, os graus de liberdade nodais. Considerando as Equações (41) e (44), a Equação (45) resulta em:

$$
\frac{\partial \mathrm{U}\left(y_{k}^{i}\right)}{\partial y_{\alpha}^{\beta}}-F_{\operatorname{ext} \alpha}^{\beta}=0 \text {. }
$$

Nessa equação, a primeira parcela representa o vetor de forças internas, conforme já ilustrado na Equação (34) para uma representação mais geral, e a segunda parcela é o vetor de forças externas $F_{\text {ext } \alpha}^{\beta}$, resultantes de forças concentradas e de forças nodais equivalentes geradas por forças distribuídas. Assim, a Equação (46) nada mais é do que a representação de um sistema de equações de equilíbrio cujas incógnitas são as posições nodais $y_{k}^{i}$. Portanto, tem-se que:

$$
\frac{\partial \mathrm{U}\left(y_{k}^{i}\right)}{\partial y_{\alpha}^{\beta}}-F_{\text {ext } \alpha}^{\beta}=0 \rightarrow F_{\text {int } \alpha}^{\beta}\left(y_{k}^{i}\right)-F_{\text {ext } \alpha}^{\beta}=0 .
$$

As componentes dos vetores de força constituem conjugados energéticos dos graus de liberdade $\beta$ pertencentes ao nó $\alpha$. Como se verá na descrição dos elementos finitos, os graus de liberdade são representados por posições do nó e por vetores generalizados da seção.

As forças externas são consideradas conservativas e não dependem das posições de aplicação. Já as forças internas dependem das posições da configuração atual, representadas pelas posições nodais, e a função vetorial $F_{\text {int } \alpha}^{\beta}\left(y_{k}^{i}\right)$ é fortemente não linear. Consequentemente, a relação obtida na Equação (47) constitui um sistema de equações também não linear.

Considerando o cálculo da energia potencial de deformação apresentado na Equação (32), a expressão do vetor de forças internas na Equação (47) se torna:

$$
F_{\text {int } \alpha}^{\beta}\left(y_{k}^{i}\right)=\frac{\partial \mathrm{U}\left(y_{k}^{i}\right)}{\partial y_{\alpha}^{\beta}}=b \int_{-1}^{1} \int_{-1}^{1} \frac{\partial u_{e}\left(\xi_{1}, \xi_{2}\right)}{\partial y_{\alpha}^{\beta}} J\left(\xi_{1}, \xi_{2}\right) d \xi_{1} d \xi_{2},
$$


que é calculada utilizando quadratura de Gauss, ficando, então:

$$
\left.F_{\text {int } \alpha}^{\beta}\left(y_{k}^{i}\right)=b \frac{\partial u_{e}\left(\xi_{1 i g}, \xi_{2 j g}\right)}{\partial y_{\alpha}^{\beta}} J\left(\xi_{1 i g}, \xi_{2 j g}\right) w_{(i g)} w_{(j g}\right) .
$$

Nessa expressão, o termo ainda indefinido é a derivada parcial da energia específica de deformação. Observando a lei constitutiva de Saint-Venant-Kirchhoff na Equação (24) e aplicando a regra da cadeia, pode-se escrever:

$$
\frac{\partial u_{e}}{\partial y_{\alpha}^{\beta}}=\frac{\partial u_{e}}{\partial E_{r s}} \frac{\partial E_{r s}}{\partial y_{\alpha}^{\beta}}=S_{r s} \frac{\partial E_{r s}}{\partial y_{\alpha}^{\beta}},
$$

na qual $E_{r s}$ são as deformações de Green e $S_{r s}$ representa o tensor de tensões de PiolaKirchhoff de segunda espécie, dado pela Equação (26). Utilizando a definição da deformação de Green (Equação (21)), a primeira derivada da energia específica de deformação pode ser escrita como:

$$
\frac{\partial u_{e}}{\partial y_{\alpha}^{\beta}}=S_{r s} \frac{\partial E_{r s}}{\partial C_{x y}} \frac{\partial C_{x y}}{\partial y_{\alpha}^{\beta}}=\frac{1}{2} S_{r s} \frac{\partial C_{r s}}{\partial y_{\alpha}^{\beta}},
$$

na qual $C_{r s}$ representa o tensor alongamento à direita de Cauchy-Green, cuja primeira derivada pode ser obtida levando em consideração a Equação (19). Deve-se atentar que somente o gradiente $\mathbf{A}^{1}$ (Equações (13) e (14)) é função das posições atuais $y_{k}^{i}$ ocupadas pela estrutura, pois o gradiente $\mathbf{A}^{0}$ (Equações (13) e (14)) depende somente das posições iniciais $x_{k}^{i}$, que são valores conhecidos e constantes. Assim, a primeira derivada do tensor alongamento à direita de Cauchy-Green resulta em:

$$
\frac{\partial \mathbf{C}}{\partial y_{\alpha}^{\beta}}=\left(\mathbf{A}^{0}\right)^{-t} \cdot \frac{\partial\left(\mathbf{A}^{1}\right)^{t}}{\partial y_{\alpha}^{\beta}} \cdot \mathbf{A}^{1} \cdot\left(\mathbf{A}^{0}\right)^{-1}+\left(\mathbf{A}^{0}\right)^{-t} \cdot\left(\mathbf{A}^{1}\right)^{t} \cdot \frac{\partial \mathbf{A}^{1}}{\partial y_{\alpha}^{\beta}} \cdot\left(\mathbf{A}^{0}\right)^{-1},
$$

na qual os índices das matrizes $\mathbf{C}, \mathbf{A}^{0}$ e $\mathbf{A}^{1}$ foram omitidos para simplificar a notação. Como a derivada da transposta é igual à transposta da derivada, a Equação (52) pode ser simplificada para:

$$
\frac{\partial \mathbf{C}}{\partial y_{\alpha}^{\beta}}=\left[\left(\mathbf{A}^{0}\right)^{-t} \cdot\left(\mathbf{A}^{1}\right)^{t} \cdot \frac{\partial \mathbf{A}^{1}}{\partial y_{\alpha}^{\beta}} \cdot\left(\mathbf{A}^{0}\right)^{-1}\right]^{t}+\left(\mathbf{A}^{0}\right)^{-t} \cdot\left(\mathbf{A}^{1}\right)^{t} \cdot \frac{\partial \mathbf{A}^{1}}{\partial y_{\alpha}^{\beta}} \cdot\left(\mathbf{A}^{0}\right)^{-1},
$$

$\operatorname{com} \frac{\partial \mathbf{A}^{1}}{\partial y_{\alpha}^{\beta}}$ sendo o único termo dessa expressão ainda não determinado, pois depende das hipóteses cinemáticas representadas na função de mapeamento posicional da configuração atual $\mathbf{f}^{1}\left(\xi_{1}, \xi_{2}\right)$ cuja definição consta nos capítulos referentes à descrição dos elementos finitos posicionais de pórtico plano homogêneo e laminado. Nestes capítulos, os termos que compõem 
$\frac{\partial \mathbf{A}^{1}}{\partial y_{\alpha}^{\beta}}$ são identificados. À exceção disso, o sistema de equações de equilíbrio na Equação (47) está totalmente definido.

Como comentado anteriormente, esse sistema é não linear e, portanto, há necessidade do emprego de um processo de solução baseado em uma estratégia incrementaliterativa.

\subsection{Processo de solução}

A estratégia de solução adotada é baseada no método de Newton-Raphson que consiste em um processo incremental-iterativo com variação controlada de incrementos de força e por uma solução iterativa do sistema de equações não lineares correspondente a esses incrementos acumulados. O processo iterativo consiste basicamente na adoção de uma tentativa inicial para a solução do sistema seguida pelo cálculo de correções sobre essa tentativa inicial. A iteração é encerrada quando critérios de convergência são satisfeitos.

O método de Newton-Raphson é a estratégia mais empregada para solução de sistemas de equações não lineares e tem como principais vantagens a convergência quadrática e a possibilidade de determinação da trajetória de equilíbrio da estrutura (CRISFIELD, 1991; BATHE, 1996; COOK et al., 2002).

Durante o processo de solução, como as posições atuais $y_{k}^{i}$ dos nós do pórtico não são conhecidas, posições-tentativa $y_{k \text { tentativa }}^{i}$ são atribuídas a $y_{k}^{i}$. Quando essas posições não verificam o equilíbrio nodal representado pela Equação (47), gera-se um resíduo que corresponde ao vetor de desbalanceamento mecânico:

$$
\mathrm{R}_{\alpha}^{\beta}\left(y_{k \text { tentativa }}^{i}\right)=F_{\text {int } \alpha}^{\beta}\left(y_{k \text { tentativa }}^{i}\right)-F_{\text {ext } \alpha}^{\beta} .
$$

Assumindo que esse vetor representa uma função vetorial contínua para posições próximas ao equilíbrio, correções para as posições-tentativa $y_{k \text { tentativa }}^{i}$ podem ser obtidas por meio

da linearização de $R_{\alpha}^{\beta}\left(y_{\text {ktentativa }}^{i}\right)$ com série de Taylor truncada em dois termos e forçando sua nulidade. Esse procedimento está descrito nas equações a seguir:

$$
\mathrm{R}_{\alpha}^{\beta}\left(y_{k}^{i}\right) \approx \mathrm{R}_{\alpha}^{\beta}\left(y_{k \text { tentativa }}^{i}\right)+\left.\frac{\partial \mathrm{R}_{\alpha}^{\beta}\left(y_{k}^{i}\right)}{\partial y_{\gamma}^{\zeta}}\right|_{y_{\text {kenativa }}^{i}} \Delta y_{\gamma}^{\zeta}
$$




$$
\begin{aligned}
& \mathrm{R}_{\alpha}^{\beta}\left(y_{\text {ktentativa }}^{i}\right)+H_{\alpha \gamma}^{\beta \zeta}\left(y_{k \text { tentativa }}^{i}\right) \Delta y_{\gamma}^{\zeta}=0 \\
& H_{\alpha \gamma}^{\beta^{\zeta}}\left(y_{k \text { tentativa }}^{i}\right) \Delta y_{\gamma}^{\zeta}=-\mathrm{R}_{\alpha}^{\beta}\left(y_{k \text { tentativa }}^{i}\right) \\
& \Delta y_{\gamma}^{\zeta}=-\left[H_{\alpha \gamma}^{\beta \zeta}\left(y_{k \text { tentativa }}^{i}\right)\right]^{-1} \mathrm{R}_{\alpha}^{\beta}\left(y_{k \text { tentativa }}^{i}\right)
\end{aligned}
$$

na qual $H_{\alpha \gamma}^{\beta \zeta}\left(y_{k_{\text {tentativa }}^{i}}\right)=\left.\frac{\partial R_{\alpha}^{\beta}\left(y_{k}^{i}\right)}{\partial y_{\gamma}^{\zeta}}\right|_{y_{k \text { tenniva }}^{i}} \quad$ é a matriz Hessiana calculada nas posições-tentativa. Essa matriz é calculada numericamente e apresenta ordem dada pelo produto entre o número de nós da discretização da estrutura e o número de graus de liberdade nodais correspondente ao elemento finito empregado. De acordo com Coda (2006), a Hessiana se torna positiva definida quando as posições-tentativa se aproximam das posições de equilíbrio da estrutura. Isso significa que a função energia potencial total se aproxima de um ponto estacionário, podendo representar um equilíbrio estável (ponto de mínimo local) ou instável (ponto de máximo local).

$\mathrm{Na}$ Equação (55), $\Delta y_{\gamma}^{\zeta}$ é uma correção a ser acrescentada às posições-tentativa para a obtenção de posições mais próximas da solução do sistema não linear. Assim, tem-se que:

$$
y_{k_{\text {tentativa }}^{i}}^{i}(\text { corrigida })=y_{k_{\text {tentativa }}^{i}}^{i}+\Delta y_{k}^{i}
$$

na qual os índices da correção foram compatibilizados com os índices das posições-tentativa.

Obtidas novas posições-tentativa, o vetor de desbalanceamento mecânico é recalculado e correções são novamente determinadas através da repetição do procedimento descrito na Equação (55). O controle sobre esse processo iterativo é feito por meio de critérios de convergência que consistem em comparar os erros relativos em posição e em força a tolerâncias pré-estabelecidas (Equação (57)). A tolerância é um valor arbitrado e pequeno que define quando o equilíbrio é atingido de forma satisfatória (CODA, 2006).

$$
\frac{\left\|\Delta y_{k}^{i}\right\|}{\left\|x_{k}^{i}\right\|}<\text { tolerância } \frac{\left\|R_{k}^{i}\right\|}{\left\|F_{\text {ext } k}^{i}\right\|}<\text { tolerância }
$$

Para finalizar a definição do processo de solução, resta somente determinar a expressão para o cálculo da matriz Hessiana. Esta matriz é dada pela derivada do vetor de desbalanceamento mecânico em relação às posições atuais $H_{\alpha \gamma}^{\beta \zeta}\left(y_{k}^{i}\right)=\frac{\partial R_{\alpha}^{\beta}\left(y_{k}^{i}\right)}{\partial y_{\gamma}^{\zeta}}$. Observando a Equação (54), pode-se verificar que para ações externas conservativas somente o vetor de forças 
internas depende das posições atuais $y_{k}^{i}$. Logo, a matriz Hessiana fica restrita a

$$
\begin{aligned}
& H_{\alpha \gamma}^{\beta^{\zeta}}\left(y_{k}^{i}\right)=\frac{\partial F_{\text {int } \alpha}^{\beta}\left(y_{k}^{i}\right)}{\partial y_{\gamma}^{\zeta}} \text {. Da Equação (48), temos que: } \\
& H_{\alpha \gamma}^{\beta \zeta}\left(y_{k}^{i}\right)=\frac{\partial^{2} \mathrm{U}}{\partial y_{\alpha}^{\beta} \partial y_{\gamma}^{\zeta}} \\
& H_{\alpha \gamma}^{\beta \zeta}\left(y_{k}^{i}\right)=b \int_{-1-1}^{1} \int_{1}^{1} \frac{\partial^{2} u_{e}\left(\xi_{1}, \xi_{2}\right)}{\partial y_{\alpha}^{\beta} \partial y_{\gamma}^{\zeta}} J\left(\xi_{1}, \xi_{2}\right) d \xi_{1} d \xi_{2} .
\end{aligned}
$$

Da mesma forma como no cálculo do vetor de forças internas na Equação (49), essa integral é obtida numericamente via quadratura de Gauss, ficando transformada no seguinte somatório:

$$
\left.\left.H_{\alpha \gamma}^{\beta \zeta}\left(y_{k}^{i}\right)=b \frac{\partial^{2} u_{e}\left(\xi_{1 i g}, \xi_{2 j g}\right)}{\partial y_{\alpha}^{\beta} \partial y_{\gamma}^{\zeta}} J\left(\xi_{1 i g}, \xi_{2 j k}\right) w_{(i g}\right)_{(j g}\right) .
$$

Nessa expressão, é necessário calcular a segunda derivada da energia específica de deformação em relação às posições nodais atuais. Para isso, aplicando a regra da cadeia sobre a primeira derivada já calculada na Equação (50), tem-se:

$$
\frac{\partial^{2} u_{e}}{\partial y_{\alpha}^{\beta} \partial y_{\gamma}^{\zeta}}=\frac{\partial}{\partial y_{\gamma}^{\zeta}}\left(S_{r s} \frac{\partial E_{r s}}{\partial y_{\alpha}^{\beta}}\right)=\frac{\partial S_{r s}}{\partial y_{\gamma}^{\zeta}} \frac{\partial E_{r s}}{\partial y_{\alpha}^{\beta}}+S_{r s} \frac{\partial^{2} E_{r s}}{\partial y_{\alpha}^{\beta} \partial y_{\gamma}^{\zeta}} .
$$

A derivada do tensor de tensões de Piola-Kirchhoff de segunda espécie pode ser definida a partir da Equação (26), resultando em:

$$
\begin{aligned}
\frac{\partial S_{11}}{\partial y_{\gamma}^{\zeta}} & =\frac{E}{1-v^{2}}\left(\frac{\partial E_{11}}{\partial y_{\gamma}^{\zeta}}+v \frac{\partial E_{22}}{\partial y_{\gamma}^{\zeta}}\right) \\
\frac{\partial S_{r s}}{\partial y_{\gamma}^{\zeta}} \leftrightarrow \quad \leftrightarrow \quad \frac{\partial S_{22}}{\partial y_{\gamma}^{\zeta}} & =\frac{E}{1-v^{2}}\left(\frac{\partial E_{22}}{\partial y_{\gamma}^{\zeta}}+v \frac{\partial E_{11}}{\partial y_{\gamma}^{\zeta}}\right) \\
\frac{\partial S_{12}}{\partial y_{\gamma}^{\zeta}} & =G\left(\frac{\partial E_{12}}{\partial y_{\gamma}^{\zeta}}+\frac{\partial E_{21}}{\partial y_{\gamma}^{\zeta}}\right) \\
\frac{\partial S_{21}}{\partial y_{\gamma}^{\zeta}} & =G\left(\frac{\partial E_{12}}{\partial y_{\gamma}^{\zeta}}+\frac{\partial E_{21}}{\partial y_{\gamma}^{\zeta}}\right) .
\end{aligned}
$$

Nas Equações (60) e (61), surge a primeira derivada das deformações de Green em relação às posições nodais atuais. Essa derivada já foi determinada nas Equações (50) a (53). Portanto, o primeiro termo da Equação (60) está totalmente definido, restando apenas determinar a segunda derivada das deformações de Green no segundo termo. Considerando a definição dessas deformações na Equação (21), tem-se que: 


$$
\frac{\partial^{2} E_{r s}}{\partial y_{\alpha}^{\beta} \partial y_{\gamma}^{\zeta}}=\frac{1}{2} \frac{\partial^{2} C_{r s}}{\partial y_{\alpha}^{\beta} \partial y_{\gamma}^{\zeta}}
$$

Partindo agora da Equação (53), tem-se que a segunda derivada do tensor alongamento à direita de Cauchy-Green, com os índices omitidos para simplificar a notação, fica definida assim:

$$
\begin{aligned}
\frac{\partial^{2} \mathbf{C}}{\partial y_{\alpha}^{\beta} \partial y_{\gamma}^{\zeta}=} & {\left[\left(\mathbf{A}^{0}\right)^{-t} \cdot \frac{\partial\left(\mathbf{A}^{1}\right)^{t}}{\partial y_{\gamma}^{\zeta}} \cdot \frac{\partial \mathbf{A}^{1}}{\partial y_{\alpha}^{\beta}} \cdot\left(\mathbf{A}^{0}\right)^{-1}+\left(\mathbf{A}^{0}\right)^{-t} \cdot\left(\mathbf{A}^{1}\right)^{t} \cdot \frac{\partial^{2} \mathbf{A}^{1}}{\partial y_{\alpha}^{\beta} \partial y_{\gamma}^{\zeta}} \cdot\left(\mathbf{A}^{0}\right)^{-1}\right]^{t}+} \\
& \left(\mathbf{A}^{0}\right)^{-t} \cdot \frac{\partial\left(\mathbf{A}^{1}\right)^{t}}{\partial y_{\gamma}^{\zeta}} \cdot \frac{\partial \mathbf{A}^{1}}{\partial y_{\alpha}^{\beta}} \cdot\left(\mathbf{A}^{0}\right)^{-1}+\left(\mathbf{A}^{0}\right)^{-t} \cdot\left(\mathbf{A}^{1}\right)^{t} \cdot \frac{\partial^{2} \mathbf{A}^{1}}{\partial y_{\alpha}^{\beta} \partial y_{\gamma}^{\zeta}} \cdot\left(\mathbf{A}^{0}\right)^{-1},
\end{aligned}
$$

sendo os termos $\frac{\partial^{2} \mathbf{A}^{1}}{\partial y_{\alpha}^{\beta} \partial y_{\gamma}^{\zeta}}$ todos nulos, pois a primeira derivada de $\mathbf{A}^{1}$ não depende das posições nodais atuais, uma vez que as funções de mapeamento posicional $\mathbf{f}^{1}$ dependem apenas linearmente do vetor posição nodal $y_{k}^{i}$. Isso será ressaltado nos dois capítulos seguintes referentes à definição dos elementos finitos de pórtico plano homogêneo e laminado.

Assim, a segunda derivada do tensor alongamento à direita de Cauchy-Green fica definida pela seguinte expressão:

$$
\frac{\partial^{2} \mathbf{C}}{\partial y_{\alpha}^{\beta} \partial y_{\gamma}^{\zeta}}=\left[\left(\mathbf{A}^{0}\right)^{-t} \cdot \frac{\partial\left(\mathbf{A}^{1}\right)^{t}}{\partial y_{\gamma}^{\zeta}} \cdot \frac{\partial \mathbf{A}^{1}}{\partial y_{\alpha}^{\beta}} \cdot\left(\mathbf{A}^{0}\right)^{-1}\right]^{t}+\left(\mathbf{A}^{0}\right)^{-t} \cdot \frac{\partial\left(\mathbf{A}^{1}\right)^{t}}{\partial y_{\gamma}^{\zeta}} \cdot \frac{\partial \mathbf{A}^{1}}{\partial y_{\alpha}^{\beta}} \cdot\left(\mathbf{A}^{0}\right)^{-1}
$$

Com esse último termo, a matriz Hessiana na Equação (58) está totalmente determinada. Vale ressaltar novamente que essa matriz resulta em uma matriz numérica, Equação (59), para um par $\left(\xi_{1}, \xi_{2}\right)$ de coordenadas adimensionais correspondente aos pontos de Gauss utilizados na integração numérica e para um vetor de posições-tentativa $y_{k \text { tentativa }}^{i}$ adotado.

Com isso, fica definido completamente o processo de solução, sendo possível agora encontrar a configuração atual da estrutura para cada incremento associado às ações externas e, assim, determinar a trajetória de equilíbrio da estrutura. Um fluxograma básico que resume todo o processo de solução baseado no método de Newton-Raphson está apresentado na Figura 20.

Nos capítulos seguintes, estão descritos os dois elementos finitos desenvolvidos neste trabalho. Os aspectos particulares que a formulação posicional assume em cada elemento são identificados e os resultados de análises numéricas realizadas em exemplos de verificação são apresentados a fim de demonstrar a consistência, a eficiência e a robustez da formulação. 


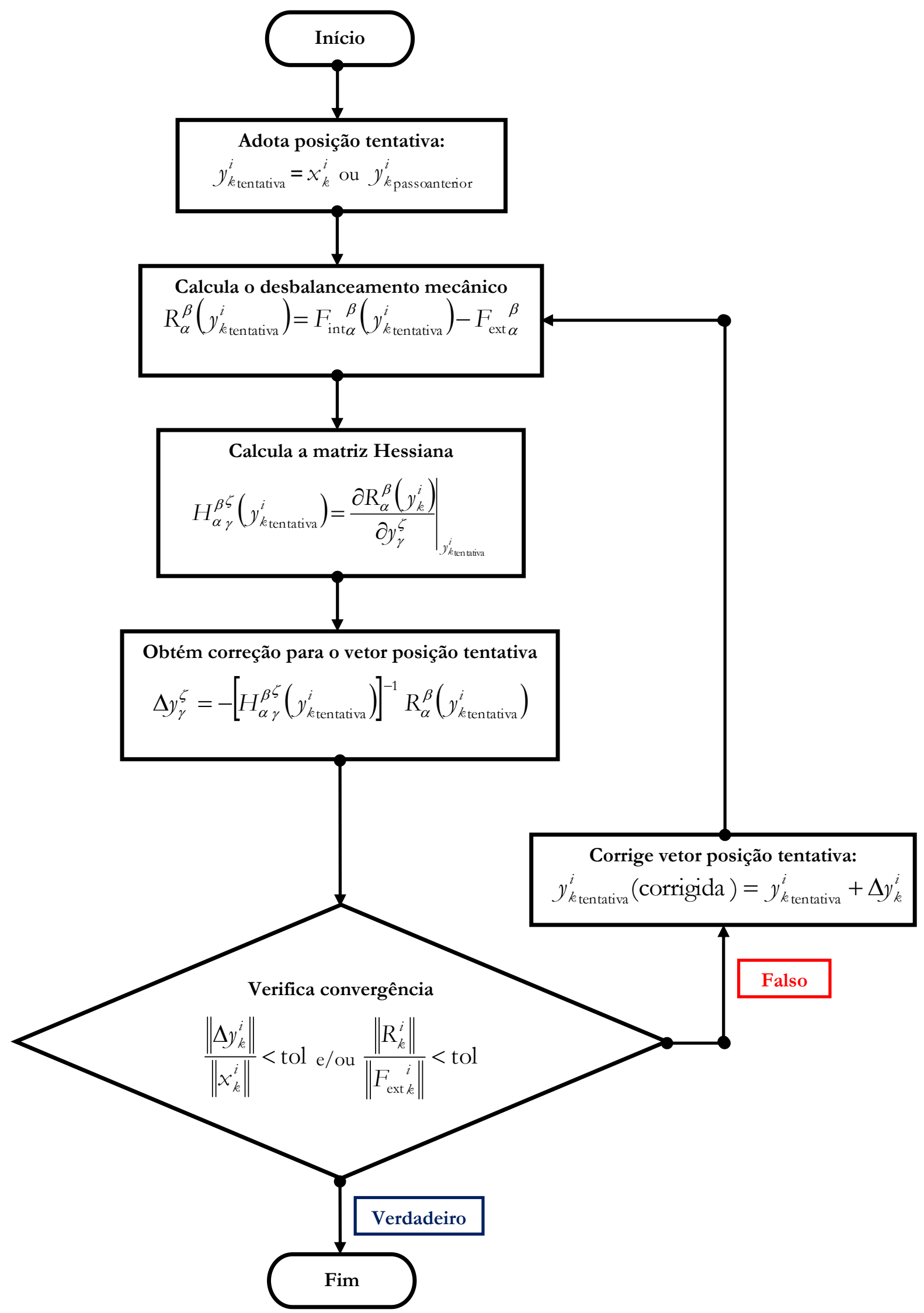

Figura 20 - Fluxograma básico do método de Newton-Raphson 



\section{CAPÍTULO 4}

\section{ELEMENTO FINITO DE PÓRTICO PLANO HOMOGÊNEO}

\subsection{Introdução}

Neste capítulo, a formulação do elemento finito de pórtico plano homogêneo é apresentada e detalhada. Suas características gerais são idênticas àquelas apresentadas no capítulo anterior e, portanto, somente os aspectos particulares são apresentados. Alguns trabalhos que deram origem a formulação desse elemento são os de Coda (2009) e de Coda e Paccola (2010, 2011).

Os pórticos planos são modelos bidimensionais empregados para representar estruturas reticuladas cuja característica mais marcante é a geometria de seus elementos os quais apresentam um eixo longitudinal bem definido e com dimensão pelo menos uma ordem de grandeza superior às dimensões da seção transversal. Devido a essa característica, o modelo estrutural assume hipóteses cinemáticas que permitem analisar um sólido tridimensional por meio da união de barras unidimensionais localizadas no eixo longitudinal dos elementos e contidas em um plano comum. As ações externas são aplicadas diretamente sobre as barras e também estão contidas no mesmo plano da estrutura (MARTHA, 2010).

Nesse sentido, é adequado classificar o elemento finito desenvolvido neste capítulo como um elemento de pórtico plano, pois as hipóteses cinemáticas adotadas permitem que as posições de qualquer ponto da barra sejam determinadas a partir da interpolação polinomial dos graus de liberdade nodais pertencentes a uma linha de referência posicionada no meio da seção transversal. Os graus de liberdade são constituídos pelas posições dos nós e por vetores generalizados que definem o plano dessa seção.

O elemento também é denominado homogêneo, pois a barra é constituída por um único material homogêneo. O modelo utilizado para representar o comportamento do material é aquele apresentado no Item 3.4. A denominação de elemento homogêneo também é adotada para diferenciar do elemento finito de pórtico plano laminado, descrito no capítulo seguinte. 
Além da descrição do elemento finito, pretende-se também realizar análises não lineares geométricas em exemplos de pórticos planos que possuem resultados numéricos e analíticos disponíveis na literatura. Para isso, um código computacional foi desenvolvido com a implementação da formulação em linguagem de programação FORTRAN. Os resultados das análises são fornecidos pelo programa por meio de dois arquivos de saída de dados que permitem a construção de trajetórias de equilíbrio e a visualização das barras nas configurações atuais utilizando o software de pós-processamento AcadView.

Busca-se com isso, verificar a consistência, a eficiência e a robustez da formulação no que diz respeito a sua capacidade de representação do comportamento não linear geométrico de diferentes problemas envolvendo modelos estruturais de pórticos planos.

\subsection{Mapeamento posicional das configurações inicial e atual}

De acordo com Coda e Paccola (2011), o mapeamento do elemento finito de pórtico plano é realizado a partir da interpolação das posições e dos vetores generalizados de pontos nodais localizados em uma linha de referência. A partir dessa interpolação, é possível definir as posições de qualquer ponto contido ou não na linha de referência. Esse mapeamento é utilizado tanto para configuração inicial como para a configuração atual. $\mathrm{Na}$ configuração inicial, os vetores generalizados são unitários, normais à linha de referência e podem ser obtidos a partir do vetor tangente. A Figura 21 ilustra a ideia do mapeamento posicional para um elemento com interpolação cúbica.

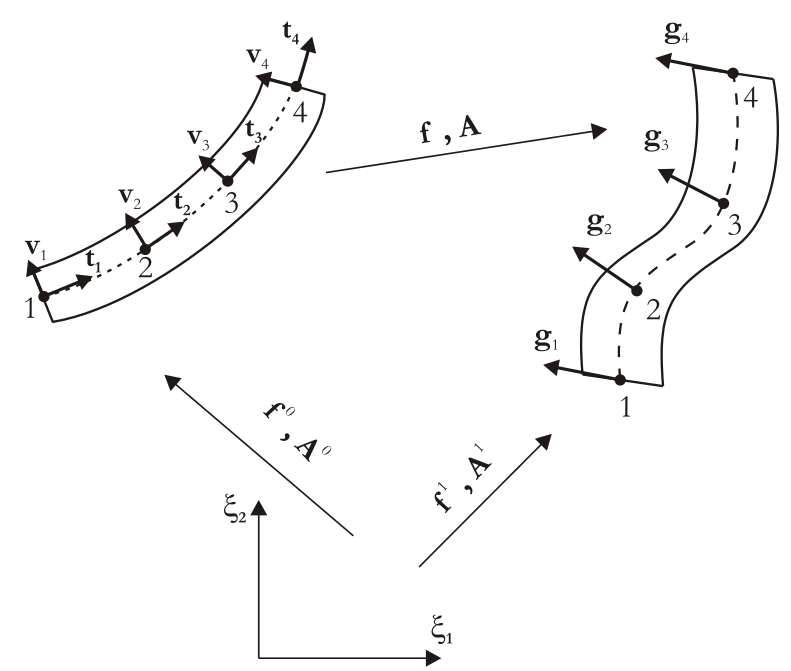

Figura 21 - Mapeamento posicional do elemento de pórtico plano homogêneo

Fonte: Coda e Paccola (2011). 
O mapeamento posicional para a configuração inicial pode ser escrito como:

$$
\begin{aligned}
& \mathbf{f}^{0}\left(\xi_{1}, \xi_{2}\right)=\mathbf{x}\left(\xi_{1}, \xi_{2}\right) \text { e } x^{i}\left(\xi_{1}, \xi_{2}\right)=\Phi_{k}\left(\xi_{1}\right) x_{k}^{i}+\frac{h_{0}}{2} \xi_{2} \Phi_{k}\left(\xi_{1}\right) v_{k}^{i} \\
& \operatorname{com} i=1,2 \text { e } k=1,2,3,4
\end{aligned}
$$

na qual $\mathbf{f}^{0}\left(\xi_{1}, \xi_{2}\right)$ representa a função de mapeamento posicional da configuração inicial $\mathbf{x}\left(\xi_{1}, \xi_{2}\right)$ a partir do espaço adimensional, $x^{i}\left(\xi_{1}, \xi_{2}\right)$ representa a posição inicial na direção $i$ de um ponto qualquer localizado no elemento, $x_{k}^{i}$ é a posição na direção $i$ do nó $k, v_{k}^{i}$ é a componente na direção $i$ do versor pertencente ao plano da seção transversal passando pelo nó $k$, $h_{0}$ é a altura dessa seção e $\Phi_{k}\left(\xi_{1}\right)$ é a função de forma constituída por um polinômio cúbico de Lagrange, associada ao nó k. Nesse mapeamento, a primeira parcela identifica as posições de todos os pontos pertencentes à linha de referência e, dado um ponto dessa linha de referência, a segunda parcela identifica as posições de todos os pontos da seção transversal. Na Figura 22, ilustra-se o mapeamento de um ponto qualquer de coordenadas adimensionais $\left(\xi_{1}=a, \xi_{2}=b\right)$.

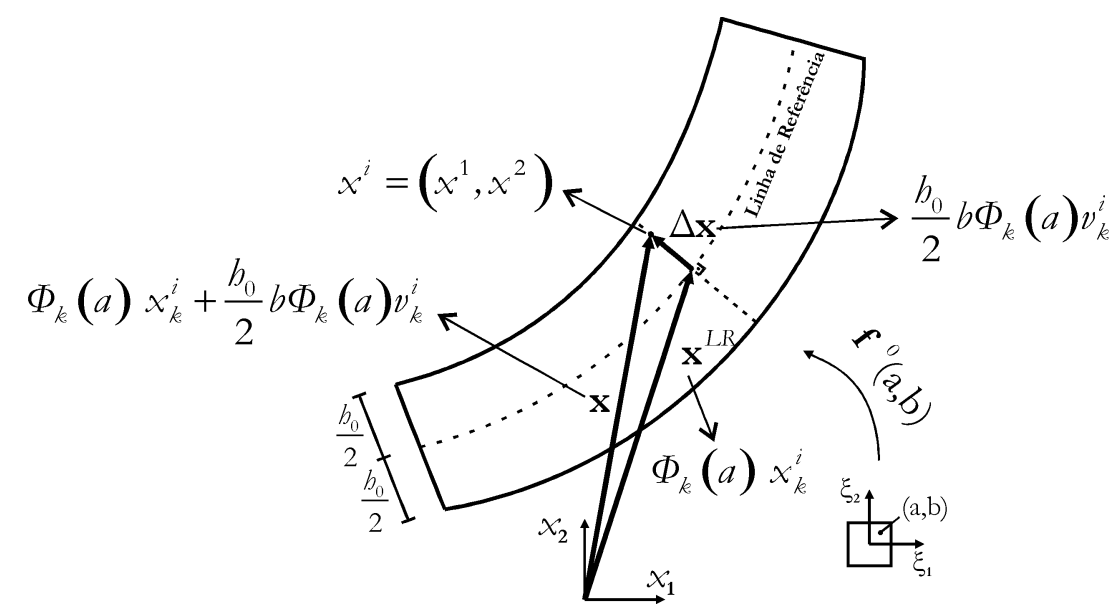

Figura 22 - Mapeamento posicional de um ponto qualquer na configuração inicial

$\mathrm{Na}$ Equação (65), as informações geométricas conhecidas são as posições nodais $x_{k}^{i}$ e a altura $h_{0}$. Os versores nodais $v_{k}^{i}$ são determinados a partir dos vetores nodais tangentes $t_{k}^{i}$ à linha de referência. Aplicando os conceitos do Cálculo Diferencial na primeira parcela da Equação (65), as componentes dos vetores tangentes nodais são expressas por:

$$
t_{k}^{i}=\left.\frac{d \Phi_{e}\left(\xi_{1}\right)}{d \xi_{1}}\right|_{\xi_{k}} x_{e}^{i}, \operatorname{com} e=1,2,3,4,
$$


sendo $\xi_{k}$ a coordenada $\xi_{1}$ correspondente ao nó $k, t_{k}^{i}$ a componente na direção $i$ do vetor tangente ao nó $k$ e $x_{e}^{i}$ a posição inicial na direção $i$ do nó $e$ cuja função de forma associada é $\Phi_{e}\left(\xi_{1}\right)$.

A partir da nulidade no produto escalar, as componentes do versor normal ficam determinadas como:

$$
v_{k}^{1}=\frac{-t_{k}^{2}}{J\left(\xi_{(k)}\right)} \quad v_{k}^{2}=\frac{t_{k}^{1}}{J\left(\xi_{(k)}\right)},
$$

na qual $v_{k}^{1}$ e $v_{k}^{2}$ representam as componentes nas direções 1 e 2 do versor normal à linha de referência no nó $k$ e $J\left(\xi_{(k)}\right)$ é o módulo do vetor tangente nodal com $\xi_{1}=\xi_{(k)} \cdot J\left(\xi_{1}\right)$ também corresponde ao Jacobiano da transformação do espaço adimensional para a configuração inicial da linha de referência. Esse Jacobiano é dado por:

$$
J\left(\xi_{1}\right)=\sqrt{t^{i}\left(\xi_{1}\right) t^{i}\left(\xi_{1}\right)} \leftrightarrow J\left(\xi_{1}\right)=\sqrt{\left[t^{1}\left(\xi_{1}\right)\right]^{2}+\left[t^{2}\left(\xi_{1}\right)\right]^{2}}
$$

Para a configuração atual, um mapeamento semelhante é empregado, mas as posições e as componentes dos vetores generalizados associados aos nós do elemento finito não são conhecidas e constituem as incógnitas do problema não linear.

O mapeamento posicional para a configuração atual pode, então, ser escrito como:

$$
\begin{aligned}
& \mathbf{f}^{1}\left(\xi_{1}, \xi_{2}\right)=\mathbf{y}\left(\xi_{1}, \xi_{2}\right) \text { e } y^{i}\left(\xi_{1}, \xi_{2}\right)=\Phi_{k}\left(\xi_{1}\right) y_{k}^{i}+\frac{h_{0}}{2} \xi_{2} \Phi_{k}\left(\xi_{1}\right) g_{k}^{i} \\
& \operatorname{com} i=1,2 \text { e } k=1,2,3,4
\end{aligned}
$$

na qual o significado dos termos são análogos ao do mapeamento da configuração inicial, mas referenciados agora à configuração atual. Nesse mapeamento, o elemento cúbico possui ao todo dezesseis graus de liberdade incógnitos, quatro em cada nó, que são as duas posições $y_{k}^{i}$ e as duas componentes do vetor generalizado $g_{k}^{i}$. É importante ressaltar novamente que a primeira parcela identifica as posições de todos os pontos pertencentes à linha de referência atual e, dado um ponto dessa linha de referência, a segunda parcela identifica as posições de todos os pontos da seção transversal. $\mathrm{Na}$ Figura 23, ilustra-se o mapeamento de um ponto qualquer de coordenadas adimensionais $\left(\xi_{1}=a, \xi_{2}=b\right)$ na configuração atual.

Apesar de ter sido mantido $h_{0}$ constante na Equação (69), a altura da seção transversal se modifica, pois o vetor generalizado pode deixar de ser unitário na configuração atual. Assim, a altura de uma seção transversal na configuração atual passa a ser: 


$$
h\left(\xi_{1}\right)=h_{0} \Phi_{k}\left(\xi_{1}\right)\left\|\mathbf{g}_{k}\right\|
$$

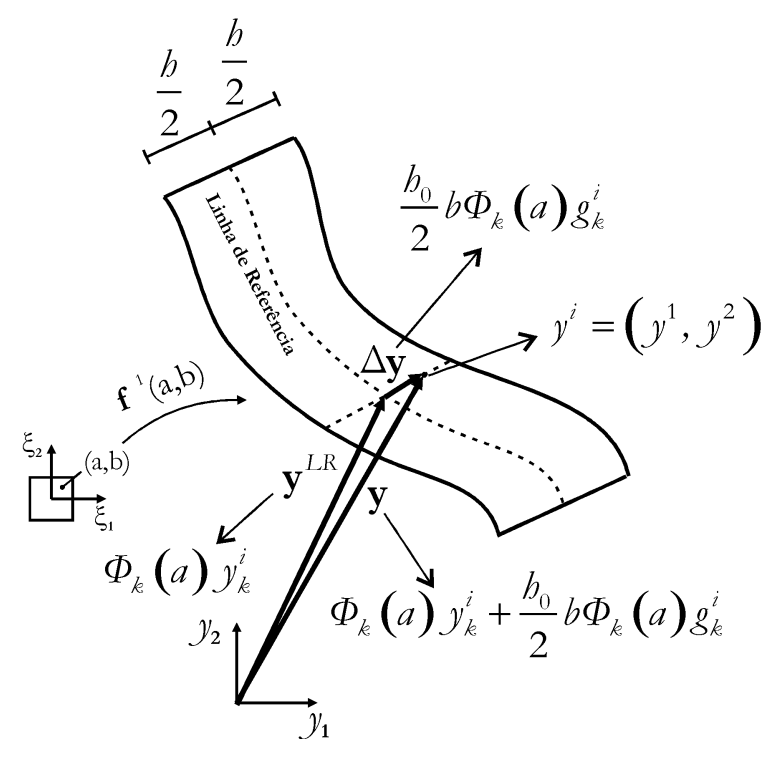

Figura 23 - Mapeamento posicional de um ponto qualquer na configuração atual

O mapeamento descrito na Equação (69) gera uma cinemática cujas seções transversais apresentam variação de altura e permanecem planas, porém não ortogonais à linha de referência. O nível em que a seção deixa de ser ortogonal à linha de referência está associado às tensões de cisalhamento envolvidas e ao módulo de elasticidade transversal.

A cinemática representada por esse mapeamento considera o efeito de Poisson no plano que contém o elemento e resulta em uma distribuição de tensão de cisalhamento transversal linear e de tensão axial transversal constante, portanto, é uma cinemática mais precisa do que as formulações baseadas nas hipóteses cinemáticas de Euler-Bernoulli e de ReissnerTimoshenko.

\subsection{Particularidades do elemento de pórtico plano homogêneo}

No Capítulo 3, toda a sequência de operações matemáticas da formulação posicional aplicada a problemas bidimensionais foi desenvolvida e, no item anterior, descreveu-se a cinemática do elemento de pórtico plano homogêneo. Logo, para definir completamente a formulação do elemento finito, fica faltando apenas identificar os termos que dependem da função de mapeamento posicional empregada. Isso está apresentado nos itens seguintes. 


\subsubsection{Gradiente das funções de mapeamento posicional}

Com a definição dos mapeamentos posicionais, a função mudança de configuração pode ser determinada através da composição de funções especificada na Equação (11) e ilustrada na Figura 16. Portanto, resta apenas descrever as componentes dos gradientes $\mathbf{A}^{0}\left(\xi_{1}, \xi_{2}\right)$ e $\mathbf{A}^{1}\left(\xi_{1}, \xi_{2}\right)$ que dependem das funções de mapeamento apresentadas nas Equações (65) e (69), respectivamente. Os termos desses gradientes foram identificados na Equação (14) e, observando as funções de mapeamento, ficam expressos por:

$$
\begin{aligned}
\mathbf{A}^{0}\left(\xi_{1}, \xi_{2}\right) & =\left[\begin{array}{ll}
\Phi_{k, 1}\left(\xi_{1}\right) x_{k}^{1}+\frac{h_{0}}{2} \xi_{2} \Phi_{k, 1}\left(\xi_{1}\right) v_{k}^{1} & \frac{h_{0}}{2} \Phi_{k}\left(\xi_{1}\right) v_{k}^{1} \\
\Phi_{k, 1}\left(\xi_{1}\right) x_{k}^{2}+\frac{h_{0}}{2} \xi_{2} \Phi_{k, 1}\left(\xi_{1}\right) v_{k}^{2} & \frac{h_{0}}{2} \Phi_{k}\left(\xi_{1}\right) v_{k}^{2}
\end{array}\right], \\
\mathbf{A}^{1}\left(\xi_{1}, \xi_{2}\right) & =\left[\begin{array}{ll}
\Phi_{k, 1}\left(\xi_{1}\right) y_{k}^{1}+\frac{h_{0}}{2} \xi_{2} \Phi_{k, 1}\left(\xi_{1}\right) g_{k}^{1} & \frac{h_{0}}{2} \Phi_{k}\left(\xi_{1}\right) g_{k}^{1} \\
\Phi_{k, 1}\left(\xi_{1}\right) y_{k}^{2}+\frac{h_{0}}{2} \xi_{2} \Phi_{k, 1}\left(\xi_{1}\right) g_{k}^{2} & \frac{h_{0}}{2} \Phi_{k}\left(\xi_{1}\right) g_{k}^{2}
\end{array}\right],
\end{aligned}
$$

$\operatorname{com} \Phi_{k, 1}\left(\xi_{1}\right)=\frac{\partial \Phi_{k}\left(\xi_{1}\right)}{\partial \xi_{1}}$. Vale ressaltar que não há necessidade de explicitar as equações que compõem o gradiente $\mathbf{A}=\mathbf{A}^{1}\left(\xi_{1}, \xi_{2}\right) \cdot\left[\mathbf{A}^{0}\left(\xi_{1}, \xi_{2}\right)\right]^{-1}$, pois a as operações matemáticas envolvidas são realizadas numericamente.

\subsubsection{Energia potencial de deformação}

Com os gradientes $\mathbf{A}^{0}\left(\xi_{1}, \xi_{2}\right)$ e $\mathbf{A}^{1}\left(\xi_{1}, \xi_{2}\right)$ definidos, a energia potencial de deformação do elemento pode ser calculada conforme o procedimento descrito no Item 3.5. Outra observação a ser feita está relacionada à integração numérica da energia de deformação na Equação (33). Para o elemento de aproximação cúbica, são empregados doze pontos de Gauss distribuídos em quatro pontos na direção de $\xi_{1}$ e em três pontos na direção de $\xi_{2}$.

\subsubsection{Energia potencial relativa às ações externas}

$\mathrm{Na}$ parcela da energia potencial relativa às ações externas, são consideradas as contribuições de forças e momentos concentrados e de forças distribuídas. A energia associada a 
essas duas últimas ações é contabilizada por meio de forças nodais equivalentes. No caso do elemento de pórtico plano homogêneo, todas as ações externas são consideradas aplicadas na linha de referência, pois os problemas analisados são todos constituídos por barras esbeltas, que é um dos pré-requisitos para o emprego de modelos de pórtico.

As ações externas são consideradas conservativas e, conforme mostrado no Item 3.6, a relação entre força e posição é energeticamente conjugada. Assim, uma energia potencial externa pode ser definida, sendo calculada pelo negativo do produto escalar entre o vetor força externa e o vetor posição atual do ponto de aplicação dessa força (Equação (40)).

No caso das forças distribuídas, são determinadas forças nodais equivalentes de forma a manter a mesma energia potencial. A Figura 24 ilustra essa transformação:

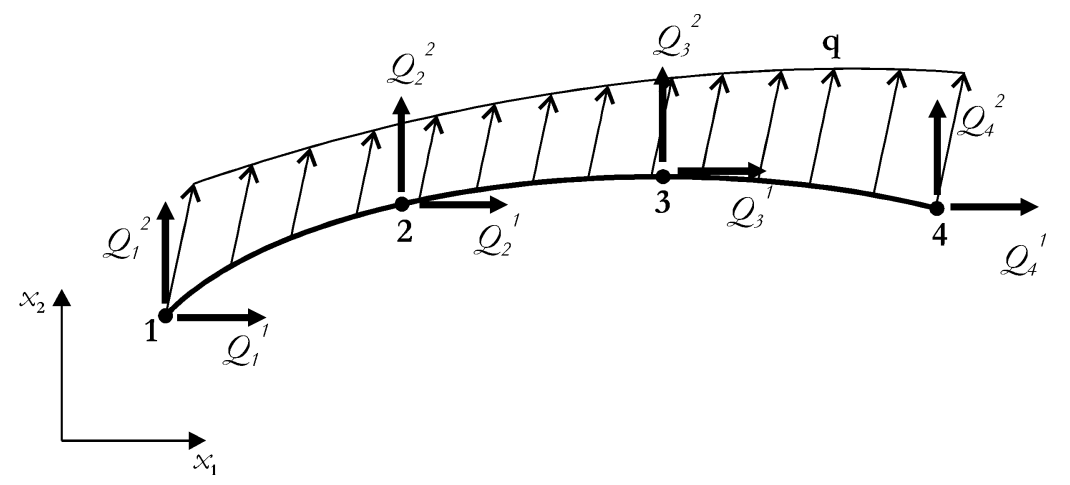

Figura 24 - Carga distribuída e forças nodais equivalentes Fonte: Coda (2006).

Assim como as posições da linha de referência, a força distribuída $q^{i}$ também é representada por uma função de interpolação polinomial dos valores $q_{e}^{i}$ nos nós do elemento. Portanto, tem-se que:

$$
q^{i}\left(\xi_{1}\right)=\Phi_{e}\left(\xi_{1}\right) q_{e}^{i}
$$

sendo $q_{e}^{i}$ o valor assumido pela força distribuída no nó $e=1,2,3,4$, com componentes nas direções globais $i=1,2$.

Utilizando a Equação (73) e a primeira parte da Equação (69) que representa o mapeamento da linha de referência na configuração atual, a parcela da energia potencial externa devido às forças distribuídas é determinada por:

$$
\Omega=-\int_{-1}^{1} q^{i}\left(\xi_{1}\right) y^{i}\left(\xi_{1}\right) J\left(\xi_{1}\right) d \xi_{1},
$$




$$
\begin{aligned}
& \Omega=-\int_{-1}^{1}\left[\Phi_{e}\left(\xi_{1}\right) q_{e}^{i}\right]\left[\Phi_{k}\left(\xi_{1}\right) y_{k}^{i}\right] J\left(\xi_{1}\right) d \xi_{1}, \\
& \Omega=-\left\{\int_{-1}^{1}\left[\Phi_{e}\left(\xi_{1}\right) q_{e}^{i}\right]\left[\Phi_{k}\left(\xi_{1}\right)\right] J\left(\xi_{1}\right) d \xi_{1}\right\} y_{k}^{i}, \\
& \Omega=-Q_{k}^{i} y_{k}^{i},
\end{aligned}
$$

na qual $J\left(\xi_{1}\right)$ é o Jacobiano da transformação do espaço adimensional para a linha de referência na configuração inicial (Equação (68)) e $Q_{k}^{i}=\int_{-1}^{1}\left[\Phi_{e}\left(\xi_{1}\right) q_{e}^{i}\right]\left[\Phi_{k}\left(\xi_{1}\right)\right] J\left(\xi_{1}\right) d \xi_{1}$ é a força nodal equivalente atuante no nó $k=1,2,3,4$ com direção $i=1,2$. A integral para cálculo de $Q_{k}^{i}$ é resolvida numericamente com a quadratura de Gauss, ficando representada pelo somatório seguinte:

$$
Q_{k}^{i}=\left\lfloor\Phi_{e}\left(\xi_{1 i g}\right) q_{e}^{i}\right\rfloor\left\lfloor\Phi_{k}\left(\xi_{1 i g}\right)\right\rfloor J\left(\xi_{1(i g)}\right) w_{(i g)},
$$

sendo $\xi_{1 i g}$ a coordenada $\xi_{1}$ do ponto de Gauss com peso $w_{(i g)}$.

No modelo discreto de elementos finitos, a ação de um carregamento distribuído aplicado sobre uma pequena região nodal pode ser considerada por meio de uma força concentrada equivalente aplicada diretamente sobre o nó. Dessa forma, faz sentido estabelecer uma energia potencial associada a forças concentradas aplicadas nos nós do elemento. Essa energia é definida por:

$$
\Omega=-P_{k}^{i} y_{k}^{i}
$$

sendo $P_{k}^{i}$ o vetor força externa aplicado no nó $k=1,2,3,4$ com componentes nas direções globais $i=1,2$ e $y_{k}^{i}$ o vetor posição nodal.

Portanto, a energia potencial de um elemento finito sujeito à ação de forças externas concentradas e distribuídas fica determinada simplesmente pela soma das contribuições das Equações (74) e (76):

$$
\Omega=-\left(P_{k}^{i}+Q_{k}^{i}\right) y_{k}^{i} \text {. }
$$

Os momentos concentrados representam outra ação externa que surge nos modelos estruturais de pórticos. Como não há parâmetros de giro associados à seção nodal, o efeito de momentos concentrados é levado em consideração através de um par de forças formando um 
binário aplicado perpendicularmente ao vetor generalizado nodal, conforme está ilustrado na Figura 25.

No Item 3.6, mostrou-se que força e posição são energeticamente conjugadas. Assim, uma energia potencial equivalente associada ao binário pode ser definida pelo negativo do produto escalar entre o vetor força que compõem o binário e o vetor posição atual do ponto de aplicação (Equação (40)). O uso do termo equivalente ficará claro quando for mostrado que a força do binário não é conservativa.

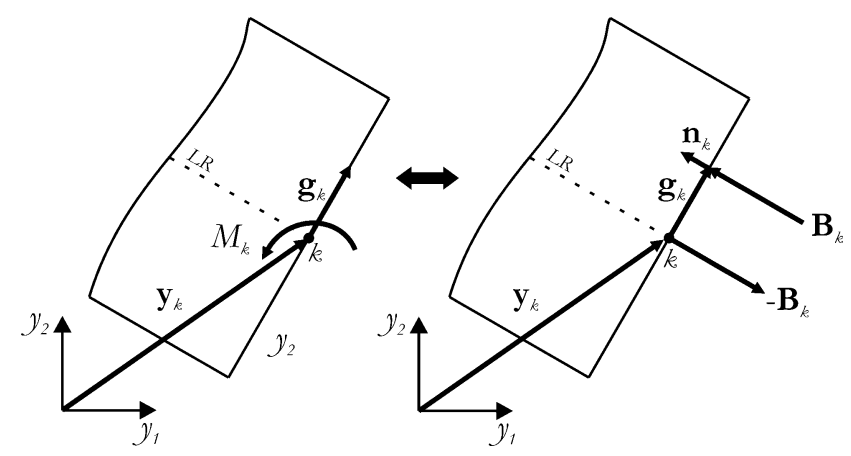

Figura 25 - Binários correspondentes ao momento concentrado

Observando a Figura 25, a energia potencial equivalente pode ser escrita como:

$$
\Omega=-\left[\mathbf{B}_{k} \cdot\left(\mathbf{y}_{k}+\mathbf{g}_{k}\right)\right]-\left[\left(-\mathbf{B}_{k}\right) \cdot \mathbf{y}_{k}\right] \leftrightarrow \Omega=-\mathbf{B}_{k} \cdot \mathbf{g}_{k}=-B_{k}^{i} g_{k}^{i},
$$

sendo $\mathbf{y}_{k}$ o vetor posição atual do nó $k$ onde está aplicado o momento, $\mathbf{g}_{k}$ o vetor generalizado da seção nodal e $\mathbf{B}_{k}$ a força que compõe o binário com componentes nas direções globais $i=1,2$.

Para determinar o vetor força do binário, é necessário definir seu módulo e direção. O sentido pode ser observado na Figura 25. O módulo de $\mathbf{B}_{k}$ é obtido de forma que seu produto com o módulo do vetor generalizado nodal corresponda ao momento concentrado $M_{k}$ aplicado no nó k. Logo, tem-se que:

$$
\left\|\mathbf{B}_{k}\right\|=\frac{M_{k}}{\left\|\mathbf{g}_{k}\right\|} \leftrightarrow \quad \sqrt{B_{(k)}^{i} B_{(k)}^{i}}=\frac{M_{k}}{\sqrt{g_{(k)}^{i} g_{(k)}^{i}}} .
$$

A direção de $\mathbf{B}_{k}$ é dada pelo versor ortogonal ao vetor generalizado $\mathbf{g}_{k}$ :

$$
\mathbf{n}_{k}=\frac{1}{\left\|\mathbf{g}_{k}\right\|}\left(-g_{k}^{2}, g_{k}^{1}\right) \quad \leftrightarrow \quad \mathbf{n}_{k}=\frac{1}{\sqrt{g_{(k)}^{j} g_{(k)}^{j}}}\left(-g_{k}^{2}, g_{k}^{1}\right)
$$


Definidos o módulo e a direção da força que compõe o binário, pode-se, então, representar o vetor $\mathbf{B}_{k}$ como:

$$
\mathbf{B}_{k}=\left\|\mathbf{B}_{k}\right\| \mathbf{n}_{k} \quad \leftrightarrow \quad \mathbf{B}_{k}=\frac{M_{k}}{\left\|\mathbf{g}_{k}\right\|^{2}}\left(-g_{(k)}^{2}, g_{(k)}^{1}\right) \quad \leftrightarrow \quad \mathbf{B}_{k}=\frac{M_{k}}{g_{(k)}^{j} g_{(k)}^{j}}\left(-g_{(k)}^{2}, g_{(k)}^{1}\right) .
$$

Retornando a expressão da energia potencial equivalente na Equação (78), identificam-se os conjugados energéticos associados às componentes $g_{k}^{1}$ e $g_{k}^{2}$ do vetor generalizado pertencente ao nó com momento concentrado aplicado. Da Equação (81), esses conjugados são dados, respectivamente, por:

$$
\begin{aligned}
& B_{k}^{1}=-\frac{M_{k}}{g_{(k)}^{j} g_{(k)}^{j}} g_{(k)}^{2} \text { conjugado de } g_{k}^{1}, \\
& B_{k}^{2}=\frac{M_{k}}{g_{(k)}^{j} g_{(k)}^{j}} g_{(k)}^{1} \text { conjugado de } g_{k}^{2} .
\end{aligned}
$$

Como pode ser observado na Equação (82), os conjugados energéticos $B_{k}^{1}$ e $B_{k}^{2}$ não são uma ação externa conservativa, pois dependem dos valores assumidos por $g_{k}^{1}$ e $g_{k}^{2}$. Assim, se justifica o termo equivalente atribuído à energia potencial associada às forças que compõem o binário. $O$ artifício de definir uma energia potencial equivalente é utilizado somente para identificar os conjugados energéticos de $g_{k}^{1}$ e de $g_{k}^{2}$.

Portanto, como a formulação aqui desenvolvida emprega ações externas conservativas que permitem definir uma energia potencial associada, a forma de considerar o efeito desses conjugados energéticos não conservativos é inseri-los diretamente nas equações de equilíbrio correspondentes aos graus de liberdade $g_{k}^{1}$ e $g_{k}^{2}$ do nó onde o momento está aplicado. Assim, para satisfazer o equilíbrio considerando a presença do momento, os conjugados energéticos $B_{k}^{1}$ e $B_{k}^{2}$ são atualizados a cada iteração durante o processo de solução (CODA; PACCOLA, 2011).

Esse procedimento voltará a ser esclarecido nos Itens 4.3 .4 e 4.3.5, referentes às equações de equilíbrio e ao processo de solução, respectivamente.

\subsubsection{Energia potencial total e equações de equilíbrio}

A energia potencial total do elemento finito é composta pelas parcelas da energia de deformação mais o potencial das ações externas atuantes (Equação (43)). Em um modelo 
discreto, vários elementos finitos são empregados para modelar a estrutura e a energia potencial total é dada pela soma das contribuições de cada elemento individualmente.

Para simplificar a contribuição de vários elementos finitos na energia potencial total, a seguinte associação é adotada para identificar os graus de liberdade:

$$
\begin{array}{lllll}
g l_{1}: y_{1} & \rightarrow & y_{k}^{1} & & \\
g l_{2}: y_{2} & \rightarrow & y_{k}^{2} & & \\
g l_{3}: g_{1} & \rightarrow & g_{k}^{1} & \rightarrow & y_{k}^{3} \\
g l_{4}: g_{2} & \rightarrow & g_{k}^{2} & \rightarrow & y_{k}^{4}
\end{array}
$$

na qual $k=1,2,3,4$ identifica localmente o nó, $i=1,2,3,4$ identifica o grau de liberdade. Os

graus de liberdade 1 e 2 representam as posições, 3 e 4 representam as componentes $g_{1}\left(g_{k}^{1}\right)$ e $g_{2}\left(g_{k}^{2}\right)$ do vetor generalizado que são, então, identificadas como $y_{k}^{3}$ e $y_{k}^{4}$.

Utilizando essa identificação, um vetor posição local $y_{k}^{i}$ do elemento finito contendo os dezesseis graus de liberdade é definido. A localização de um dado grau de liberdade nesse vetor posição é determinada com auxílio do número do nó $k$ e do próprio grau de liberdade nodal $i$. A regra para localização no vetor é dada por:

$$
y_{k \text { (nó local })}^{i \text { (grade liberdade })} \rightarrow 4(k-1)+i
$$

Uma identificação análoga à Equação (83) também é empregada para definir o vetor de forças internas $F_{\text {int } k}^{i}$ e o vetor de forças externas $F_{\text {ext } k}^{i}$ do elemento. Nesses vetores, os termos com $i$ igual a 1 e 2 são componentes de forças nodais atuantes nas direções globais 1 e 2 , respectivamente, e os termos com $i$ igual a 3 e 4 são conjugados energéticos das componentes $g_{1}\left(g_{k}^{1}\right)$ e $g_{2}\left(g_{k}^{2}\right)$ do vetor generalizado nodal, respectivamente.

Nos modelos discretos, há muitos elementos finitos e um mesmo nó pode pertencer a vários elementos. Assim, definem-se vetores posição $y_{k}^{i}$, força interna $F_{\text {inte }}^{i}$ e força externa $F_{\text {ext } k}^{i}$ globais que recebem contribuição de todos os elementos utilizados na discretização da estrutura. Para a montagem desses vetores globais, a mesma regra de identificação apresentada nas Equações (83) e (84) é empregada, mas a numeração do nó k deixa de ser local e passa a ser a numeração global atribuída durante a geração da malha, conforme ilustra a Figura 26. A relação da Equação (84) passa a ser:

$$
y_{k \text { (nó global) }}^{i \text { (grau de liberdade) }} \rightarrow 4(k-1)+i \text { com } i=1,2,3,4 \text { e } k=1, \ldots, N
$$

sendo $N$ o número de nós da discretização. 
Assumindo a relação da Equação (85), a soma das contribuições de cada elemento finito na função de energia potencial total da estrutura pode ser realizada. Considerando a parcela de energia das ações externas (Equação (77)), pode-se reescrever a Equação (44) como:

$$
\Pi\left(y_{k}^{i}\right)=U\left(y_{k}^{i}\right)-\left(P_{k}^{i}+Q_{k}^{i}\right) y_{k}^{i}
$$

na qual $\Pi\left(y_{k}^{i}\right)$ representa a função de energia potencial total cuja determinação depende apenas do vetor posição atual $y_{k}^{i}$ que contém os graus de liberdade de todos os nós utilizados na discretização. A determinação de $y_{k}^{i}$ é feita através da solução do sistema de equações não lineares definido na Equação (47), que tem o significado físico de equilíbrio nodal.

$\mathrm{Na}$ Equação (86), não há a parcela de energia equivalente devida a momentos concentrados. $\mathrm{O}$ efeito desses momentos é considerado somente na equação de equilíbrio com a contribuição do binário correspondente $\mathbf{B}_{k}$ dado pelas Equações (81) e (82) no vetor de forças externas.
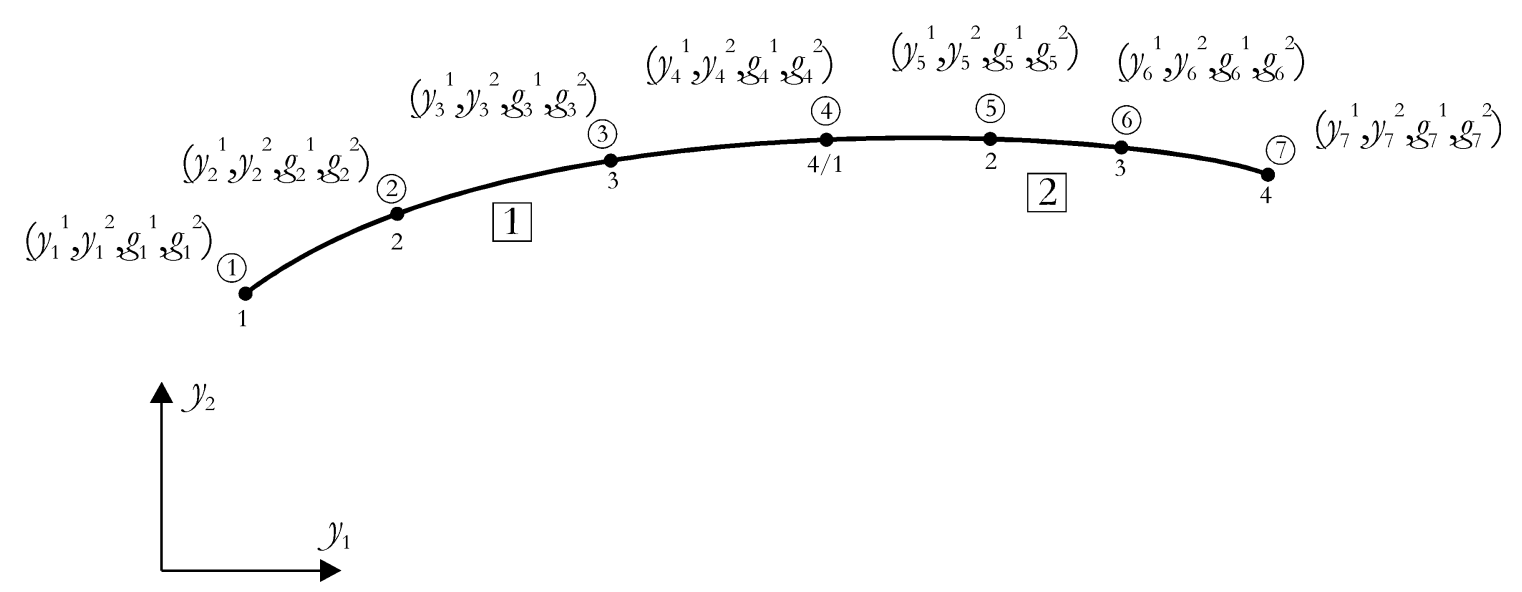

Figura 26 - Associação de dois elementos finitos de pórtico plano homogêneo

Fonte: Coda (2006).

As equações de equilíbrio foram obtidas por meio do princípio da energia potencial total estacionária e estão definidas na Equação (47). Considerando a função de energia potencial total do elemento finito de pórtico plano homogêneo, determinado na Equação (86), e os conjugados energéticos das Equações (81) e (82) devido ao efeito de momentos concentrados, as equações de equilíbrio podem ser escritas como:

$$
F_{\text {int } \alpha}^{\beta}\left(y_{k}^{i}\right)-\left[P_{\alpha}^{\beta}+Q_{\alpha}^{\beta}+B_{\alpha}^{\beta}\left(y_{k}^{i}\right)\right]=0
$$


Nessa equação, o vetor de forças internas foi definido na Equação (48) e calculado com quadratura de Gauss na Equação (49). Para o elemento de pórtico plano homogêneo descrito aqui, são empregados doze pontos de Gauss em todas as integrações numéricas. Esses pontos são distribuídos em um domínio retangular com quatro pontos ao longo da direção longitudinal e três pontos ao longo da direção transversal.

$\mathrm{Na}$ ocasião da definição do vetor de forças internas no Item 3.7, ficou pendente a descrição dos termos que compõem $\frac{\partial \mathbf{A}^{1}}{\partial y_{\alpha}^{\beta}}$ na Equação (53), pois dependem da função de mapeamento posicional adotada. Com a definição de $\mathbf{f}^{1}\left(\xi_{1}, \xi_{2}\right)$ na Equação $(69)$, de $\mathbf{A}^{1}\left(\xi_{1}, \xi_{2}\right)$ na Equação (72) e considerando a notação apresentada na Equação (83), $\frac{\partial \mathbf{A}^{1}}{\partial y_{\alpha}^{\beta}}$ fica representada por matrizes constituídas de termos diferentes dependendo do grau de liberdade ao qual a derivada está sendo avaliada. Assim, os termos de $\frac{\partial \mathbf{A}^{1}}{\partial y_{\alpha}^{\beta}}$ ficam definidos conforme pode ser observado nas equações a seguir:

$$
\begin{aligned}
& \frac{\partial \mathbf{A}^{1}\left(\xi_{1}, \xi_{2}\right)}{\partial y_{\alpha}^{1}}=\left[\begin{array}{cc}
\Phi_{\alpha, 1}\left(\xi_{1}\right) & 0 \\
0 & 0
\end{array}\right] \\
& \frac{\partial \mathbf{A}^{1}\left(\xi_{1}, \xi_{2}\right)}{\partial y_{\alpha}^{2}}=\left[\begin{array}{cc}
0 & 0 \\
\Phi_{\alpha, 1}\left(\xi_{1}\right) & 0
\end{array}\right] \\
& \frac{\partial \mathbf{A}^{1}\left(\xi_{1}, \xi_{2}\right)}{\partial y_{\alpha}^{3}}=\left[\begin{array}{cc}
\frac{h_{0}}{2} \xi_{2} \Phi_{\alpha, 1}\left(\xi_{1}\right) & \frac{h_{0}}{2} \Phi_{\alpha}\left(\xi_{1}\right) \\
0 & 0
\end{array}\right], \\
& \frac{\partial \mathbf{A}^{1}\left(\xi_{1}, \xi_{2}\right)}{\partial y_{\alpha}^{4}}=\left[\begin{array}{cc}
0 & 0 \\
\frac{h_{0}}{2} \xi_{2} \Phi_{\alpha, 1}\left(\xi_{1}\right) & \frac{h_{0}}{2} \Phi_{\alpha}\left(\xi_{1}\right)
\end{array}\right] .
\end{aligned}
$$

Vale ressaltar que os termos dessas matrizes não dependem das posições nodais atuais $y_{k}^{i}$. Assim, sua derivada segunda $\frac{\partial^{2} \mathbf{A}^{1}}{\partial y_{\alpha}^{\beta} \partial y_{\gamma}^{\zeta}}$, que surge na definição da matriz Hessiana na Equação (63), é nula. Definidos todos os termos necessários para calcular o vetor de forças internas $F_{\text {int } \alpha}^{\beta}\left(y_{k}^{i}\right)$, o problema agora se resume em determinar as posições atuais $y_{k}^{i}$ que satisfazem a Equação de equilíbrio (87). 


\subsubsection{Processo de solução}

O processo de solução empregado neste trabalho já foi apresentado no Item 3.8. Aqui são apresentados apenas alguns detalhes que dependem da formulação do elemento finito desenvolvido.

Durante o processo de solução, as posições atuais $y_{k}^{i}$ dos nós do pórtico não são conhecidas e posições-tentativa $y_{k \text { tentativa }}^{i}$ são atribuídas. Como essas posições não verificam o equilíbrio nodal representado pela Equação de equilíbrio (87), gera-se um resíduo que corresponde ao vetor de desbalanceamento mecânico:

$$
\mathrm{R}_{\alpha}^{\beta}\left(y_{k \text { tentativa }}^{i}\right)=F_{\text {int } \alpha}^{\beta}\left(y_{k \text { tentativa }}^{i}\right)-\left[P_{\alpha}^{\beta}+Q_{\alpha}^{\beta}+B_{\alpha}^{\beta}\left(y_{k \text { tentativa }}^{i}\right)\right]
$$

Apesar de não ter sido definida uma energia potencial devida a momentos concentrados, a parcela $B_{\alpha}^{\beta}\left(y_{k \text { tentativa }}^{i}\right)$ é adicionada no cálculo do vetor de desbalanceamento mecânico para que as posições de equilíbrio encontradas considerem o efeito desses momentos.

A matriz Hessiana $H_{\alpha \gamma}^{\beta^{\zeta}}\left(y_{k \text { tentativa }}^{i}\right)$ do elemento de pórtico plano homogêneo apresenta dimensão igual $4 \mathrm{~N}$, com $N$ sendo o número de nós da discretização e 4 o número de graus de liberdade nodais. A localização dos termos dessa matriz é feita seguindo uma regra de atribuição semelhante à apresentada na Equação (84), no caso da Hessiana do elemento, e na Equação (85), no caso da Hessiana global da estrutura. A atribuição global segue a regra abaixo:

$$
H_{\alpha \gamma}^{\beta \zeta}\left(y_{k \text { tentativa }}^{i}\right) \rightarrow \begin{aligned}
& \text { Linha: } 4(\alpha-1)+\beta \\
& \text { Coluna: } 4(\gamma-1)+\zeta
\end{aligned} \text { com } \beta \text { e } \zeta=1,2,3,4 \text { e } \alpha \text { e } \gamma=1, \ldots, N
$$

Essa matriz é determinada numericamente conforme apresentado na Equação (59) e a quantidade de pontos de Gauss empregada é a mesma utilizada para obter o vetor de forças internas na Equação (49).

Antes das análises numéricas para verificação da formulação, é necessário descrever como é realizada a ligação entre elementos com direções diferentes. É óbvio que para elementos colineares não é necessário realizar a ligação, pois o vetor generalizado que representa a seção transversal é o mesmo para ambos os elementos.

Como não há graus de liberdade de giro no mapeamento empregado, um procedimento especial de acoplamento entre elementos com direções diferentes é necessário. Esse procedimento é baseado na técnica de penalização. 


\subsubsection{Ligações entre elementos não colineares}

O acoplamento entre elementos com direções diferentes é realizado através de um modelo de molas que permite representar ligações rígidas, semirrígidas e articuladas. O modelo desenvolvido permite acoplar todos os graus de liberdade nodais. Para as posições, a mola trabalha com deslocamento relativo entre os nós dos elementos e, para o vetor generalizado, a mola trabalha com o giro relativo entre os vetores generalizados dos elementos. Na Figura 27, ilustra-se o modelo de acoplamento e apresenta a nomenclatura adotada para identificar os parâmetros de rigidez.

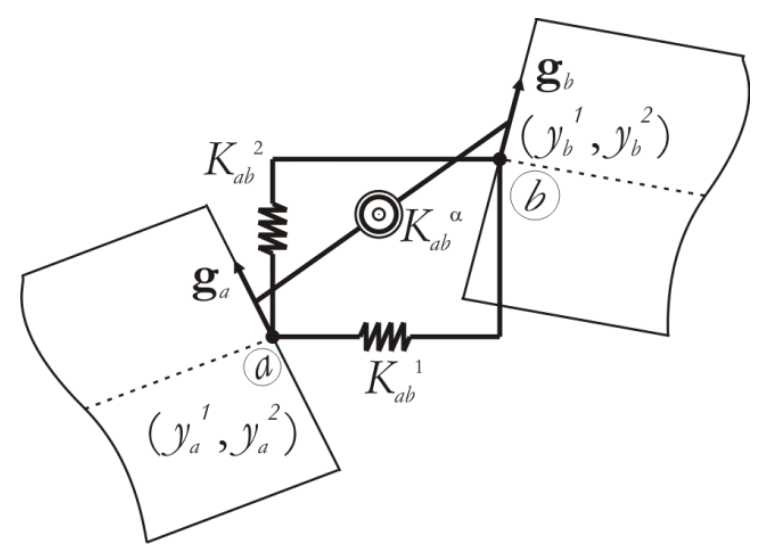

Figura 27 - Modelo de acoplamento entre elementos

Com esse modelo, é possível representar diferentes formas de acoplamento entre os elementos e sempre com a possibilidade de ter a rigidez da ligação variando desde articulada até perfeitamente rígida. Também é possível representar condições de contorno flexíveis. Algumas possibilidades de acoplamento estão ilustradas na Figura 28.

Do ponto de vista matemático, esse modelo de acoplamento entre barras nada mais é do que o emprego de uma técnica para imposição de restrições conhecida como penalização. Alguns modelos semelhantes aplicados a formulações posicionais podem ser encontrados em Coda e Paccola (2014), Reis e Coda (2014) e Silva (2014) que demostram a simplicidade e eficiência dessa técnica. 


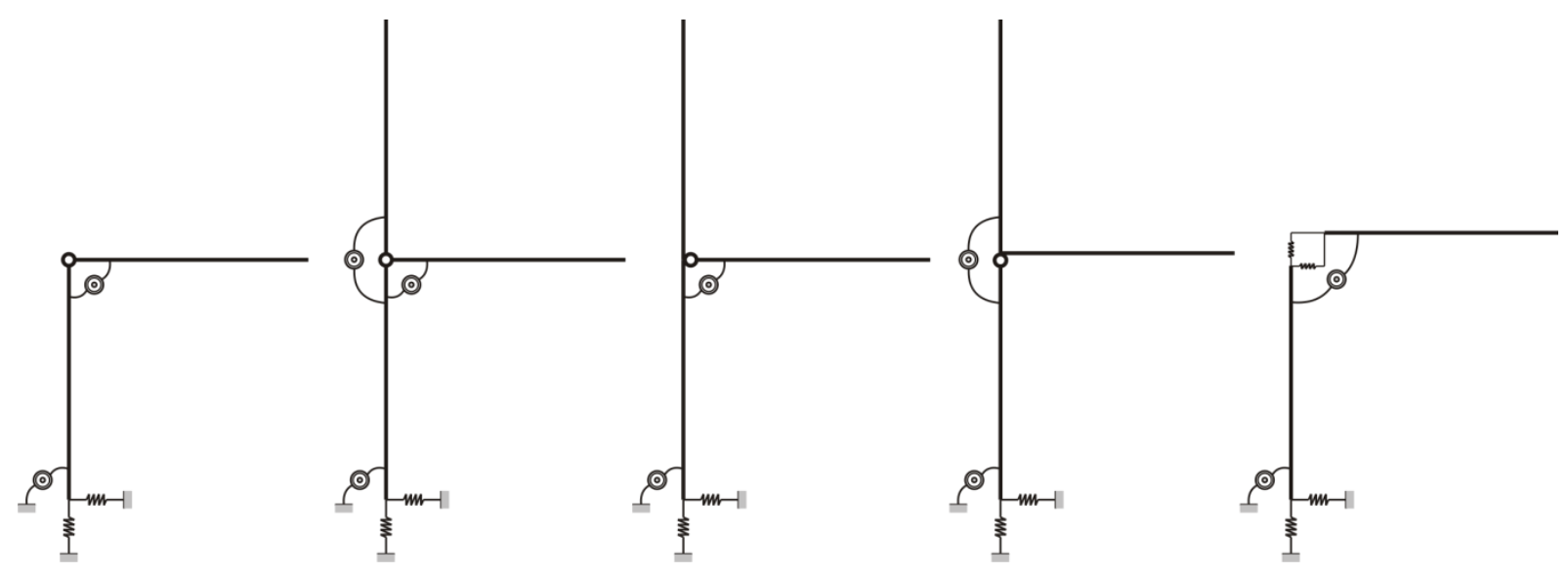

Figura 28 - Exemplos de possibilidades para ligação entre elementos Fonte: Adaptado de Coda e Paccola (2014).

Apresentado o modelo de acoplamento, resta determinar as expressões para o cálculo da energia de deformação acumulada nas molas e, dessa forma, considerar sua contribuição na energia potencial total, expressa na Equação (86).

A energia acumulada nas molas depende de grandezas relativas entre os nós dos elementos acoplados. As molas de acoplamento das posições nodais relacionam força e deslocamento relativo e a energia de deformação acumulada pode ser obtida por:

$$
U=\frac{1}{2} K_{a b}^{i}\left(\Delta y_{b}^{i}-\Delta y_{a}^{i}\right)^{2}
$$

na qual $\Delta y_{a}^{i}$ e $\Delta y_{b}^{i}$ são as componentes na direção $i=1,2$ dos deslocamentos nodais de $a$ e $b$, respectivamente. $K_{a b}^{i}$ é a rigidez da mola ou fator de penalização correspondente à direção $i$ (Figura 27). $\Delta y_{a}^{i}$ e $\Delta y_{b}^{i}$ são obtidos pela diferença entre a posição do nó na configuração atual e a posição na configuração inicial:

$$
\begin{aligned}
& \Delta y_{a}^{i}=y_{a}^{i}-x_{a}^{i} \\
& \Delta y_{b}^{i}=y_{b}^{i}-x_{b}^{i} .
\end{aligned}
$$

As molas de acoplamento dos vetores generalizados relacionam momento e rotação relativa entre os vetores. A energia potencial de deformação acumulada pode ser obtida por:

$$
U=\frac{1}{2} K_{a b}^{\alpha}\left({ }^{p} \alpha_{b}-{ }^{p} \alpha_{a}\right)^{2}
$$

na qual ${ }^{p} \alpha_{a}$ e ${ }^{p} \alpha_{b}$ são as rotações acumuladas dos vetores generalizados $\mathbf{g}_{a}$ e $\mathbf{g}_{b}$, respectivamente, desde a configuração inicial até à configuração correspondente ao incremento 
de carregamento $p . K_{a b}^{\alpha}$ é a rigidez ou o fator de penalização (Figura 27). As rotações acumuladas são calculadas por:

$$
\begin{aligned}
& { }^{p} \alpha_{a}={ }^{p-1} \alpha_{a}+\theta_{a}, \\
& { }^{p} \alpha_{b}={ }^{p-1} \alpha_{b}+\theta_{b},
\end{aligned}
$$

sendo ${ }^{p-1} \alpha_{a}$ e ${ }^{p-1} \alpha_{b}$ as rotações acumuladas desde a configuração inicial até a configuração correspondente ao incremento de carregamento anterior $p-1 . \theta_{a}$ e $\theta_{b}$ são as rotações ocorridas entre os passos de carregamento. Na Figura 29, ilustram-se essas rotações para o vetor generalizado $\mathbf{g}_{a}$. A identificação é análoga para o vetor $\mathbf{g}_{b}$.

Na Equação (94) e na Figura 29, ${ }^{p-1} \alpha_{a},{ }^{p-1} \alpha_{b},{ }^{p-1} \mathbf{g}_{a}$ e ${ }^{p-1} \mathbf{g}_{b}$ são valores conhecidos do incremento de carregamento anterior. Assim, para determinar ${ }^{p} \alpha_{a}$ e ${ }^{p} \alpha_{b}$, é necessário calcular as rotações $\theta_{a}$ e $\theta_{b}$ ocorridas entre os incrementos anterior e atual. Uma relação para calcular $\theta_{a}$, e analogamente para $\theta_{b}$, pode ser obtida considerando os produtos vetorial e escalar entre os vetores generalizados ${ }^{p-1} \mathbf{g}_{a}$ e ${ }^{p} \mathbf{g}_{a}$.
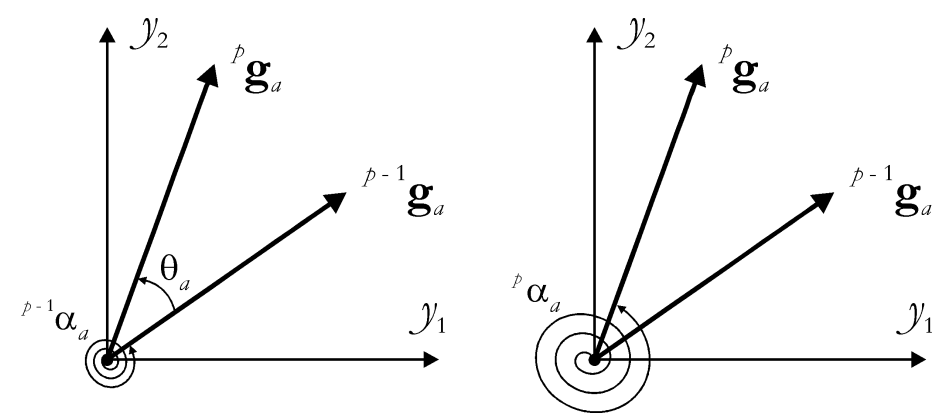

Figura 29 - Identificação das rotações de um vetor generalizado nodal

A partir do produto vetorial, pode-se expressar o seno de $\theta_{a}$ :

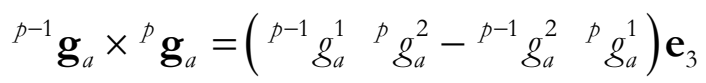

$$
\begin{aligned}
& \left\|{ }^{p-1} \mathbf{g}_{a} \times{ }^{p} \mathbf{g}_{a}\right\|=\left\|{ }^{p-1} \mathbf{g}_{a}\right\|\left\|^{p} \mathbf{g}_{a}\right\| \operatorname{sen} \theta_{a} \\
& \operatorname{sen} \theta_{a}=\frac{{ }^{p-1} g_{a}^{1}{ }^{p} g_{a}^{2}-{ }^{p-1} g_{a}^{2}{ }^{p} g_{a}^{1}}{\left\|{ }^{p-1} \mathbf{g}_{a}\right\|\left\|^{p} \mathbf{g}_{a}\right\|},
\end{aligned}
$$


sendo $\mathbf{e}_{3}$ o versor da direção 3 com sentido positivo saindo do plano. Na expressão do seno, o numerador fornece o sinal correspondente ao sentido da rotação de $\mathbf{g}_{a}$ entre os incrementos de carregamento $p-1$ e $p$. Utilizando a mesma ideia e o produto escalar, pode-se expressar o cosseno de $\theta_{a}$ :

$$
\begin{aligned}
& { }^{p-1} \mathbf{g}_{a} \cdot{ }^{p} \mathbf{g}_{a}={ }^{p-1} g_{a}^{1} \quad{ }^{p} g_{a}^{1}+{ }^{p-1} g_{a}^{2} \quad{ }^{p} g_{a}^{2} \\
& \left\|{ }^{p-1} \mathbf{g}_{a} \cdot{ }^{p} \mathbf{g}_{a}\right\|=\left\|{ }^{p-1} \mathbf{g}_{a}\right\|\|\|^{p} \mathbf{g}_{a} \| \cos \theta_{a} \\
& \cos \theta_{a}=\frac{{ }^{p-1} g_{a}^{1}{ }^{p} g_{a}^{1}+{ }^{p-1} g_{a}^{2} \quad g_{a}^{2}}{\left\|{ }^{p-1} \mathbf{g}_{a}\right\|\left\|^{p} \mathbf{g}_{a}\right\|} .
\end{aligned}
$$

Conhecido o seno e o cosseno, a tangente pode ser calculada por:

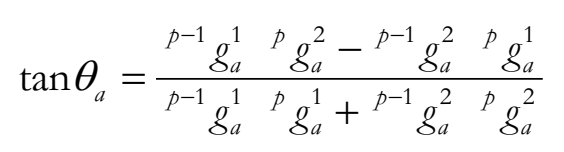

e o ângulo $\theta_{a}$ fica determinado pela inversa:

$$
\theta_{a}=\arctan \left(\begin{array}{cccc}
p^{p-1} g_{a}^{1} & p^{p} g_{a}^{2}-{ }^{p-1} g_{a}^{2} & { }^{p} g_{a}^{1} \\
\hline p^{p-1} g_{a}^{1} & { }^{p} g_{a}^{1}+{ }^{p-1} g_{a}^{2} & { }^{p} g_{a}^{2}
\end{array}\right) \operatorname{com}\left|\theta_{a}\right|<\frac{\pi}{2} .
$$

Para que o ângulo fornecido pela função arco tangente seja coerente com a rotação do vetor $\mathbf{g}_{a}$ entre os incrementos de carregamento $p-1$ e $p$, é necessário que a dimensão desse incremento não resulte em uma rotação fora do intervalo $-\pi / 2<\theta_{a}<\pi / 2$. Com essa restrição, a função arco tangente fornece o valor correto do ângulo, pois o denominador assume sempre valores positivos e o numerador fica com o sinal coerente ao sentido da rotação (positivo se anti-horário e negativo se horário). Isso não constitui uma limitação importante, pois o próprio processo de solução incremental-iterativo já exige o emprego de incrementos de carga adequados para que haja convergência. Analogamente $\theta_{b}$ é dado por:

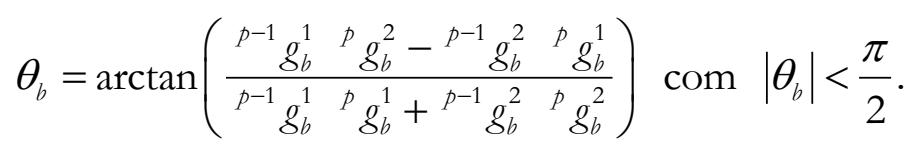

Definidos todos os termos necessários para calcular a energia potencial de deformação das molas de ligação nas Equações (91) e (93), pode-se determinar a contribuição no vetor de força interna e na matriz Hessiana globais da estrutura. Considerando inicialmente as molas de acoplamento das posições nodais, a contribuição no vetor de forças internas pode ser 
obtida com a derivada da energia de deformação (Equação (91)) em relação às posições nodais acopladas. Logo, tem-se que:

$$
\begin{aligned}
& F_{\text {int } a}^{i}=\frac{\partial U}{\partial y_{a}^{i}} \quad \rightarrow \quad F_{\text {int } a}^{i}=-K_{a b}^{(i)}\left(\Delta y_{b}^{i}-\Delta y_{a}^{i}\right) \\
& F_{\text {int } b}^{i}=\frac{\partial U}{\partial y_{b}^{i}} \quad \rightarrow \quad F_{\text {int } b}^{i}=K_{a b}^{(i)}\left(\Delta y_{b}^{i}-\Delta y_{a}^{i}\right) \text { com } i=1,2,
\end{aligned}
$$

na qual se observou a Equação (92) para definir a derivada. A contribuição dessas componentes no vetor de força interna segue a mesma regra de atribuição apresentada na Equação (85).

Para determinar a contribuição na matriz Hessiana, aplica-se a segunda derivada na energia de deformação em relação às posições nodais acopladas. Considerando a primeira derivada calculada na Equação (100) e observando novamente a Equação (92), chegam-se aos termos não nulos da matriz Hessiana:

$$
\begin{aligned}
& H_{a a}^{i(i)}=\frac{\partial F_{\text {int } a}^{i}}{\partial y_{a}^{(i)}} \rightarrow H_{a a}^{i(i)}=K_{a b}^{i} \\
& H_{a b}^{i(i)}=\frac{\partial F_{\text {int } i}^{i}}{\partial y_{b}^{(i)}} \rightarrow H_{a b}^{i(i)}=-K_{a b}^{i} \\
& H_{b b}^{i(i)}=\frac{\partial F_{\text {int } b}^{i}}{\partial y_{b}^{(i)}} \rightarrow H_{b b}^{i(i)}=K_{a b}^{i} \\
& H_{b a}^{i(i)}=\frac{\partial F_{\text {int } b}^{i}}{\partial y_{a}^{(i)}} \rightarrow H_{b a}^{i(i)}=-K_{a b}^{i} \quad \operatorname{com} i=1,2 .
\end{aligned}
$$

A contribuição desses termos na matriz Hessiana é realizada de acordo com a regra de atribuição apresentada na Equação (90).

Em relação às molas de acoplamento dos vetores generalizados nodais, a contribuição no vetor de força interna global da estrutura pode ser obtida com a derivada da energia de deformação (Equação (93)) em relação às componentes dos vetores generalizados do incremento de carregamento atual $p$. As forças internas resultantes das molas de acoplamento dos vetores generalizados constituem conjugados energéticos desses vetores. Assim, deve-se considerar a associação apresentada na Equação (83) para identificar os graus de liberdade nodais no elemento de pórtico plano homogêneo e a regra da Equação (85) para a atribuição no vetor de força interna global.

A fim de simplificar a notação, os vetores generalizados referentes ao incremento de carregamento $p$ serão representados nas equações seguintes simplesmente por $\mathbf{g}_{a}=\left(g_{a}^{1}, g_{a}^{2}\right) \mathrm{e}$ $\mathbf{g}_{b}=\left(g_{b}^{1}, g_{b}^{2}\right)$. 
Para calcular a derivada, é importante salientar que os vetores generalizados do incremento anterior $p-1$ são valores constantes, conhecidos e, portanto, não são incógnitas do problema. Além disso, devem ser observadas as Equações (94), (98), (99) e a aplicação da regra da cadeia. Por exemplo, o cálculo do conjugado energético referente à componente $g_{a}^{1}$ é obtido por:

$$
F_{\text {int } a}^{3}=\frac{\partial U}{\partial y_{a}^{3}}=\frac{\partial U}{\partial g_{a}^{1}} \leftrightarrow \leftrightarrow \quad F_{\text {int } a}^{3}=\frac{\partial U}{\partial^{p} \alpha_{a}} \frac{\partial^{p} \alpha_{a}}{\partial \theta_{a}} \frac{\partial \theta_{a}}{\partial g_{a}^{1}},
$$

observando a expressão da energia na Equação (93) e a da rotação na Equação (94), tem-se:

$$
F_{\text {int } a}^{3}=-K_{a b}^{\alpha}\left({ }^{p} \alpha_{b}-{ }^{p} \alpha_{a}\right) \frac{\partial \theta_{a}}{\partial g_{a}^{1}}
$$

De forma análoga, procede-se para os demais conjugados energéticos. Ficando todas as componentes expressas por:

$$
\begin{aligned}
& F_{\mathrm{int} a}^{3}=-K_{a b}^{\alpha}\left({ }^{p} \alpha_{b}-{ }^{p} \alpha_{a}\right) \frac{\partial \theta_{a}}{\partial g_{a}^{1}} \\
& F_{\mathrm{int} a}^{4}=-K_{a b}^{\alpha}\left({ }^{p} \alpha_{b}-{ }^{p} \alpha_{a}\right) \frac{\partial \theta_{a}}{\partial g_{a}^{2}} \\
& F_{\mathrm{int} b}^{3}=K_{a b}^{\alpha}\left({ }^{p} \alpha_{b}-{ }^{p} \alpha_{a}\right) \frac{\partial \theta_{b}}{\partial g_{b}^{1}} \\
& F_{\mathrm{int} b}^{4}=K_{a b}^{\alpha}\left({ }^{p} \alpha_{b}-{ }^{p} \alpha_{a}\right) \frac{\partial \theta_{b}}{\partial g_{b}^{2}} .
\end{aligned}
$$

As derivadas de $\theta_{a}$ e $\theta_{b}$ em relação às componentes dos vetores generalizados podem ser determinadas a partir de suas Equações (98) e (99), respectivamente. Essas derivadas são dadas por:

$$
\begin{array}{ll}
\frac{\partial \theta_{a}}{\partial g_{a}^{1}}=-\frac{g_{a}^{2}}{\left\|\mathbf{g}_{a}\right\|^{2}} & \frac{\partial \theta_{a}}{\partial g_{a}^{2}}=\frac{g_{a}^{1}}{\left\|\mathbf{g}_{a}\right\|^{2}} \\
\frac{\partial \theta_{b}}{\partial g_{b}^{1}}=-\frac{g_{b}^{2}}{\left\|\mathbf{g}_{b}\right\|^{2}} & \frac{\partial \theta_{b}}{\partial g_{b}^{2}}=\frac{g_{b}^{1}}{\left\|\mathbf{g}_{b}\right\|^{2}},
\end{array}
$$

que substituindo na Equação (104), resultam nas expressões finais para os conjugados energéticos dos vetores generalizados acoplados:

$$
F_{\text {int } a}^{3}=K_{a b}^{\alpha}\left({ }^{p} \alpha_{b}-{ }^{p} \alpha_{a}\right) \frac{g_{a}^{2}}{\left\|\mathbf{g}_{a}\right\|^{2}}
$$




$$
\begin{aligned}
& F_{\text {int } a}^{4}=-K_{a b}^{\alpha}\left({ }^{p} \alpha_{b}-{ }^{p} \alpha_{a}\right) \frac{g_{a}^{1}}{\left\|\mathbf{g}_{a}\right\|^{2}} \\
& F_{\text {int } b}^{3}=-K_{a b}^{\alpha}\left({ }^{p} \alpha_{b}-{ }^{p} \alpha_{a}\right) \frac{g_{b}^{2}}{\left\|\mathbf{g}_{b}\right\|^{2}} \\
& F_{\text {int } b}{ }^{4}=K_{a b}^{\alpha}\left({ }^{p} \alpha_{b}-{ }^{p} \alpha_{a}\right) \frac{g_{b}^{1}}{\left\|\mathbf{g}_{b}\right\|^{2}} .
\end{aligned}
$$

A contribuição da mola de acoplamento dos vetores generalizados na matriz Hessiana é obtida a partir da segunda derivada da energia de deformação (Equação (93)) em relação às componentes dos vetores generalizados do incremento de carregamento atual $p$. Os resultados da primeira derivada já estão representados na Equação (106). Novamente, a contribuição na matriz Hessiana global da estrutura se faz de acordo com a regra de atribuição apresentada na Equação (90).

Considerando a Equação (106) e observando as Equações (94), (98) e (99), os termos não nulos da Hessiana devidos à mola de acoplamento dos vetores generalizados podem ser determinados. Tomemos, por exemplo, o termo da matriz Hessiana $H_{a a}^{33}$ :

$$
\begin{aligned}
& H_{a a}^{33}=\frac{\partial F_{\text {int } a}^{3}}{\partial y_{a}^{3}}=\frac{\partial F_{\text {int } a}^{3}}{\partial g_{a}^{1}} \\
& H_{a a}^{33}=-K_{a b}^{\alpha} \frac{\partial^{p} \alpha_{a}}{\partial g_{a}^{1}} \frac{g_{a}^{2}}{\left\|\mathbf{g}_{a}\right\|^{2}}+K_{a b}^{\alpha}\left({ }^{p} \alpha_{b}-{ }^{p} \alpha_{a}\right)\left[\frac{0-g_{a}^{2} \frac{\partial\left\|\mathbf{g}_{a}\right\|^{2}}{\partial g_{a}^{1}}}{\left\|\mathbf{g}_{a}\right\|^{4}}\right] .
\end{aligned}
$$

Através da regra da cadeia, a derivada $\frac{\partial^{p} \alpha_{a}}{\partial g_{a}^{1}}$ é expressa por:

$$
\frac{\partial^{p} \alpha_{a}}{\partial g_{a}^{1}}=\frac{\partial^{p} \alpha_{a}}{\partial \theta_{a}} \frac{\partial \theta_{a}}{\partial g_{a}^{1}} \quad \rightarrow \quad \frac{\partial^{p} \alpha_{a}}{\partial g_{a}^{1}}=\frac{\partial \theta_{a}}{\partial g_{a}^{1}}
$$

Considerando a Equação (105), obtém-se:

$$
\frac{\partial^{p} \alpha_{a}}{\partial g_{a}^{1}}=-\frac{g_{a}^{2}}{\left\|\mathbf{g}_{a}\right\|^{2}}
$$

Para completar a definição da Equação (107), a derivada $\frac{\partial\left\|\mathbf{g}_{a}\right\|^{2}}{\partial g_{a}^{1}}$ pode ser expressa por: 
$\frac{\partial\left\|\mathbf{g}_{a}\right\|^{2}}{\partial g_{a}^{1}}=\frac{\partial\left[\left(g_{a}^{1}\right)^{2}+\left(g_{a}^{2}\right)^{2}\right]}{\partial g_{a}^{1}} \rightarrow \frac{\partial\left\|\mathbf{g}_{a}\right\|^{2}}{\partial g_{a}^{1}}=2 g_{a}^{1}$,

com isso, o termo $H_{a a}^{33}$ fica determinado por:

$$
H_{a a}^{33}=\frac{K_{a b}^{\alpha}}{\left\|\mathbf{g}_{a}\right\|^{4}}\left[\left(g_{a}^{2}\right)^{2}-2 g_{a}^{1} g_{a}^{2}\left({ }^{p} \boldsymbol{\alpha}_{b}-{ }^{p} \boldsymbol{\alpha}_{a}\right)\right] .
$$

Operando de forma análoga, todos os termos da matriz Hessiana devidos à mola de acoplamento dos vetores generalizados podem ser determinados e estão representados pelo conjunto de Equações (112).

$$
\begin{aligned}
& H_{a a}^{33}=\frac{K_{a b}^{\alpha}}{\left\|\mathbf{g}_{a}\right\|^{4}}\left[\left(g_{a}^{2}\right)^{2}-2 g_{a}^{1} g_{a}^{2}\left({ }^{p} \boldsymbol{\alpha}_{b}-{ }^{p} \boldsymbol{\alpha}_{a}\right)\right] \\
& H_{a a}^{34}=\frac{K_{a b}^{\alpha}}{\left\|\mathbf{g}_{a}\right\|^{4}}\left\{-g_{a}^{1} g_{a}^{2}+\left[\left(g_{a}^{1}\right)^{2}-\left(g_{a}^{2}\right)^{2}\right]\left({ }^{p} \boldsymbol{\alpha}_{b}-{ }^{p} \boldsymbol{\alpha}_{a}\right)\right\} \text { e } H_{a a}^{43}=H_{a a}^{34} \\
& H_{a b}^{33}=-\frac{K_{a b}^{\alpha}}{\left\|\mathbf{g}_{a}\right\|^{2}\left\|\mathbf{g}_{b}\right\|^{2}} g_{a}^{2} g_{b}^{2} \text { e } H_{b a}^{33}=H_{a b}^{33} \\
& H_{a b}^{34}=\frac{K_{a b}^{\alpha}}{\left\|\mathbf{g}_{a}\right\|^{2}\left\|\mathbf{g}_{b}\right\|^{2} g_{a}^{2} g_{b}^{1} \text { e } H_{b a}^{43}=H_{a b}^{34}} \\
& H_{a a}^{44}=\frac{K_{a b}^{\alpha}}{\left\|\mathbf{g}_{a}\right\|^{4}}\left[\left(g_{a}^{1}\right)^{2}+2 g_{a}^{1} g_{a}^{2}\left({ }^{p} \boldsymbol{\alpha}_{b}-{ }^{p} \boldsymbol{\alpha}_{a}\right)\right] \\
& H_{a b}^{43}=\frac{K_{a b}^{\alpha}}{\left\|\mathbf{g}_{a}\right\|^{2}\left\|\mathbf{g}_{b}\right\|^{2} g_{a}^{1} g_{b}^{2} \text { e } H_{b a}^{34}=H_{a b}^{43}} \\
& H_{b b}^{44}=\frac{K_{a b}^{\alpha}}{\left\|\mathbf{g}_{b}\right\|^{4}}\left[\left(g_{b}^{1}\right)^{2}-2 g_{b}^{1} g_{b}^{2}\left({ }^{p} \boldsymbol{\alpha}_{b}-{ }^{p} \boldsymbol{\alpha}_{a}\right)\right] . \\
& H_{a b}^{44}=-\frac{K_{a b}^{\alpha}}{\left\|\mathbf{g}_{a}\right\|^{2}\left\|\mathbf{g}_{b}\right\|^{2}} g_{a}^{1} g_{b}^{1} \text { e } H_{b a}^{44}=H_{a b}^{44} \\
& H_{b b}^{33}=\frac{K_{a b}^{\alpha}}{\left\|\mathbf{g}_{b}\right\|^{4}}\left[\left(g_{b}^{2}\right)^{2}+2 g_{b}^{1} g_{b}^{2}\left({ }^{p} \boldsymbol{\alpha}_{b}-{ }^{p} \boldsymbol{\alpha}_{a}\right)\right] \\
& K_{a b}^{\alpha} \|^{4}\left\{g_{b}^{1} g_{b}^{2}+\left[\left(g_{b}^{1}\right)^{2}-\left(g_{b}^{2}\right)^{2}\right]\left({ }^{p} \boldsymbol{\alpha}_{b}-{ }^{p} \boldsymbol{\alpha}_{a}\right)\right\} \text { e } H_{b b}^{43}=H_{b b}^{34}
\end{aligned}
$$

A fim de verificar a formulação do elemento de pórtico plano homogêneo, vários exemplos foram analisados e os resultados obtidos são apresentados no item seguinte e comparados aos resultados de soluções analíticas e numéricas encontradas na literatura. 


\subsection{Exemplos numéricos}

Neste item, são apresentados os resultados de análises realizadas em exemplos com soluções analíticas e numéricas disponíveis na literatura. Os exemplos foram organizados em três conjuntos de forma a avaliar diferentes aspectos da formulação aqui desenvolvida.

No primeiro conjunto, analisa-se uma viga com extremidades engastada e livre submetida aos três tipos de ações externas possíveis de serem consideradas na formulação do elemento, que são: força concentrada, momento concentrado e força distribuída. O objetivo principal é verificar a capacidade da formulação de resolver problemas submetidos a esses diferentes tipos de ações externas. Além disso, também se faz uma análise de convergência para avaliar a eficiência do elemento finito.

No segundo conjunto, três pórticos com geometria simétrica são analisados. Os pórticos são o losango com nós articulados e rígidos, o quadrado com todos os nós rígidos e o arco achatado senoidal. O interesse maior na análise desses pórticos reside em verificar a capacidade de solução de problemas com diferentes geometrias e condições de contorno.

Por fim, o terceiro conjunto de exemplos é formado por um pórtico com dois níveis ou pavimentos. Diferentes análises são realizadas nas quais as condições de contorno são constituídas por apoios simples, apoios com rigidez elástica à rotação e engastes. As ligações entre as barras são consideradas rígidas e semirrígidas com três valores diferentes para a rigidez à rotação. Dessa forma, espera-se verificar principalmente a capacidade da formulação em representar o comportamento de pórticos formados por ligações semirrígidas.

Os resultados obtidos são comparados com soluções analíticas e numéricas encontradas na literatura, bem como, com resultados numéricos fornecidos por análises realizadas no software Ansys ${ }^{\circledR}$. O elemento finito BEAM188 com funções de forma cúbicas foi empregado para modelar as barras do pórtico. A formulação do BEAM188 adota as hipóteses cinemáticas de Reissner-Timoshenko que correspondem às mesmas hipóteses do elemento desenvolvido neste trabalho. O elemento de acoplamento COMBIN40 com comportamento linear-elástico para as relações rotação-momento e deslocamento-força foi empregado para modelar as ligações semirrígidas.

Buscam-se com essas análises verificar os diversos aspectos da formulação do elemento de pórtico plano homogêneo e também avaliar sua eficiência e consistência. 


\subsubsection{Exemplo 4.1: Viga em balanço solicitada por ações externas variadas}

Neste primeiro exemplo, analisa-se uma viga em balanço sujeita a três tipos de ações externas, conforme está ilustrado na Figura 30. As características geométricas da seção transversal e os parâmetros elásticos do material também estão representados na referida figura.

Em todas as análises, as ações externas foram aplicadas em 10 incrementos iguais e o processo de solução baseado no método de Newton-Raphson foi controlado por meio dos critérios de convergência em posição e em força com tolerâncias de $10^{-9}$ e $10^{-6}$ respectivamente. A fim de avaliar a capacidade de convergência da formulação, a viga foi discretizada com um número de elementos finitos variando entre 1, 2, 4, 8 e 16.
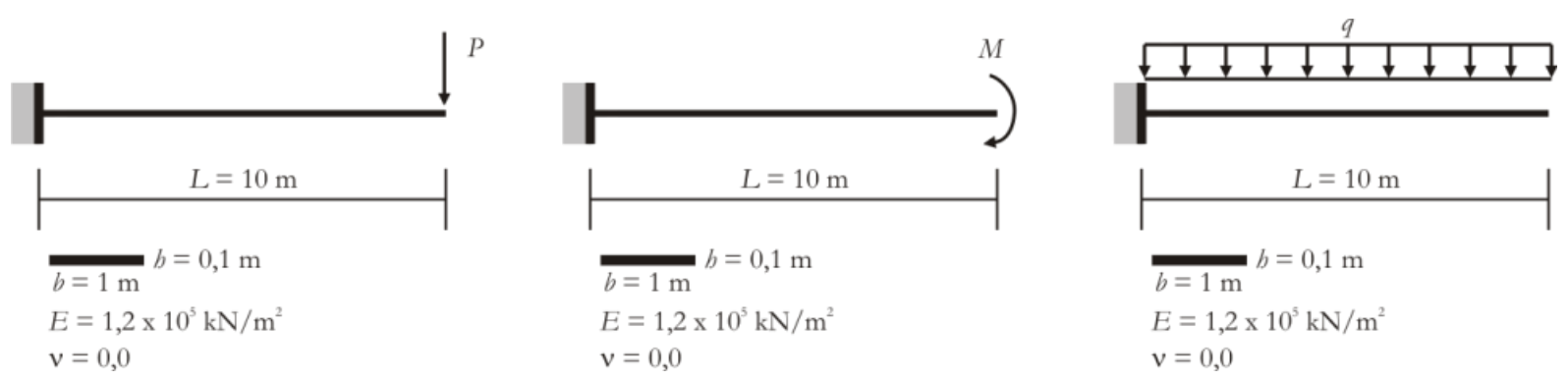

Figura 30 - Geometria, carregamento e parâmetros elásticos do Exemplo 4.1

Os resultados das análises são apresentados através das trajetórias de equilíbrio referentes aos deslocamentos horizontal (u) e vertical (v) do nó da extremidade direita (Figura 31, Figura 32 e Figura 33). Para comparação e verificação dos resultados obtidos com o elemento desenvolvido neste trabalho, são mostrados nas curvas de equilíbrio os resultados das seguintes soluções:

- analítica apresentada por Mattiasson (1981) para o caso com força concentrada na extremidade direita (Figura 31);

- analítica de Hsiao (1987) para o caso com momento concentrado na extremidade direita (Figura 32);

- numérica de Wang, Lee e Zienkiewicz (1961) e de Yang (1973) para o caso com força distribuída (Figura 33).

Em todos os casos, também foram realizadas análises numéricas no Ansys ${ }^{\circledR}$ e os resultados estão representados nas trajetórias de equilíbrio. A viga foi discretizada com dezesseis elementos BEAM188. 
Capítulo 4 - Elemento finito de pórtico plano homogêneo
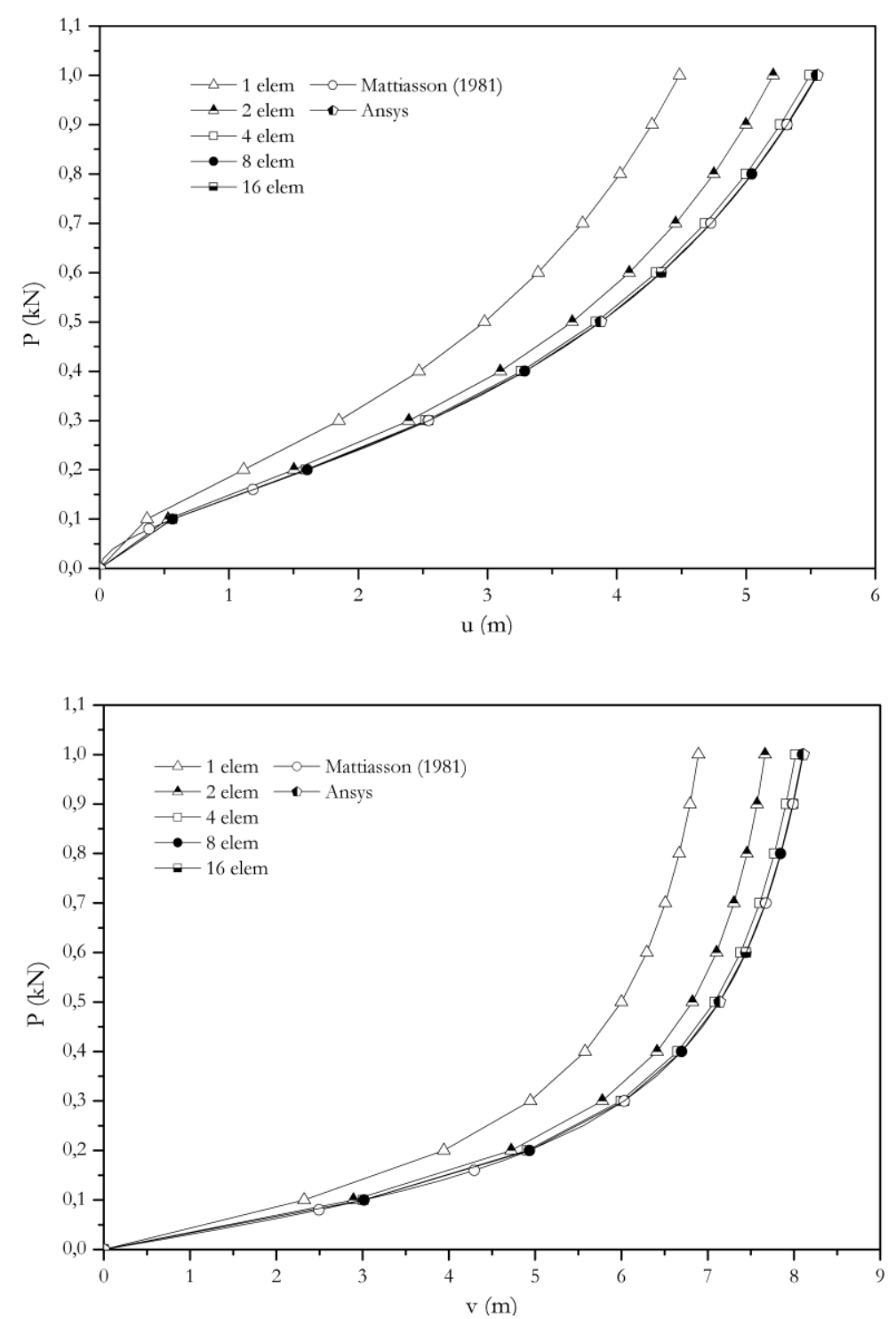

Figura 31 - Trajetória de equilíbrio para a viga com força concentrada

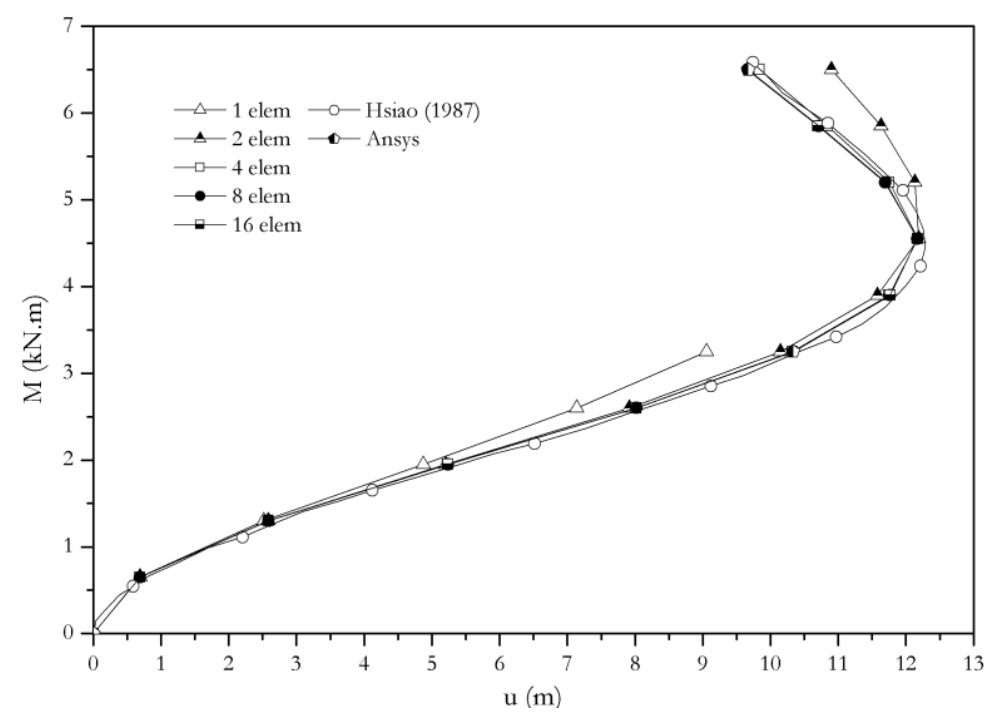




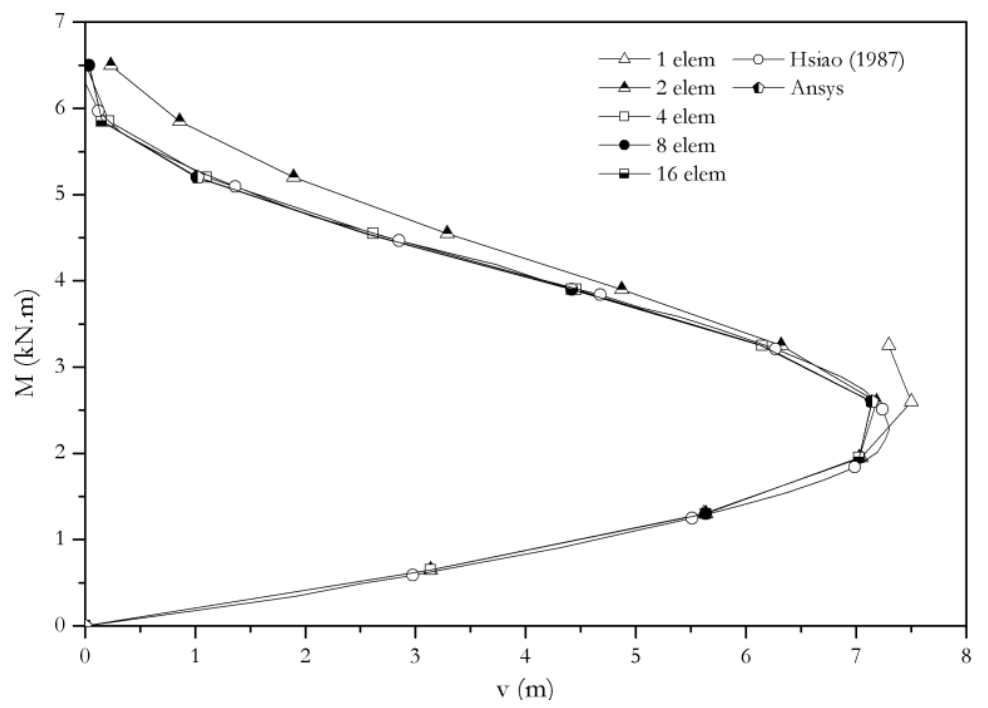

Figura 32 - Trajetória de equilíbrio para a viga com momento concentrado
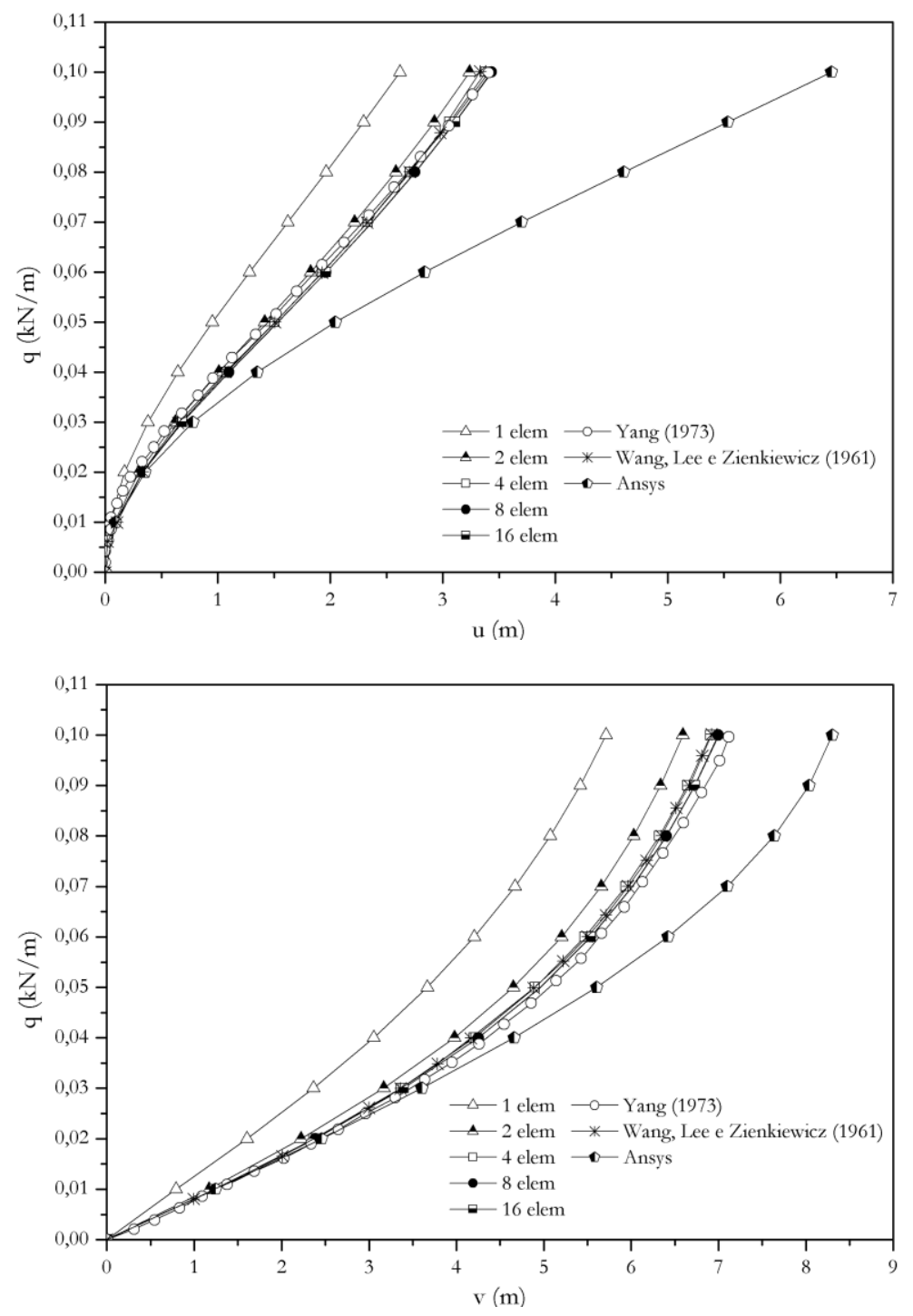

Figura 33 - Trajetória de equilíbrio para a viga com força distribuída 
Os resultados das análises para os três casos de carregamento considerados neste exemplo apresentaram excelente concordância com os diversos resultados analíticos e numéricos utilizados como referência. Apenas o caso com força distribuída apresentou uma diferença significativa em relação aos resultados obtidos com o Ansys ${ }^{\circledR}$ que representaram um comportamento bem mais flexível. Apesar disso, as comparações com os resultados numéricos de Wang, Lee e Zienkiewicz (1961) e de Yang (1973) verificam a consistência da formulação posicional.

Uma verificação sobre o procedimento correto para aplicação do carregamento distribuído foi realizada e não foi encontrado nenhum erro na forma como o exemplo foi modelado no Ansys ${ }^{\circledR}$. A justificativa para a discrepância significativa dos resultados exige, portanto, uma investigação mais criteriosa sobre a forma como a força distribuída é transformada em forças nodais equivalentes na formulação do elemento BEAM188, não sendo objetivo da presente pesquisa.

Diante da ótima concordância dos resultados apresentados pelo elemento de pórtico posicional com os resultados analíticos e numéricos de referência, considera-se verificada a capacidade da formulação em representar corretamente o efeito das principais ações externas presentes nos modelos de pórticos. Em relação à análise de convergência, observou-se uma convergência quadrática do refinamento $h$ realizado e praticamente não houve melhora significativa na resposta a partir de uma discretização com quatro elementos finitos.

$\mathrm{Na}$ Figura 34, estão representadas diversas configurações deformadas da viga com os deslocamentos correspondentes às direções globais 1 e 2 ilustrados por meio de um esquema de cores. As imagens foram obtidas com o software de pós-processamento AcadView.

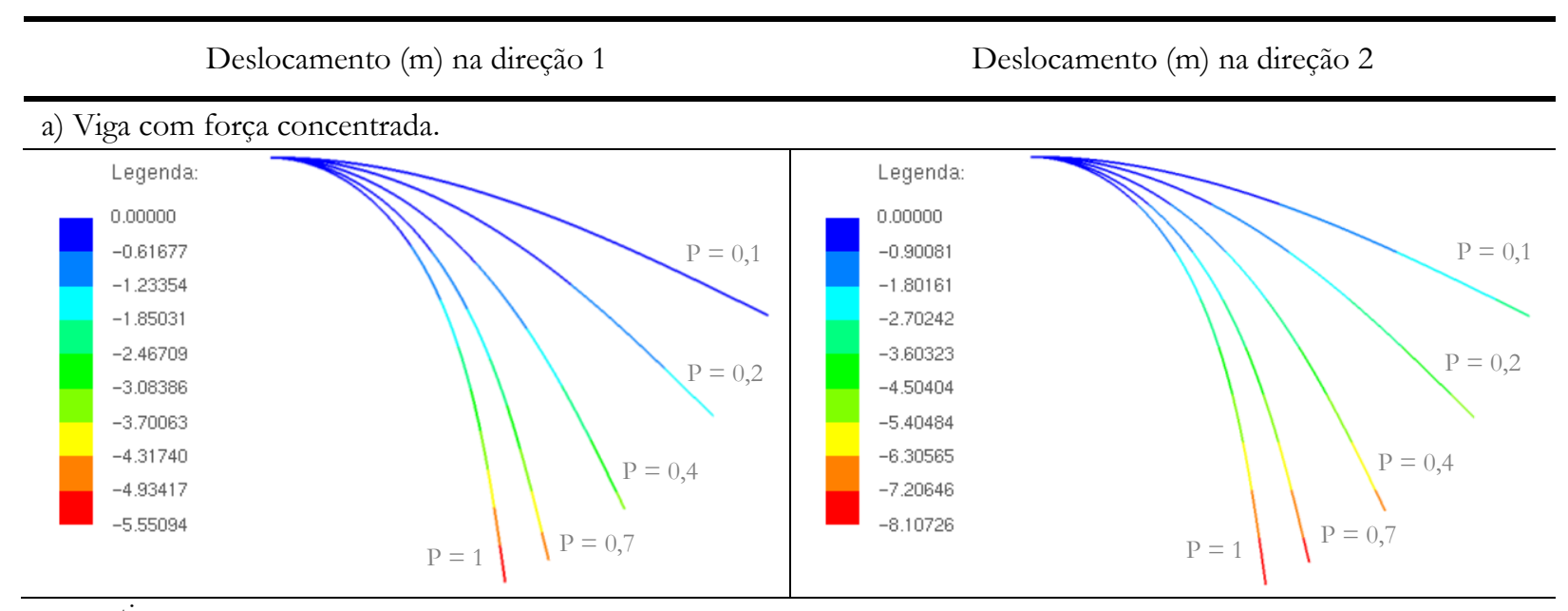

... continua 


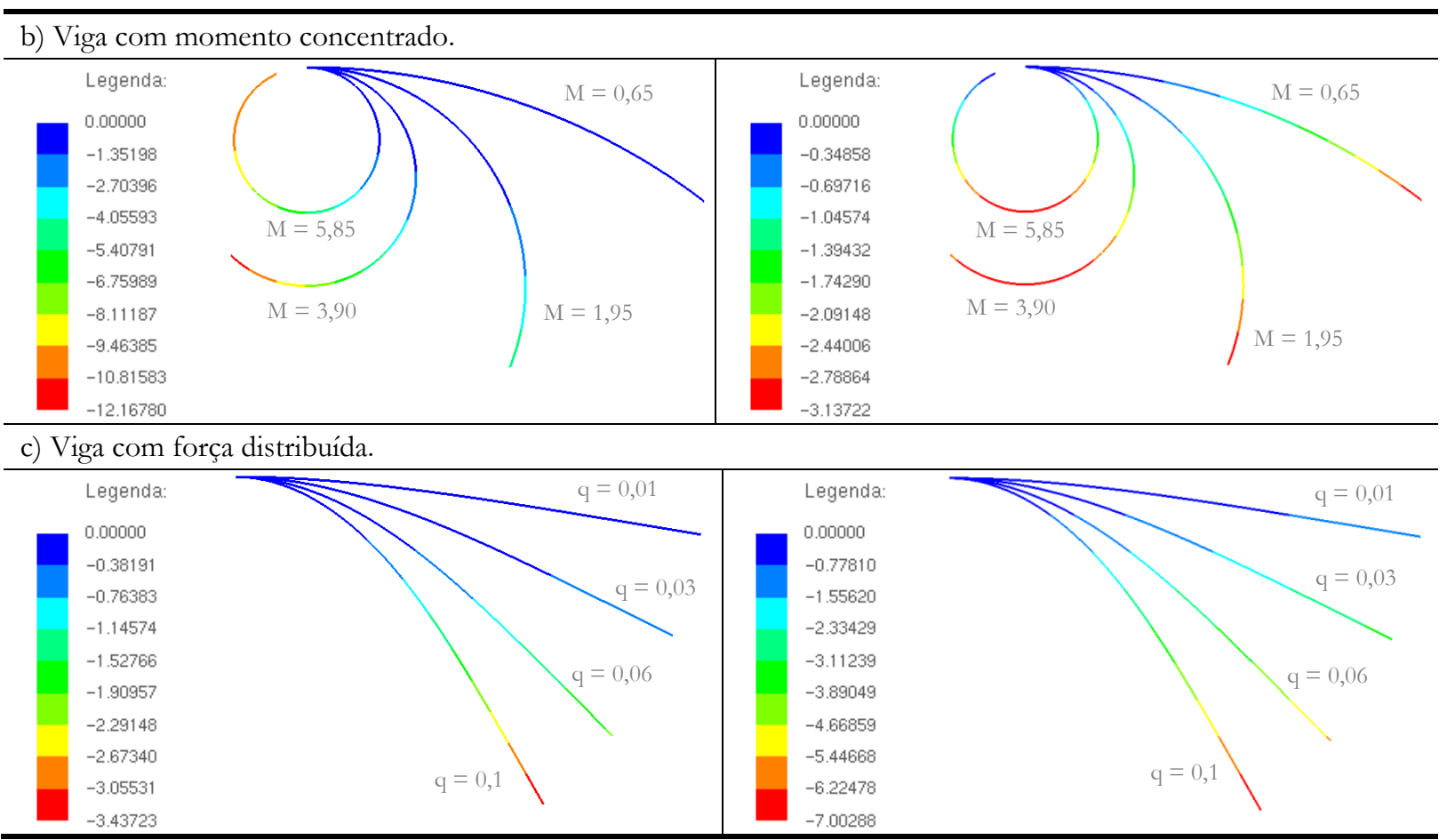

Figura 34 - Configurações deslocadas das vigas em balanço para alguns incrementos de carga

\subsubsection{Exemplo 4.2: Pórticos planos com diferentes geometrias e condições de contorno}

Neste segundo conjunto de exemplos, dois quadros com formas de losango e de quadrado são analisados. A geometria, o carregamento e os parâmetros elásticos dos materiais empregados estão representados na Figura 35. Devido à dupla simetria, somente um quarto dos quadros foi considerado, o que possibilitou a representação de diferentes condições de contorno.

Um terceiro pórtico cuja forma é representada por um arco achatado senoidal também é analisado. Neste exemplo, avaliam-se principalmente: o acoplamento rígido entre elementos com direções diferentes, a representação aproximada de uma geometria senoidal a partir de uma geometria polinomial cúbica e a solução por meio de um procedimento no qual a posição é controlada em vez da força. Na Figura 35, também estão ilustradas as características do arco. 

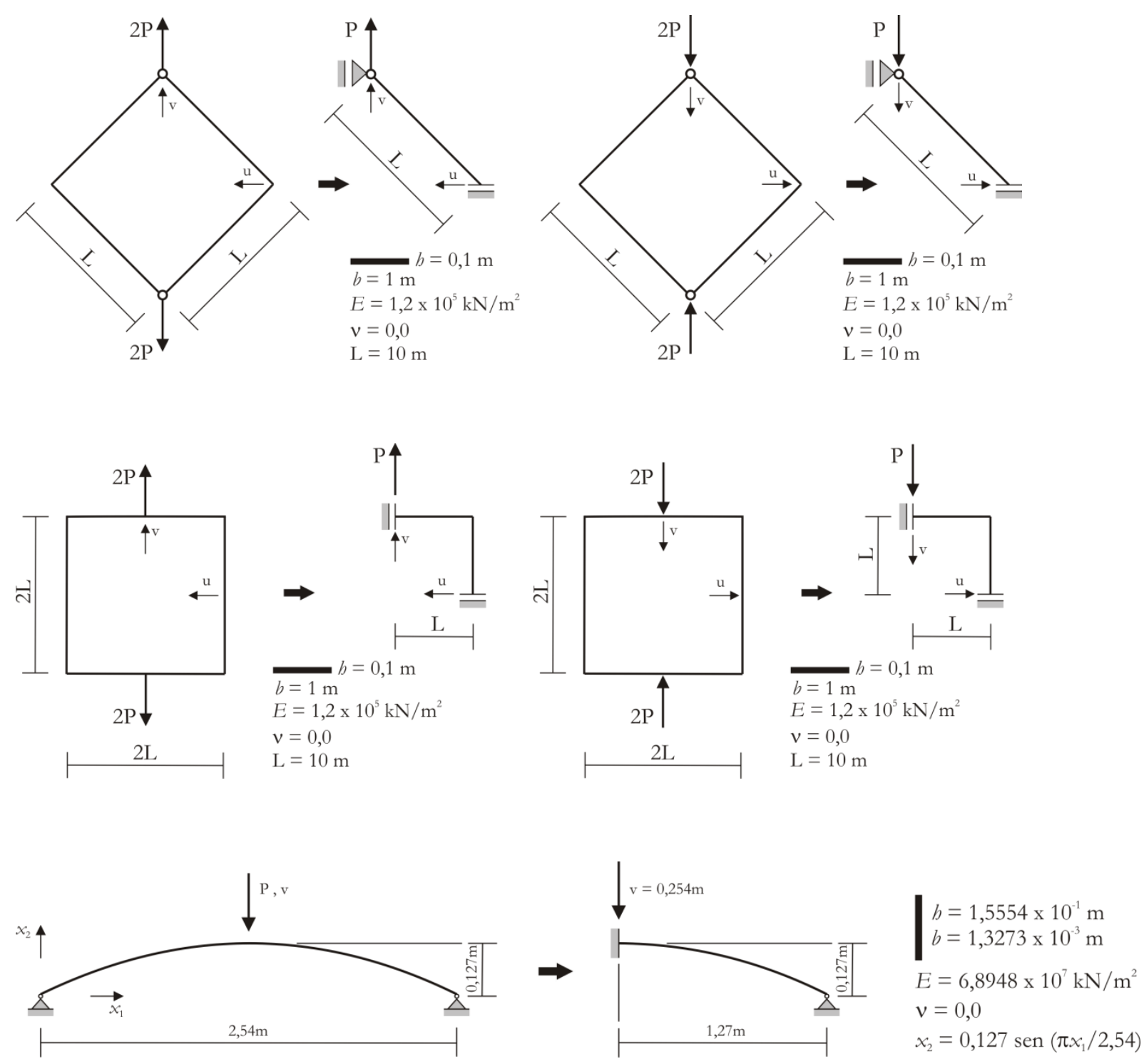

Figura 35 - Geometria, carregamento e parâmetros elásticos do Exemplo 4.2

Nas análises dos quadros, o processo de solução baseado no método de NewtonRaphson é empregado. A força concentrada é aplicada em 10 incrementos iguais e os critérios de convergência adotados são em posição e em força com tolerâncias de $10^{-9}$ e $10^{-6}$ respectivamente.

Duas situações são consideradas: uma com a força positiva (tracionando) e uma com a força negativa (comprimindo). Os resultados das análises são apresentados através das trajetórias de equilíbrio referentes aos deslocamentos horizontal (u) do nó direito e vertical (v) do nó superior (Figura 36 e Figura 37). Além disso, os resultados da solução analítica fornecida por Mattiasson (1981) e das análises numéricas realizadas no Ansys ${ }^{\circledR}$ também estão representados nas trajetórias de equilíbrio para possibilitar uma avaliação da resposta obtida. No Ansys ${ }^{\circledR}$, a estrutura foi novamente discretizada com o elemento BEAM188. 
$\mathrm{Na}$ análise do arco achatado senoidal, o processo de solução com controle de posição é realizado por meio da restrição da posição vertical do nó superior. Nesse processo, um deslocamento prescrito de 0,254m é aplicado em 10 incrementos iguais e, a cada incremento, o método de Newton-Raphson é novamente empregado para a determinação das posições na configuração atual dos demais nós livres. O controle de posição é necessário porque as configurações atuais do arco achatado apresentam pontos limites e trechos alternados de equilíbrio estável e instável, caracterizando o fenômeno de snap-through. Os critérios de convergência adotados são os mesmos dos quadros.

Esse problema foi apresentado por Meek e Tan (1984) cujos resultados numéricos são empregados como referência para comparação. Além disso, os resultados de uma análise numérica realizada no Ansys ${ }^{\circledR}$ com o elemento BEAM188 também são utilizados. A comparação e avaliação dos resultados obtidos com o elemento posicional são feitas a partir da trajetória de equilíbrio referente ao deslocamento vertical (v) do nó superior, conforme está ilustrado na Figura 38.

A fim de avaliar a capacidade de convergência da formulação, todos os casos foram analisados variando a discretização em 1, 2, 4, 8 e 16 elementos finitos por barra ou trecho. Novamente, identificou-se convergência dos resultados a partir de 4 elementos. Dessa forma, essa é a discretização adotada.

Analisando as curvas de equilíbrio para os três problemas considerados, verifica-se uma excelente concordância entre os resultados obtidos com a formulação posicional do elemento de pórtico plano homogêneo e os resultados analíticos e numéricos empregados como referência. Assim, fica demonstrada a robustez do elemento finito para modelar e solucionar problemas de pórticos planos com geometrias e condições de contorno diversas.

O processo de solução com controle de posição também mostrou ser bastante eficiente para resolver problemas cujas configurações atuais passam por pontos limites e por equilíbrios estáveis e instáveis. Além de tudo isso, pode-se verificar que as configurações atuais obtidas e representadas na Figura 39 são qualitativamente coerentes com o comportamento estrutural esperado em função da geometria e do carregamento atuante nas estruturas analisadas. 

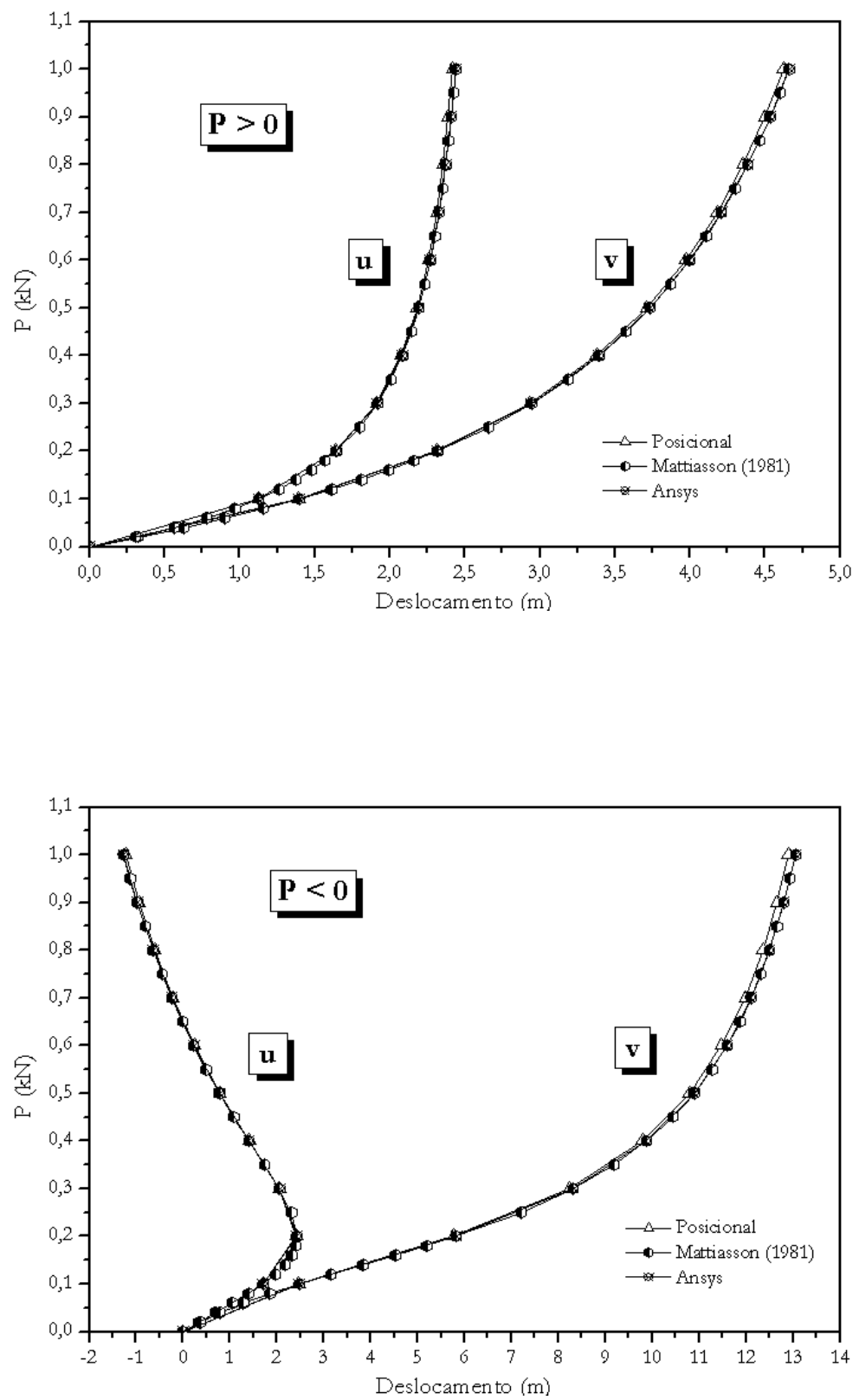

Figura 36 - Trajetória de equilíbrio para o quadro em forma de losango 

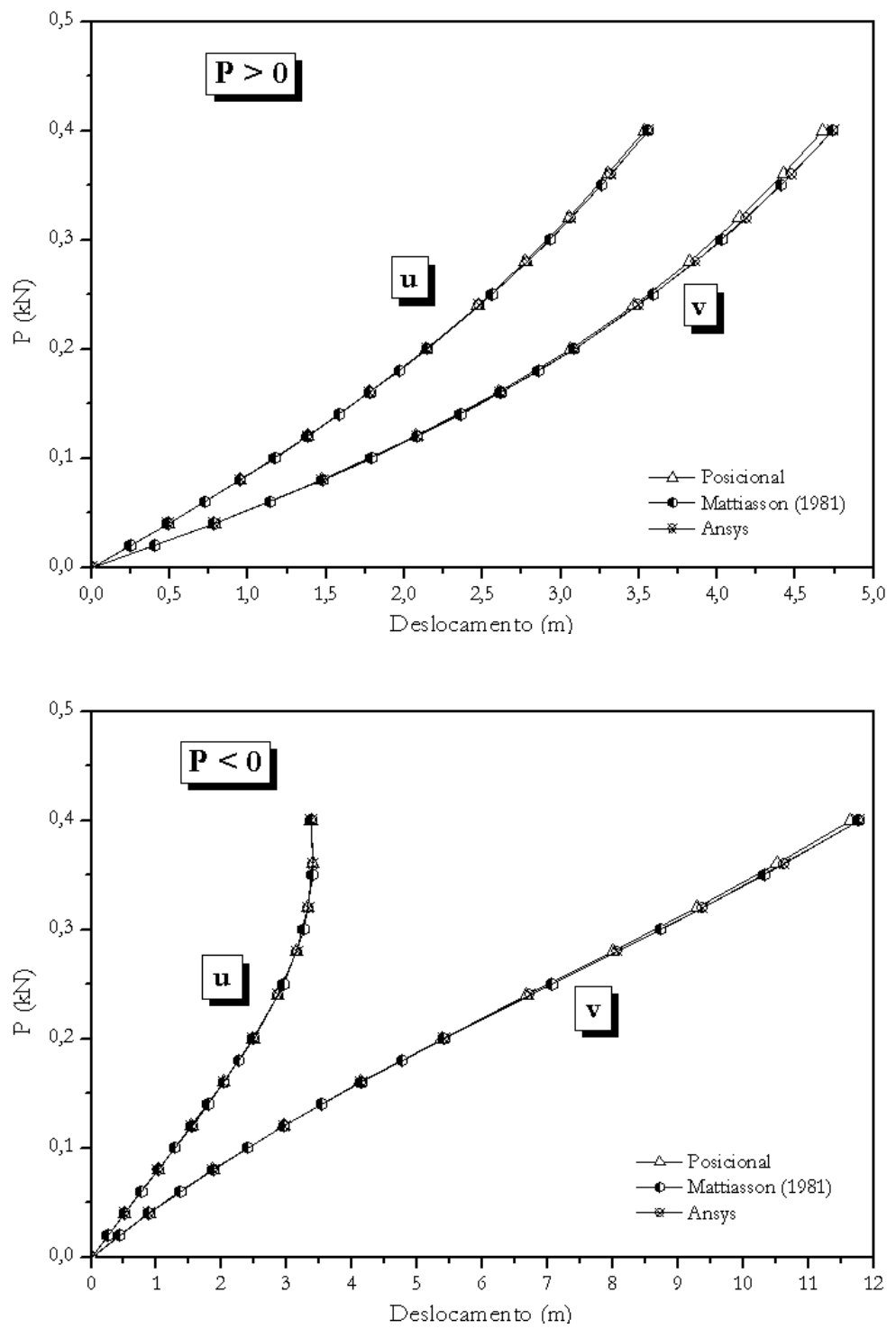

Figura 37 - Trajetória de equilíbrio para o quadro em forma de quadrado

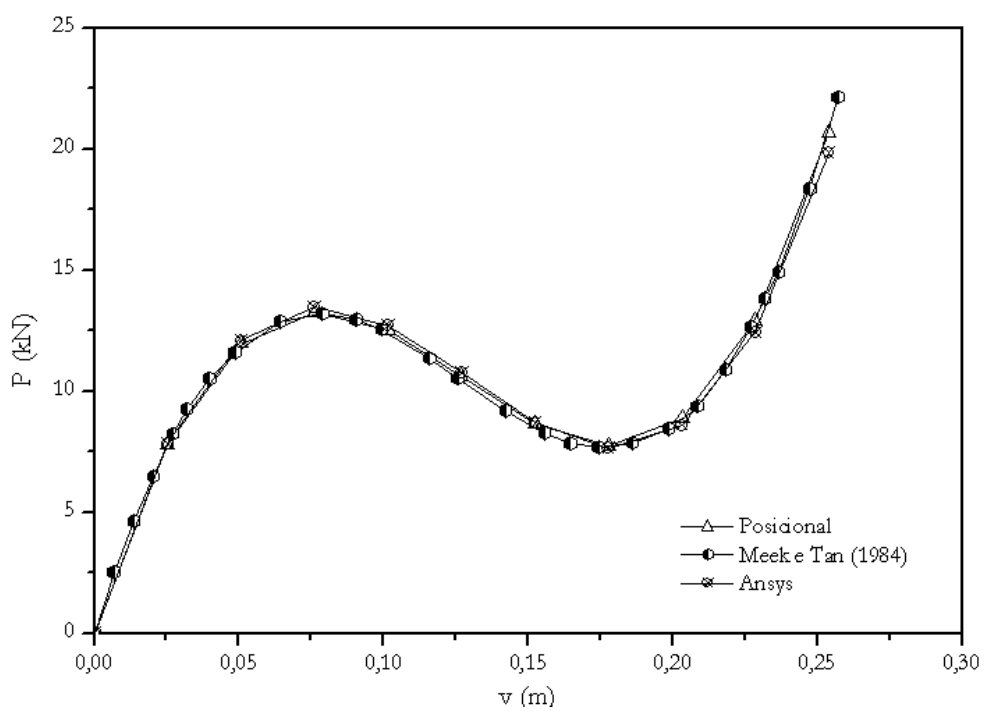

Figura 38 - Trajetória de equilíbrio para o arco achatado senoidal 
Capítulo 4 - Elemento finito de pórtico plano homogêneo

Deslocamento (m) na direção 1

Deslocamento (m) na direção 2

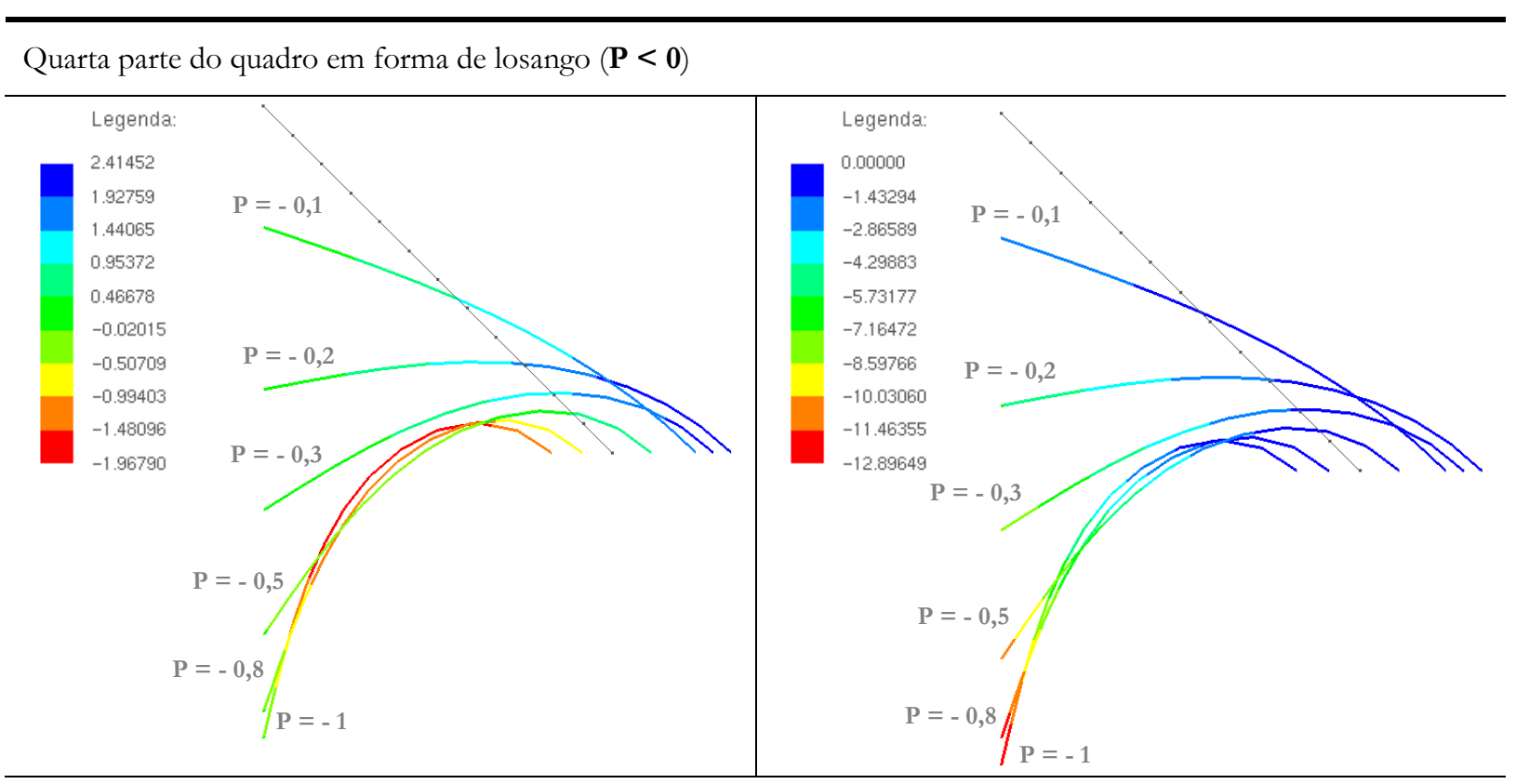

Quarta parte do quadro em forma de losango $(\mathbf{P}>\mathbf{0})$

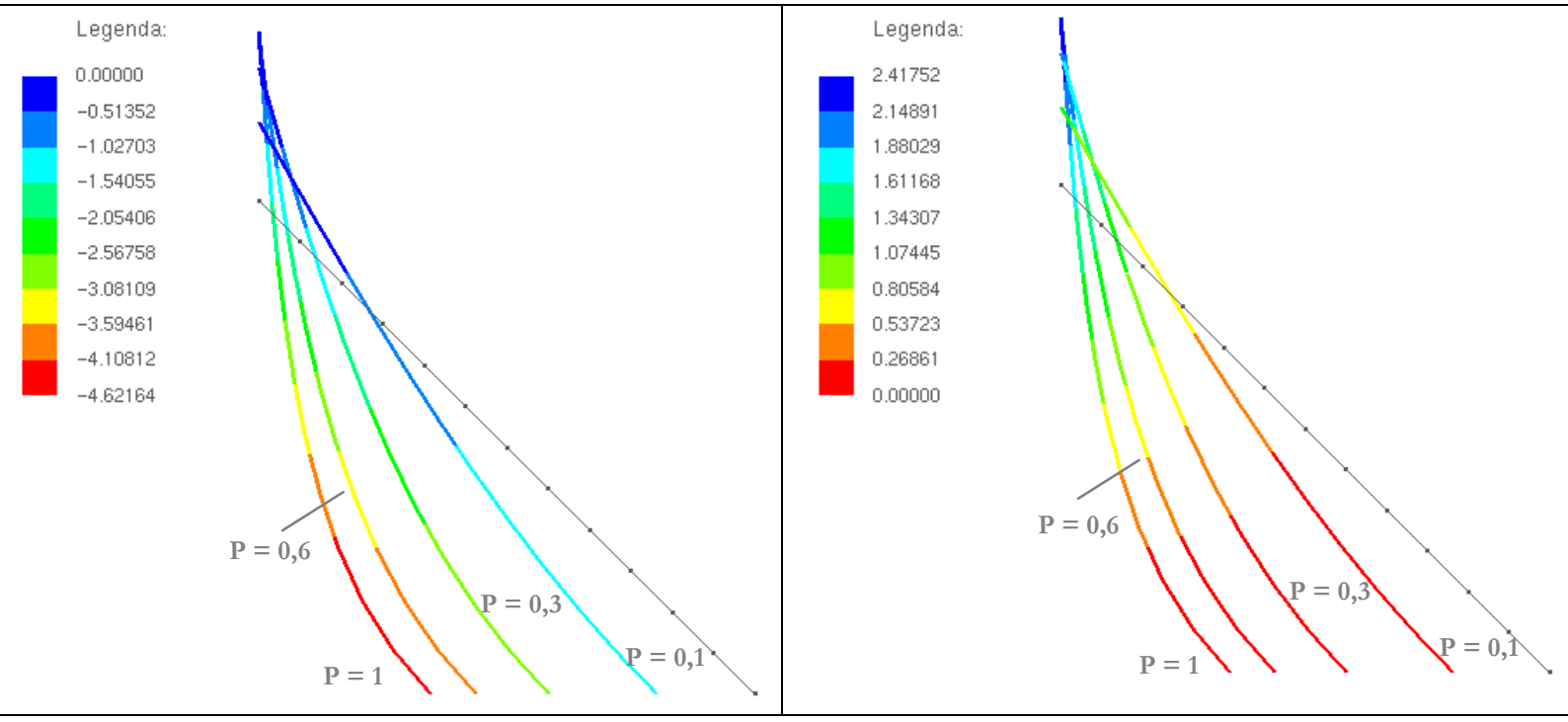

Quarta parte do quadro em forma de quadrado $(\mathbf{P}<\mathbf{0})$

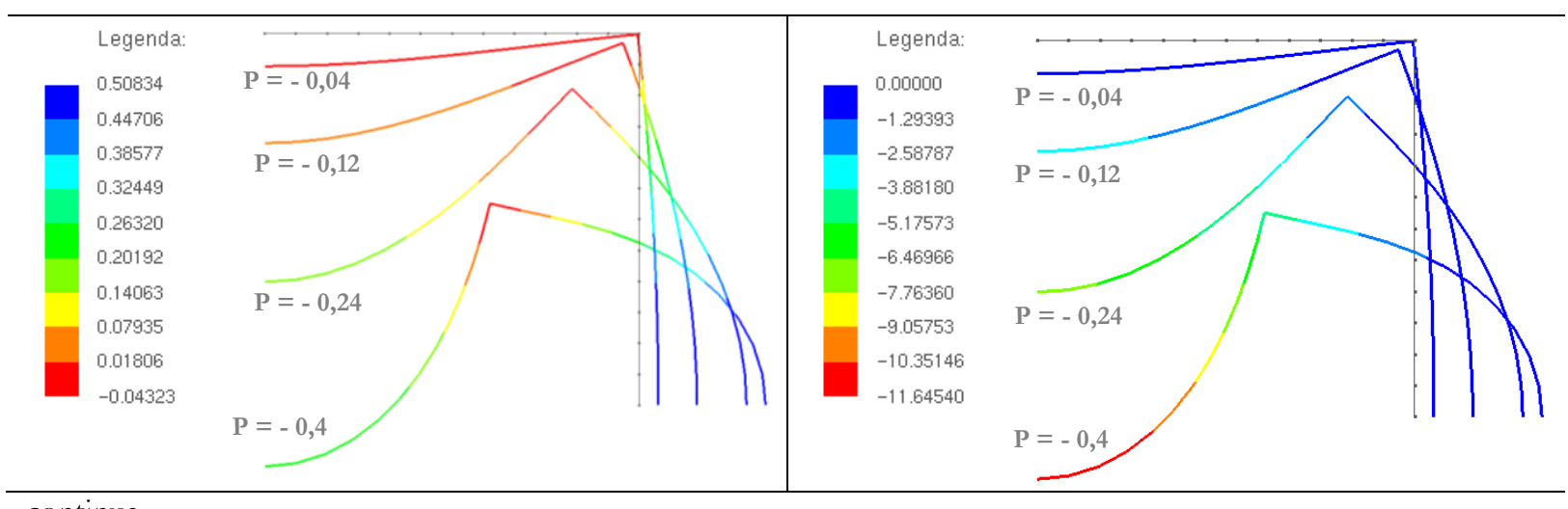

continua $\ldots$ 


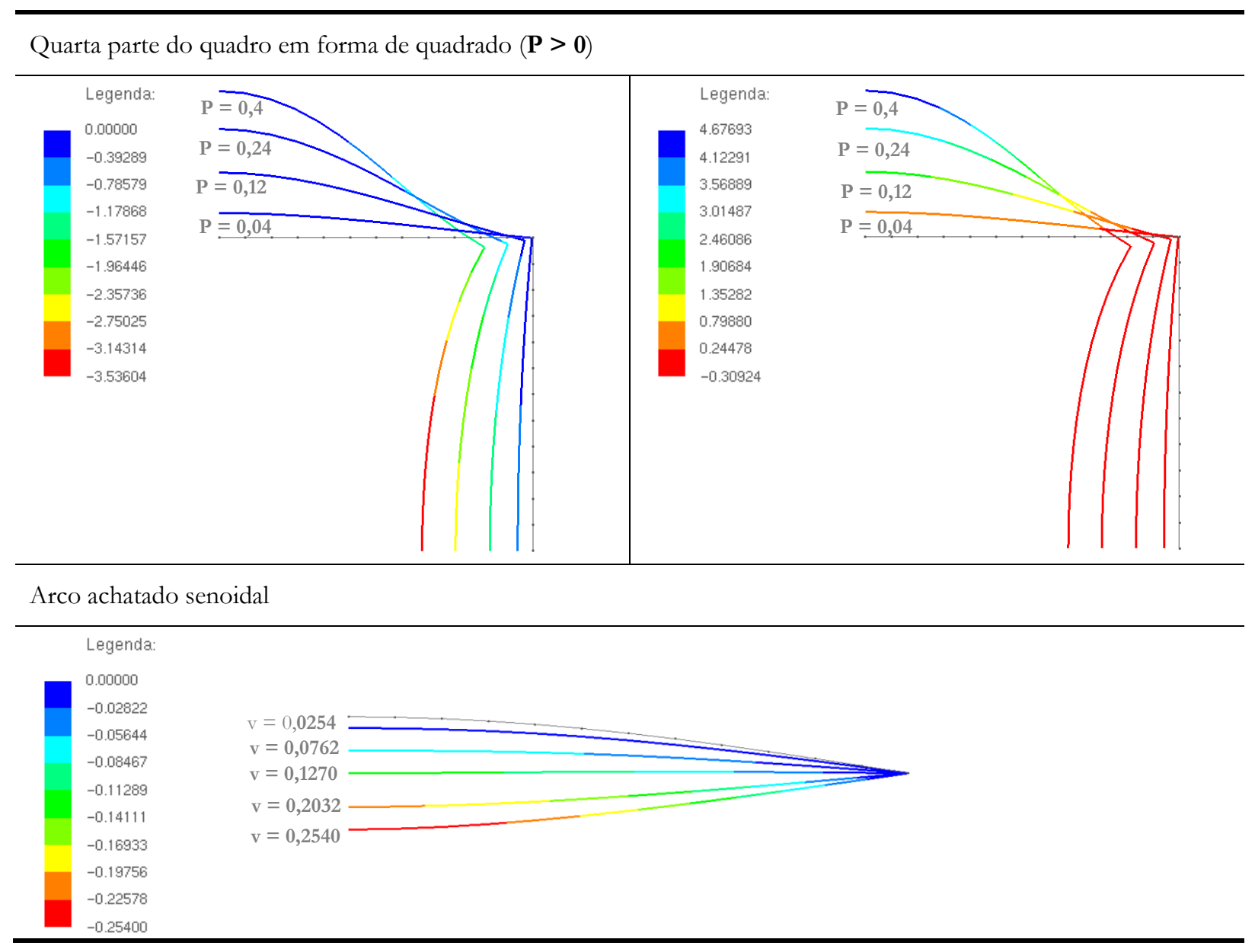

Figura 39 - Configurações atuais dos quadros e do arco para alguns incrementos de carga ou posição

\subsubsection{Exemplo 4.3: Pórtico com ligações semirrígidas}

No exemplo anterior, verificou-se a eficiência da formulação para representar problemas com diferentes condições de contorno e com ligações articuladas ou rígidas entre as barras do pórtico. Como mostrado no Item 4.3.6, qualquer relação elástica linear para as ligações e para os apoios podem ser modeladas com a técnica de penalização. Nesse sentido, este último conjunto de exemplos avalia principalmente este aspecto.

Para isso, três problemas de pórticos com ligações semirrígidas são estudados. Os pórticos apresentam geometria e carregamentos semelhantes, modificando-se apenas as condições de contorno, que são formadas por apoios simples no primeiro problema, por apoios simples com uma rigidez elástica a rotação no segundo e por engastes no terceiro. No segundo problema, a rigidez à rotação do apoio é de $1990,7 \mathrm{kNm}$ que corresponde a $0,1(\mathrm{EI} / \mathrm{L})_{\text {pilar }}$. 
Em cada um dos pórticos, quatro análises são realizadas: uma considerando as ligações rígidas e as outras três considerando as ligações semirrígidas com rigidez à rotação de $4491 \mathrm{kNm}, 9730 \mathrm{kNm}$ e $30705 \mathrm{kNm}$, respectivamente.

Estes problemas constituem uma importante referência encontrada na literatura e foram propostos originalmente por Liu e Chen (1988). Alguns trabalhos que os utilizaram para verificação das formulações propostas são os de Chan e Chui (2000), de Pinheiro e Silveira (2005) e de Reis e Coda (2014).

Liu e Chen (1988) consideraram relações momento-rotação não lineares para as ligações semirrígidas. No presente trabalho, essas relações são consideradas elástico-lineares e, portanto, somente os resultados para o caso estudado por esses autores com ligações rígidas foram utilizados como referência para comparação.

Para os problemas com ligações semirrígidas, e também com ligação rígida, são utilizados os resultados obtidos de análises realizadas no Ansys ${ }^{\circledR}$ com emprego do elemento BEAM188 para modelagem das barras e do elemento de acoplamento COMBIN40 para modelagem das ligações semirrígidas. O processo incremental-iterativo empregado foi idêntico ao das análises com a formulação posicional que consistiu em aplicar incrementos iguais de $50 \mathrm{kN}$ até a perda de estabilidade do pórtico. As configurações atuais correspondentes a cada incremento foram determinadas através do método de Newton-Raphson com tolerâncias de $10^{-9}$ e $10^{-6}$ para os critérios de convergência em posição e em força, respectivamente.

A geometria, o carregamento e os parâmetros elásticos dos materiais empregados estão representados na Figura 40. Liu e Chen (1988) consideraram seções transversais correspondentes aos perfis metálicos W14x48 $\left(\mathrm{I}=2,0146 \times 10^{-4} \mathrm{~m}^{4}, \mathrm{~A}=9,0968 \times 10^{-3} \mathrm{~m}^{2}\right)$ para as vigas e $\operatorname{W} 12 \times 96\left(I=3,4672 \times 10^{-4} \mathrm{~m}^{4}, \mathrm{~A}=1,8194 \times 10^{-2} \mathrm{~m}^{2}\right)$ para os pilares. Nos modelos estruturais de pórtico, as seções transversais podem ser representadas por parâmetros geométricos gerais como a inércia e a área. Assim, todas as análises consideraram seções transversais retangulares com dimensões tais que a inércia e a área são equivalentes a dos perfis metálicos empregados por Liu e Chen (1988).

Diante dos resultados dos dois exemplos anteriores, a discretização adotada para modelagem dos pórticos é composta de quatro elementos finitos por trecho nos pilares e seis elementos finitos nas vigas. Essa quantidade de seis elementos foi utilizada somente para manter a mesma proporção dimensional dos elementos finitos dos trechos de pilares, pois quatro elementos por barra já conduz a resultados convergentes. 

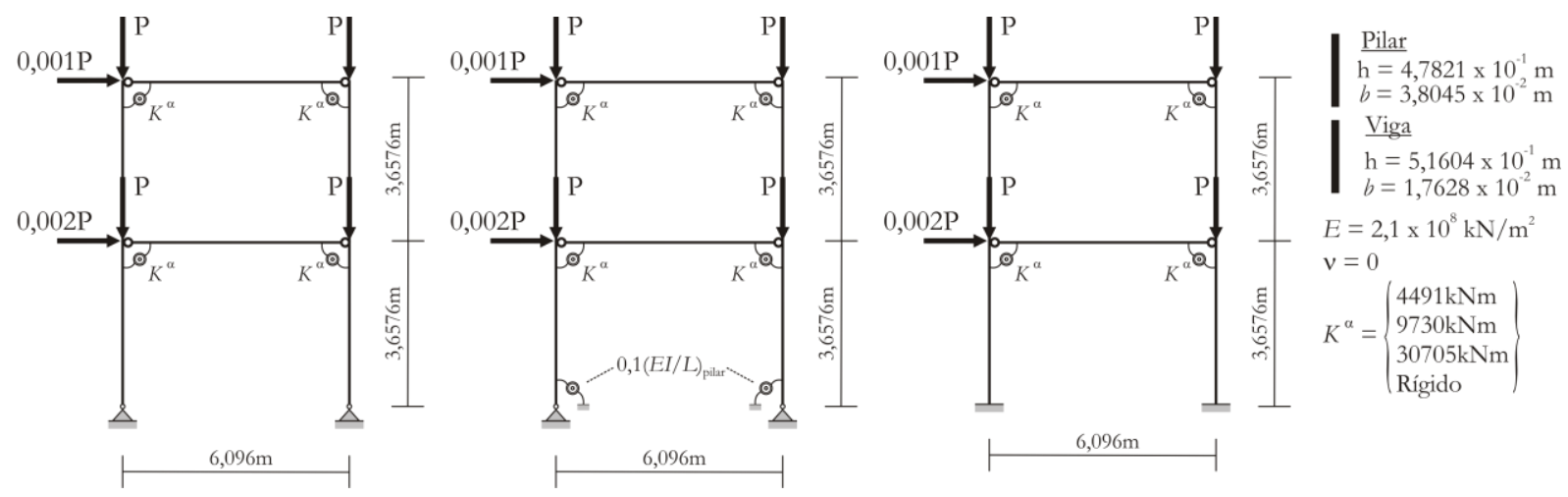

Figura 40 - Geometria, carregamento e parâmetros elásticos do Exemplo 4.3

Como dito anteriormente, o carregamento foi incrementado até a desestabilização dos pórticos que foi identificada pela formação de trechos com rigidez muito baixa nas trajetórias de equilíbrio referentes ao deslocamento horizontal do nó superior esquerdo. Essas trajetórias estão ilustradas na Figura 41, Figura 42 e Figura 43 e foram representadas até um deslocamento correspondente a $0,30 \mathrm{~m}$. Para esse nível de deslocamento, é possível identificar a perda de estabilidade em todos os casos estudados.

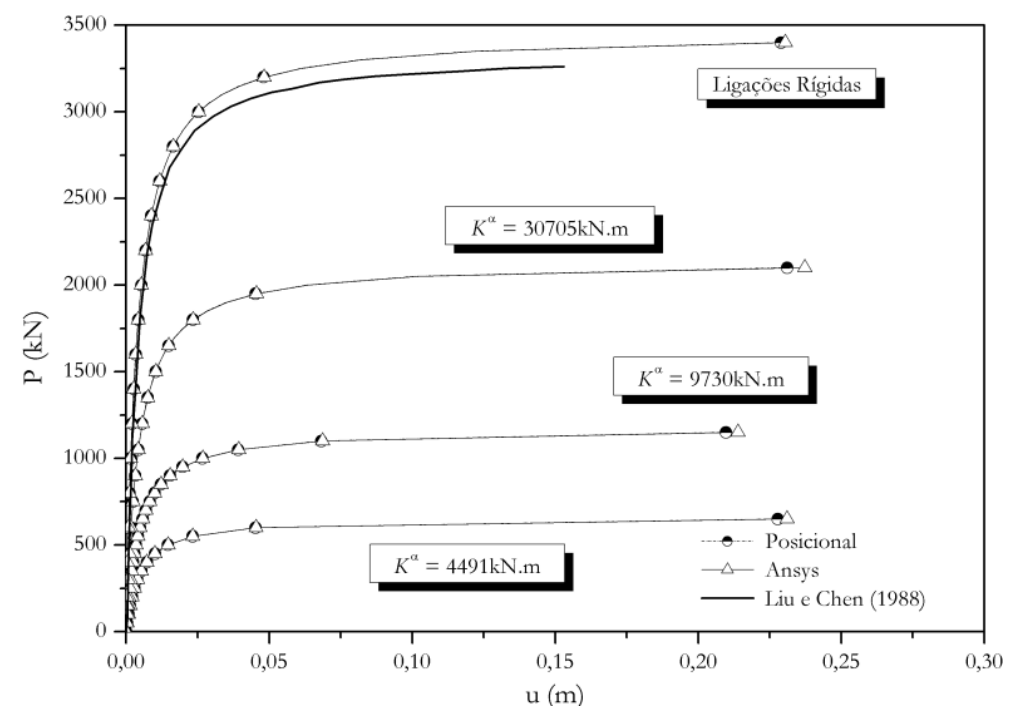


Capítulo 4 - Elemento finito de pórtico plano homogêneo

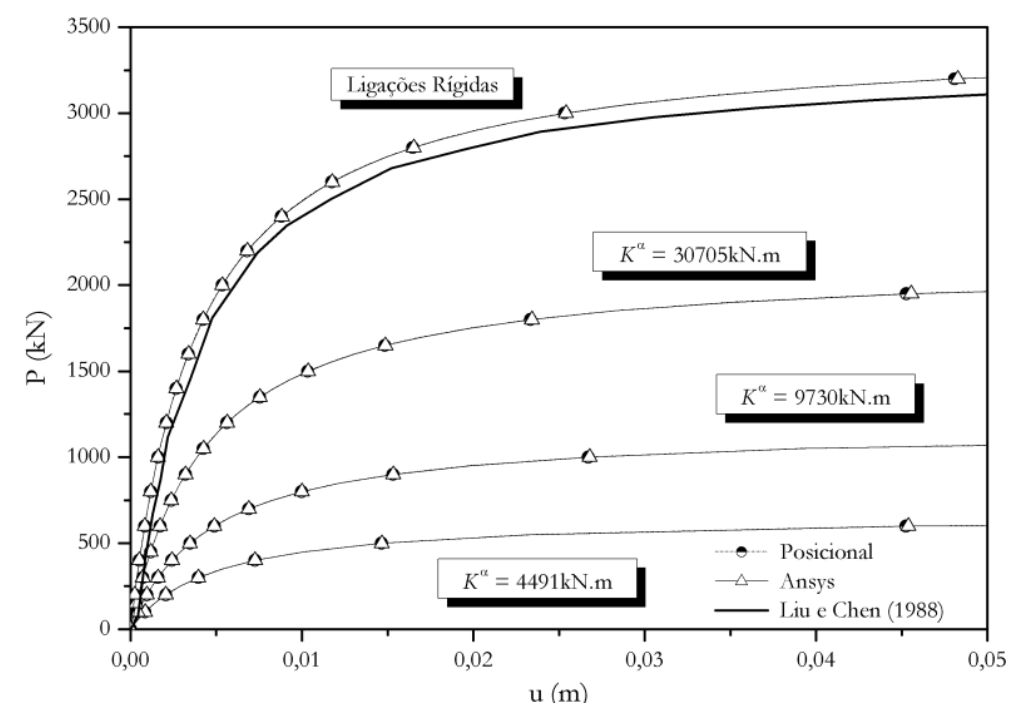

Figura 41 - Trajetórias de equilíbrio para o pórtico com apoios simples (superior). Trecho inicial (inferior)
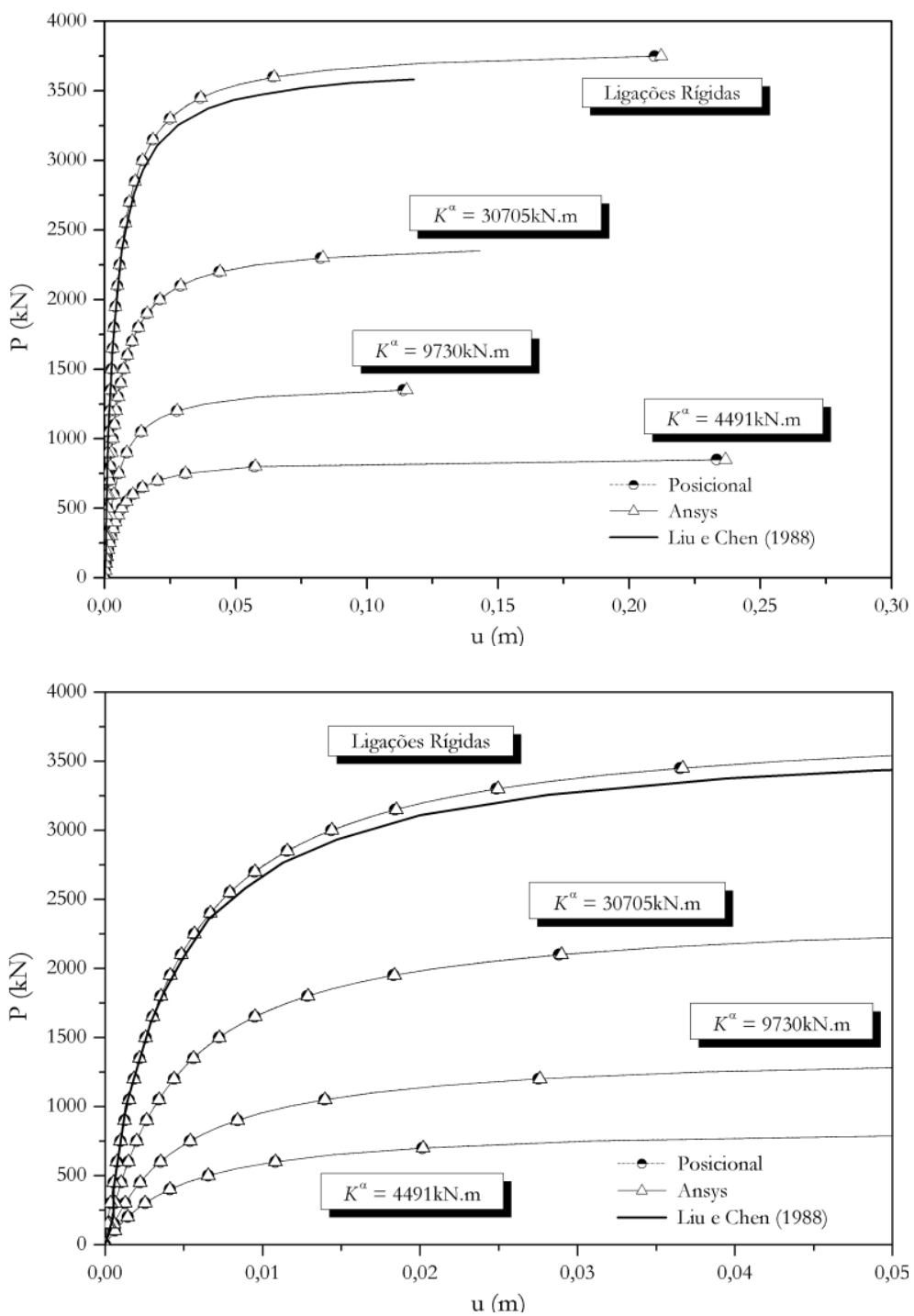

Figura 42 - Trajetórias de equilíbrio para o pórtico com apoios simples com uma rigidez elástica à rotação (superior). Trecho inicial (inferior). 

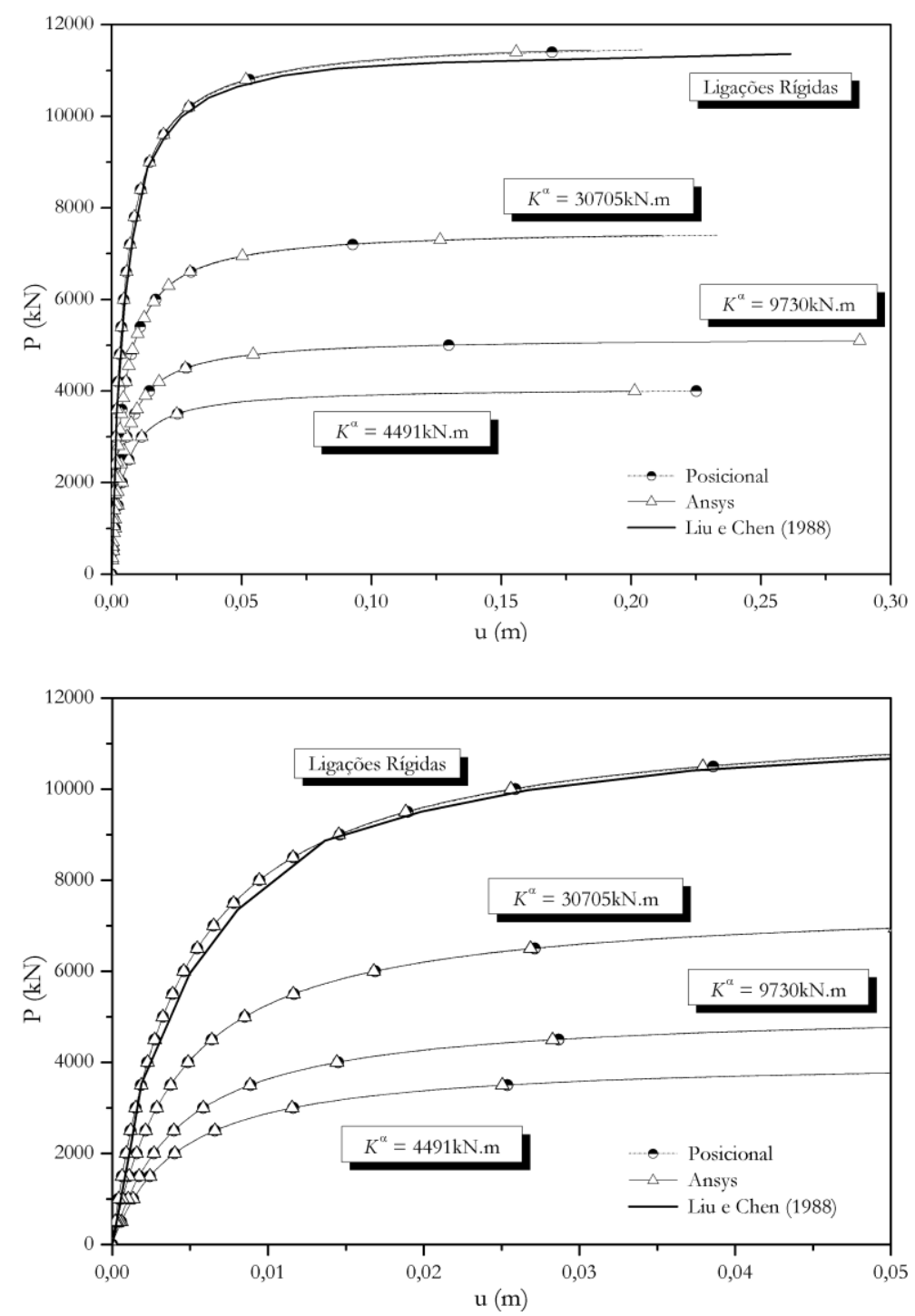

Figura 43 - Trajetórias de equilíbrio para o pórtico com apoios engastados (superior). Trecho inicial (inferior).

Os resultados obtidos com a formulação posicional foram bastante coerentes, pois, em todas as análises, os pórticos apresentaram maior capacidade de carga à medida que a rigidez das ligações foi aumentada. Além disso, ao compararmos os resultados das análises de uma mesma rigidez da ligação, observa-se maior capacidade de carga com o aumento da rigidez à rotação dos apoios. Portanto, a influência significativa da rigidez das ligações e dos apoios para estabilidade de um pórtico não contraventado foi verificada e está em conformidade com as conclusões análogas constatadas por Liu e Chen (1988) e por Chan e Chui (2000).

Em todas as trajetórias de equilíbrio, os resultados da formulação posicional praticamente coincidem com os obtidos utilizando o Ansys ${ }^{\circledR}$, mostrando a consistência da formulação. Apesar disso, os resultados fornecidos por Liu e Chen (1988) para o caso de ligações rígidas representaram um comportamento um pouco mais flexível nos trechos onde há perda de estabilidade. No entanto, as diferenças nas forças aplicadas representam um erro máximo, em 
relação aos resultados de Liu e Chen (1988), de 0,4\%, 1,3\% e 0,5\% para os casos com apoio simples, apoio elástico à rotação e apoio engastado, respectivamente. Esse erro, portanto, é pequeno diante dos seguintes aspectos:

- características bastante distintas entre a formulação posicional e a formulação de Liu e Chen (1988) que é corrotacional com emprego da cinemática de Euler-Bernoulli e da lei constitutiva de Hooke e que adota um elemento finito híbrido para modelar as barras com ligações semirrígidas;

- não identificação das tolerâncias empregadas nos critérios de convergência, bem como, do processo incremental adotado por Liu e Chen (1988);

- representação da seção transversal na formulação posicional e nas análises realizadas no Ansys ${ }^{\circledR}$ com uma seção retangular equivalente.

\subsection{Considerações}

A análise dos três conjuntos de exemplos mostrou que a formulação posicional do elemento de pórtico plano homogêneo proposta neste capítulo é bastante consistente, eficiente e robusta para resolver problemas estruturais representados com modelos de pórtico plano sujeitos a efeitos não lineares oriundos da ocorrência de grandes deslocamentos e rotações. O elemento apresenta um grau de liberdade a mais (4 por nó) se comparado às formulações que trabalham com o giro da seção nodal como grau de liberdade. No entanto, as distribuições de tensões de cisalhamento e tensões axiais na direção transversal podem ser representadas de forma mais precisa e justificam plenamente um possível aumento de custo computacional gerado por esse grau de liberdade a mais.

A capacidade de representar diferentes tipos de carregamentos como forças e momentos concentrados e forças distribuídas foi verificada no primeiro conjunto de exemplos. Mostrou-se também a convergência a partir de uma discretização em quatro elementos por barra. Os resultados obtidos foram excelentes, pois praticamente coincidiram com os resultados analíticos e numéricos encontrados na literatura.

No segundo conjunto de exemplos, diferentes tipos de condições de contorno e o acoplamento entre elementos com direções diferentes foram avaliados. Os resultados novamente foram ótimos. O processo de solução com controle de posição foi empregado para resolver o problema do arco achatado senoidal e se mostrou eficiente para determinar configurações de equilíbrio críticas e instáveis, típicas do fenômeno de snap-through. 
Por fim, o foco se concentrou na avaliação da consistência da técnica de penalização adotada para realizar o acoplamento entre barras e também para representar ligações semirrígidas e apoios flexíveis com comportamento elástico linear. Os resultados das análises dos três pórticos com diferentes condições de contorno e diferentes rigidezes das ligações foram bastante consistentes e representaram coerentemente o efeito das ligações e das condições de contorno no comportamento estrutural. Os resultados obtidos com o Ansys ${ }^{\circledR}$ praticamente coincidiram com os resultados da formulação posicional.

Diante de todas essas observações, pode-se afirmar que a formulação tem elevada capacidade de solucionar problemas não lineares geométricos de modelos estruturais formados por pórticos planos submetidos a ações externas diversas e constituídos por ligações rotuladas, rígidas ou semirrígidas e diferentes condições de contorno, podendo ser rígidas ou flexíveis. É importante ressaltar também que a implementação computacional realizada em linguagem FORTRAN foi feita corretamente e, portanto, está verificada. 


\section{CAPÍTULO 5}

\section{ELEMENTO FINITO DE PÓRTICO PLANO LAMINADO}

\subsection{Introdução}

Neste capítulo, a formulação do elemento finito de pórtico plano laminado é detalhada. Suas características gerais são idênticas àquelas apresentadas no Capítulo 3 e, portanto, somente os aspectos particulares são descritos.

A cinemática do elemento laminado é semelhante a do elemento homogêneo quando a seção transversal é composta por apenas uma lâmina. No caso de seções laminadas, uma expansão da cinemática do elemento homogêneo é realizada de forma a permitir que as lâminas tenham a possibilidade de giro independente e variação de espessura, mas com posições de interface compatibilizadas. Isso é feito atribuindo vetores generalizados nodais independentes à seção de cada lâmina.

O mapeamento posicional do elemento nas configurações inicial e atual é realizado a partir das posições de uma linha de referência que pode estar localizada em qualquer lâmina. Dessa forma, os graus de liberdade do elemento são constituídos pelas posições dos nós na linha de referência e por vetores generalizados que definem o plano da seção de cada lâmina.

O elemento desenvolvido possibilita haver diferentes materiais homogêneos e isotrópicos em cada lâmina e o modelo constitutivo utilizado para representar o comportamento desses materiais é aquele apresentado no Item 3.4.

Nos Capítulos 1 e 2, foram descritos os aspectos importantes a serem considerados nas formulações para análise de laminados com vistas a detecção do processo de falha. Como comentado, a teoria Layerwise assume hipóteses que permitem a representação da anisotropia no plano do laminado, da heterogeneidade transversal, do efeito Zig-Zag e da continuidade interlaminar.

O elemento finito proposto neste trabalho apresenta uma cinemática baseada na teoria Layerwise, mas com posições compatibilizadas intrinsecamente pelas próprias funções de mapeamento posicional. A formulação é não linear geométrica com a possibilidade de ocorrência de grandes deslocamentos e rotações e a cinemática proposta permite representar o efeito 
Zig-Zag e a heterogeneidade transversal. A anisotropia no plano do laminado não é considerada, pois o modelo estrutural é de pórtico plano.

Distribuições de tensão axial na direção longitudinal e principalmente de tensão axial e de cisalhamento na direção transversal são obtidas com excelente precisão. A continuidade interlaminar das tensões transversais não é garantida, mas a descontinuidade é menor, pois as deformações transversais ficam descontínuas devido ao giro independente das lâminas. Essa descontinuidade das tensões transversais pode ser reduzida aumentando a discretização da seção, já que o número de lâminas do modelo numérico é independente do número de lâminas que compõe o laminado. Feito isso, a continuidade interlaminar é facilmente recuperada calculando a média das tensões obtidas para as lâminas adjacentes a uma dada interface.

O elemento proposto permite a análise de pórticos planos constituídos por laminados finos ou espessos, não ficando sujeito a problemas de mau condicionamento matricial para esses tipos de problemas. O mau condicionamento surge na modelagem de laminados finos e devido presença de lâminas finas, mesmo em laminados espessos. Grandes variações de propriedades elásticas dos materiais constituintes das lâminas podem também levar a problemas de mau condicionamento matricial.

Assim, quando são empregados elementos finitos bidimensionais ou elementos finitos desenvolvidos com base na teoria Layerwise de Reddy (2004a) para analisar pórticos planos laminados, imprecisões nos resultados para as distribuições de tensão, principalmente as transversais, podem surgir, exigindo um refinamento excessivo da malha de elementos finitos para evitar o mau condicionamento.

O elemento finito proposto neste trabalho é uma alternativa, pois com malhas bem menos refinadas é possível obter resultados precisos para as distribuições de deslocamentos e tensões ao longo da seção transversal do laminado, viabilizando, portanto, futuras modelagens do processo de falha por delaminação ou deslizamento.

Além da descrição do elemento finito neste capítulo, são apresentados também os resultados de análises não lineares geométricas realizadas em exemplos de vigas laminadas que possuem resultados numéricos e analíticos disponíveis na literatura. Exemplos de pórticos planos laminados também são propostos e analisados. Em todos os exemplos, são feitas análises numéricas no software Ansys ${ }^{\circledR}$ utilizando elementos finitos bidimensionais. O objetivo é verificar os resultados obtidos com o elemento proposto neste trabalho e comparar sua eficiência em relação aos elementos finitos bidimensionais. Além disso, as análises são realizadas a fim de verificar a consistência, a eficiência e a robustez da formulação no que diz respeito principalmente à representação correta das distribuições de tensões. 
Um código computacional foi desenvolvido com a implementação da formulação em linguagem de programação FORTRAN. Os resultados das análises são fornecidos pelo programa por meio de arquivos de saída de dados que permitem a construção de trajetórias de equilíbrio, a visualização das configurações atuais e a visualização das distribuições de deslocamentos, deformações e tensões. O software de pós-processamento AcadView é empregado para a visualização dos resultados.

\subsection{Mapeamento posicional das configurações inicial e atual}

O mapeamento do elemento finito de pórtico plano laminado é realizado a partir da interpolação das posições de pontos nodais localizados em uma linha de referência (lr - com letras minúsculas) e dos vetores generalizados tangentes aos planos nodais de cada lâmina. Com essa interpolação, é possível definir as posições de qualquer ponto do elemento.

O mapeamento posicional é realizado de maneira tal que a linha de referência pode ser atribuída a qualquer lâmina e não há necessidade de estar localizada no centro da lâmina Essa liberdade para escolha do posicionamento da linha de referência permite atribuir restrição nas posições de nós localizados em qualquer ponto da seção transversal do elemento e não somente no centroide da seção como no caso do elemento de pórtico plano homogêneo.

A configuração inicial e a configuração atual têm suas posições mapeadas de maneira semelhante. Na configuração inicial, a localização da linha de referência e as posições dos nós são informações fornecidas durante o pré-processamento. Os vetores generalizados são unitários, normais à linha de referência e podem ser obtidos a partir do vetor tangente.

$\mathrm{Na}$ configuração atual, as posições dos nós da linha de referência e os vetores generalizados de cada lâmina constituem os graus de liberdade do elemento, sendo as incógnitas do problema não linear. Na Figura 44, ilustra-se a ideia do mapeamento posicional para um elemento constituído por cinco lâminas e grau cúbico para a interpolação polinomial longitudinal empregada.

Para permitir a localização da linha de referência em qualquer lâmina e em uma posição qualquer dentro desta lâmina, o mapeamento posicional de uma determinada lâmina nas configurações inicial e atual depende se essa lâmina coincide com a Lâmina de Referência (LR com letras maiúsculas) ou se está acima ou abaixo desta. Dessa forma, três expressões distintas para o mapeamento posicional são necessárias. 


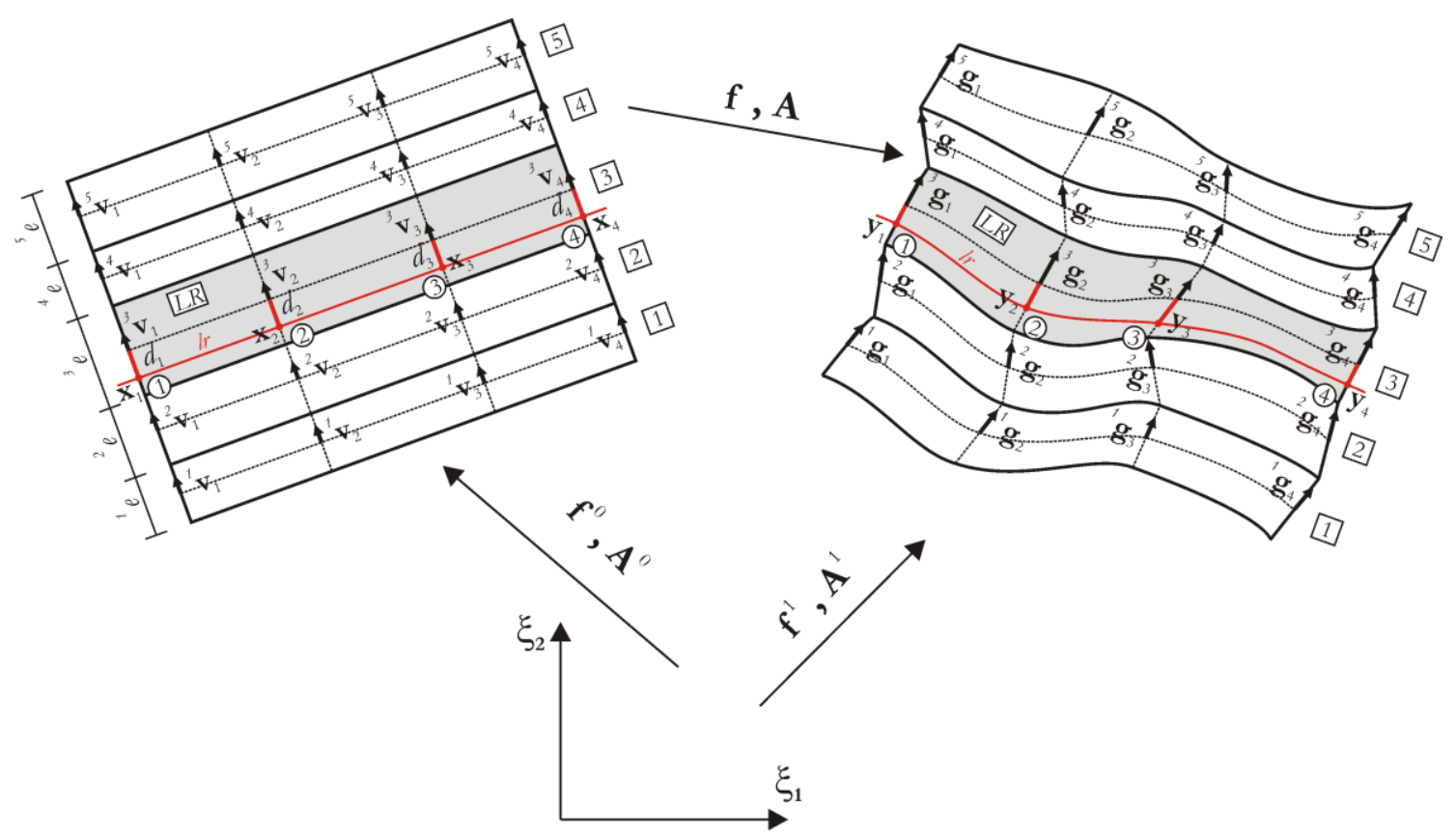

Figura 44 - Mapeamento posicional do elemento de pórtico plano laminado

Seja k uma lâmina a ser mapeada na configuração inicial. As equações do mapeamento posicional ficam expressas por:

a) Mapeamento para a lâmina k igual à Lâmina de Referência (LR):

$$
\begin{aligned}
& { }^{k} \mathbf{f}^{0}\left(\xi_{1}, \xi_{2}\right)={ }^{k} \mathbf{x}\left(\xi_{1}, \xi_{2}\right) \\
& { }^{k} x^{i}\left(\xi_{1}, \xi_{2}\right)=\left[x_{j}^{i} \Phi_{j}\left(\xi_{1}\right)\right]+\left\{\left[d_{j} \Phi_{j}\left(\xi_{1}\right)\right]+\frac{{ }^{k} e}{2} \xi_{2}\right\}\left[{ }^{k} v_{w}^{i} \Phi_{w}\left(\xi_{1}\right)\right] \\
& \operatorname{com} i=1,2 \text { e } j, w=1, \ldots,(g r+1) .
\end{aligned}
$$

Nessa equação, ${ }^{k} \mathbf{f}^{0}\left(\xi_{1}, \xi_{2}\right)$ representa a função de mapeamento posicional da configuração inicial ${ }^{k} \mathbf{x}\left(\xi_{1}, \xi_{2}\right)$ a partir do espaço adimensional para a lâmina $k=L R$, ${ }^{k} x^{i}\left(\xi_{1}, \xi_{2}\right)$ representa a posição inicial na direção $i$ de um ponto qualquer localizado em $k, x_{j}^{i}$ é a posição na direção $i$ do nó $j$ localizado na linha de referência $(l r), d_{j}$ é a distancia entre o nó $j$ na linha de referência e o centro da lâmina $k,{ }^{k} e$ é a espessura da lâmina $k,{ }^{k} v_{w}^{i}$ é a componente na direção $i$ do versor pertencente ao plano da seção transversal da lâmina $k$ passando pelo nó $w$ e $\Phi_{w}\left(\xi_{1}\right)$ é a função de forma associada ao nó $w$ constituída por um polinômio de Lagrange com grau correspondente à variável $g r$. Os versores ${ }^{k} v_{w}^{i}$ normais ao eixo localizado no centro das lâminas são obtidos de forma análoga aos versores do elemento de 
pórtico plano homogêneo, conforme apresentado no Item 4.2. As lâminas são consideradas sempre paralelas na configuração inicial, assim o versor de cada lâmina é idêntico ao versor normal à linha de referência.

Nesse mapeamento, a primeira parcela identifica as posições de todos os pontos pertencentes à linha de referência e, dado um ponto dessa linha de referência, a segunda parcela identifica as posições de todos os pontos da seção transversal da lâmina k. Quando $\xi_{2}=-1$ o ponto está localizado na interface inferior de $k$, quando $\xi_{2}=-2 \frac{\left\lfloor d_{j} \Phi_{j}\left(\xi_{1}\right)\right\rfloor}{{ }^{k} e}$ o ponto está localizado na linha de referência, quando $\xi_{2}=0$ o ponto está localizado no centro de $k$ e quando $\xi_{2}=1$ o ponto está localizado na interface superior de $k . \mathrm{Na}$ Figura 45 , é ilustrado o mapeamento de um ponto qualquer de coordenadas adimensionais $\left(\xi_{1}=a, \xi_{2}=b\right)$.

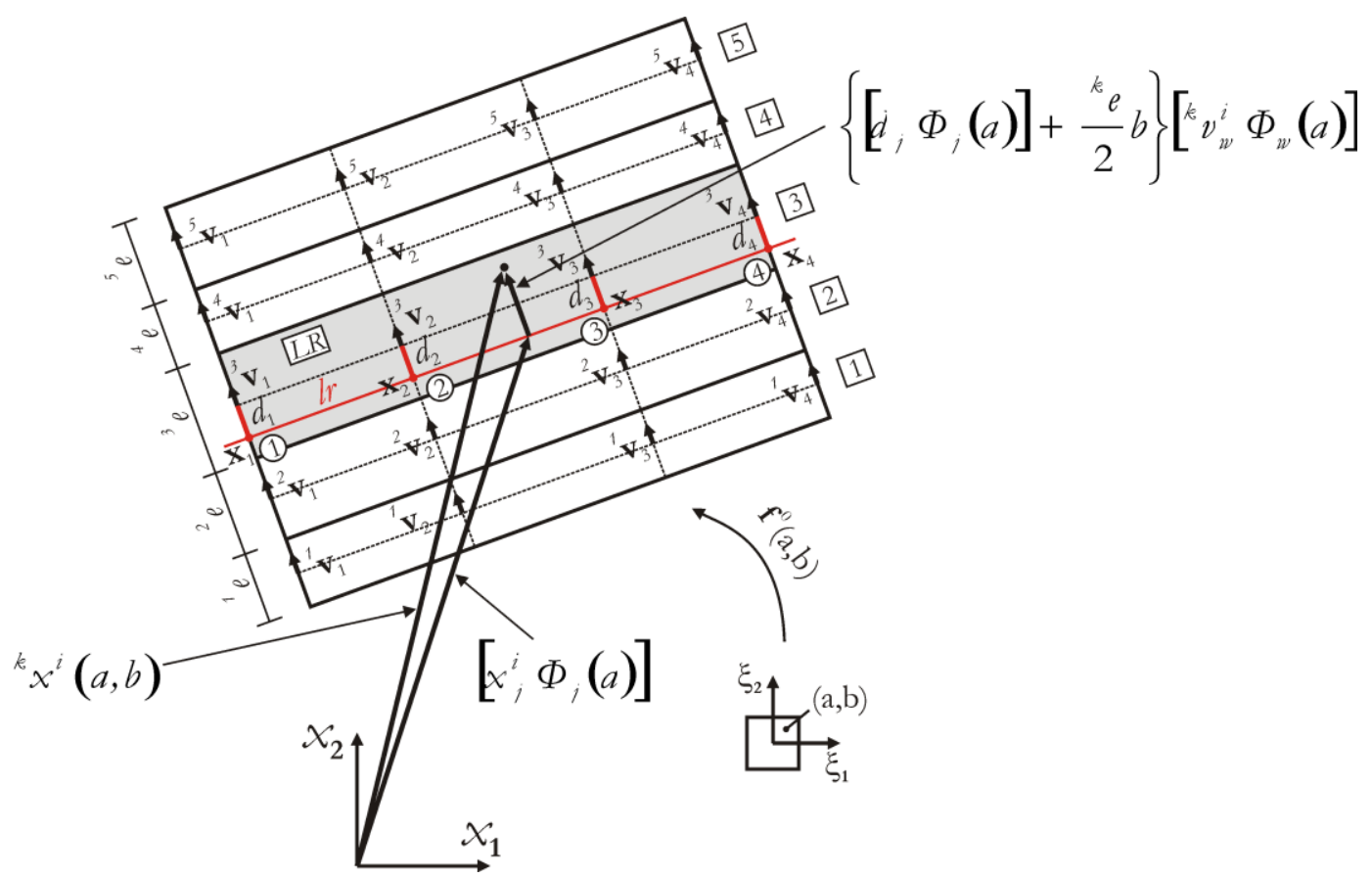

Figura 45 - Mapeamento posicional de um ponto qualquer da Lâmina de Referência na configuração inicial

b) Mapeamento para as lâminas k abaixo da Lâmina de Referência (LR):

$$
\begin{aligned}
&{ }^{k} \mathbf{f}^{0}\left(\xi_{1}, \xi_{2}\right)={ }^{k} \mathbf{x}\left(\xi_{1}, \xi_{2}\right) \\
&{ }^{k} x^{i}\left(\xi_{1}, \xi_{2}\right)= {\left[x_{j}^{i} \Phi_{j}\left(\xi_{1}\right)\right]+\left\{\left[d_{j} \Phi_{j}\left(\xi_{1}\right)\right]-\frac{{ }^{L R} e}{2}\right\}\left[{ }^{L R} v_{w}^{i} \Phi_{w}\left(\xi_{1}\right)\right] } \\
&-\sum_{m=k+1}^{L R-1} e\left[m v_{j}^{i} \Phi_{j}\left(\xi_{1}\right)\right]+{ }^{k} e\left[{ }^{k} v_{j}^{i} \Phi_{j}\left(\xi_{1}\right)\right] \frac{\xi_{2}-1}{2}
\end{aligned}
$$

$\operatorname{com} i=1,2$ e $j, w=1, \ldots,(g r+1)$. 
Nessa equação, ${ }^{L R} e$ e ${ }^{L R} v_{w}^{i}$ são a espessura da $L R$ e a componente na direção $i$ do versor pertencente ao plano da seção transversal da $L R$ passando pelo nó $w$, respectivamente. ${ }^{m} e \mathrm{e}^{m} v_{w}^{i}$ são análogos para as lâminas inferiores a $L R$, ou seja, da lâmina $k+1$ à $L R-1$. As demais variáveis têm descrição semelhante a da Equação (113).

No mapeamento representado na Equação (114), a primeira parcela identifica as posições de todos os pontos pertencentes à linha de referência e, dado um ponto dessa linha de referência, a segunda parcela identifica a posição do ponto localizado na interface inferior da $L R$ e a terceira parcela localiza o ponto na interface inferior da lâmina imediatamente superior à lâmina mapeada. Por fim, a quarta parcela mapeia todos os pontos da seção transversal da lâmina k. Quando $\xi_{2}=-1$ o ponto está localizado na interface inferior de $k$, quando $\xi_{2}=0$ o ponto está localizado no centro de $k$ e quando $\xi_{2}=1$ o ponto está localizado na interface superior de $k$. $\mathrm{Na}$ Figura 46, há uma ilustração do mapeamento de um ponto qualquer com coordenadas adimensionais $\left(\xi_{1}=a, \xi_{2}=b\right)$.

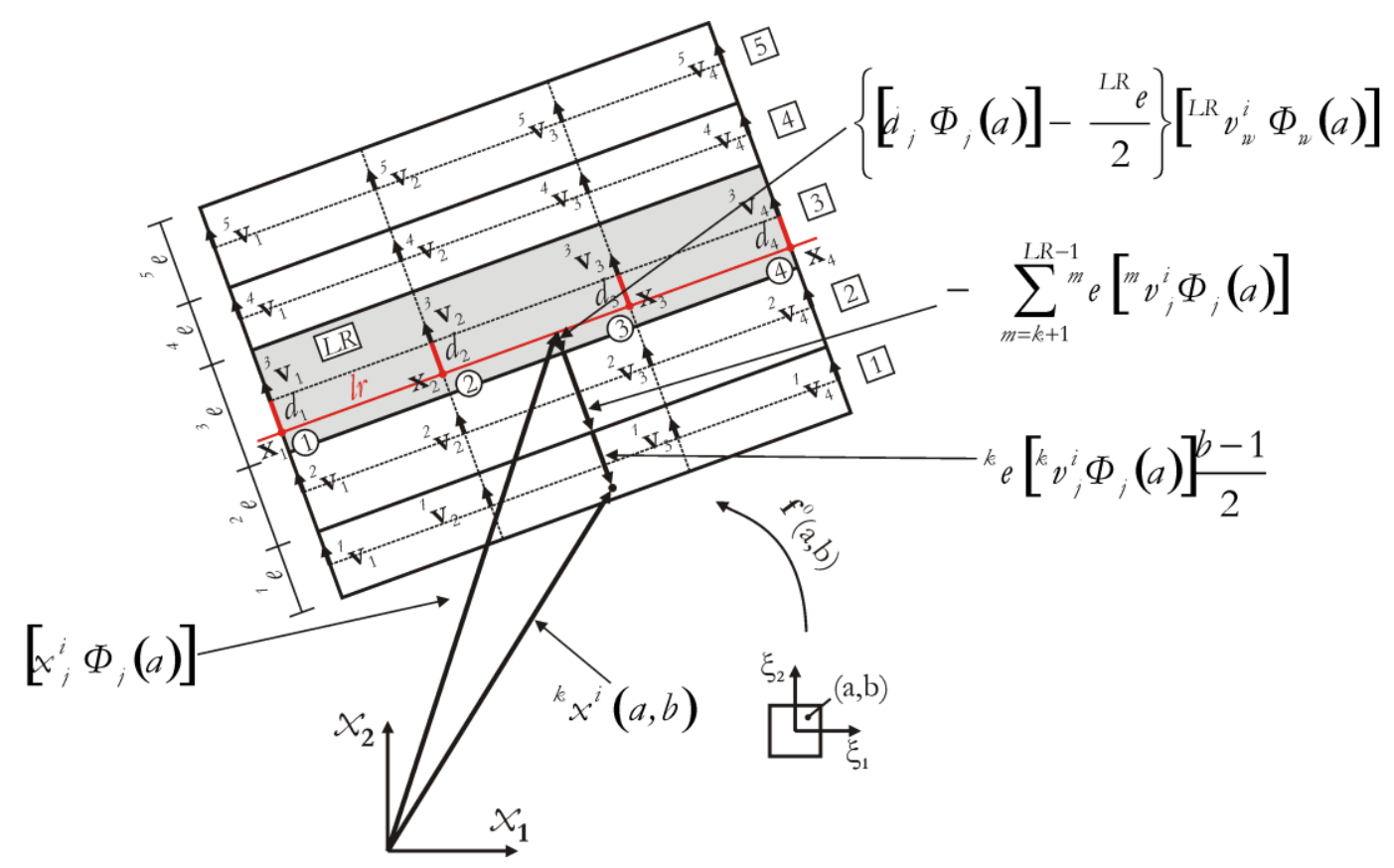

Figura 46 - Mapeamento posicional de um ponto qualquer na configuração inicial de uma lâmina inferior à Lâmina de Referência.

c) Mapeamento para as lâminas k acima da Lâmina de Referência (LR): 


$$
\begin{aligned}
{ }^{k} \mathbf{f}^{0}\left(\xi_{1}, \xi_{2}\right)= & { }^{k} \mathbf{x}\left(\xi_{1}, \xi_{2}\right) \\
{ }^{k} x^{i}\left(\xi_{1}, \xi_{2}\right)= & {\left[x_{j}^{i} \Phi_{j}\left(\xi_{1}\right)\right]+\left\{\left[d_{j} \Phi_{j}\left(\xi_{1}\right)\right]+\frac{{ }^{L R} e}{2}\right\}\left[{ }^{L R} v_{w}^{i} \Phi_{w}\left(\xi_{1}\right)\right] } \\
& +\sum_{m=L R+1}^{k-1} m^{m} e\left[v^{m}{ }_{j}^{i} \Phi_{j}\left(\xi_{1}\right)\right]+{ }^{k} e\left[{ }^{k} v_{j}^{i} \Phi_{j}\left(\xi_{1}\right)\right] \frac{\xi_{2}+1}{2}
\end{aligned}
$$

$\operatorname{com} i=1,2$ e $j, w=1, \ldots,(g r+1)$.

Nessa equação, "me e "m $v_{w}^{i}$ são, para cada lâmina $m$ de $L R+1$ à $k-1$, a espessura e a componente na direção $i$ do versor pertencente ao plano da seção transversal da lâmina $m$ no plano nodal $w$, respectivamente. As demais variáveis têm descrição semelhante às descrições das Equações (113) e (114).

Nesse mapeamento, a primeira parcela identifica as posições de todos os pontos pertencentes à linha de referência e, dado um ponto dessa linha de referência, a segunda parcela identifica a posição do ponto localizado na interface superior da $L R$ e a terceira parcela localiza o ponto na interface superior da lâmina imediatamente inferior à lâmina mapeada. Por fim, a quarta parcela mapeia todos os pontos da seção transversal da lâmina $k$. Quando $\xi_{2}=-1$ o ponto está localizado na interface inferior de $k$, quando $\xi_{2}=0$ o ponto está localizado no centro $k$ e quando $\xi_{2}=1$ o ponto está localizado na interface superior de k. Na Figura 47, há uma ilustração do mapeamento de um ponto qualquer com coordenadas adimensionais $\left(\xi_{1}=a, \xi_{2}=b\right)$.

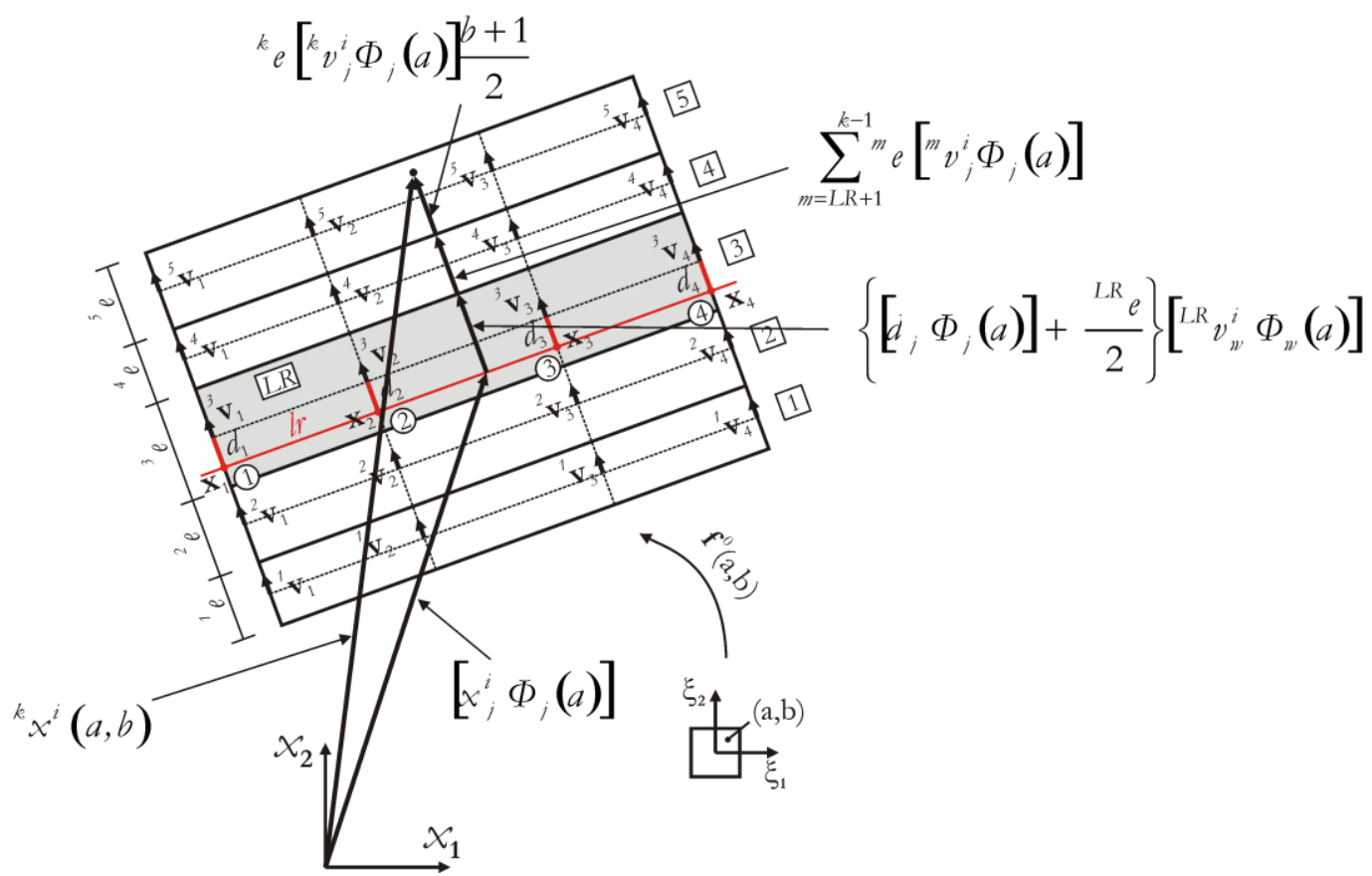

Figura 47 - Mapeamento posicional de um ponto qualquer na configuração inicial de uma lâmina superior à Lâmina de Referência. 
O mapeamento posicional para a configuração atual é totalmente análogo ao mapeamento da configuração inicial, bastando substituir as posições iniciais ${ }^{k} x^{i}$ e $x_{j}^{i}$ pelas posições atuais ${ }^{k} y^{i}$ e $y_{j}^{i}$ e os versores ${ }^{L R} v_{j}^{i}, " v_{j}^{i} \mathrm{e}^{k} v_{j}^{i}$ pelos vetores generalizados ${ }^{L R} g_{j}^{i}$, ${ }^{m} g_{j}^{i} \quad \mathrm{e}^{k} g_{j}^{i}$ em todas as expressões de mapeamento.

Dessa forma, os mapeamentos das lâminas na configuração atual ficam expressos por:

a) Mapeamento da lâmina k igual à Lâmina de Referência (LR):

$$
\begin{aligned}
& { }^{k} \mathbf{f}^{1}\left(\xi_{1}, \xi_{2}\right)={ }^{k} \mathbf{y}\left(\xi_{1}, \xi_{2}\right) \\
& { }^{k} y^{i}\left(\xi_{1}, \xi_{2}\right)=\left[y_{j}^{i} \Phi_{j}\left(\xi_{1}\right)\right]+\left\{\left[d_{j} \Phi_{j}\left(\xi_{1}\right)\right]+\frac{{ }^{k} e}{2} \xi_{2}\right\}\left[{ }^{k} g_{w}^{i} \Phi_{w}\left(\xi_{1}\right)\right] \\
& \operatorname{com} i=1,2 \text { e } j, w=1, \ldots,(g r+1) .
\end{aligned}
$$

b) Mapeamento das lâminas k abaixo da Lâmina de Referência (LR):

$$
\begin{aligned}
{ }^{k} \mathbf{f}^{1}\left(\xi_{1}, \xi_{2}\right)= & { }^{k} \mathbf{y}\left(\xi_{1}, \xi_{2}\right) \\
{ }^{k} y^{i}\left(\xi_{1}, \xi_{2}\right)= & {\left[y_{j}^{i} \Phi_{j}\left(\xi_{1}\right)\right]+\left\{\left[d_{j} \Phi_{j}\left(\xi_{1}\right)\right]-\frac{{ }^{L R} e}{2}\right\}\left[L R g_{w}^{i} \Phi_{m}\left(\xi_{1}\right)\right] } \\
& -\sum_{m=k+1}^{L R-1}{ }^{m} e\left[{ }^{m} g_{j}^{i} \Phi_{j}\left(\xi_{1}\right)\right]+{ }^{k} e\left[{ }^{k} g_{j}^{i} \Phi_{j}\left(\xi_{1}\right)\right] \frac{\xi_{2}-1}{2}
\end{aligned}
$$

$\operatorname{com} i=1,2 \mathrm{e} j, w=1, \ldots,(g r+1)$.

c) Mapeamento das lâminas k acima da Lâmina de Referência (LR):

$$
\begin{aligned}
{ }^{k} \mathbf{f}^{1}\left(\xi_{1}, \boldsymbol{\xi}_{2}\right)= & { }^{k} \mathbf{y}\left(\xi_{1}, \boldsymbol{\xi}_{2}\right) \\
{ }^{k} y^{i}\left(\xi_{1}, \xi_{2}\right)= & {\left[y_{j}^{i} \Phi_{j}\left(\xi_{1}\right)\right]+\left\{\left[d_{j} \Phi_{j}\left(\xi_{1}\right)\right]+\frac{{ }^{L R} e}{2}\right\}\left[{ }^{L R} g_{w}^{i} \Phi_{w}\left(\xi_{1}\right)\right] } \\
& +\sum_{m=L R+1}^{k-1}{ }^{m} e\left[{ }^{m} g_{j}^{i} \Phi_{j}\left(\xi_{1}\right)\right]+{ }^{k} e\left[{ }^{k} g_{j}^{i} \Phi_{j}\left(\xi_{1}\right)\right] \frac{\xi_{2}+1}{2}
\end{aligned}
$$

$\operatorname{com} i=1,2 \mathrm{e} j, w=1, \ldots,(g r+1)$. 
Nessas expressões, as posições atuais dos nós localizados na linha de referência, representadas por $y_{j}^{i}$, e os vetores generalizados das seções nodais de cada lâmina ${ }^{k} g_{j}^{i}$ constituem os graus de liberdade do elemento finito laminado. O elemento foi desenvolvido de forma a permitir o emprego de qualquer número de lâminas para compor a seção transversal e qualquer grau para as funções aproximadoras polinomiais. Assim, o número de graus de liberdade $(n g \emptyset)$ do elemento fica escrito em função da quantidade de lâminas utilizadas no modelo numérico (nlam) e do grau de aproximação empregado:

$n g l=2(g r+1)($ nlam +1$)$

na qual $(g r+1)$ representa o número de nós do elemento e $2($ nlam +1$)$ o número de graus de liberdade por nó.

Apesar de $d_{j} \mathrm{e}^{k} e$ terem sido mantidas constantes nas expressões do mapeamento da configuração atual, o elemento permite a variação da posição da linha de referência (lr e da espessura das lâminas, pois o vetor generalizado pode deixar de ser unitário na configuração atual. Assim, a distância $D\left(\xi_{1}\right)$ da linha de referência (lr r ao centro da Lâmina de Referência $(L R)$ e a espessura das lâminas ${ }^{k} E\left(\xi_{1}\right)$ na configuração atual passam a ser:

$$
\begin{aligned}
& D\left(\xi_{1}\right)=\left[d_{j} \Phi_{j}\left(\xi_{1}\right)\right]\left\{\left\|{ }^{L R} \mathbf{g}_{w}\right\| \Phi_{w}\left(\xi_{1}\right)\right\} \\
& { }^{k} E\left(\xi_{1}\right)={ }^{k} e\left\{\left\|{ }^{k} \mathbf{g}_{w}\right\| \Phi_{w}\left(\xi_{1}\right)\right\}
\end{aligned}
$$

com $j$ e $w=1, \ldots,(g r+1)$ representando os nós do elemento.

O mapeamento descrito nas Equações (116), (117) e (118) gera uma cinemática cujas seções transversais permanecem planas apenas nas lâminas o que permite representar o efeito Zig-Zag peculiar aos compósitos laminados. O nível em que as seções das lâminas deixam de ser ortogonais à linha de referência (lr) está associado às tensões de cisalhamento envolvidas e ao módulo de elasticidade transversal do material de cada lâmina. Esse mapeamento corresponde a uma cinemática semelhante a das teorias Layerwise completas, pois, além do efeito Zig-Zag, a variação de espessura nas lâminas é considerada.

Definidas as funções de mapeamento posicional das configurações inicial e atual para o elemento laminado, prossegue-se para a descrição dos aspectos da formulação geral apresentada no Capítulo 3 que dependem dessas funções de mapeamento. 


\subsection{Particularidades do elemento finito de pórtico plano laminado}

No Capítulo 3, toda a sequência de operações matemáticas da formulação posicional aplicada a problemas bidimensionais foi desenvolvida e, no item anterior, descreveu-se a cinemática do elemento de pórtico plano laminado. Logo, para definir completamente a formulação do elemento finito, fica faltando apenas identificar os termos que dependem da função de mapeamento posicional empregada. Isso está apresentado nos itens seguintes.

\subsubsection{Gradiente das funções de mapeamento posicional}

No Item 3.3, a função mudança de configuração foi determinada a partir de uma composição entre as funções de mapeamento das configurações inicial e atual (Equação (11)). Como visto no item anterior, as funções de mapeamento são definidas para cada lâmina. Assim, tanto a função mudança de configuração $\mathbf{f}$ como seu gradiente $\mathbf{A}$ são definidos também para cada lâmina k. Isso é uma diferença importante em relação ao elemento de pórtico plano homogêneo, que apresentava $\mathbf{f}$ e $\mathbf{A}$ calculados para toda a barra.

Da mesma forma como as funções de mapeamento posicionais, os gradientes $\mathbf{A}^{0}\left(\xi_{1}, \xi_{2}\right)$ e $\mathbf{A}^{1}\left(\xi_{1}, \xi_{2}\right)$ são especificados em três grupos: para a Lâmina de Referência $(L R)$, para as lâminas abaixo de $L R$ e para as lâminas acima de $L R$. Os termos das matrizes que compõem esses gradientes são calculados observando a Equação (14) e as funções de mapeamento da configuração inicial (Equações (113), (114) e (115) e da configuração atual (Equações (116), (117) e (118)). Assim, os termos desses gradientes ficam expressos por:

a) Gradientes da lâmina k igual à Lâmina de Referência (LR):

$$
{ }^{k} \mathbf{A}^{0}\left(\xi_{1}, \xi_{2}\right)=\left[\begin{array}{l|l}
{\left[x_{j}^{1} \Phi_{j, 1}\left(\xi_{1}\right)\right]+\left[d_{j} \Phi_{j, 1}\left(\xi_{1}\right)\right]\left[{ }^{k} v_{w}^{1} \Phi_{w}\left(\xi_{1}\right)\right]} & { }^{k} e \\
+\left\{\left[d_{j} \Phi_{j}\left(\xi_{1}\right)\right]+\frac{{ }^{k} e}{2} \xi_{2}\right\}\left[{ }^{k} v_{w}^{1} \Phi_{w, 1}\left(\xi_{1}\right)\right] & \left.{ }^{1} \Phi_{w}\left(\xi_{1}\right)\right] \\
\hdashline\left[x_{j}^{2} \Phi_{j, 1}\left(\xi_{1}\right)\right]+\left[d_{j} \Phi_{j, 1}\left(\xi_{1}\right)\right]\left[{ }^{k} v_{w}^{2} \Phi_{w}\left(\xi_{1}\right)\right] & \\
+\left\{\left[d_{j} \Phi_{j}\left(\xi_{1}\right)\right]+\frac{{ }^{k} e}{2} \xi_{2}\right\}\left[{ }^{k} v_{w}^{2} \Phi_{w, 1}\left(\xi_{1}\right)\right] & \frac{{ }^{k} e}{2}\left[{ }^{k} v_{w}^{2} \Phi_{w}\left(\xi_{1}\right)\right]
\end{array}\right]
$$




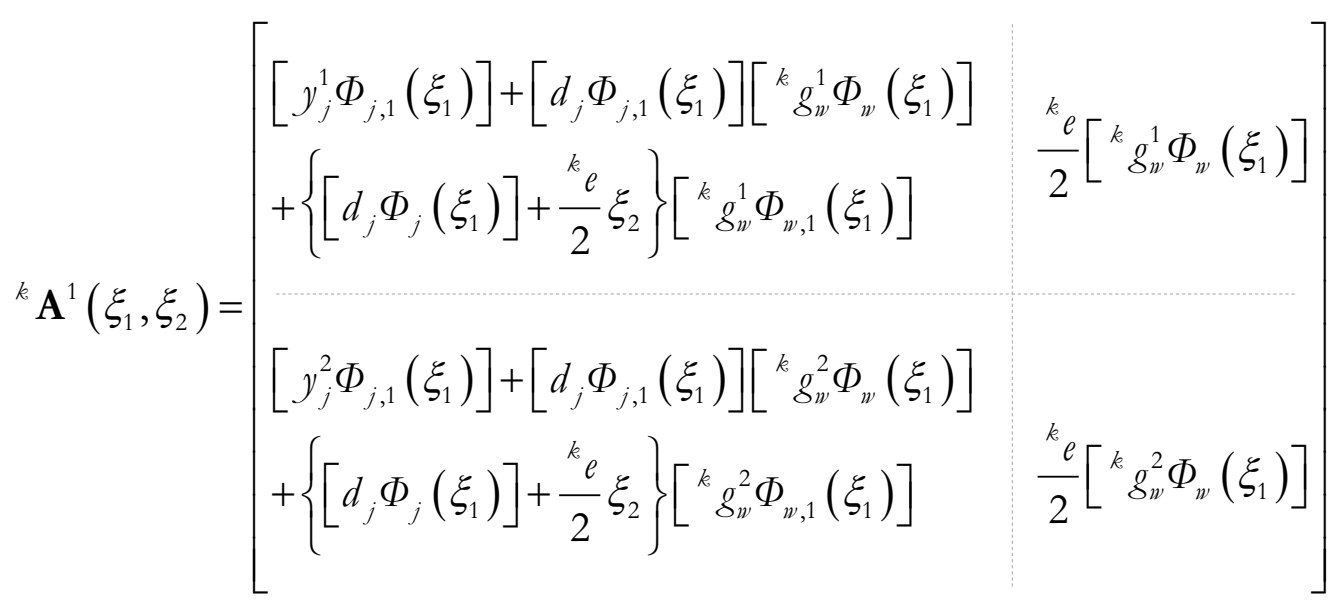

b) Gradientes das lâminas k abaixo da Lâmina de Referência (LR):

$$
\begin{aligned}
& { }^{k} \mathbf{A}^{0}\left(\xi_{1}, \xi_{2}\right)=\left[\begin{array}{l}
{\left[x_{j}^{1} \Phi_{j, 1}\left(\xi_{1}\right)\right]+\left[d_{j} \Phi_{j, 1}\left(\xi_{1}\right)\right]\left[{ }^{L R} v_{w}^{1} \Phi_{w}\left(\xi_{1}\right)\right]+\left\{\left[d_{j} \Phi_{j}\left(\xi_{1}\right)\right]-\frac{{ }^{L R} e}{2}\right\}} \\
\times\left[{ }^{L R} v_{w}^{1} \Phi_{w, 1}\left(\xi_{1}\right)\right]-\sum_{m=k+1}^{L R-1} m e\left[m v_{j}^{1} \Phi_{j, 1}\left(\xi_{1}\right)\right]+{ }^{k} e\left[{ }^{k} v_{j}^{1} \Phi_{j, 1}\left(\xi_{1}\right)\right] \frac{\xi_{2}-1}{2} \\
{\left[x_{j}^{2} \Phi_{j, 1}\left(\xi_{1}\right)\right]+\left[d_{j} \Phi_{j, 1}\left(\xi_{1}\right)\right]\left[{ }^{L R} v_{w}^{2} \Phi_{w}\left(\xi_{1}\right)\right]+\left\{\left[d_{j} \Phi_{j}\left(\xi_{1}\right)\right]-\frac{{ }^{L R} e}{2}\right\}} \\
\times\left[{ }^{L R} v_{w}^{2} \Phi_{w, 1}\left(\xi_{1}\right)\right]-\sum_{m=k+1}^{L R-1} m e\left[v_{j}^{2} \Phi_{j, 1}\left(\xi_{1}\right)\right]+{ }^{k} e\left[{ }^{k} v_{j}^{2} \Phi_{j, 1}\left(\xi_{1}\right)\right] \frac{\xi_{2}-1}{2}
\end{array}\right. \\
& \frac{{ }^{k} e}{2}\left[{ }^{k} v_{j}^{1} \Phi_{j}\left(\xi_{1}\right)\right] \\
& \left.\frac{{ }^{k} e}{2}\left[{ }^{k} v_{j}^{2} \Phi_{j}\left(\xi_{1}\right)\right]\right] \\
& {\left[\left[y_{j}^{1} \Phi_{j, 1}\left(\xi_{1}\right)\right]+\left[d_{j} \Phi_{j, 1}\left(\xi_{1}\right)\right]\left[{ }^{L R} g_{w}^{1} \Phi_{w}\left(\xi_{1}\right)\right]+\left\{\left[d_{j} \Phi_{j}\left(\xi_{1}\right)\right]-\frac{{ }^{L R}}{2}\right\}\right.} \\
& \times\left[{ }^{L R} g_{w}^{1} \Phi_{w, 1}\left(\xi_{1}\right)\right]-\sum_{m=k+1}^{L R-1} m e\left[{ }^{m} g_{j}^{1} \Phi_{j, 1}\left(\xi_{1}\right)\right]+{ }^{k} e\left[{ }^{k} g_{j}^{1} \Phi_{j, 1}\left(\xi_{1}\right)\right] \frac{\xi_{2}-1}{2} \\
& { }^{k} \mathbf{A}^{1}\left(\xi_{1}, \xi_{2}\right)= \\
& {\left[y_{j}^{2} \Phi_{j, 1}\left(\xi_{1}\right)\right]+\left[d_{j} \Phi_{j, 1}\left(\xi_{1}\right)\right]\left[{ }^{L R} g_{w}^{2} \Phi_{w}\left(\xi_{1}\right)\right]+\left\{\left[d_{j} \Phi_{j}\left(\xi_{1}\right)\right]-\frac{{ }^{L R} e}{2}\right\}} \\
& \times\left[{ }^{L R} g_{w}^{2} \Phi_{w, 1}\left(\xi_{1}\right)\right]-\sum_{m=k+1}^{L R-1} e^{m}\left[{ }^{m} g_{j}^{2} \Phi_{j, 1}\left(\xi_{1}\right)\right]+{ }^{k} e\left[{ }^{k} g_{j}^{2} \Phi_{j, 1}\left(\xi_{1}\right)\right] \frac{\xi_{2}-1}{2} \\
& \frac{{ }^{k} e}{2}\left[{ }^{k} g_{j}^{1} \Phi_{j}\left(\xi_{1}\right)\right] \\
& \left.\frac{{ }^{k} e}{2}\left[{ }^{k} g_{j}^{2} \Phi_{j}\left(\xi_{1}\right)\right]\right]
\end{aligned}
$$


c) Gradientes das lâminas k acima da Lâmina de Referência (LR):

$$
\begin{aligned}
& { }^{k} \mathbf{A}^{0}\left(\xi_{1}, \xi_{2}\right)=\left[\begin{array}{l}
{\left[x_{j}^{1} \Phi_{j, 1}\left(\xi_{1}\right)\right]+\left[d_{j} \Phi_{j, 1}\left(\xi_{1}\right)\right]\left[{ }^{L R} v_{w}^{1} \Phi_{w}\left(\xi_{1}\right)\right]+\left\{\left[d_{j} \Phi_{j}\left(\xi_{1}\right)\right]+\frac{{ }^{L R} e}{2}\right\}} \\
\times\left[{ }^{L R} v_{w}^{1} \Phi_{w, 1}\left(\xi_{1}\right)\right]+\sum_{m=L R+1}^{k-1} m e\left[m v_{j}^{1} \Phi_{j, 1}\left(\xi_{1}\right)\right]+{ }^{k} e\left[{ }^{k} v_{j}^{1} \Phi_{j, 1}\left(\xi_{1}\right)\right] \frac{\xi_{2}+1}{2} \\
{\left[x_{j}^{2} \Phi_{j, 1}\left(\xi_{1}\right)\right]+\left[d_{j} \Phi_{j, 1}\left(\xi_{1}\right)\right]\left[{ }^{L R} v_{w}^{2} \Phi_{w}\left(\xi_{1}\right)\right]+\left\{\left[d_{j} \Phi_{j}\left(\xi_{1}\right)\right]+\frac{{ }^{L R} e}{2}\right\}} \\
\times\left[{ }^{L R} v_{w}^{2} \Phi_{w, 1}\left(\xi_{1}\right)\right]+\sum_{m=L R+1}^{k-1} m e\left[v_{j}^{2} \Phi_{j, 1}\left(\xi_{1}\right)\right]+{ }^{k} e\left[{ }^{k} v_{j}^{2} \Phi_{j, 1}\left(\xi_{1}\right)\right] \frac{\xi_{2}+1}{2}
\end{array}\right. \\
& \frac{{ }^{k} e}{2}\left[{ }^{k} v_{j}^{1} \Phi_{j}\left(\xi_{1}\right)\right] \\
& \left.\frac{{ }^{k} e}{2}\left[{ }^{k} v_{j}^{2} \Phi_{j}\left(\xi_{1}\right)\right]\right] \\
& {\left[\left[y_{j}^{1} \Phi_{j, 1}\left(\xi_{1}\right)\right]+\left[d_{j} \Phi_{j, 1}\left(\xi_{1}\right)\right]\left[{ }^{L R} g_{w}^{1} \Phi_{w}\left(\xi_{1}\right)\right]+\left\{\left[d_{j} \Phi_{j}\left(\xi_{1}\right)\right]+\frac{{ }^{L R} e}{2}\right\}\right.} \\
& \times\left[{ }^{L R} g_{w}^{1} \Phi_{w, 1}\left(\xi_{1}\right)\right]+\sum_{m=L R+1}^{k-1} e^{m} e\left[{ }^{m} g_{j}^{1} \Phi_{j, 1}\left(\xi_{1}\right)\right]+{ }^{k} e\left[{ }^{k} g_{j}^{1} \Phi_{j, 1}\left(\xi_{1}\right)\right] \frac{\xi_{2}+1}{2} \\
& { }^{k} \mathbf{A}^{1}\left(\xi_{1}, \xi_{2}\right)= \\
& {\left[y_{j}^{2} \Phi_{j, 1}\left(\xi_{1}\right)\right]+\left[d_{j} \Phi_{j, 1}\left(\xi_{1}\right)\right]\left[{ }^{L R} g_{w}^{2} \Phi_{w}\left(\xi_{1}\right)\right]+\left\{\left[d_{j} \Phi_{j}\left(\xi_{1}\right)\right]+\frac{{ }^{L R} e}{2}\right\}} \\
& {\left[\times\left[{ }^{L R} g_{w}^{2} \Phi_{w, 1}\left(\xi_{1}\right)\right]+\sum_{m=L R+1}^{k-1}{ }^{m} e\left[{ }^{m} g_{j}^{2} \Phi_{j, 1}\left(\xi_{1}\right)\right]+{ }^{k} e\left[{ }^{k} g_{j}^{2} \Phi_{j, 1}\left(\xi_{1}\right)\right] \frac{\xi_{2}+1}{2}\right.} \\
& \left.\frac{{ }^{k} e}{2}\left[{ }^{k} g_{j}^{1} \Phi_{j}\left(\xi_{1}\right)\right]\right] \\
& \left.\frac{{ }^{k} e}{2}\left[{ }^{k} g_{j}^{2} \Phi_{j}\left(\xi_{1}\right)\right]\right]
\end{aligned}
$$

Nas Equações (120) a (125), $\Phi_{j, 1}\left(\xi_{1}\right)=\frac{\partial \Phi_{j}\left(\xi_{1}\right)}{\partial \xi_{1}}$ e $\Phi_{w, 1}\left(\xi_{1}\right)=\frac{\partial \Phi_{w}\left(\xi_{1}\right)}{\partial \xi_{1}}$.

Vale ressaltar, que apesar dos termos que compõem os gradientes ${ }^{k} \mathbf{A}^{0}\left(\xi_{1}, \xi_{2}\right)$ e ${ }^{k} \mathbf{A}^{1}\left(\xi_{1}, \xi_{2}\right)$ nas equações acima serem bastante extensos, as operações matemáticas que envolvem esses gradientes ficam facilitadas, pois são realizadas numericamente. Assim, não há necessidade de explicitar as equações que compõem o gradiente ${ }^{k} \mathbf{A}={ }^{k} \mathbf{A}^{1}\left(\xi_{1}, \xi_{2}\right) \cdot\left[{ }^{k} \mathbf{A}^{0}\left(\xi_{1}, \xi_{2}\right)\right]^{-1}$. 


\subsubsection{Energia potencial de deformação}

No Item 3.4, a lei constitutiva do material foi descrita. No caso do elemento laminado, essa lei é atribuída no nível das lâminas que podem ou não apresentar parâmetros elásticos distintos das demais. Dessa forma, a energia específica de deformação descrita na Equação (24) é agora aplicada para cada lâmina separadamente.

Com os gradientes ${ }^{k} \mathbf{A}^{0}\left(\xi_{1}, \xi_{2}\right)$ e ${ }^{k} \mathbf{A}^{1}\left(\xi_{1}, \xi_{2}\right)$ definidos para qualquer lâmina $k$ do laminado, a energia potencial de deformação da lâmina pode ser calculada conforme o procedimento descrito no Item 3.5. Partindo das Equações (24), (31) e (32), a energia potencial de deformação de uma lâmina $k$ pode ser escrita como:

$$
\begin{aligned}
& { }^{k} u_{e}=\frac{1}{2} \frac{{ }^{k} E}{1-\left({ }^{k} v\right)^{2}}\left[\left({ }^{k} E_{11}\right)^{2}+\left({ }^{k} E_{22}\right)^{2}+2\left({ }^{k} v\right)\left({ }^{k} E_{11}\right)\left({ }^{k} E_{22}\right)+\frac{1-{ }^{k} v}{2}\left({ }^{k} E_{12}+{ }^{k} E_{21}\right)^{2}\right] \\
& { }^{k} \mathrm{U}=\int_{{ }^{k} \mathrm{~V}_{0}}^{k} u_{e} d^{k} \mathrm{~V}_{0} \\
& { }^{k} \mathrm{U}={ }^{k} b \int_{-1}^{1} \int_{-1}^{1}{ }^{k} u_{e}\left(\xi_{1}, \xi_{2}\right)^{k} J\left(\xi_{1}, \xi_{2}\right) d \xi_{1} d \xi_{2},
\end{aligned}
$$

na qual a repetição do índice $k$ não implica em somatório. Essa integral é calculada numericamente com a quadratura de Gauss de forma análoga a Equação (33).

A energia calculada na Equação (127) se refere a uma única lâmina k. Como energia é uma grandeza escalar, a energia de deformação do elemento laminado pode ser obtida por meio de um simples somatório das energias de cada lâmina. Logo, tem-se que:

$$
\mathrm{U}^{\mathrm{elm}}=\sum_{k=1}^{\text {nlam }}{ }^{k} \mathrm{U}
$$

\subsubsection{Energia potencial relativa às ações externas}

$\mathrm{Na}$ parcela da energia potencial relativa às ações externas, são consideradas as contribuições de forças e momentos concentrados e de forças distribuídas. A energia associada a essa última ação é contabilizada a partir de forças nodais equivalentes.

A formulação do elemento de pórtico plano laminado foi desenvolvida de forma a permitir a aplicação de forças externas em qualquer posição do elemento, pois os problemas analisados abrangem desde laminados finos a espessos. Principalmente nos laminados espessos, é importante considerar a força na posição correta para que as distribuições de tensões obtidas 
sejam mais precisas e também para possibilitar uma melhor comparação com os resultados obtidos a partir de análises utilizando elementos finitos bidimensionais.

Essa é uma característica interessante e que constitui uma contribuição do elemento finito proposto. Apesar de ser um elemento de pórtico plano, a formulação apresenta uma flexibilidade na aplicação de carregamentos semelhante a dos elementos finitos bidimensionais.

As ações externas são consideradas conservativas e a relação entre força e posição é energeticamente conjugada. Assim, uma energia potencial externa pode ser calculada pelo negativo do produto escalar entre o vetor força externa e o vetor posição atual do ponto de aplicação dessa força (Equação (40)).

As forças concentradas são consideradas aplicadas em qualquer ponto ao longo de uma seção nodal. Como o mapeamento das posições varia se a lâmina corresponde à Lâmina de Referência $(L R)$ ou se está abaixo ou acima desta, a energia potencial associada fica dependendo de qual lâmina a força está sendo aplicada. Além disso, como a força pode ser aplicada em uma posição não coincidente com o nó localizado na linha de referência (lr r), surgem conjugados energéticos equivalentes e associados às componentes dos vetores generalizados das lâminas.

Considerando as funções de mapeamento posicional da configuração atual apresentadas nas Equações (116), (117) e (118) e substituindo $\Phi_{n}\left(\xi_{1}=\xi_{1 n}\right)=1$ para a função de forma associada ao nó $n$ cuja seção contém a força aplicada e zero nas demais funções de forma, a energia potencial relativa a uma força concentrada pode ser calculada com as seguintes expressões:

a) Força aplicada na lâmina k igual à Lâmina de Referência (LR):

$\Omega=-\mathbf{P}_{n} \cdot{ }^{k} \mathbf{y}\left(\xi_{1 n}, \xi_{2 n}\right)$

$\Omega=-P_{n}^{i} y_{n}^{i}-\left[P_{n}^{i}\left(d_{n}+\frac{{ }^{k} e}{2} \xi_{2 n}\right)\right]{ }^{k} g_{n}^{i}$

$\Omega=-P_{n}^{i} y_{n}^{i}-{ }^{k} M_{n}^{i k} g_{n}^{i}$

com $i=1,2$.

b) Força aplicada em uma lâmina k abaixo da Lâmina de Referência (LR): 
$\Omega=-\mathbf{P}_{n} \cdot{ }^{k} \mathbf{y}\left(\xi_{1 n}, \xi_{2 n}\right)$

$\Omega=-P_{n}^{i} y_{n}^{i}-\left[P_{n}^{i}\left(d_{n}-\frac{L R}{2}\right)\right] L R g_{n}^{i}-\sum_{m=k+1}^{L R-1}\left[\left(-P_{n}^{i} m^{m} e\right)^{m} g_{n}^{i}\right]-\left[P_{n}^{i}\left(k_{e} \frac{\xi_{2 n}-1}{2}\right)\right]{ }^{k} g_{n}^{i}$

$\Omega=-P_{n}^{i} y_{n}^{i}-{ }^{L R} M_{n}^{i}{ }^{L R} g_{n}^{i}-\sum_{m=k+1}^{L R-1}\left({ }^{m} M_{n}^{i} m g_{n}^{i}\right)-{ }^{k} M_{n}^{i k} g_{n}^{i}$

$\operatorname{com} i=1,2$.

c) Força aplicada em uma lâmina k acima da Lâmina de Referência (LR):

$\Omega=-\mathbf{P}_{n} \cdot{ }^{k} \mathbf{y}\left(\xi_{1 n}, \xi_{2 n}\right)$

$\Omega=-P_{n}^{i} y_{n}^{i}-\left[P_{n}^{i}\left(d_{n}+\frac{{ }^{L R} e}{2}\right)\right]{ }^{L R} g_{n}^{i}-\sum_{m=L R+1}^{k-1}\left[\left(P_{n}^{i \prime \prime} e\right)^{m} g_{n}^{i}\right]-\left[P_{n}^{i}\left({ }^{k} e \frac{\xi_{2 n}+1}{2}\right)\right]{ }^{k} g_{n}^{i}$

$\Omega=-P_{n}^{i} y_{n}^{i}-{ }^{L R} M_{n}^{i L R} g_{n}^{i}-\sum_{m=L R+1}^{k-1}\left({ }^{m} M_{n}^{i m} g_{n}^{i}\right)-{ }^{k} M_{n}^{i k} g_{n}^{i}$

$\operatorname{com} i=1,2$.

Nessas expressões, a repetição dos índices $k$ e $n$ não implica em somatório. Os termos escritos com a letra $M$ são os conjugados energéticos associados aos vetores generalizados das lâminas da seção nodal $n$ que contém a força concentrada e $\xi_{2 n}$ é a coordenada adimensional correspondente à posição na espessura da lâmina k na qual a força está aplicada.

O procedimento para consideração de forças distribuídas é semelhante ao apresentado para o elemento de pórtico plano homogêneo (Item 4.3.3). Entretanto, no elemento laminado, a força distribuída pode estar aplicada em qualquer posição e não somente na linha de referência (lr ). Assim, a energia potencial associada pode ser calculada conforme a Equação (74), mas com a consideração do mapeamento das posições da força distribuída em uma determinada lâmina k. O ponto de aplicação da força em relação à espessura da lâmina é identificado através do cálculo da coordenada adimensional $\xi_{2}=\xi_{2 q}$.

A expressão para cálculo da energia potencial fica escrita como:

$\Omega=-\int_{-1}^{1}{ }^{k} q^{i}\left(\xi_{1}\right){ }^{k} y^{i}\left(\xi_{1}, \xi_{2 q}\right)^{k} J\left(\xi_{1}\right) d \xi_{1}, \operatorname{com} i=1,2$,

na qual ${ }^{k} q^{i}\left(\xi_{1}\right)$ é a força distribuída, representada por uma interpolação polinomial conforme a

Equação (73), ${ }^{k} y^{i}\left(\xi_{1}, \xi_{2 q}\right)$ é o mapeamento das posições atuais da força distribuída na lâmina $k$ 
$\mathrm{e}^{k} J\left(\xi_{1}\right)$ é o Jacobiano da transformação do espaço adimensional para a linha de mapeamento dessas posições na configuração inicial, calculado conforme a Equação (68). A repetição do índice $k$ não implica em somatório.

Ao aplicar a força distribuída em uma posição fora da linha de referência (lr), além das forças nodais equivalentes, surgem conjugados energéticos equivalentes associados às componentes dos vetores generalizados das lâminas influenciadas pela força e em todas as seções nodais. Da mesma forma como no caso de forças concentradas, é necessário considerar as possibilidades de a força distribuída estar aplicada na Lâmina de Referência (LR) e abaixo ou acima desta. Para cada uma dessas três situações, devem ser empregadas as correspondentes funções de mapeamento posicional da configuração atual (Equações (116), (117) e (118)) e de mapeamento posicional da configuração inicial (Equações (113), (114) e (115). Estas últimas são necessárias para a determinação do Jacobiano ${ }^{k} J\left(\xi_{1}\right)$.

Para isso, basta definir as componentes do vetor tangente à linha de aplicação da força distribuída na configuração inicial, conforme pode ser observado na Equação (68). Essas componentes são obtidas com a derivada da posição inicial em relação à coordenada adimensional $\xi_{1}$ :

$$
{ }^{k} t^{i}\left(\xi_{1}\right)=\frac{d^{k} x^{i}\left(\xi_{1}, \xi_{2 q}\right)}{d \xi_{1}}, \operatorname{com} i=1,2
$$

sendo ${ }^{k} t^{i}\left(\xi_{1}\right)$ a componente na direção $i$ do vetor tangente à linha de aplicação da força distribuída localizada na lâmina $k \mathrm{e}^{k} x^{i}\left(\xi_{1}, \xi_{2 q}\right)$ é a função de mapeamento dessa linha na configuração inicial.

Portanto, as expressões para a determinação da energia potencial relativa à força distribuída aplicada em uma lâmina k do elemento, bem como das derivadas da Equação (133), são definidas por:

a) Para lâmina k igual à Lâmina de Referência $(L R)$ :

$$
\begin{aligned}
\frac{d^{k} x^{i}\left(\xi_{1}, \xi_{2 q}\right)}{d \xi_{1}} & =\left[x_{j}^{i} \Phi_{j, 1}\left(\xi_{1}\right)\right]+\left[d_{j} \Phi_{j, 1}\left(\xi_{1}\right)\right]\left[{ }^{k} v_{w}^{i} \Phi_{w}\left(\xi_{1}\right)\right] \\
& +\left\{\left[d_{j} \Phi_{j}\left(\xi_{1}\right)\right]+\frac{{ }^{k} e}{2} \xi_{2 q}\right\}\left[{ }^{k} v_{w}^{i} \Phi_{w, 1}\left(\xi_{1}\right)\right]
\end{aligned}
$$




$$
\begin{aligned}
\Omega= & -\left\{\int_{-1}^{1}\left[{ }^{k} q_{w}^{i} \Phi_{w}\left(\xi_{1}\right)\right] \Phi_{j}\left(\xi_{1}\right)^{k} J\left(\xi_{1}\right) d \xi_{1}\right\} y_{j}^{i} \\
& -\left\{\int_{-1}^{1}\left[{ }^{k} q_{j}^{i} \Phi_{j}\left(\xi_{1}\right)\right]\left\{\left[d_{z} \Phi_{z}\left(\xi_{1}\right)\right]+\frac{{ }^{k} e}{2} \xi_{2 q}\right\} \Phi_{w}\left(\xi_{1}\right)^{k} J\left(\xi_{1}\right) d \xi_{1}\right\}{ }^{k} g_{w}^{i} \\
\Omega= & -Q_{j}^{i} y_{j}^{i}-{ }^{k} M_{w}^{i k} g_{w}^{i} \\
\operatorname{com} & i=1,2 \mathrm{e} j, w, z=1, \ldots,(g r+1) .
\end{aligned}
$$

b) Para lâminas k abaixo da Lâmina de Referência (LR):

$$
\begin{aligned}
\frac{d^{k} x^{i}\left(\xi_{1}, \xi_{2 q}\right)}{d \xi_{1}}= & {\left[x_{j}^{i} \Phi_{j, 1}\left(\xi_{1}\right)\right]+\left[d_{j} \Phi_{j, 1}\left(\xi_{1}\right)\right]\left[{ }^{L R} v_{w}^{i} \Phi_{w}\left(\xi_{1}\right)\right]+\left\{\left[d_{j} \Phi_{j}\left(\xi_{1}\right)\right]-\frac{{ }^{L R} e}{2}\right\} } \\
& \times\left[{ }^{L R} v_{w}^{i} \Phi_{w, 1}\left(\xi_{1}\right)\right]-\sum_{m=k+1}^{L R-1}{ }^{m} e\left[{ }^{m} v_{j}^{i} \Phi_{j, 1}\left(\xi_{1}\right)\right]+{ }^{k} e\left[{ }^{k} v_{j}^{i} \Phi_{j, 1}\left(\xi_{1}\right)\right] \frac{\xi_{2 q}-1}{2} \\
\Omega= & -\left\{\int_{-1}^{1}\left[{ }^{k} q_{w}^{i} \Phi_{w}\left(\xi_{1}\right)\right] \Phi_{j}\left(\xi_{1}\right)^{k} J\left(\xi_{1}\right) d \xi_{1}\right\} y_{j}^{i} \\
& -\left\{\int_{-1}^{1}\left[{ }^{k} q_{j}^{i} \Phi_{j}\left(\xi_{1}\right)\right]\left\{\left[d_{z} \Phi_{z}\left(\xi_{1}\right)\right]-\frac{{ }^{L R} e}{2}\right\} \Phi_{w}\left(\xi_{1}\right)^{k} J\left(\xi_{1}\right) d \xi_{1}\right\}{ }^{L R} g_{w}^{i} \\
& -\sum_{m=k+1}^{L R-1}\left\{-\left\{\int_{-1}^{1}\left[{ }^{k} q_{w}^{i} \Phi_{w}\left(\xi_{1}\right)\right]{ }^{m} e \Phi_{j}\left(\xi_{1}\right)^{k} J\left(\xi_{1}\right) d \xi_{1}\right\}{ }^{m} g_{j}^{i}\right\} \\
& -\left\{\int_{-1}^{1}\left[{ }^{k} q_{w}^{i} \Phi_{w}\left(\xi_{1}\right)\right]^{k} e \Phi_{j}\left(\xi_{1}\right) \frac{\xi_{2 q}-1}{2}{ }^{k} J\left(\xi_{1}\right) d \xi_{1}\right\}^{k} g_{j}^{i} \\
\Omega=- & Q_{j}^{i} y_{j}^{i}-{ }^{L R} M_{w}^{i}{ }^{L R} g_{w}^{i}-\sum_{m=k+1}^{L R-1}\left({ }^{m} M_{j}^{i m} g_{j}^{i}\right)-{ }^{k} M_{j}^{i k} g_{j}^{i} \\
\operatorname{com} & i=1,2 \mathrm{e} j, w, z=1, \ldots,(g r+1) .
\end{aligned}
$$

c) Para lâminas k acima da Lâmina de Referência (LR):

$$
\begin{aligned}
\frac{d^{k} x^{i}\left(\xi_{1}, \xi_{2 q}\right)}{d \xi_{1}} & =\left[x_{j}^{i} \Phi_{j, 1}\left(\xi_{1}\right)\right]+\left[d_{j} \Phi_{j, 1}\left(\xi_{1}\right)\right]\left[{ }^{L R} v_{w}^{i} \Phi_{w}\left(\xi_{1}\right)\right]+\left\{\left[d_{j} \Phi_{j}\left(\xi_{1}\right)\right]+\frac{{ }^{L R} e}{2}\right\} \\
& \times\left[{ }^{L R} v_{w}^{i} \Phi_{w, 1}\left(\xi_{1}\right)\right]+\sum_{m=L R+1}^{k-1} m e\left[v^{m} v_{j, 1}^{i}\left(\xi_{1}\right)\right]+{ }^{k} e\left[{ }^{k} v_{j}^{i} \Phi_{j, 1}\left(\xi_{1}\right)\right] \frac{\xi_{2 q}+1}{2}
\end{aligned}
$$




$$
\begin{aligned}
\Omega= & -\left\{\int_{-1}^{1}\left[{ }^{k} q_{w}^{i} \Phi_{w}\left(\xi_{1}\right)\right] \Phi_{j}\left(\xi_{1}\right)^{k} J\left(\xi_{1}\right) d \xi_{1}\right\} y_{j}^{i} \\
& -\left\{\int_{-1}^{1}\left[{ }^{k} q_{j}^{i} \Phi_{j}\left(\xi_{1}\right)\right]\left\{\left[d_{z} \Phi_{z}\left(\xi_{1}\right)\right]+\frac{{ }^{L R} e}{2}\right\} \Phi_{w}\left(\xi_{1}\right)^{k} J\left(\xi_{1}\right) d \xi_{1}\right\}{ }^{L R} g_{w}^{i} \\
& -\sum_{m=L R+1}^{k-1}\left\{\left\{\int_{-1}^{1}\left[{ }^{k} q_{w}^{i} \Phi_{w}\left(\xi_{1}\right)\right]^{m} e \Phi_{j}\left(\xi_{1}\right)^{k} J\left(\xi_{1}\right) d \xi_{1}\right\}^{m} g_{j}^{i}\right\} \\
& -\left\{\int_{-1}^{1}\left[{ }^{k} q_{w}^{i} \Phi_{w}\left(\xi_{1}\right)\right]^{k} e \Phi_{j}\left(\xi_{1}\right) \frac{\xi_{2 q}+1}{2}{ }^{k} J\left(\xi_{1}\right) d \xi_{1}\right\}^{k} g_{j}^{i} \\
\Omega=- & Q_{j}^{i} y_{j}^{i}-{ }^{L R} M_{w}^{i} L R g_{w}^{i}-\sum_{m=L R+1}^{k-1}\left({ }^{m} M_{j}^{i m} g_{j}^{i}\right)-{ }^{k} M_{j}^{i k} g_{j}^{i} \\
\operatorname{com} i & =1,2 \mathrm{e} j, w, z=1, \ldots,(g r+1) .
\end{aligned}
$$

Nessas expressões, a repetição do índice $k$ não implica em somatório. Os termos escritos com as letras $Q$ e $M$ representam as forças nodais equivalentes e os conjugados energéticos equivalentes associados aos vetores generalizados das lâminas, respectivamente. Todas as integrais acima são calculadas numericamente através da quadratura de Gauss.

Diante de tudo isso, pode-se determinar a energia potencial externa do elemento finito laminado sujeito à ação de forças concentradas e distribuídas aplicadas em uma posição qualquer do elemento como a soma das parcelas definidas nas Equações (129), (130) e (131) para forças concentradas e definidas nas Equações (134), (135) e (136) para forças distribuídas. Uma forma resumida para representar a energia potencial relativa às ações externas é a seguinte:

$$
\Omega=-\left(P_{j}^{i}+Q_{j}^{i}\right) y_{j}^{i}-{ }^{m} M_{j}^{i m} g_{j}^{i}
$$

na qual $i=1$ e $2, j=1, \ldots,(g r+1)$ e $m=1, \ldots, n l a m . P_{j}^{i}$ e $Q_{j}^{i}$ representam as forças concentradas e as forças nodais equivalentes, respectivamente, com componentes nas direções $i$ aplicadas no nó $j$ localizado na linha de referência. O termo ${ }^{m} M_{j}^{i}$ representa os conjugados energéticos associados aos vetores generalizados das lâminas $m$.

Como podem ser observadas, todas as ações externas são conservativas, pois são independentes da configuração atual representada na Equação (137) pelas posições nodais $y_{j}^{i}$ e pelos vetores generalizados ${ }^{m} g_{j}^{i}$.

Além dessas ações externas, também é possível considerar a ação de momentos concentrados $\left(M_{n}\right)$ aplicados em uma determinada seção nodal $n$. Como a seção transversal é 
laminada, a parcela de momento atribuída a cada uma das lâminas $k\left({ }^{k} M_{n}\right)$ é definida pelo produto do momento concentrado por um fator igual a razão entre a espessura da lâmina $\left({ }^{k} e\right)$ e a espessura total do laminado $\left(h_{0}\right)$. Assim, tem-se que:

$$
{ }^{k} M_{n}=M_{n} \frac{{ }^{k} e}{b_{0}} .
$$

Feito isso, a consideração do efeito dos momentos concentrados em cada lâmina é inteiramente análoga ao procedimento apresentado para o elemento finito homogêneo (Item 4.3.3). Dessa forma, os conjugados energéticos definidos na Equação (82) passam a ser escritos como:

$$
\begin{aligned}
& { }^{k} B_{n}^{1}=-\frac{{ }^{(k)} e}{b_{0}} \frac{M_{(n)}}{{ }^{(k)} g_{(n)}^{i}{ }^{(k)} g_{(n)}^{i}}{ }^{k} g_{n}^{2} \text { conjugado de }{ }^{k} g_{n}^{1}, \\
& { }^{k} B_{n}^{2}=\frac{{ }^{(k)} e}{h_{0}} \frac{M_{(n)}}{{ }^{(k)} g_{(n)}^{i}{ }^{(k)} g_{(n)}^{i}}{ }^{k} g_{n}^{1} \text { conjugado de }{ }^{k} g_{n}^{2} .
\end{aligned}
$$

com $i=1$ e 2 e $k=1, \ldots$, nlam. O índice $n$ se refere à seção nodal na qual o momento está sendo aplicado.

Esses conjugados energéticos não são conservativos como os definidos para as forças concentradas e distribuídas, pois dependem dos valores assumidos por ${ }^{k} g_{n}^{1} \mathrm{e}^{k} g_{n}^{2}$. Portanto, para satisfazer o equilíbrio com a presença do momento, os conjugados energéticos ${ }^{k} B_{n}^{1}$ e ${ }^{k} B_{n}^{2}$ são considerados apenas na equação de equilíbrio, sendo atualizados a cada iteração durante o processo de solução.

\subsubsection{Energia potencial total e equações de equilíbrio}

Conforme foi definida na Equação (43), a energia potencial total do elemento finito é composta pelas parcelas da energia de deformação mais o potencial das ações externas atuantes. Em um modelo discreto, vários elementos finitos são empregados para analisar a estrutura e a energia potencial total é dada pela soma das contribuições de cada elemento individualmente.

A representação empregada para considerar a contribuição de vários elementos nos diversos vetores de posição e forças é análoga àquela apresentada para o elemento finito homogêneo. A mudança está relacionada apenas à quantidade de graus de liberdade. Dessa forma, a sequência do texto é bastante semelhante à apresentada no Item 4.3.4 referente ao elemento homogêneo. 
A contribuição de vários elementos finitos na energia potencial total pode ser feita assumindo a seguinte associação para identificar os graus de liberdade:

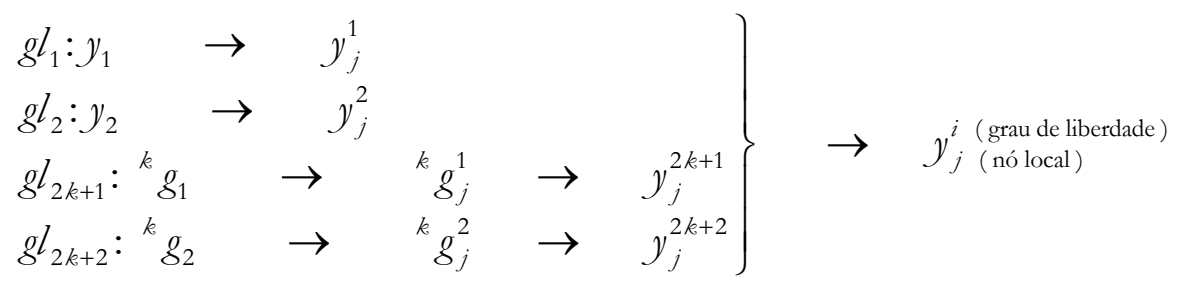

sendo $j=1, \ldots,($ grau +1$)$ o número do nó local, $k=1, \ldots$, nlam o número da lâmina, $i=1, \ldots, 2($ nlam +1$)$ o grau de liberdade nodal. A interpretação dada para $i$ é a seguinte: 1 e 2 se referem às posições do nó localizado na linha de referência, $2 k+1$ e $2 k+2$ se referem às componentes dos vetores generalizados ${ }^{k} g_{1}\left({ }^{k} g_{j}^{1}\right)$ e ${ }^{k} g_{2}\left({ }^{k} g_{j}^{2}\right)$ de cada lâmina, respectivamente. Essa mesma regra é empregada também para o vetor de posições na configuração inicial $x_{j}^{i}$.

Utilizando essa identificação, um vetor posição local $y_{k}^{i}$ do elemento finito contendo todos os graus de liberdade pode ser definido. A localização de um dado grau de liberdade nesse vetor posição é determinada com auxílio do número do nó local $j$ e do próprio grau de liberdade nodal $i$. A regra para localização no vetor é dada por:

$$
y_{j(\text { nó local })}^{i(\text { grau de liberdade })} \rightarrow 2(\text { nlam }+1)(j-1)+i
$$

Uma identificação análoga à Equação (140) também é empregada para definir o vetor de forças internas $F_{\text {int } j}{ }^{i}$ e o vetor de forças externas $F_{\text {ext } j}{ }^{i}$ do elemento. Nesses vetores, a interpretação dada para $i$ é a seguinte: 1 e 2 se referem às componentes de forças nodais atuantes nas direções globais 1 e 2 , respectivamente, e os termos com $i$ igual a $2 k+1$ e $2 k+2$ são conjugados energéticos das componentes dos vetores generalizados ${ }^{k} g_{1}\left({ }^{k} g_{j}^{1}\right)$ e ${ }^{k} g_{2}\left({ }^{k} g_{j}^{2}\right)$ de cada lâmina, respectivamente.

Nos modelos discretos, há muitos elementos finitos e um mesmo nó pode pertencer a vários elementos. Assim, definem-se vetores posição $y_{j}^{i}$, força interna $F_{\text {int } j}^{i}$ e força externa $F_{\text {ext } j}^{i}$ globais. Esses vetores recebem contribuição de todos os elementos utilizados na discretização da estrutura. Para a montagem desses vetores globais, a mesma regra de identificação apresentada nas Equações (140) e (141) é empregada, mas a numeração do nó $j$ deixa de ser local e passa a ser a numeração global atribuída durante a geração da malha. A relação passa a ser: 
$y_{j}^{i}$ (nó gó dobal) $^{\text {(iberdade) }} \rightarrow 2($ nlam +1$)(j-1)+i \operatorname{com} j=1, \ldots, N$

sendo $N$ o número de nós da discretização.

Assumindo a relação da Equação (142), a soma das contribuições de cada elemento finito na função de energia potencial total da estrutura pode ser realizada. Considerando a parcela de energia de deformação (Equações (127) e (128)) e de energia das ações externas (Equação (137)) adaptada à relação da Equação (142), pode-se reescrever a Equação (44) como:

$$
\Pi\left(y_{j}^{i}\right)=U\left(y_{j}^{i}\right)-\left(P_{j}^{i}+Q_{j}^{i}+M_{j}^{i}\right) y_{j}^{i}
$$

na qual $\Pi\left(y_{j}^{i}\right)$ representa a função de energia potencial total cuja determinação depende apenas do vetor posição atual $y_{j}^{i}$ que contém os graus de liberdade nodais de todos os elementos finitos utilizados na discretização. A determinação de $y_{j}^{i}$ é feita a partir da solução do sistema de equações não lineares definido na Equação (47) que tem o significado físico de equilíbrio nodal. Os termos $P_{j}^{i}$ e $Q_{j}^{i}$ representam as forças concentradas e as forças nodais equivalentes, respectivamente. Essas forças são diferentes de zero apenas para os graus de liberdade $i$ igual a 1 e 2. O termo $M_{j}^{i}$ representa os conjugados energéticos associados aos vetores generalizados das lâminas, oriundos da aplicação de forças concentradas e distribuídas fora da linha de referência (lir). O termo $M_{j}^{i}$ é não nulo apenas para os graus de liberdade $i$ diferente de 1 e 2 .

$\mathrm{Na}$ Equação (143), não há os conjugados energéticos gerados pela ação de momentos concentrados, pois não são conservativos. O efeito desses momentos é considerado somente na equação de equilíbrio por meio da contribuição do conjugado energético calculado com a Equação (139).

As equações de equilíbrio foram obtidas com base no princípio da energia potencial total estacionária e estão definidas na Equação (47). Considerando a função de energia potencial total do elemento finito de pórtico plano laminado, determinada na Equação (143), e os conjugados energéticos da Equação (139) devido ao efeito de momentos concentrados, as equações de equilíbrio podem ser escritas como:

$$
F_{\text {int } \alpha}^{\beta}\left(y_{j}^{i}\right)-\left[P_{\alpha}^{\beta}+Q_{\alpha}^{\beta}+M_{\alpha}^{\beta}+B_{\alpha}^{\beta}\left(y_{j}^{i}\right)\right]=0
$$

Nessa equação, o vetor de forças internas é calculado conforme definido na Equação (48), mas, como a energia de deformação no elemento de pórtico plano laminado é 
definida para cada lâmina (Equação (127)), a Equação (48) se transforma em um somatório de integrais. Logo, tem-se:

$$
F_{\text {int } \alpha}^{\beta}\left(y_{j}^{i}\right)=\sum_{k=1}^{n \operatorname{lam}}\left[{ }^{k} b \int_{-1}^{1} \int_{-1}^{1} \frac{\partial^{k} u_{e}\left(\xi_{1}, \xi_{2}\right)}{\partial y_{\alpha}^{\beta}}{ }^{k} J\left(\xi_{1}, \xi_{2}\right) d \xi_{1} d \xi_{2}\right]
$$

que é calculada utilizando quadratura de Gauss, ficando, então:

$$
F_{\text {int } \alpha}^{\beta}\left(y_{k}^{i}\right)=\sum_{k=1}^{\text {nlam }}\left[{ }^{k} b \frac{\partial^{k} u_{e}\left(\xi_{1 i g}, \xi_{2 j g}\right)}{\partial y_{\alpha}^{\beta}}{ }^{k} J\left(\xi_{1 i g}, \xi_{2 j g}\right) w_{(i g)} w_{(j g)}\right] \text {. }
$$

$\mathrm{Na}$ ocasião da definição do vetor de forças internas no Item 3.7, ficou pendente a descrição dos termos que compõem $\left(\frac{\partial \mathbf{A}^{1}}{\partial y_{\alpha}^{\beta}} \rightarrow \frac{\partial^{k} \mathbf{A}^{1}}{\partial y_{\alpha}^{\beta}}\right)$ na Equação (53), pois dependem da função de mapeamento posicional adotada. No caso do elemento laminado, o gradiente ${ }^{k} \mathbf{A}^{1}\left(\xi_{1}, \xi_{2}\right)$ varia se a lâmina é a Lâmina de Referência ou se é uma lâmina abaixo ou acima desta, conforme foi definido nas Equações (122), (124) e (126). Considerando a notação apresentada na Equação (140), a derivada do gradiente $\frac{\partial^{k} \mathbf{A}^{1}}{\partial y_{\alpha}^{\beta}}$ fica representada por matrizes cujos termos dependem tanto da lâmina considerada como do grau de liberdade ao qual a derivada está sendo avaliada. Assim, um conjunto de possibilidades para $\frac{\partial^{k} \mathbf{A}^{1}}{\partial y_{\alpha}^{\beta}}$ são identificadas conforme pode ser observado nas equações a seguir:

a) Lâmina k igual à Lâmina de Referência (LR):

- Para $\beta=1$ e 2 :

$$
\frac{\partial^{k} \mathbf{A}^{1}\left(\xi_{1}, \xi_{2}\right)}{\partial y_{\alpha}^{1}}=\left[\begin{array}{cc}
\Phi_{\alpha, 1}\left(\xi_{1}\right) & 0 \\
0 & 0
\end{array}\right] \quad \frac{\partial^{k} \mathbf{A}^{1}\left(\xi_{1}, \xi_{2}\right)}{\partial y_{\alpha}^{2}}=\left[\begin{array}{cc}
0 & 0 \\
\Phi_{\alpha, 1}\left(\xi_{1}\right) & 0
\end{array}\right],
$$

- Para $\beta=2 k+1$ e $2 k+2$, com $k=L R$ :

$$
\begin{gathered}
\frac{\partial^{k} \mathbf{A}^{1}\left(\xi_{1}, \xi_{2}\right)}{\partial y_{\alpha}^{2 k+1}}=\left[\begin{array}{cc}
{\left[d_{j} \Phi_{j, 1}\left(\xi_{1}\right)\right] \Phi_{\alpha}\left(\xi_{1}\right)+\left\{\left[d_{j} \Phi_{j}\left(\xi_{1}\right)\right]+\frac{{ }^{k} e}{2} \xi_{2}\right\} \Phi_{\alpha, 1}\left(\xi_{1}\right)} & \frac{{ }^{k} e}{2} \Phi_{\alpha}\left(\xi_{1}\right) \\
0 & 0
\end{array}\right] \\
\frac{\partial^{k} \mathbf{A}^{1}\left(\xi_{1}, \xi_{2}\right)}{\partial y_{\alpha}^{2 k+2}}=\left[\begin{array}{cc}
0 & 0 \\
{\left[d_{j} \Phi_{j, 1}\left(\xi_{1}\right)\right] \Phi_{\alpha}\left(\xi_{1}\right)+\left\{\left[d_{j} \Phi_{j}\left(\xi_{1}\right)\right]+\frac{{ }^{k} e}{2} \xi_{2}\right\} \Phi_{\alpha, 1}\left(\xi_{1}\right)} & \frac{{ }^{k} e}{2} \Phi_{\alpha}\left(\xi_{1}\right)
\end{array}\right],
\end{gathered}
$$


- Para os demais graus de liberdade $(\beta \neq 1,2$ e $\beta \neq 2 L R+1,2 L R+2)$ :

$$
\frac{\partial^{k} \mathbf{A}^{1}\left(\xi_{1}, \xi_{2}\right)}{\partial y_{\alpha}^{\beta}}=\left[\begin{array}{ll}
0 & 0 \\
0 & 0
\end{array}\right] \text {. }
$$

b) Lâminas k abaixo da Lâmina de Referência (LR):

- Para $\beta=1 \mathrm{e} 2$ :

$$
\frac{\partial^{k} \mathbf{A}^{1}\left(\xi_{1}, \xi_{2}\right)}{\partial y_{\alpha}^{1}}=\left[\begin{array}{cc}
\Phi_{\alpha, 1}\left(\xi_{1}\right) & 0 \\
0 & 0
\end{array}\right] \quad \frac{\partial^{k} \mathbf{A}^{1}\left(\xi_{1}, \xi_{2}\right)}{\partial y_{\alpha}^{2}}=\left[\begin{array}{cc}
0 & 0 \\
\Phi_{\alpha, 1}\left(\xi_{1}\right) & 0
\end{array}\right]
$$

- Para $\beta=2 L R+1$ e $2 L R+2$,

$$
\begin{gathered}
\frac{\partial^{k} \mathbf{A}^{1}\left(\xi_{1}, \xi_{2}\right)}{\partial y_{\alpha}^{2 L R+1}}=\left[\begin{array}{cc}
{\left[d_{j} \Phi_{j, 1}\left(\xi_{1}\right)\right] \Phi_{\alpha}\left(\xi_{1}\right)+\left\{\left[d_{j} \Phi_{j}\left(\xi_{1}\right)\right]-\frac{{ }^{L R} e}{2}\right\} \Phi_{\alpha, 1}\left(\xi_{1}\right)} & 0 \\
0 & 0
\end{array}\right] \\
\frac{\partial^{k} \mathbf{A}^{1}\left(\xi_{1}, \xi_{2}\right)}{\partial y_{\alpha}^{2 L R+2}}=\left[\begin{array}{cc}
0 & 0 \\
{\left[d_{j} \Phi_{j, 1}\left(\xi_{1}\right)\right] \Phi_{\alpha}\left(\xi_{1}\right)+\left\{\left[d_{j} \Phi_{j}\left(\xi_{1}\right)\right]-\frac{{ }^{L R} e}{2}\right\} \Phi_{\alpha, 1}\left(\xi_{1}\right)} & 0
\end{array}\right],
\end{gathered}
$$

- Para $2(k+1)+1 \leq \beta \leq 2(L R-1)+2$ :

$$
\frac{\partial^{k} \mathbf{A}^{1}\left(\xi_{1}, \xi_{2}\right)}{\partial y_{\alpha}^{2 m+1}}=\left[\begin{array}{cc}
-{ }^{m} e \Phi_{\alpha, 1}\left(\xi_{1}\right) & 0 \\
0 & 0
\end{array}\right] \quad \frac{\partial^{k} \mathbf{A}^{1}\left(\xi_{1}, \xi_{2}\right)}{\partial y_{\alpha}^{2 m+2}}=\left[\begin{array}{cc}
0 & 0 \\
-{ }^{m} e \Phi_{\alpha, 1}\left(\xi_{1}\right) & 0
\end{array}\right],
$$

com $k+1 \leq m \leq L R-1$,

- Para $\beta=2 k+1$ e $2 k+2$ :

$$
\begin{gathered}
\frac{\partial^{k} \mathbf{A}^{1}\left(\xi_{1}, \xi_{2}\right)}{\partial y_{\alpha}^{2 k+1}}=\left[\begin{array}{cc}
{ }^{k} e \Phi_{\alpha, 1}\left(\xi_{1}\right) \frac{\xi_{2}-1}{2} & \frac{{ }^{k} e}{2} \Phi_{\alpha}\left(\xi_{1}\right) \\
0 & 0
\end{array}\right] \\
\frac{\partial^{k} \mathbf{A}^{1}\left(\xi_{1}, \xi_{2}\right)}{\partial y_{\alpha}^{2 k+2}}=\left[\begin{array}{cc}
0 & 0 \\
{ }^{k}{ }_{e} \Phi_{\alpha, 1}\left(\xi_{1}\right) \frac{\xi_{2}-1}{2} & \frac{{ }^{k} e}{2} \Phi_{\alpha}\left(\xi_{1}\right)
\end{array}\right],
\end{gathered}
$$

- Para os demais graus de liberdade $(\beta \neq 1,2, \beta<2 k+1$ e $\beta>2 L R+2)$ :

$$
\frac{\partial^{k} \mathbf{A}^{1}\left(\xi_{1}, \xi_{2}\right)}{\partial y_{\alpha}^{\beta}}=\left[\begin{array}{ll}
0 & 0 \\
0 & 0
\end{array}\right]
$$


c) Lâminas ke acima da Lâmina de Referência (LR):

- Para $\beta=1 \mathrm{e} 2$ :

$\frac{\partial^{k} \mathbf{A}^{1}\left(\xi_{1}, \xi_{2}\right)}{\partial y_{\alpha}^{1}}=\left[\begin{array}{cc}\Phi_{\alpha, 1}\left(\xi_{1}\right) & 0 \\ 0 & 0\end{array}\right] \quad \frac{\partial^{k} \mathbf{A}^{1}\left(\xi_{1}, \xi_{2}\right)}{\partial y_{\alpha}^{2}}=\left[\begin{array}{cc}0 & 0 \\ \Phi_{\alpha, 1}\left(\xi_{1}\right) & 0\end{array}\right]$,

- Para $\beta=2 L R+1$ e $2 L R+2$,:

$\frac{\partial^{k} \mathbf{A}^{1}\left(\xi_{1}, \xi_{2}\right)}{\partial y_{\alpha}^{2 L R+1}}=\left[\begin{array}{cc}{\left[d_{j} \Phi_{j, 1}\left(\xi_{1}\right)\right] \Phi_{\alpha}\left(\xi_{1}\right)+\left\{\left[d_{j} \Phi_{j}\left(\xi_{1}\right)\right]+\frac{{ }^{L R} e}{2}\right\} \Phi_{\alpha, 1}\left(\xi_{1}\right)} & 0 \\ 0 & 0\end{array}\right]$
$\frac{\partial^{k} \mathbf{A}^{1}\left(\xi_{1}, \xi_{2}\right)}{\partial y_{\alpha}^{2 L R+2}}=\left[\begin{array}{cc}0 & 0 \\ {\left[d_{j} \Phi_{j, 1}\left(\xi_{1}\right)\right] \Phi_{\alpha}\left(\xi_{1}\right)+\left\{\left[d_{j} \Phi_{j}\left(\xi_{1}\right)\right]+\frac{{ }^{L R} e}{2}\right\} \Phi_{\alpha, 1}\left(\xi_{1}\right)} & 0\end{array}\right]$,

- Para $2(L R+1)+1 \leq \beta \leq 2(k-1)+2$ :

$\frac{\partial^{k} \mathbf{A}^{1}\left(\xi_{1}, \xi_{2}\right)}{\partial y_{\alpha}^{2 m+1}}=\left[\begin{array}{cc}{ }^{m} e \Phi_{\alpha, 1}\left(\xi_{1}\right) & 0 \\ 0 & 0\end{array}\right] \quad \frac{\partial^{k} \mathbf{A}^{1}\left(\xi_{1}, \xi_{2}\right)}{\partial y_{\alpha}^{2 m+2}}=\left[\begin{array}{cc}0 & 0 \\ { }^{m} e \Phi_{\alpha, 1}\left(\xi_{1}\right) & 0\end{array}\right]$,

com $L R+1 \leq m \leq k-1$,

- Para $\beta=2 k+1 \mathrm{e} 2 k+2$ :

$\frac{\partial^{k} \mathbf{A}^{1}\left(\xi_{1}, \xi_{2}\right)}{\partial y_{\alpha}^{2 k+1}}=\left[\begin{array}{cc}{ }^{k} e \Phi_{\alpha, 1}\left(\xi_{1}\right) \frac{\xi_{2}+1}{2} & \frac{{ }^{k} e}{2} \Phi_{\alpha}\left(\xi_{1}\right) \\ 0 & 0\end{array}\right]$

$\frac{\partial^{k} \mathbf{A}^{1}\left(\xi_{1}, \xi_{2}\right)}{\partial y_{\alpha}^{2 k+2}}=\left[\begin{array}{cc}0 & 0 \\ { }^{k} e \Phi_{\alpha, 1}\left(\xi_{1}\right) \frac{\xi_{2}+1}{2} & \frac{{ }^{k} e}{2} \Phi_{\alpha}\left(\xi_{1}\right)\end{array}\right]$,

- Para os demais graus de liberdade $(\beta \neq 1,2, \beta<2 L R+1$ e $\beta>2 k+2)$ :

$$
\frac{\partial^{k} \mathbf{A}^{1}\left(\xi_{1}, \xi_{2}\right)}{\partial y_{\alpha}^{\beta}}=\left[\begin{array}{ll}
0 & 0 \\
0 & 0
\end{array}\right] \text {. }
$$

Vale ressaltar que todos os termos das matrizes acima não dependem do vetor de posições nodais atuais $y_{j}^{i}$. Assim, a segunda derivada $\frac{\partial^{2}\left({ }^{k} \mathbf{A}^{1}\right)}{\partial y_{\alpha}^{\beta} \partial y_{\gamma}^{\zeta}}$, que surge na definição da matriz Hessiana na Equação (63), é nula. 
Definidos todos os termos necessários para calcular o vetor de forças internas $F_{\text {int } \alpha}^{\beta}\left(y_{j}^{i}\right)$, o problema agora se resume em determinar as posições atuais $y_{j}^{i}$ que satisfazem a Equação de equilíbrio (144).

\subsubsection{Processo de solução}

O processo de solução empregado neste trabalho já foi descrito no Item 3.8. Aqui são apresentados apenas alguns detalhes particulares do elemento finito laminado.

Durante o processo de solução, as posições atuais $y_{k}^{i}$ dos nós do pórtico não são conhecidas e posições-tentativa $y_{k \text { tentativa }}^{i}$ são atribuídas. Como essas posições não verificam o equilíbrio nodal representado pela Equação de equilíbrio (144), gera-se um resíduo que corresponde ao vetor de desbalanceamento mecânico:

$$
R_{\alpha}^{\beta}\left(y_{j \text { tentativa }}^{i}\right)=F_{\text {int } \alpha}^{\beta}\left(y_{j \text { tentativa }}^{i}\right)-\left[P_{\alpha}^{\beta}+Q_{\alpha}^{\beta}+M_{\alpha}^{\beta}+B_{\alpha}^{\beta}\left(y_{j \text { tentativa }}^{i}\right)\right] .
$$

Apesar de não ter sido definida uma energia potencial devida a momentos concentrados, a parcela $B_{\alpha}^{\beta}\left(y_{j_{\text {tentativa }}^{i}}\right)$ é adicionada no cálculo do vetor de desbalanceamento mecânico para que as posições de equilíbrio encontradas considerem o efeito desses momentos.

A matriz Hessiana $H_{\alpha \gamma}^{\beta \zeta}\left(y_{j_{\text {tentativa }}^{i}}\right)$ para o elemento de pórtico plano laminado apresenta dimensão igual $2($ nlam +1$) N$, sendo $N$ o número de nós da discretização e 2(nlam+1) o número de graus de liberdade nodais. O cálculo dessa matriz é realizado a partir de um somatório da Equação (58) aplicada em cada lâmina do elemento. Assim, tem-se que a Hessiana é obtida por:

$$
H_{\alpha \gamma}^{\beta \zeta}\left(y_{j}^{i}\right)=\sum_{k=1}^{\text {nlam }}\left[{ }^{k} b \int_{-1}^{1} \int_{-1}^{1} \frac{\partial^{2}\left[{ }^{k} u_{e}\left(\xi_{1}, \xi_{2}\right)\right]^{k}}{\partial y_{\alpha}^{\beta} \partial y_{\gamma}^{\zeta}} J\left(\xi_{1}, \xi_{2}\right) d \xi_{1} d \xi_{2}\right] .
$$

A localização dos termos dessa matriz é feita seguindo uma regra de atribuição semelhante à apresentada na Equação (141) no caso da Hessiana do elemento e na Equação (142) no caso da Hessiana global da estrutura. A atribuição global segue a regra abaixo:

$$
\begin{aligned}
& H_{\alpha \gamma}^{\beta \zeta}\left(y_{j \text { tentativa }}^{i}\right) \rightarrow \begin{array}{l}
\text { Linha: } 2(\text { nlam }+1)(\alpha-1)+\beta \\
\text { Coluna: } 2(\text { nlam }+1)(\gamma-1)+\zeta
\end{array} \\
& \operatorname{com} \beta \text { e } \zeta=1, \ldots, 2(\text { nlam }+1) \text { e } \alpha \text { e } \gamma=1, \ldots, N .
\end{aligned}
$$


Essa matriz é determinada numericamente conforme apresentado na Equação (59) aplicada para cada lâmina e a quantidade de pontos de Gauss empregada é a mesma utilizada para obter o vetor de forças internas na Equação (146).

Os últimos aspectos particulares da formulação posicional do elemento laminado são relativos ao emprego da técnica utilizada para fazer a ligação (acoplamento) entre barras.

\subsubsection{Ligações entre elementos não colineares}

O procedimento para realizar a ligação entre elementos laminados com direções diferentes é semelhante ao procedimento apresentado no Item 4.3.6 para o elemento de pórtico plano homogêneo. A única diferença é que agora há uma quantidade de molas de acoplamento dos vetores generalizados igual ao número de lâminas do elemento. Na Figura 48, há uma ilustração da ligação para um caso particular de cinco lâminas. Nessa figura, $K_{a b}^{i}(i=1,2)$ representa a rigidez da mola de acoplamento das posições $y_{a}^{i}$ e $y_{b}^{i}$ dos nós $a$ e $b$ localizados na linha de referência e ${ }^{k} K_{a b}^{\alpha}$ representa a rigidez da mola de acoplamento dos vetores generalizados ${ }^{k} g_{a}^{i} \mathrm{e}^{k} g_{b}^{i}$ das lâminas $k=1, \ldots$, nlam pertencentes aos dois elementos acoplados.

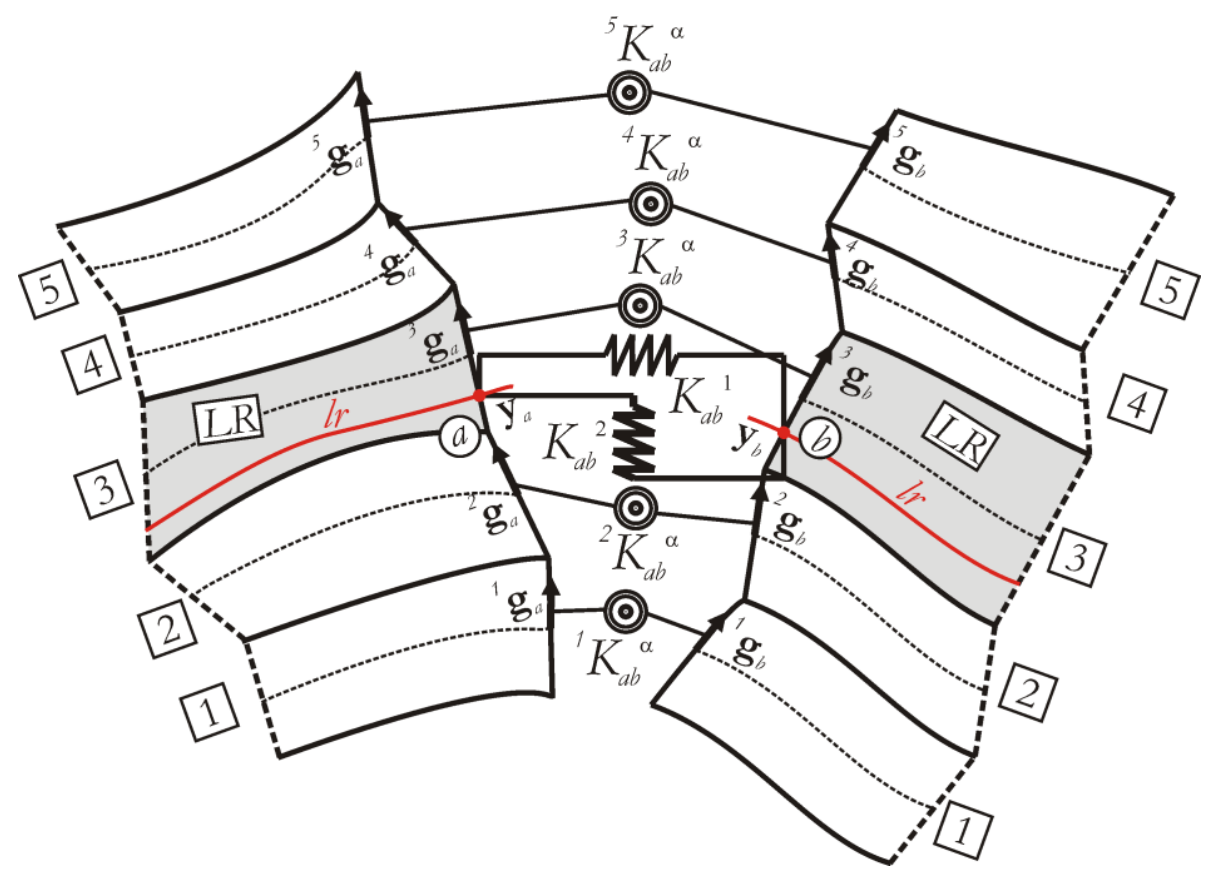

Figura 48 - Modelo de acoplamento entre elementos laminados

A contribuição das molas no vetor de forças internas e na matriz Hessiana globais é feita com a mesma regra de atribuição apresentada na Equação (142). 
Após a determinação das posições na configuração atual, prossegue-se com a descrição do procedimento necessário para calcular deslocamentos, deformações e tensões.

\subsection{Pós-processamento}

Com a determinação das posições da configuração atual para um dado incremento de carregamento, os resultados de deslocamentos, deformações e tensões só dependem das coordenadas adimensionais $\left(\xi_{1}, \xi_{2}\right)$ correspondentes a um ponto qualquer do elemento.

Para avaliar os resultados das análises, foram implementadas rotinas de pósprocessamento que calculam deslocamentos, deformações e tensões em pontos localizados nas seções nodais do elemento, $\xi_{1}=\xi_{1}$ com $j$ representando os nós, e nas interfaces e meio das lâminas cujas coordenadas adimensionais são dadas por $\xi_{2}=-1,0$ e 1 . Os resultados são organizados em arquivos de saída que permitem a montagem de trajetórias de equilíbrio e de distribuições de deslocamentos, deformações e tensões ao longo de uma seção transversal. Além disso, são gerados arquivos de dados que permitem a visualização das imagens da estrutura na configuração atual com um mapa de cores para representar os resultados. O software AcadView foi utilizado para geração das imagens.

A seguir, apresentam-se as sequências de passos necessários para calcular os resultados de deslocamentos, deformações de Green e tensões de Piola-Kirchhoff de segunda espécie em um dado ponto de uma lâmina $k$ do elemento com coordenadas adimensionais $\left(\xi_{1}, \xi_{2}\right)$.

- Deslocamentos ${ }^{k} \mathbf{u}\left(\xi_{1}, \xi_{2}\right)=\left\{\begin{array}{l}{ }^{k} u^{1}\left(\xi_{1}, \xi_{2}\right) \\ { }^{k} u^{2}\left(\xi_{1}, \xi_{2}\right)\end{array}\right\}$ :

a) Determinação da posição inicial ${ }^{k} x^{i}\left(\xi_{1}, \xi_{2}\right)$ com auxílio das funções de mapeamento da configuração inicial, Equações (113), (114) e (115;

b) Determinação da posição atual ${ }^{k} y^{i}\left(\xi_{1}, \xi_{2}\right)$ com auxílio das funções de mapeamento da configuração atual, Equações (116), (117) e (118);

c) Cálculo do deslocamento por meio da diferença ${ }^{k} u^{i}\left(\xi_{1}, \xi_{2}\right)={ }^{k} y^{i}\left(\xi_{1}, \xi_{2}\right)-{ }^{k} x^{i}\left(\xi_{1}, \xi_{2}\right) ;$

- Deformações de Green ${ }^{k} \mathbf{E}\left(\xi_{1}, \xi_{2}\right)$ :

a) Determinação de ${ }^{k} \mathbf{A}^{0}\left(\xi_{1}, \xi_{2}\right)$ através das Equações (121), (123) e (125); 
b) Determinação de ${ }^{k} \mathbf{A}^{1}\left(\xi_{1}, \xi_{2}\right)$ através das Equações (122), (124) e (126);

c) Determinação do gradiente da função mudança de configuração ${ }^{k} \mathbf{A}\left(\xi_{1}, \xi_{2}\right)$ conforme a Equação (12);

d) Determinação do tensor alongamento à direita de Cauchy-Green ${ }^{k} \mathbf{C}\left(\xi_{1}, \xi_{2}\right)$ conforme Equação (19);

e) Cálculo das deformações de Green conforme sua definição na Equação (21);

- Tensões de Piola-Kirchhoff de segunda espécie ${ }^{k} \mathbf{S}\left(\xi_{1}, \xi_{2}\right)$ :

a) Conhecidas as deformações de Green, basta substituir os valores obtidos na lei constitutiva de Saint-Venant-Kirchhoff, representada na Equação (26).

Essas tensões utilizam a configuração inicial como referência. Como um dos objetivos deste trabalho é obtenção de uma distribuição de tensões mais precisas com vistas à representação da falha do laminado, é importante determinar também as tensões reais conhecidas como tensões de Cauchy ${ }^{k} \mathbf{T}\left(\xi_{1}, \xi_{2}\right)$ que utilizam a configuração atual como referência. Conhecidos ${ }^{k} \mathbf{A}\left(\xi_{1}, \xi_{2}\right)$ e ${ }^{k} \mathbf{S}\left(\xi_{1}, \xi_{2}\right)$, as tensões de Cauchy são determinadas por (OGDEN, 1984):

$$
\begin{aligned}
& { }^{k} \mathbf{T}\left(\xi_{1}, \xi_{2}\right)=\frac{\left[{ }^{k} \mathbf{A}\left(\xi_{1}, \xi_{2}\right)\right]^{t} \cdot{ }^{k} \mathbf{S}\left(\xi_{1}, \xi_{2}\right) \cdot{ }^{k} \mathbf{A}\left(\xi_{1}, \xi_{2}\right)}{{ }^{k} J\left(\xi_{1}, \xi_{2}\right)} \\
& \operatorname{com}{ }^{k} J\left(\xi_{1}, \xi_{2}\right)=\operatorname{det}\left[{ }^{k} \mathbf{A}\left(\xi_{1}, \xi_{2}\right)\right] .
\end{aligned}
$$

Nessa equação, ${ }^{k} \mathbf{A}\left(\xi_{1}, \xi_{2}\right),{ }^{k} \mathbf{S}\left(\xi_{1}, \xi_{2}\right)$ e ${ }^{k} \mathbf{T}\left(\xi_{1}, \xi_{2}\right)$ constituem matrizes de ordem dois. $\left[{ }^{k} \mathbf{A}\left(\xi_{1}, \xi_{2}\right)\right]^{t}$ é a matriz transposta de ${ }^{k} \mathbf{A}\left(\xi_{1}, \xi_{2}\right)$. A repetição do índice $k$ não implica em somatório.

Todos os resultados calculados acima são relacionados às direções do sistema de referência global. No entanto, é interessante obter esses resultados também no sistema de referência local do elemento para facilitar a interpretação física. Nessa referência, é possível identificar as componentes de deformações e tensões na direção longitudinal e transversal do laminado.

$\mathrm{Na}$ Figura 49, ilustram-se os sistemas de referência global e local para um elemento na configuração inicial: 


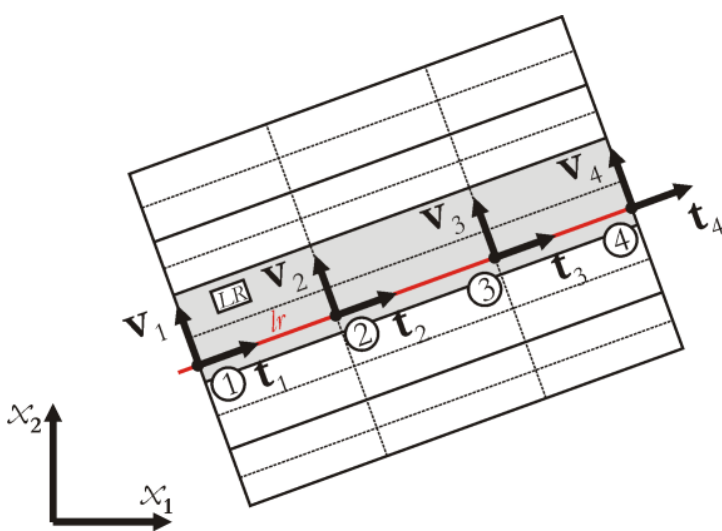

Figura 49 - Sistemas de referência local e global no elemento laminado

Com exceção da tensão de Cauchy, os demais resultados são relativos à configuração inicial. Assim, pode-se obter uma matriz de rotação do sistema global para o local a partir do mapeamento da linha de referência do elemento na configuração inicial (Equação (113)). O versor tangente $\mathbf{t}_{j}$ ao elemento é dado por:

$$
{ }^{L R} x^{i}\left(\xi_{1}, 0\right)=x_{j}^{i} \Phi_{j}\left(\xi_{1}\right) \rightarrow t^{i}\left(\xi_{1}\right)=\frac{x_{j}^{i} \Phi_{j, 1}\left(\xi_{1}\right)}{\sqrt{\left[x_{w}^{a} \Phi_{w, 1}\left(\xi_{1}\right)\right]\left[x_{z}^{a} \Phi_{z, 1}\left(\xi_{1}\right)\right]}},
$$

com $a, i=1$ e 2 representando a direção e $j, w, z=1, \ldots,($ grau +1$)$ representando os nós do elemento.

O versor normal $\mathbf{v}_{j}$ é obtido de forma que o produto vetorial com o versor tangente $\mathbf{t}_{j}$ resulte sempre na direção do versor saindo do plano. Com isso, tem-se que:

$$
v^{i}\left(\xi_{1}\right)=\left(-t^{2}\left(\xi_{1}\right), t^{1}\left(\xi_{1}\right)\right)
$$

A matriz de rotação fica, então, escrita como:

$$
\mathbf{R}\left(\xi_{1}\right)=\left[\begin{array}{ll}
t^{1}\left(\xi_{1}\right) & t^{2}\left(\xi_{1}\right) \\
v^{1}\left(\xi_{1}\right) & v^{2}\left(\xi_{1}\right)
\end{array}\right]
$$

Assim, os deslocamentos, as deformações de Green e as tensões de Piola-Kirchhoff de segunda espécie obtidos nas direções globais podem ser rotacionados para as direções locais do elemento, respectivamente, por meio de:

$$
\begin{aligned}
& { }^{k} \mathbf{u}\left(\xi_{1}, \xi_{2}\right)_{\text {local }}=\mathbf{R}\left(\xi_{1}\right) \cdot{ }^{k} \mathbf{u}\left(\xi_{1}, \xi_{2}\right)_{\text {global }} \\
& { }^{k} \mathbf{E}\left(\xi_{1}, \xi_{2}\right)_{\text {local }}=\mathbf{R}\left(\xi_{1}\right) \cdot{ }^{k} \mathbf{E}\left(\xi_{1}, \xi_{2}\right) \text { global } \cdot\left[\mathbf{R}\left(\xi_{1}\right)\right]^{t} \\
& { }^{k} \mathbf{S}\left(\xi_{1}, \xi_{2}\right)_{\text {local }}=\mathbf{R}\left(\xi_{1}\right) \cdot{ }^{k} \mathbf{S}\left(\xi_{1}, \xi_{2}\right)_{\text {global }} \cdot\left[\mathbf{R}\left(\xi_{1}\right)\right]^{t} .
\end{aligned}
$$


A fim de verificar a formulação do elemento de pórtico plano laminado, vários exemplos foram analisados e os resultados obtidos são comparados aos resultados de soluções analíticas e numéricas encontradas na literatura.

\subsection{Exemplos numéricos}

Ao todo foram analisados cinco exemplos que possibilitaram avaliar diferentes aspectos da formulação. Os resultados obtidos com o elemento finito proposto neste trabalho são comparados aos resultados obtidos a partir de soluções analíticas e aos resultados obtidos através de análises numéricas, com elementos finitos bidimensionais, realizadas no software Ansys ${ }^{\circledR}$. Neste último caso, o elemento finito empregado foi o PLANE42. Esse é um elemento finito bidimensional retangular com quatro nós que emprega funções de forma lineares para interpolar os deslocamentos nodais.

Nas análises realizadas no Ansys ${ }^{\circledR}$, foi empregada uma discretização bastante refinada cujos resultados são utilizados como referência para comparação. Além disso, também foram realizadas análises com discretizações equivalentes às discretizações utilizadas nas análises feitas com o elemento finito laminado. Para isso, um número de elementos PLANE42 igual ao número de lâminas foi adicionado entre dois nós da discretização com o elemento de pórtico plano laminado. Buscou-se com isso, comparar o desempenho do elemento proposto neste trabalho em relação aos elementos finitos bidimensionais que podem apresentar problemas de mau condicionamento matricial quando utilizados na análise de pórticos planos laminados. Isso pode levar à necessidade de refinamento da malha de elementos finitos bidimensionais $\mathrm{e}$ consequentemente ao aumento do custo computacional.

O objetivo com a análise dos quatro primeiros exemplos é verificar os diferentes aspectos da formulação. Assim, o primeiro exemplo é constituído por uma viga biapoiada homogênea sujeita à ação de um carregamento distribuído uniforme. Nesse exemplo, o principal objetivo é verificar a convergência da discretização tanto em relação ao número de elementos quanto em relação ao número de lâminas empregadas para representar a seção transversal. $\mathrm{O}$ problema foi analisado para três situações com a relação entre vão e altura da viga $\left(S=L / h_{0}\right)$ assumindo os valores de 2, 4 e 10. Em todas as análises, verificam-se as distribuições de deslocamentos e tensões ao longo da seção transversal em diferentes pontos da viga.

No segundo exemplo, analisa-se uma viga sanduíche biapoiada com carregamento distribuído uniforme aplicado na face superior. A viga é semelhante a do primeiro problema e também foi analisada para as três relações vão e altura $(S=2,4$ e 10). O objetivo principal com 
esse exemplo é verificar a precisão das distribuições de deslocamentos e tensões ao longo da seção transversal para o caso laminado, bem como avaliar a eficiência do elemento em problemas cuja relação $S$ varia desde fina até espessa. Além disso, a possibilidade de aplicação de forças distribuídas fora da linha de referência é verificada.

No terceiro exemplo, uma viga sanduíche biapoiada semelhante a dos dois casos anteriores foi analisada. Uma única relação entre vão e altura da viga $(S=4)$ foi considerada, porém três combinações entre o módulo de elasticidade das lâminas nas faces e da lâmina do núcleo foram consideradas: modelos AAA, ABA e ACA. A viga é submetida à ação de uma força concentrada aplicada na face superior da seção localizada na metade do vão. Nesse exemplo, verifica-se a capacidade do elemento em representar com precisão as distribuições de deslocamentos e tensões à medida que o módulo de elasticidade do núcleo é reduzido $(\mathrm{A} \rightarrow \mathrm{B} \rightarrow \mathrm{C}$ ). Além disso, os resultados obtidos permitem avaliar a eficiência da formulação na consideração de forças concentradas aplicadas fora da linha de referência.

O quarto exemplo é destinado a verificar a técnica empregada para realizar o acoplamento entre barras. Para isso, o problema do pórtico com ligações semirrígidas já estudado utilizando o elemento de pórtico plano homogêneo (Item 4.4.3) é novamente analisado. Como o objetivo deste exemplo é verificar a técnica de acoplamento entre barras, foi considerada uma discretização da seção em cinco lâminas de mesmo material. Apenas o caso cujos apoios possuem rigidez elástica à rotação foi analisado. Os resultados obtidos são comparados aos já apresentados na Figura 42.

Verificada a formulação nos exemplos anteriores, dois pórticos constituídos por um e por cinco pavimentos, com seções laminadas, foram propostos e analisados. Os resultados das distribuições de deslocamentos ao longo da seção transversal de alguns pontos são apresentados.

Até onde prosseguiu a revisão bibliográfica deste trabalho, não foram encontrados exemplos de pórticos planos laminados na literatura. Todos os problemas encontrados se restringiam a vigas laminadas analisadas no regime linear. Assim, este exemplo contribui com resultados que poderão ser empregados em verificações futuras de formulações que tratem do problema de análise não linear geométrica de pórticos planos laminados.

Em resumo, buscou-se, com essas análises, verificar os diversos aspectos da formulação do elemento de pórtico plano laminado além de avaliar sua eficiência e consistência.

\subsubsection{Exemplo 5.1: Viga homogênea biapoiada com força distribuída}

Neste primeiro exemplo, analisa-se uma viga simples biapoiada e homogênea sujeita 
à ação de um carregamento distribuído uniforme, conforme ilustra a Figura 50. As características geométricas da seção transversal e os parâmetros elásticos do material também estão representados na referida figura.

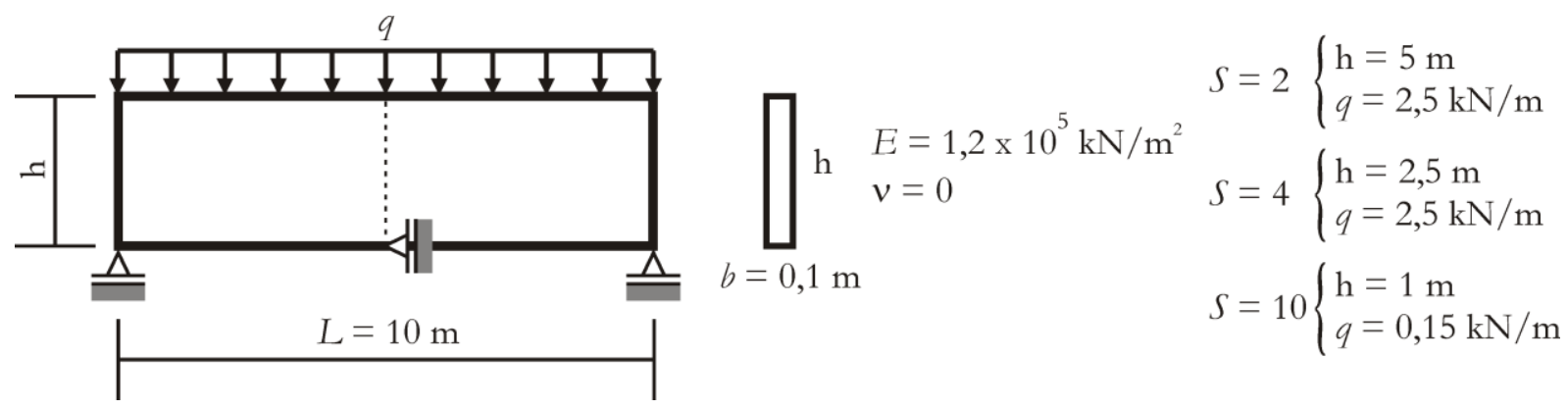

Figura 50 - Geometria, carregamento e parâmetros elásticos para o problema do Exemplo 5.1

Em todas as análises, a força distribuída foi aplicada em um único incremento, pois o valor da força considerada é baixo para manter o problema no regime de pequenas deformações e para permitir uma comparação com a solução analítica obtida a partir da Teoria Clássica de Vigas (TCV) que se baseia nas hipóteses cinemáticas de Euler-Bernoulli. Além disso, um coeficiente de Poisson (v) nulo também é adotado. Vale ressaltar que a força distribuída é aplicada na face superior da viga enquanto a linha de referência está localizada na face inferior, onde estão os apoios.

O problema foi analisado para três situações com a relação entre vão e altura da viga $(S=L / h)$ assumindo os valores de 2,4 e 10 . Buscou-se, com isso, verificar a capacidade da formulação em representar com precisão as distribuições de deslocamentos e tensões para problemas com relações entre vão e altura correspondentes a vigas esbeltas e a vigas altas (vigasparede).

A fim de avaliar a capacidade de convergência da formulação, a viga foi discretizada com um número de elementos finitos cúbicos variando entre 2, 4, 8 e 16. Foram empregadas 20 lâminas para discretizar a seção transversal, pois essa foi a quantidade de lâminas que forneceu uma boa distribuição para a tensão de cisalhamento transversal. Isso foi verificado para o caso da viga $\operatorname{com} S=10$, que foi analisada através de uma discretização composta por 4 elementos finitos e por um número de lâminas que variou entre 1, 2, 4, 8, 20 e 40.

O processo de solução baseado no método de Newton-Raphson foi controlado por meio dos critérios de convergência em posição e em força com tolerâncias de $10^{-9}$ e $10^{-6}$ respectivamente. A quantidade de pontos de Gauss empregada nas integrações numéricas do vetor de forças internas e da matriz Hessiana foi de 4 x 20 (vão x altura) em cada lâmina. Essa quantidade de pontos de Gauss foi adotada após um estudo comparativo dos valores obtidos 
para o deslocamento horizontal $u$ da face inferior da seção localizada a 2,5 $\mathrm{m}$ do apoio da esquerda, do deslocamento vertical $v$ e da tensão axial S11 da face inferior da seção localizada no meio do vão da viga. Nesse estudo, as integrações numéricas foram realizadas com a quantidade de pontos de Gauss variável até um limite de 20 x 20.

Esse estudo foi realizado para a viga do caso $S=10$, discretizada com 4 elementos finitos e com um número de lâminas que variou entre 1, 2, 3, 4, 8 e 20 lâminas. Os resultados obtidos estão resumidos na Tabela 2. As seguintes observações podem ser apontadas:

- nos três primeiros blocos da referida tabela, somente a quantidade de pontos ao longo da direção transversal foi variada. Quanto maior o número de lâminas, as variações nos resultados foram maiores à medida que número de pontos de Gauss é aumentado;

- na parte esquerda do último bloco da tabela, somente a quantidade pontos de Gauss ao longo da direção longitudinal variou. Não se observa mudança significativa nos resultados a partir de 4 pontos. O caso com 4 pontos de Gauss consta na parte direita do terceiro bloco;

- na parte direita do último bloco, foram variadas as quantidades de pontos de Gauss em ambas as direções. Não se observam diferenças significativas em relação aos resultados apresentados na parte direita do terceiro bloco, na qual somente os pontos de Gauss ao longo da direção transversal foram variados.

Dessas observações, é razoável assumir que 4 pontos de Gauss ao longo da direção longitudinal é suficiente para o elemento finito com grau de interpolação cúbico e que mais pontos de Gauss ao longo da direção transversal são necessários quanto maior o número de lâminas adotado.

A forma como foi realizada a implementação computacional da formulação não permite a adoção de quantidades diferentes de pontos de Gauss em cada lâmina. Assim, não foi possível identificar se há diferenças na quantidade de pontos de Gauss necessária para as lâminas próximas à Lâmina de Referência e para as lâminas distantes desta.

Dessa forma, para garantia de uma integração numérica correta e como os problemas apresentados neste trabalho não possuem uma quantidade de graus de liberdade elevada, foram adotados 4 × 20 pontos de Gauss em todas as análises realizadas. 
Tabela 2 - Avaliação da quantidade de pontos de Gauss necessária para as integrações numéricas do elemento de pórtico plano laminado no Exemplo 5.1

\begin{tabular}{|c|c|c|c|c|c|c|c|}
\hline \multirow{2}{*}{$\begin{array}{c}\text { Pontos } \\
\text { de Gauss }\end{array}$} & \multicolumn{3}{|c|}{1 lâmina } & \multirow{2}{*}{$\begin{array}{c}\text { Pontos } \\
\text { de Gauss }\end{array}$} & \multicolumn{3}{|c|}{4 lâminas } \\
\hline & $u(\mathrm{~m})$ & $v(\mathrm{~m})$ & $\begin{array}{c}\mathrm{S} 11 \\
\left(\mathrm{kN} / \mathrm{m}^{2}\right) \\
\end{array}$ & & $u(\mathrm{~m})$ & $v(\mathrm{~m})$ & $\begin{array}{c}\mathrm{S} 11 \\
\left(\mathrm{kN} / \mathrm{m}^{2}\right)\end{array}$ \\
\hline $4 \times 2$ & $-0,002144$ & $-0,019961$ & 113,737024 & $4 \times 2$ & $-0,002548$ & $-0,025574$ & 135,495750 \\
\hline $4 \times 3$ & $-0,002144$ & $-0,019961$ & 113,737010 & $4 \times 3$ & $-0,002375$ & $-0,022548$ & 126,297080 \\
\hline $4 \times 5$ & $-0,002144$ & $-0,019961$ & 113,737010 & $4 \times 5$ & $-0,002248$ & $-0,021030$ & 119,572011 \\
\hline $4 \times 10$ & $-0,002144$ & $-0,019961$ & 113,737010 & $4 \times 10$ & $-0,002179$ & $-0,020327$ & 115,932967 \\
\hline $4 \times 20$ & $-0,002144$ & $-0,019961$ & 113,737010 & $4 \times 20$ & $-0,002159$ & $-0,020135$ & 114,881454 \\
\hline \multirow{2}{*}{$\begin{array}{l}\text { Pontos } \\
\text { de Gauss }\end{array}$} & & 2 lâminas & & \multirow{2}{*}{$\begin{array}{c}\text { Pontos } \\
\text { de Gauss }\end{array}$} & \multicolumn{3}{|c|}{8 lâminas } \\
\hline & $u(\mathrm{~m})$ & $v(\mathrm{~m})$ & $\begin{array}{c}\mathrm{S} 11 \\
\left(\mathrm{kN} / \mathrm{m}^{2}\right) \\
\end{array}$ & & $u(\mathrm{~m})$ & $v(\mathrm{~m})$ & $\begin{array}{c}\mathrm{S} 11 \\
\left(\mathrm{kN} / \mathrm{m}^{2}\right) \\
\end{array}$ \\
\hline $4 \times 2$ & $-0,002099$ & $-0,021158$ & 111,449269 & $4 \times 2$ & $-0,003101$ & $-0,030401$ & 165,169914 \\
\hline $4 \times 3$ & $-0,002124$ & $-0,020207$ & 112,807079 & $4 \times 3$ & $-0,002612$ & $-0,024656$ & 139,076808 \\
\hline $4 \times 5$ & $-0,002143$ & $-0,020040$ & 113,784196 & $4 \times 5$ & $-0,002332$ & $-0,021803$ & 124,188458 \\
\hline $4 \times 10$ & $-0,002147$ & $-0,020012$ & 114,014730 & $4 \times 10$ & $-0,002202$ & $-0,020543$ & 117,249456 \\
\hline $4 \times 20$ & $-0,002147$ & $-0,020007$ & 114,029694 & $4 \times 20$ & $-0,002167$ & $-0,020207$ & 115,364708 \\
\hline \multirow{2}{*}{$\begin{array}{c}\text { Pontos } \\
\text { de Gauss }\end{array}$} & & 3 lâminas & & \multirow{2}{*}{$\begin{array}{c}\text { Pontos } \\
\text { de Gauss }\end{array}$} & \multicolumn{3}{|c|}{20 lâminas } \\
\hline & $u(\mathrm{~m})$ & $v(\mathrm{~m})$ & $\begin{array}{c}\mathrm{S} 11 \\
\left(\mathrm{kN} / \mathrm{m}^{2}\right)\end{array}$ & & $u(\mathrm{~m})$ & $v(\mathrm{~m})$ & $\begin{array}{c}\mathrm{S} 11 \\
\left(\mathrm{kN} / \mathrm{m}^{2}\right)\end{array}$ \\
\hline $4 \times 2$ & $-0,002334$ & $-0,023585$ & 124,035986 & $4 \times 2$ & $-0,003692$ & $-0,035329$ & 196,978881 \\
\hline $4 \times 3$ & $-0,002264$ & $-0,021541$ & 120,352736 & $4 \times 3$ & $-0,002813$ & $-0,026404$ & 149,917355 \\
\hline $4 \times 5$ & $-0,002204$ & $-0,020622$ & 117,158811 & $4 \times 5$ & $-0,002396$ & $-0,022374$ & 127,620487 \\
\hline $4 \times 10$ & $-0,002166$ & $-0,020202$ & 115,168208 & $4 \times 10$ & $-0,002218$ & $-0,020688$ & 118,123628 \\
\hline $4 \times 20$ & $-0,002154$ & $-0,020087$ & 114,557295 & $4 \times 20$ & $-0,002171$ & $-0,020248$ & 115,631889 \\
\hline \multirow{2}{*}{$\begin{array}{c}\text { Pontos } \\
\text { de Gauss }\end{array}$} & & 20 lâminas & & \multirow{2}{*}{$\begin{array}{l}\text { Pontos } \\
\text { de Gauss }\end{array}$} & \multicolumn{3}{|c|}{20 lâminas } \\
\hline & $u(\mathrm{~m})$ & $v(\mathrm{~m})$ & $\begin{array}{c}\mathrm{S} 11 \\
(\mathrm{kN} / \mathrm{m} 2) \\
\end{array}$ & & $u(\mathrm{~m})$ & $v(\mathrm{~m})$ & $\begin{array}{c}\mathrm{S} 11 \\
(\mathrm{kN} / \mathrm{m} 2) \\
\end{array}$ \\
\hline $3 \times 3$ & $-0,002575$ & $-0,026522$ & 114,567676 & $3 \times 2$ & $-0,003158$ & $-0,035440$ & 120,956560 \\
\hline $5 \times 3$ & $-0,002813$ & $-0,026404$ & 149,917515 & $5 \times 3$ & $-0,002813$ & $-0,026404$ & 149,917515 \\
\hline $8 \times 3$ & $-0,002813$ & $-0,026404$ & 149,917515 & $8 \times 5$ & $-0,002396$ & $-0,022374$ & 127,620609 \\
\hline $10 \times 3$ & $-0,002813$ & $-0,026404$ & 149,917515 & $10 \times 10$ & $-0,002218$ & $-0,020688$ & 118,123734 \\
\hline $20 \times 3$ & $-0,002813$ & $-0,026404$ & 149,917515 & $20 \times 20$ & $-0,002171$ & $-0,020248$ & 115,631992 \\
\hline
\end{tabular}

Na Figura 51, constam os resultados de uma análise de convergência para o caso da viga cuja relação entre vão e altura $(S)$ é igual a 10. A viga é discretizada com 4 elementos cúbicos e apenas o número de lâminas é variado. Como pode ser observado, a partir de 1 lâmina na 
discretização da seção, os resultados para o deslocamento $u$ e para a tensão axial S11 já coincidem com a solução analítica e com a solução numérica obtida no Ansys ${ }^{\circledR}$ a partir de uma discretização bastante refinada. No entanto, a tensão de cisalhamento S12 somente foi representada de forma razoável a partir de uma discretização com 8 lâminas. De 20 para 40 lâminas, a melhora na representação da tensão S12 só ocorreu nas faces inferior e superior, onde os valores são os mais baixos.

Como não houve ganho significativo nas distribuições de tensões após o aumento de 20 para 40 lâminas, em todas as demais análises realizadas neste exemplo e nos Exemplos 5.2, 5.3 e 5.5, uma discretização da seção com 20 lâminas foi adotada. Para os Exemplo 5.4, somente 5 lâminas são adotadas, pois apenas os deslocamentos globais dos nós são avaliados.

a) Deslocamento na direção $1(u)$ para seção a 2,5 $\mathrm{m}$ do apoio esquerdo

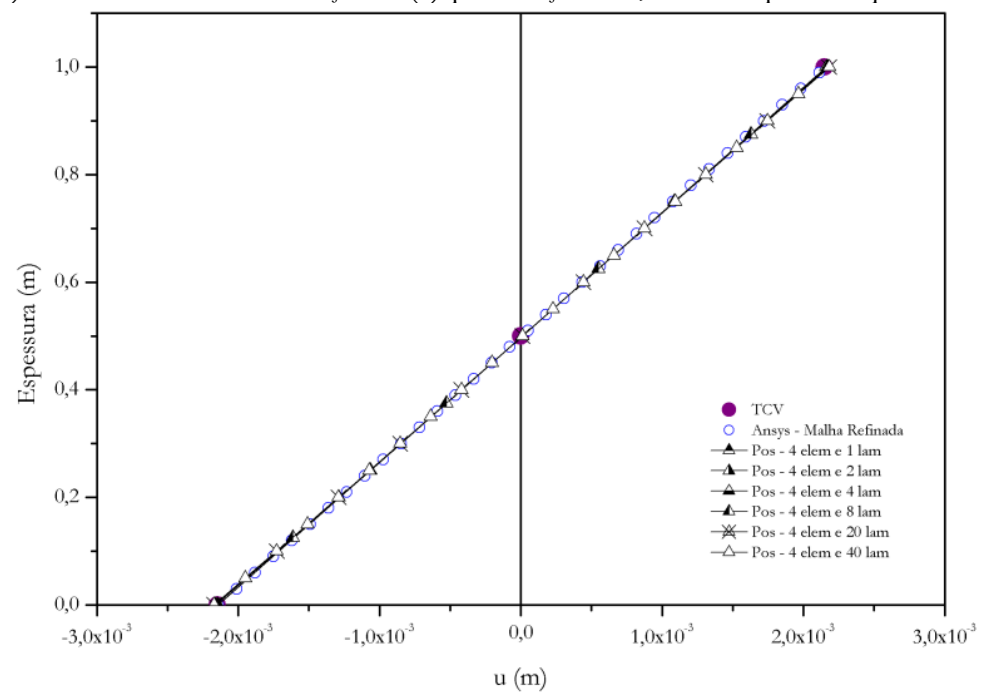

b) Tensão axial S11 para seção localizada no meio do vão

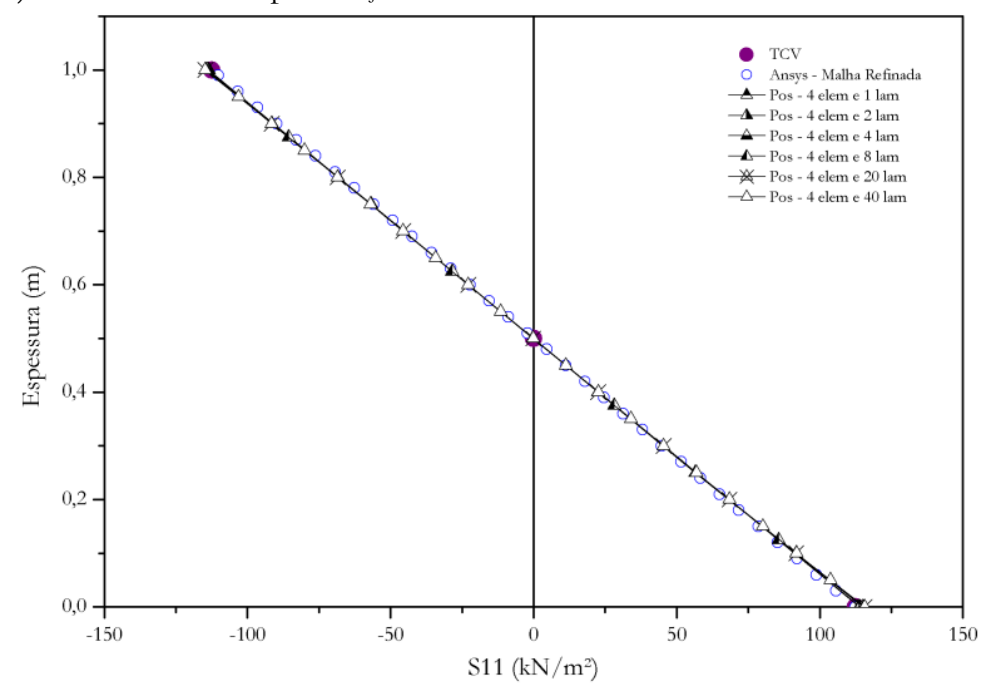


c) Tensão de cisalhamento $\mathrm{S} 12$ para seção a 2,5 $\mathrm{m}$ do apoio esquerdo

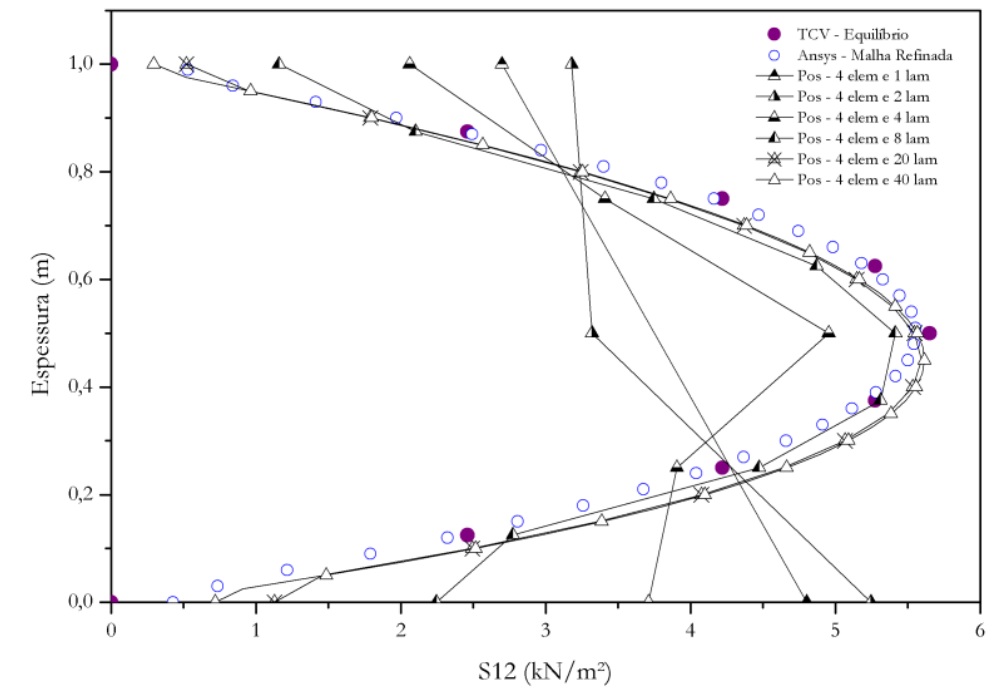

Figura 51 - Resultados do Exemplo 5.1 para uma discretização com 4 elementos cúbicos e variação do número de lâminas (Caso $\operatorname{com} S=10)$.

Apresentada a análise de convergência para o número de lâminas, as análises das vigas com uma relação entre vão e altura $(S)$ iguais a 2, 4 e 10 foram realizadas variando apenas o número de elementos finitos (4, 8 e 16 elementos). Os resultados das distribuições de deslocamento horizontal $u$, de tensão axial na direção longitudinal S11, de tensão axial na direção transversal S22 e de tensão de cisalhamento S12 são apresentados nas Figura 52, Figura 53, Figura 54 e Figura 55, respectivamente. Todas as tensões representadas são médias entre elementos e a continuidade interlaminar das tensões é representada calculando a média dos valores obtidos nas interfaces das lâminas adjacentes. Nessas figuras, também constam os resultados médios obtidos através de análises numéricas realizadas no Ansys ${ }^{\circledR}$ com emprego do elemento finito bidimensional PLANE42. A equivalência entre as malhas do elemento finito posicional e do elemento PLANE42 foi feita de forma a haver um elemento PLANE42 entre dois nós e um em cada lâmina. O número de graus de liberdade também é conservado. Essa equivalência resulta na seguinte associação:

- Posicional com 4 elementos cúbicos e 20 lâminas $\Leftrightarrow$ PLANE42 com malha de 12 x 20 elementos;

- Posicional com 8 elementos cúbicos e 20 lâminas $\Leftrightarrow$ PLANE42 com malha de 24 x 20 elementos;

- Posicional com 16 elementos cúbicos e 20 lâminas $\Leftrightarrow \quad$ PLANE42 com malha de 48 x 20 elementos. 
Os resultados analíticos obtidos a partir da TCV (somente para o caso com $S=10$ ) e os obtidos por meio de análises no Ansys ${ }^{\circledR}$ utilizando uma discretização bastante refinada também são apresentados e adotados como referência para avaliar a precisão dos resultados obtidos com o elemento de pórtico plano laminado.

As distribuições de deslocamentos apresentadas na Figura 52 foram obtidas corretamente já com uma discretização em 4 elementos finitos. A forma da seção foi representada em conformidade com os resultados da solução analítica baseada na TCV, no caso com $S=10$, e da solução numérica obtida no Ansys ${ }^{\circledR}$ com uma malha refinada. Vale ressaltar, que o elemento finito proposto foi capaz de representar a forma curva da seção para o caso da viga $\operatorname{com} S=2$.

Observa-se também que os resultados obtidos com as malhas equivalentes no Ansys ${ }^{\circledR}$ demonstram alguma influência do mau condicionamento matricial sofrido pelo elemento finito bidimensional. Para a viga com $S=10$, os elementos PLANE42 possuem maior distorção e houve diferenças na distribuição de deslocamentos obtida. Já para a viga com $S=2$, os elementos PLANE42 são menos distorcidos devido à maior altura da viga e praticamente não há diferenças na distribuição de deslocamentos. Todos esses aspectos apontados acima são também verificados para a distribuição de tensões axiais S11 na direção longitudinal, como pode ser visto na Figura 53.

Conforme apresentado nas Figura 54 e Figura 55, as distribuições de tensão axial S22 e de tensão de cisalhamento S12 exigiram uma discretização maior (8 elementos finitos) para uma representação aceitável. No entanto, uma boa concordância com os resultados da solução analítica baseada na TCV, no caso com $S=10$ e tensão S12, e da solução numérica obtida no Ansys ${ }^{\circledR}$ com uma malha refinada foi alcançada para uma discretização com 16 elementos finitos.

Apesar da exigência de uma maior discretização, os resultados obtidos no Ansys ${ }^{\circledR}$ com malhas equivalentes não foram melhores do que os obtidos com o elemento de pórtico plano laminado. Isso é observado principalmente para as distribuições de cisalhamento S12 no caso das vigas com $S=4$ e $S=10$. Nessas vigas, o elemento bidimensional PLANE42 parece sofrer com problemas de mau condicionamento matricial devido a uma maior distorção do elemento gerada pela discretização equivalente e pela menor altura das vigas. 
a) Viga $\operatorname{com} S=2$

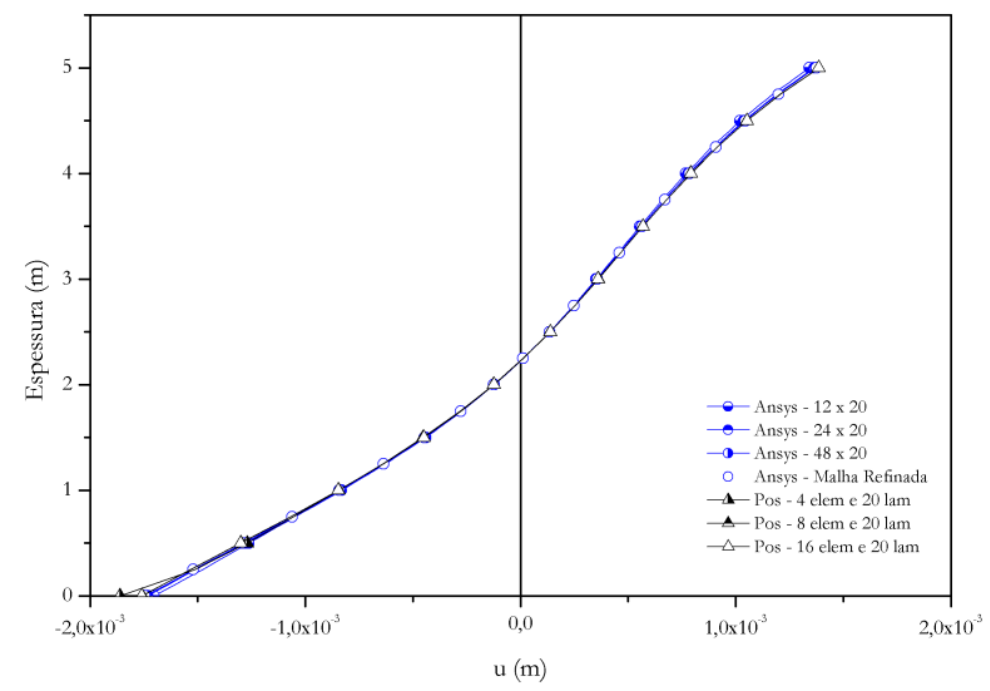

b) Viga $\operatorname{com} S=4$

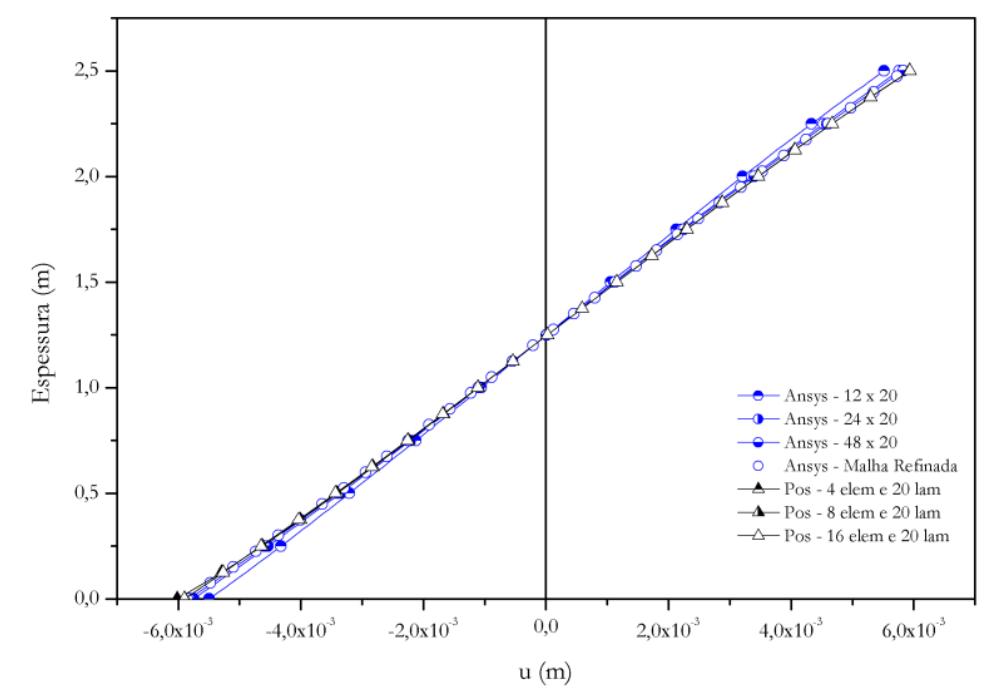

c) Viga $\operatorname{com} S=10$

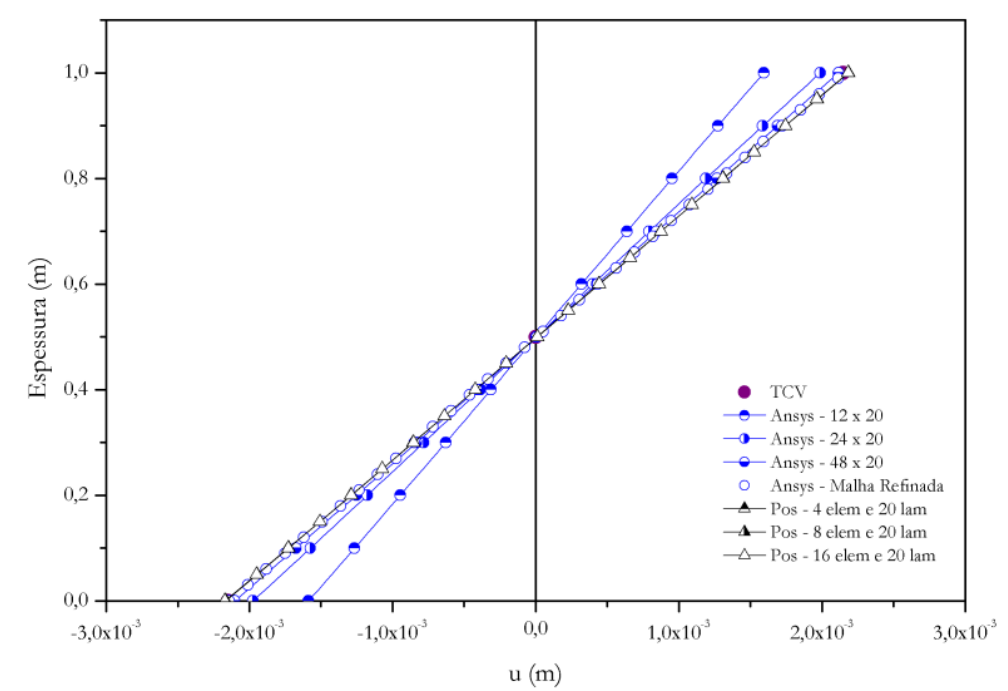

Figura 52 - Resultados do Exemplo 5.1: Deslocamento na direção 1 (u) para seção a 2,5 m do apoio esquerdo. 
a) Viga $\operatorname{com} S=2$

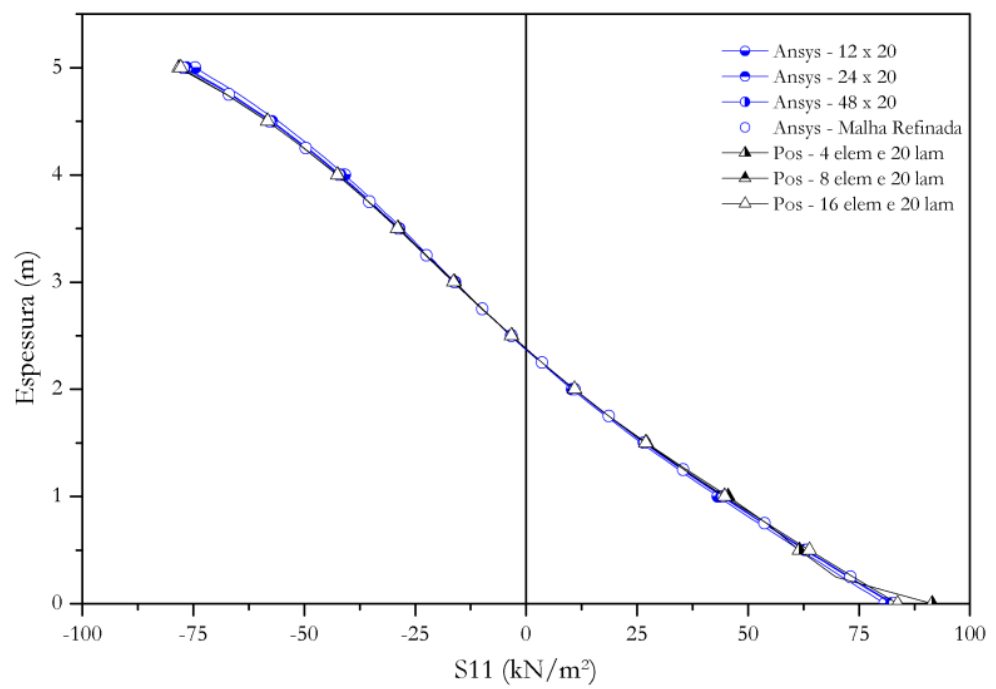

b) Viga $\operatorname{com} S=4$

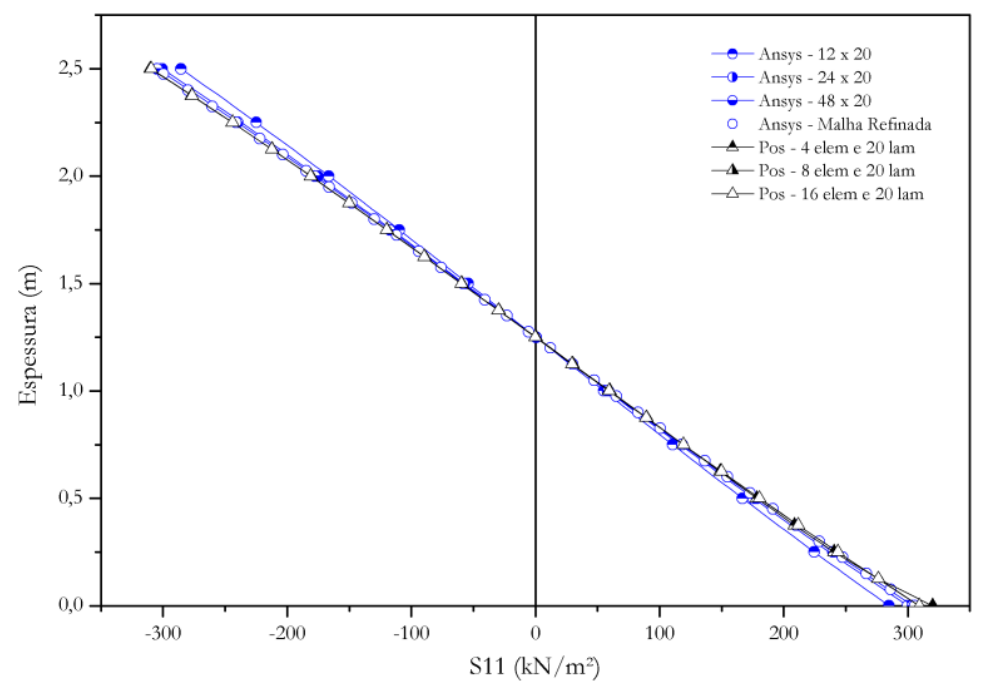

c) Viga $\operatorname{com} S=10$

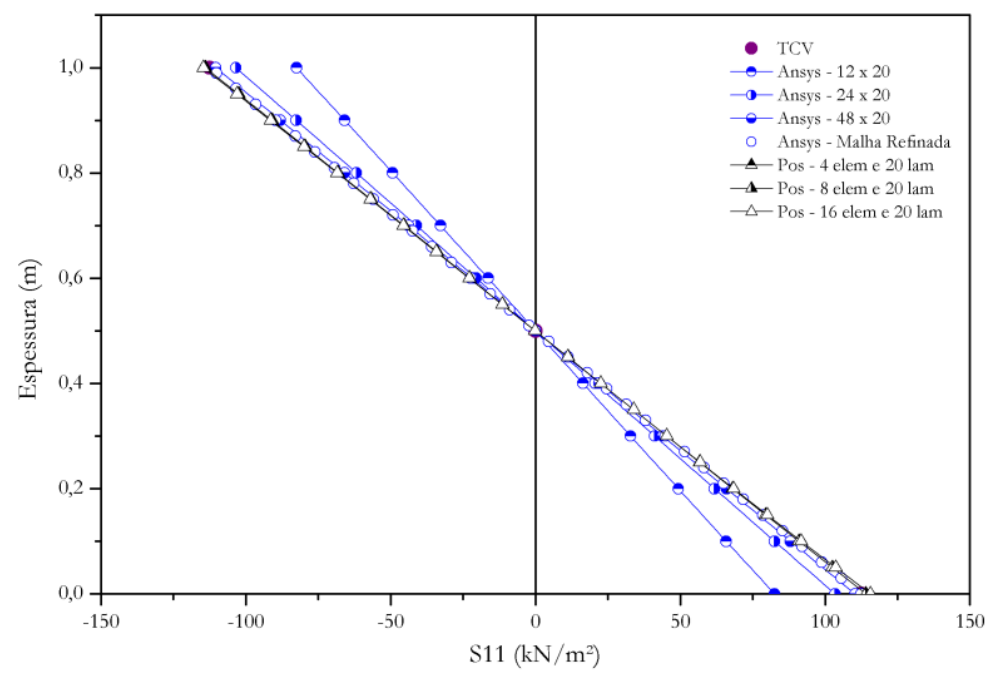

Figura 53 - Resultados do Exemplo 5.1: Tensão axial S11 para seção localizada no meio do vão. 
a) Viga $\operatorname{com} S=2$

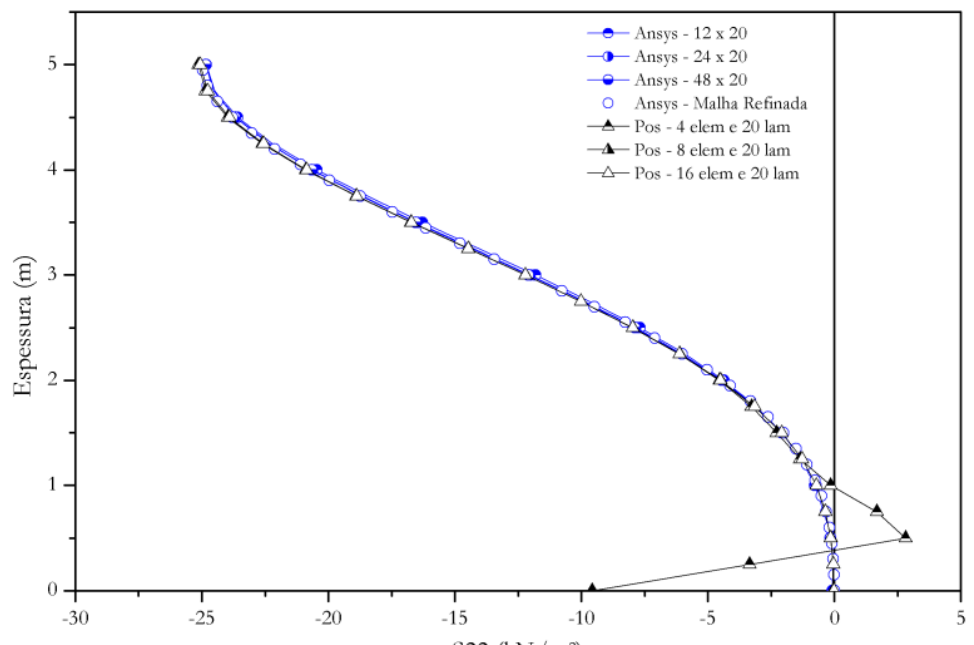

b) Viga $\operatorname{com} S=4$

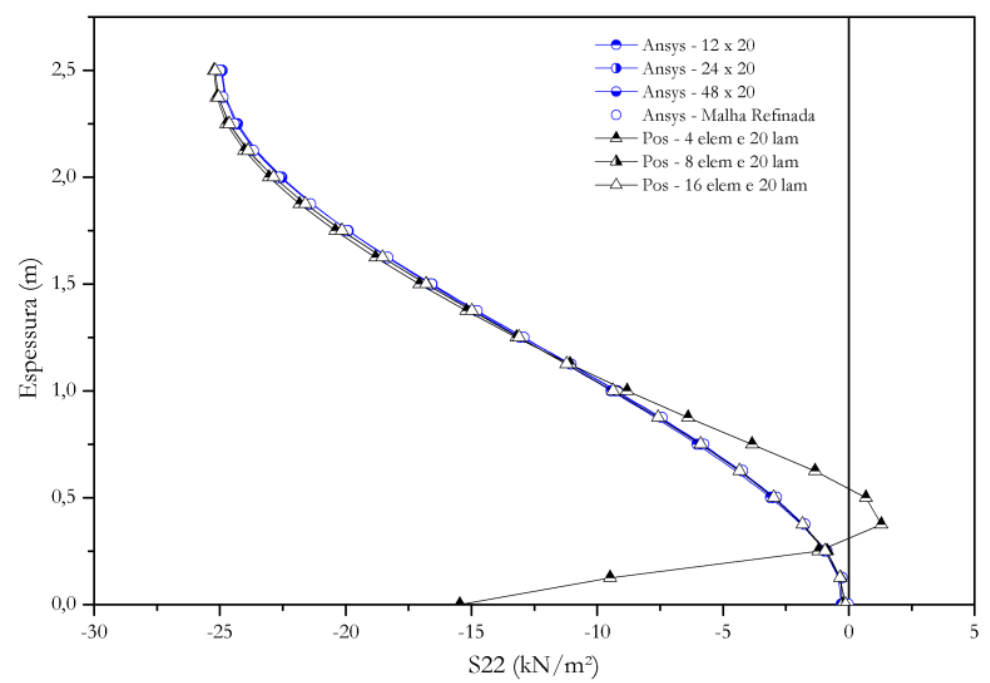

c) Viga $\operatorname{com} S=10$

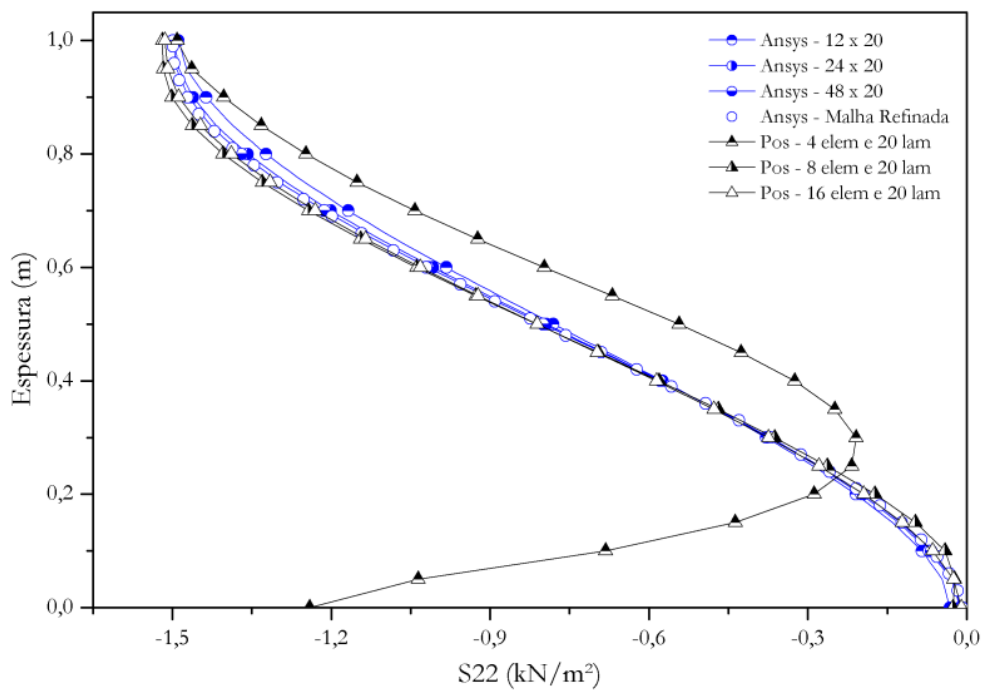

Figura 54 - Resultados do Exemplo 5.1: Tensão axial S22 para seção localizada no meio do vão. 
a) Viga $\operatorname{com} S=2$

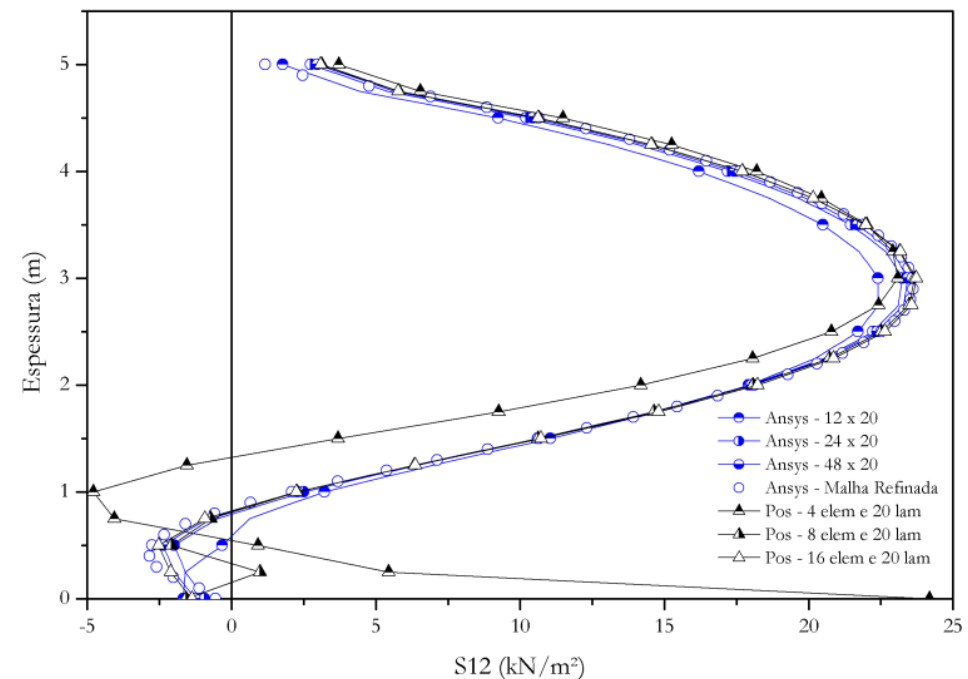

b) Viga $\operatorname{com} S=4$

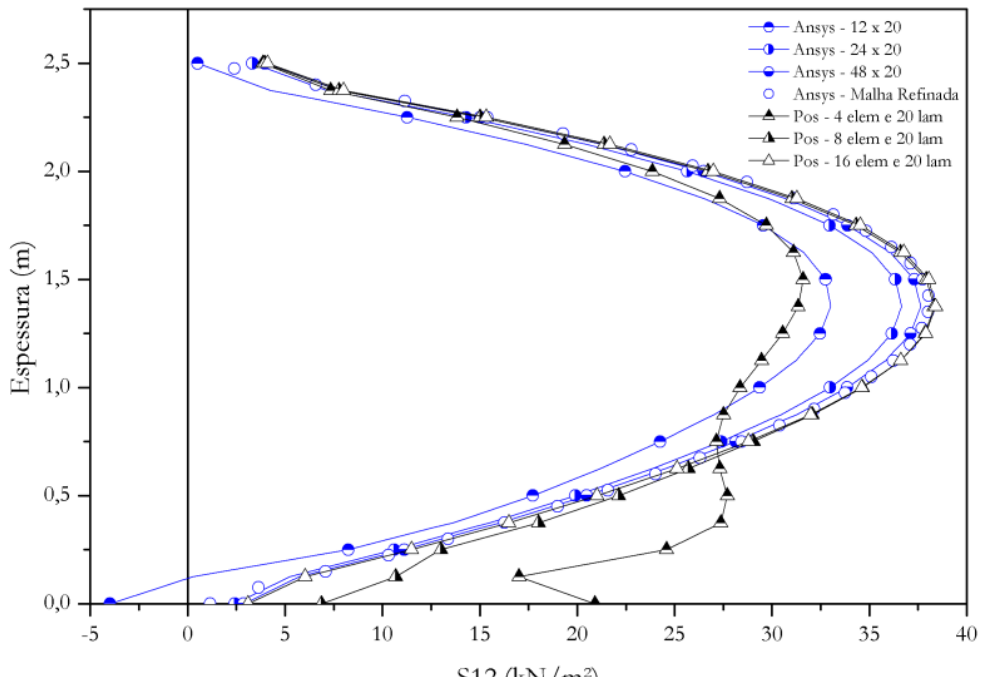

c) Viga $\operatorname{com} S=10$

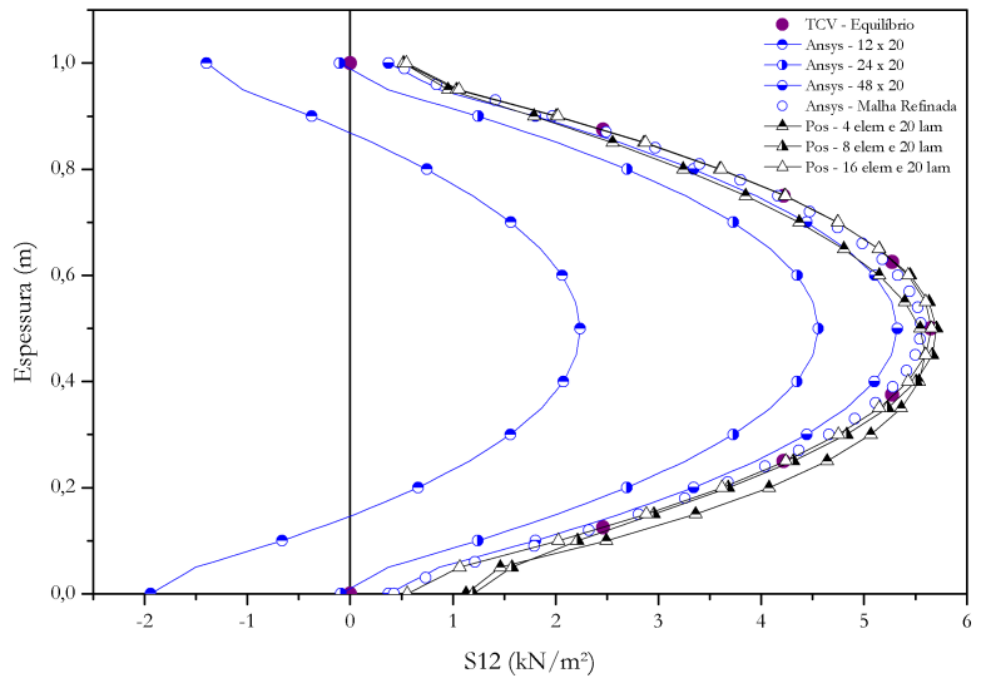

Figura 55 - Resultados do Exemplo 5.1: Tensão de cisalhamento S12 para seção a 2,5 m do apoio esquerdo. 
Para ilustrar os deslocamentos e as tensões obtidos com o elemento de pórtico plano laminado na viga completa, imagens com os mapas de cores dos resultados para a viga esbelta $(S=10)$ discretizada com 16 elementos e 20 lâminas são apresentadas na Figura 56.

a) Deslocamento horizontal $u(\mathrm{~m})$

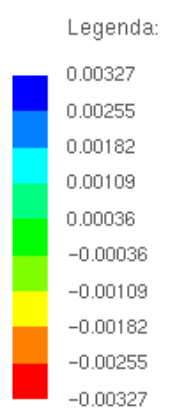

b) Deslocamento vertical $v(\mathrm{~m})$
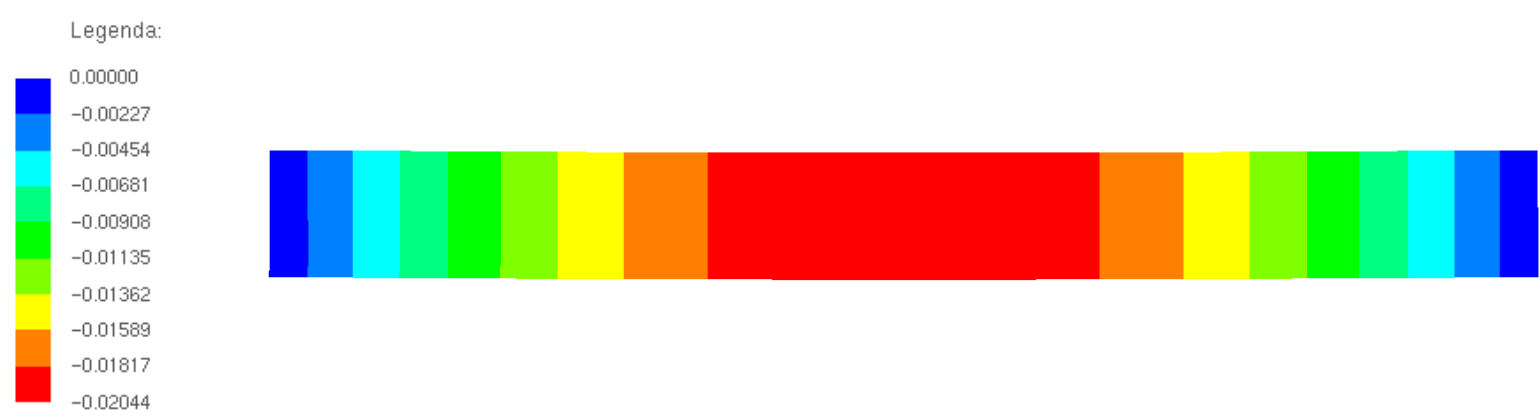

c) Tensão axial longitudinal S11 $\left(\mathrm{kN} / \mathrm{m}^{2}\right)$

$$
\text { Legenda: }
$$

113.90548
88.59290

63.28032

37.96775

12.65517

$-12.65741$

$-37.96999$

$-63.28257$

$-88.59515$

$-113.90773$

d) Tensão axial transversal S22 $\left(\mathrm{kN} / \mathrm{m}^{2}\right)$

Legenda:
23.35229
1.63629
$-20.07970$
$-41.79570$
$-63.51169$
$-85.22769$
$-106.94368$
$-128.65968$
$-150.37567$
$-172.09167$
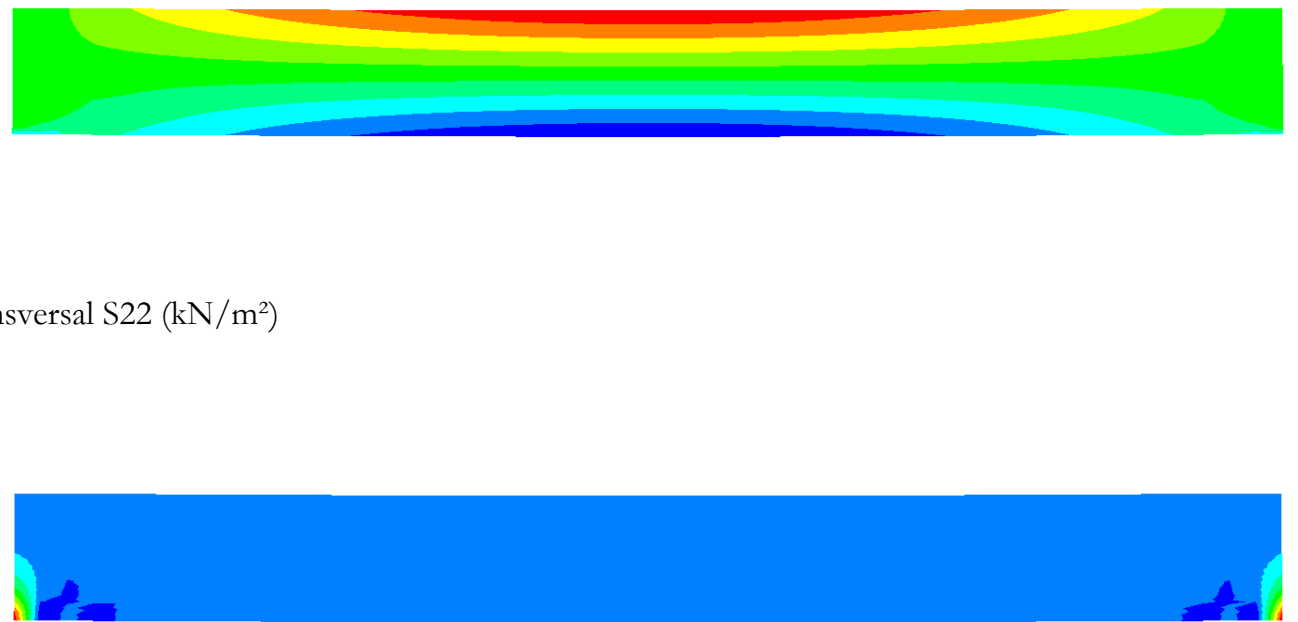
e) Tensão de cisalhamento $\mathrm{S} 12\left(\mathrm{kN} / \mathrm{m}^{2}\right)$

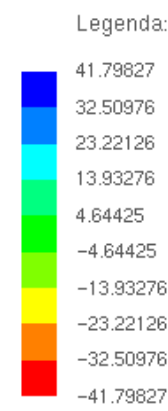

Figura 56 - Resultados do Exemplo 5.1: Mapa de cores para os deslocamentos e tensões na viga com $S=10$.

\subsubsection{Exemplo 5.2: Viga sanduíche biapoiada com força distribuída}

A mesma viga do exemplo anterior é analisada, mas agora a seção é composta por três lâminas formando um compósito laminado do tipo sanduíche. As lâminas das faces possuem espessura correspondente a 5\% da altura total e módulo de elasticidade igual a 100 vezes o módulo de elasticidade da lâmina que compõe o núcleo. As características geométricas da seção transversal e os parâmetros elásticos do material estão representados na Figura 57.

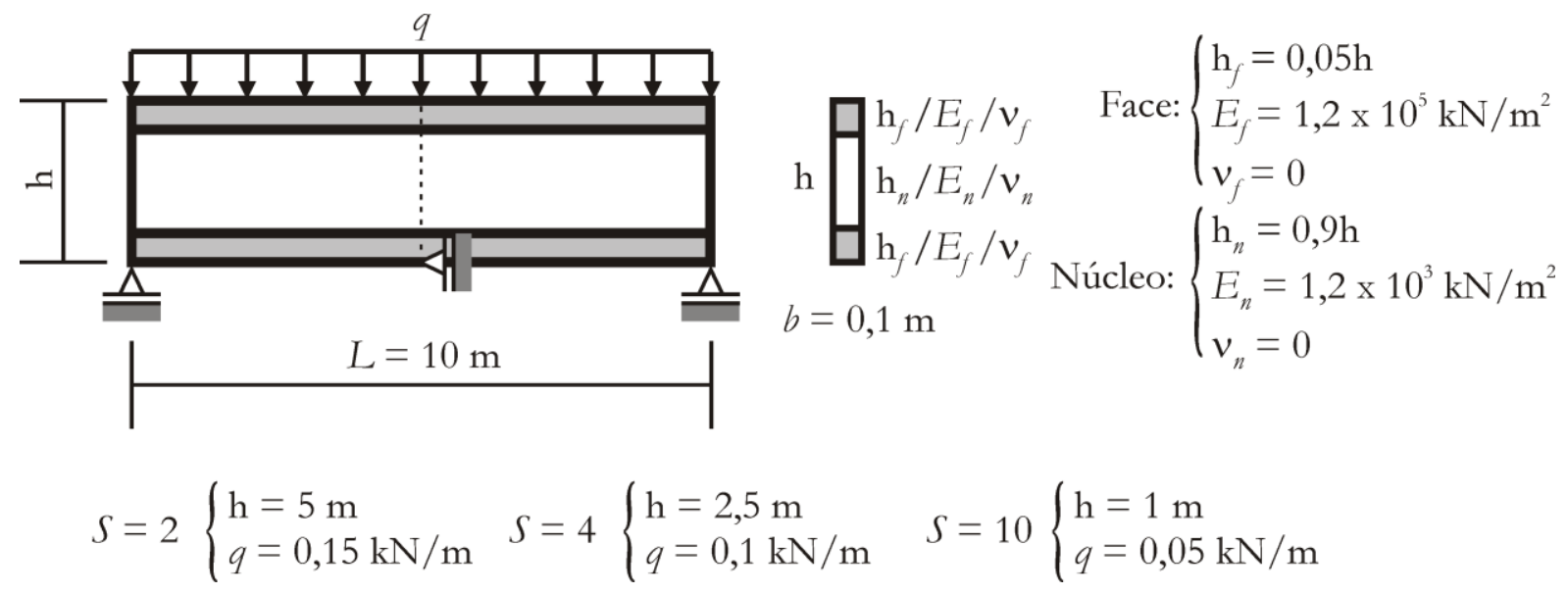

Figura 57 - Geometria, carregamento e parâmetros elásticos do problema: Exemplo 5.2

O problema foi analisado novamente para três situações com a relação entre vão e altura da viga $\left(S=L / h_{0}\right)$ assumindo os valores de 2,4 e 10 . Buscou-se, com isso, verificar também para o caso de uma viga laminada a capacidade da formulação em representar com precisão as distribuições de deslocamentos e tensões em problemas com diferentes relações de esbeltez. A viga foi discretizada com 16 elementos finitos e 20 lâminas (Figura 58), estando 4 na lâmina da face inferior, 12 na lâmina do núcleo e 4 na lâmina da face superior (notação: 4/12/4). 
Essa discretização foi adotada em função das observações extraídas das análises de convergência realizadas no exemplo anterior.

a) Malha de elementos finitos posicionais (16 elementos, 20 lâminas e 2058 graus de liberdade)

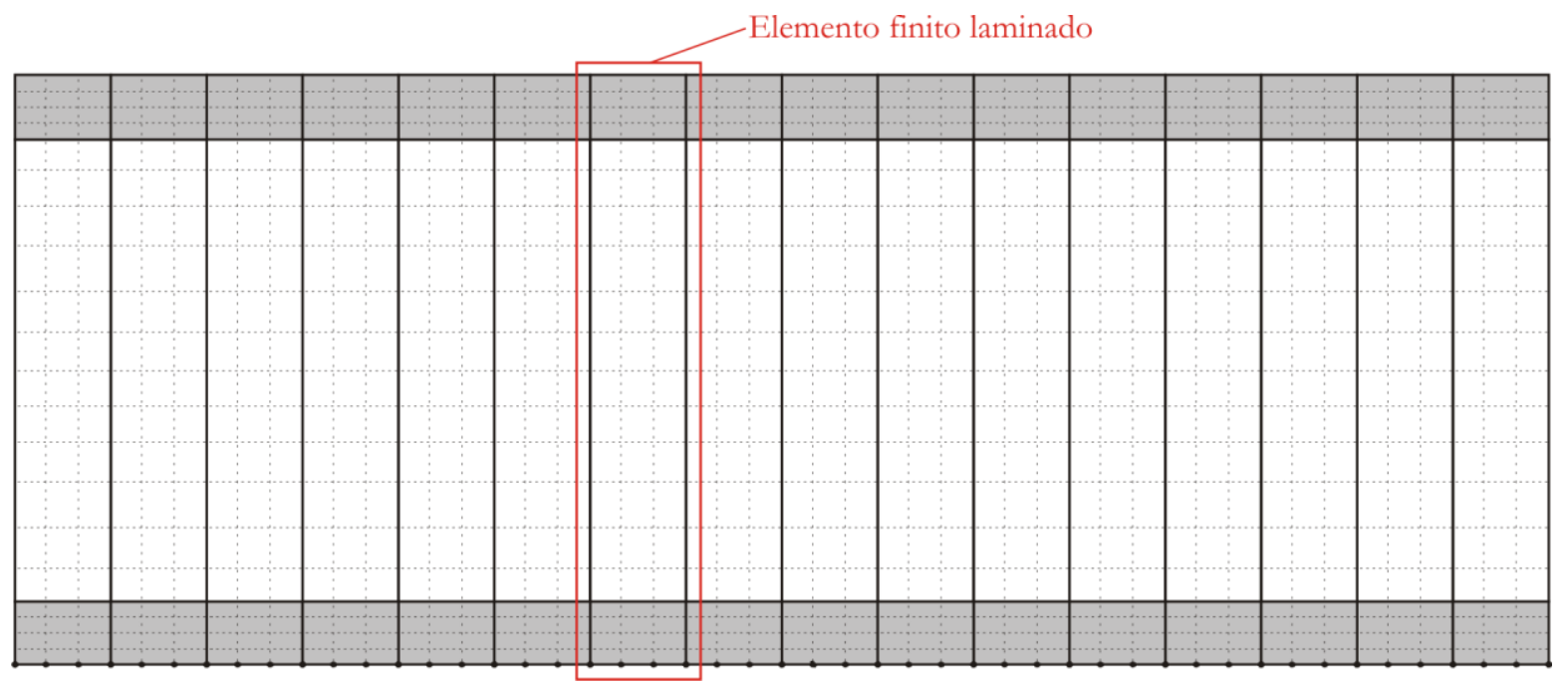

b) Malha equivalente de elementos finitos PLANE42 (960 elementos e 2058 graus de liberdade)

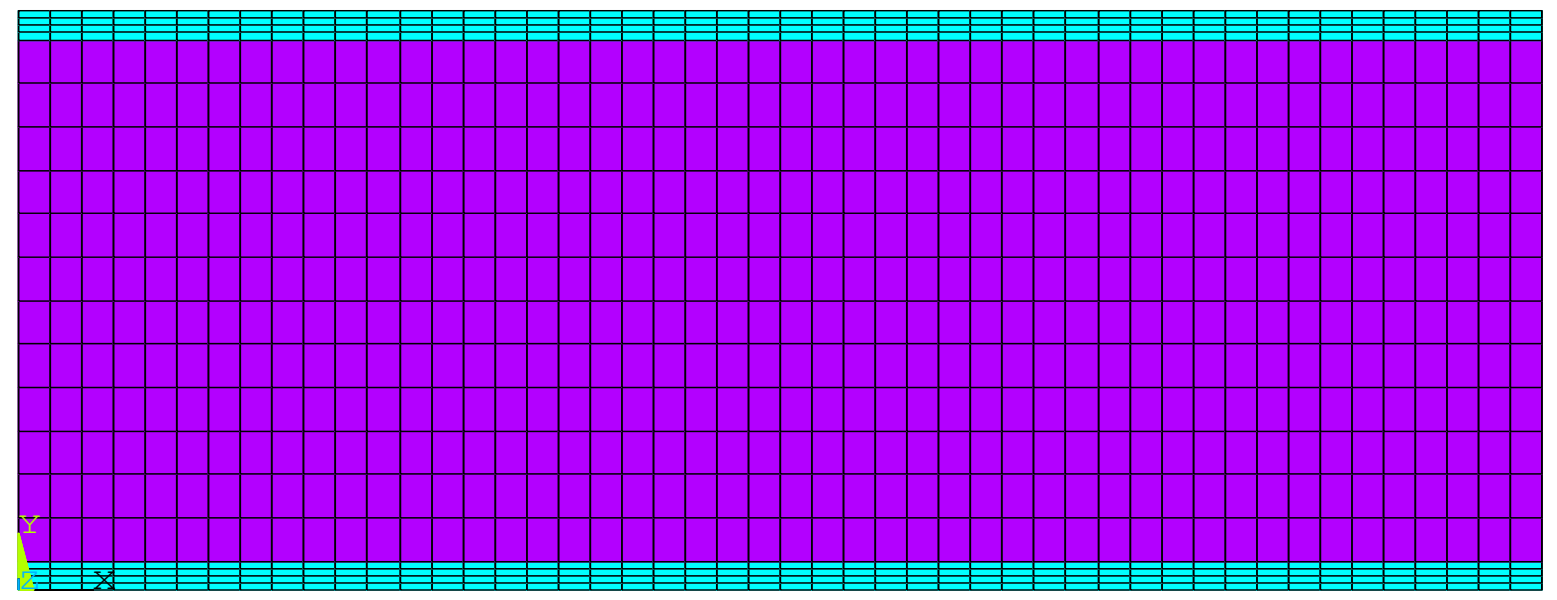

c) Malha refinada de elementos finitos PLANE42 (20000 elementos e 40602 graus de liberdade)

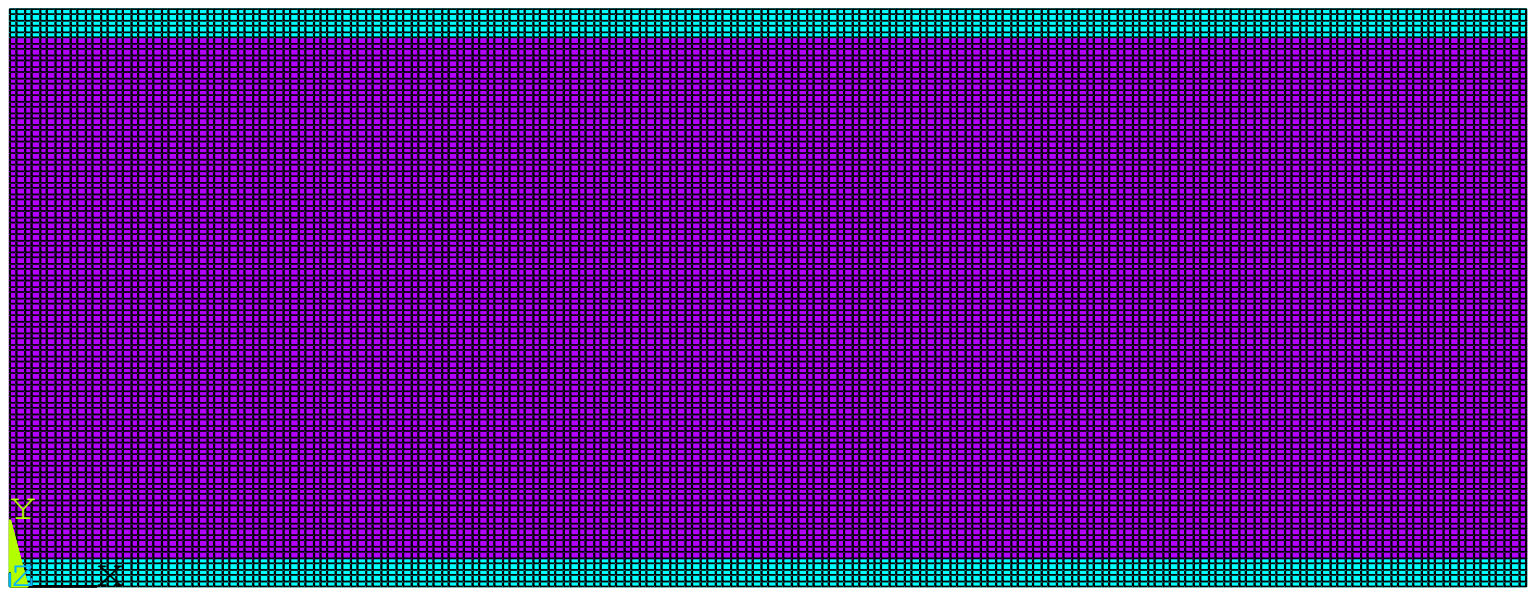

Figura 58 - Malhas de elementos finitos empregadas no Exemplo 5.2 para o caso $\operatorname{com} S=2$ 
Em todas as análises, a força distribuída foi aplicada em um único incremento e o processo de solução baseado no método de Newton-Raphson foi controlado por meio dos critérios de convergência em posição e em força com tolerâncias de $10^{-9}$ e $10^{-6}$, respectivamente. A quantidade de pontos de Gauss empregada nas integrações numéricas do vetor de forças internas e da matriz Hessiana foi de 4 x 20 em cada lâmina da discretização.

Os resultados das análises são apresentados através das distribuições de deslocamento horizontal $u$ (Figura 59), de tensão axial longitudinal S11 (Figura 60), de tensão axial transversal S22 (Figura 61) e de tensão de cisalhamento S12 (Figura 62). Todas as tensões representadas são médias entre elementos e a continuidade interlaminar da tensão axial S11 entre lâminas de mesmo material e das tensões transversais S12 e S22 entre quaisquer lâminas é representada calculando a média dos valores obtidos nas interfaces das lâminas adjacentes. Nessas figuras, também constam os resultados médios obtidos a partir de análises numéricas realizadas no Ansys ${ }^{\circledR}$ com emprego do elemento finito bidimensional PLANE42. A equivalência entre as malhas do elemento finito posicional e do elemento PLANE42 (Figura 58) foi feita de forma análoga a do exemplo anterior. Essa equivalência resulta na seguinte associação:

- Posicional com 16 elementos cúbicos e 20 lâminas (4/12/4) $\Leftrightarrow \quad$ PLANE42 com malha de 48 x 20 elementos, sendo 20 distribuídos em 4/12/4.

Os resultados obtidos a partir de análises numéricas realizadas no Ansys ${ }^{\circledR}$ utilizando uma discretização bastante refinada (Figura 58) também são apresentados e adotados como referência.

Dessa forma, a precisão dos resultados obtidos com o elemento de pórtico plano laminado foi excelente, pois uma ótima concordância com os resultados de referência foi alcançada conforme se observa na representação do deslocamento horizontal $u$, da tensão axial longitudinal S11, da tensão axial transversal S22 e da tensão de cisalhamento S12 nas Figura 59, Figura 60, Figura 61, Figura 62, respectivamente.

Os resultados obtidos no Ansys ${ }^{\circledR}$ com emprego do elemento finito bidimensional PLANE42 através de uma malha equivalente apresentaram menor precisão para as tensões S11 e S12 na região em torno das interfaces entre as lâminas. Essa menor precisão é atribuída a um possível mau condicionamento matricial gerado tanto pela distorção do elemento PLANE42 como também pela mudança das propriedades elásticas do material na região de interfaces.

Em função do desempenho alcançado, a possibilidade de aplicação de forças distribuídas fora da linha de referência do elemento pode ser considerada consistente. Todas essas observações ressaltam a adequabilidade e a eficiência do elemento proposto para analisar problemas planos esbeltos (pórticos) ou não (chapas), constituídos por compósitos laminados. 
a) Viga $\operatorname{com} S=2$

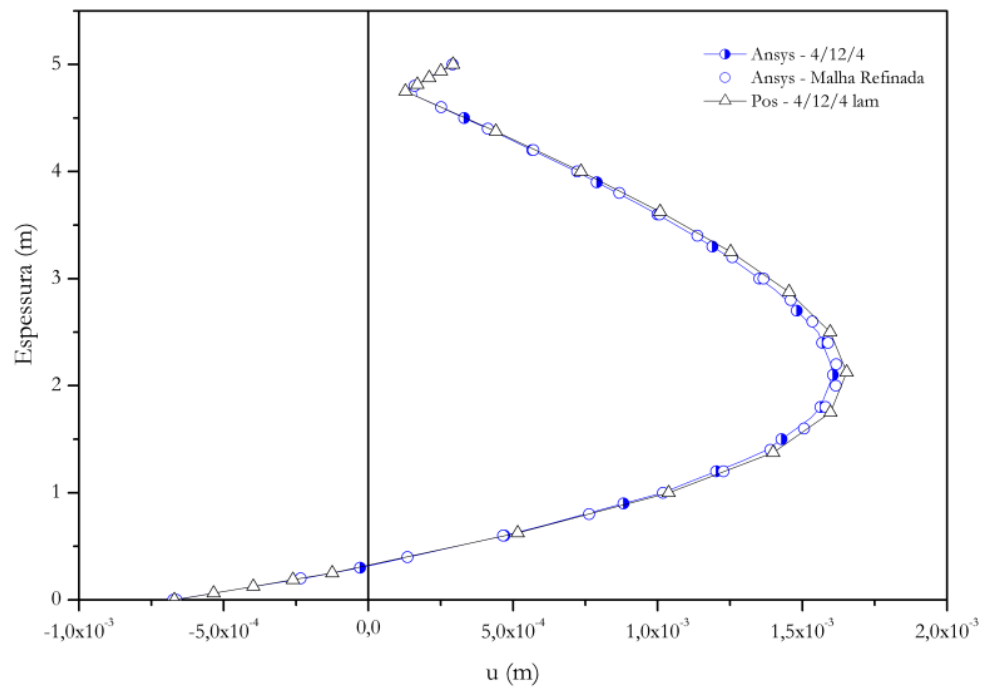

b) Viga $\operatorname{com} S=4$

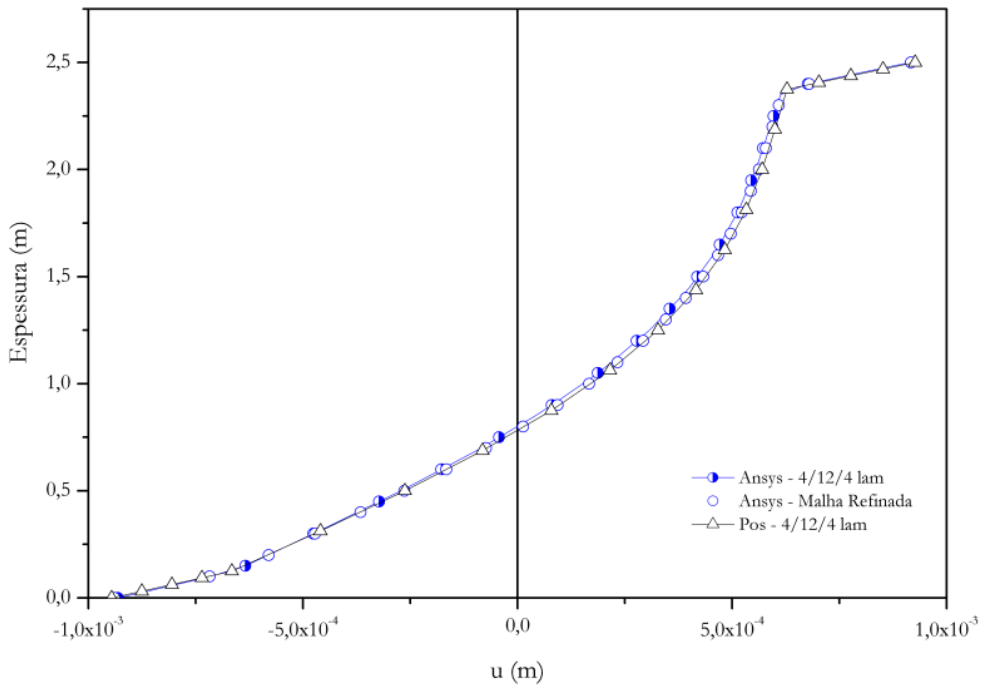

c) Viga $\operatorname{com} S=10$

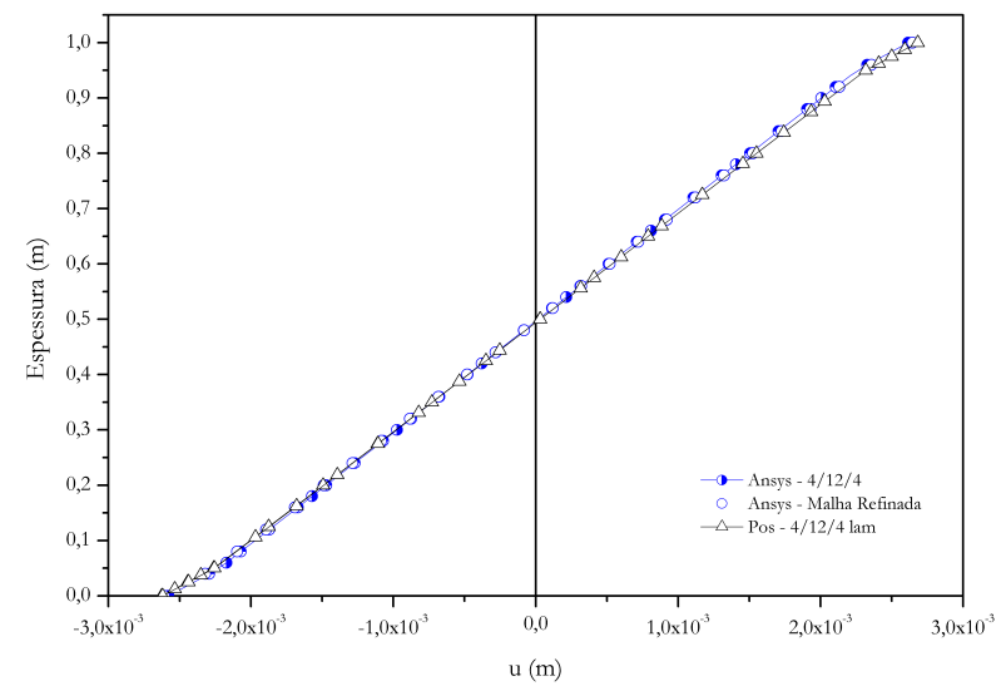

Figura 59 - Resultados do Exemplo 5.2: Deslocamento na direção 1 (u) para seção a 2,5 m do apoio esquerdo. 
a) Viga $\operatorname{com} S=2$

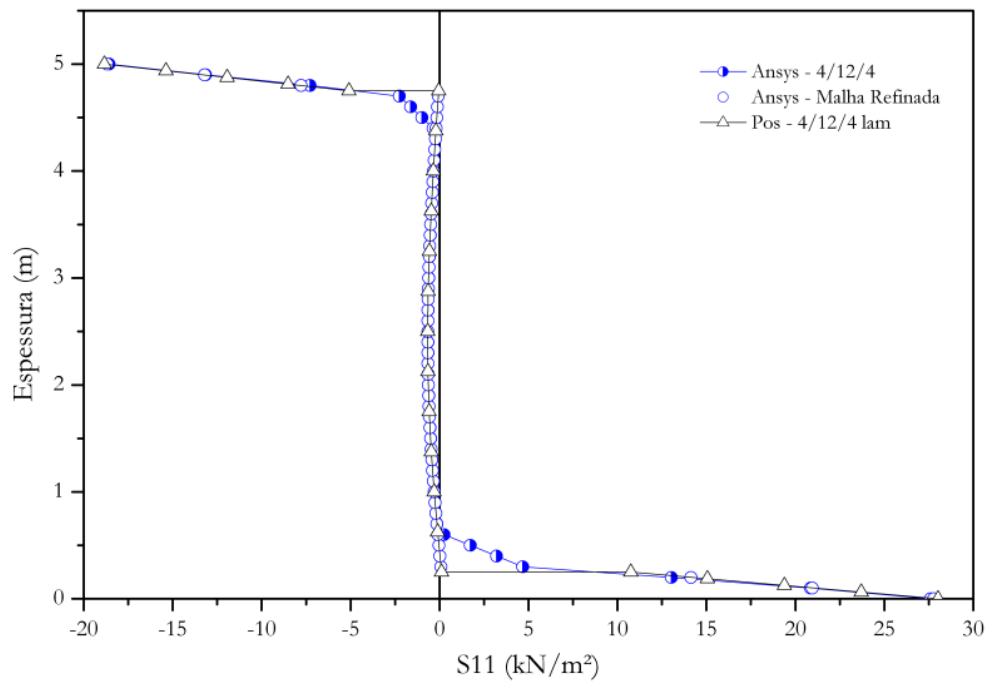

b) Viga $\operatorname{com} S=4$

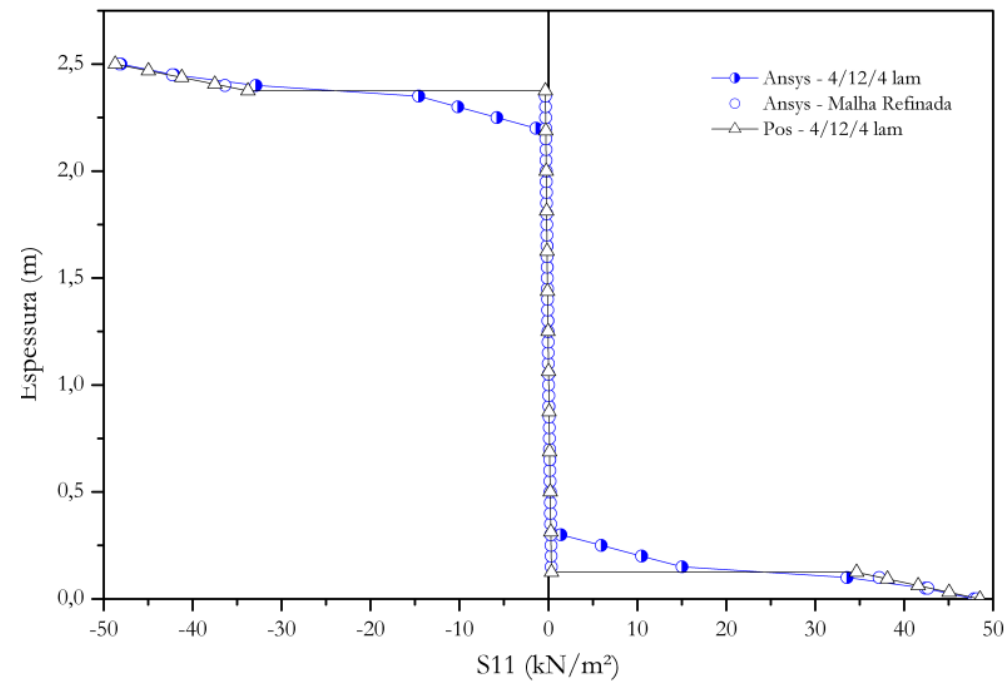

c) Viga $\operatorname{com} S=10$

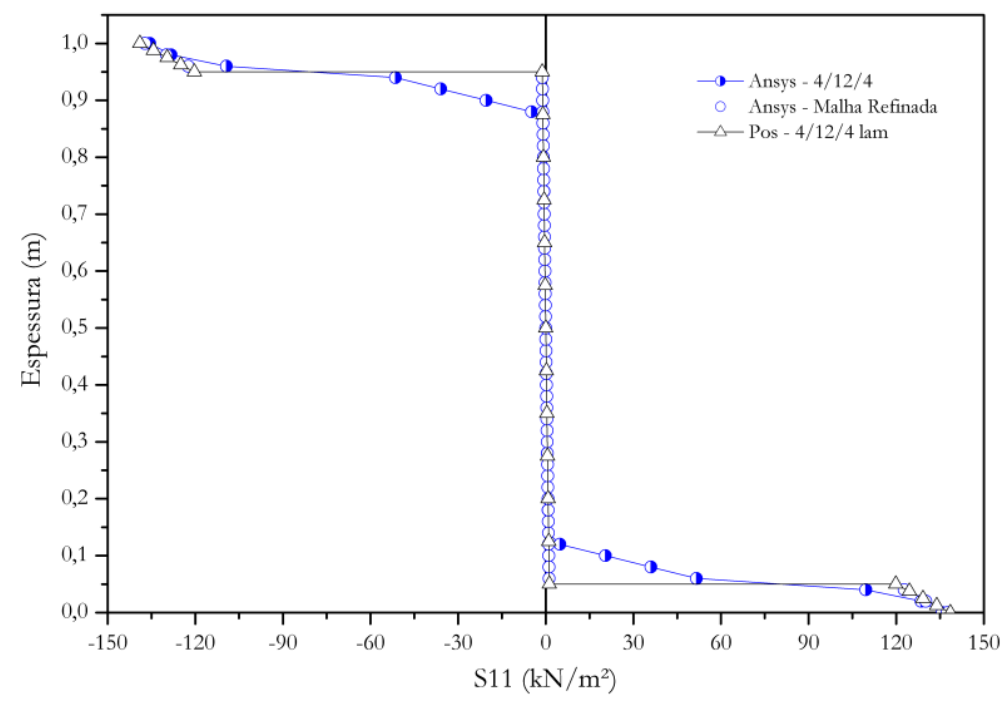

Figura 60 - Resultados do Exemplo 5.2: Tensão axial S11 para seção localizada no meio do vão. 
a) Viga $\operatorname{com} S=2$

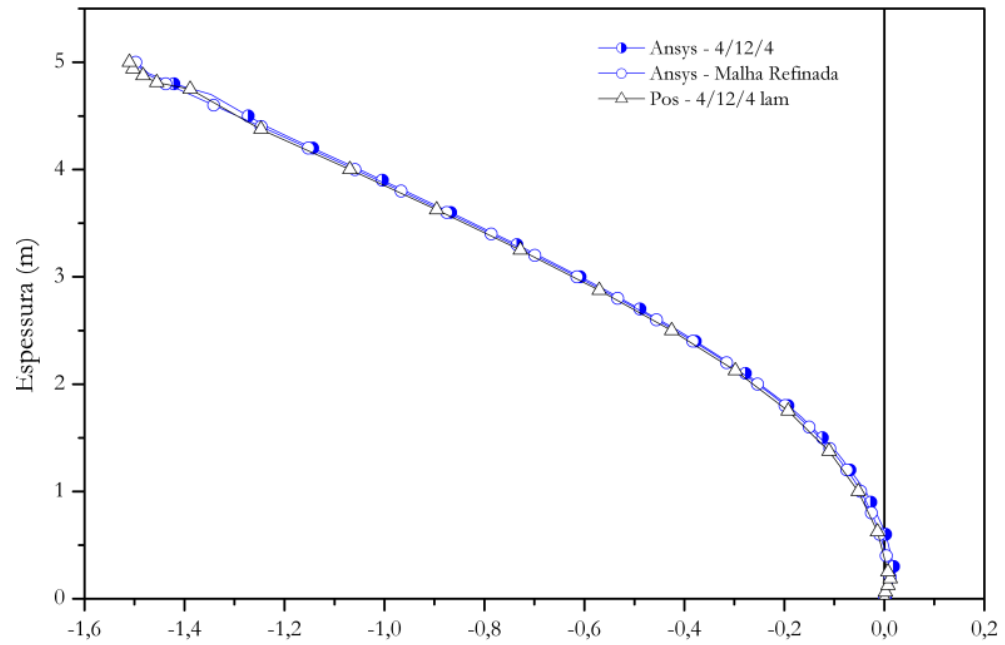

b) Viga $\operatorname{com} S=4$

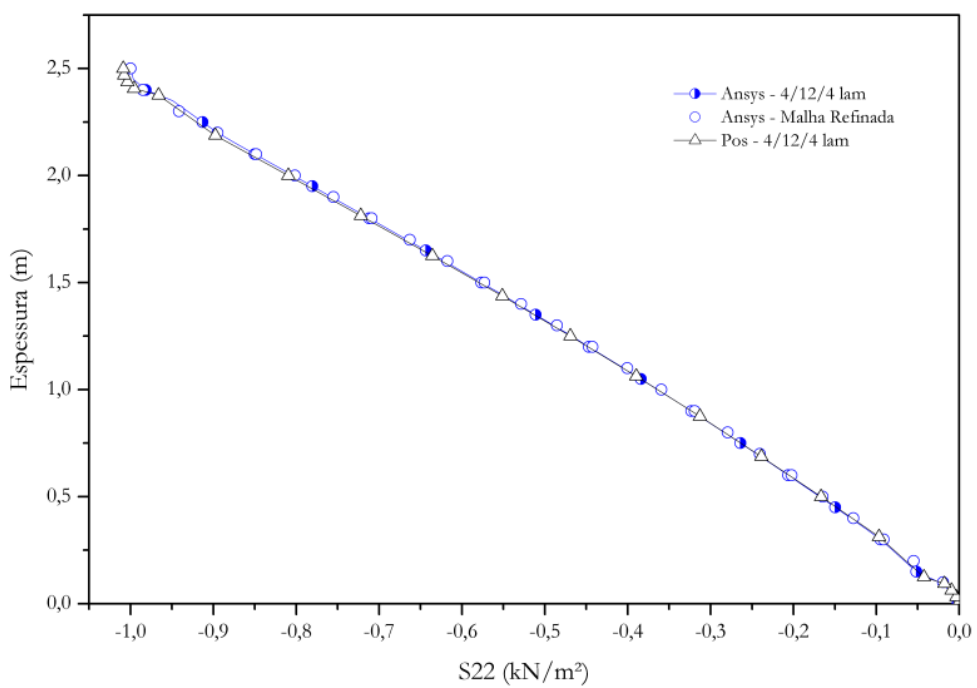

c) Viga $\operatorname{com} S=10$

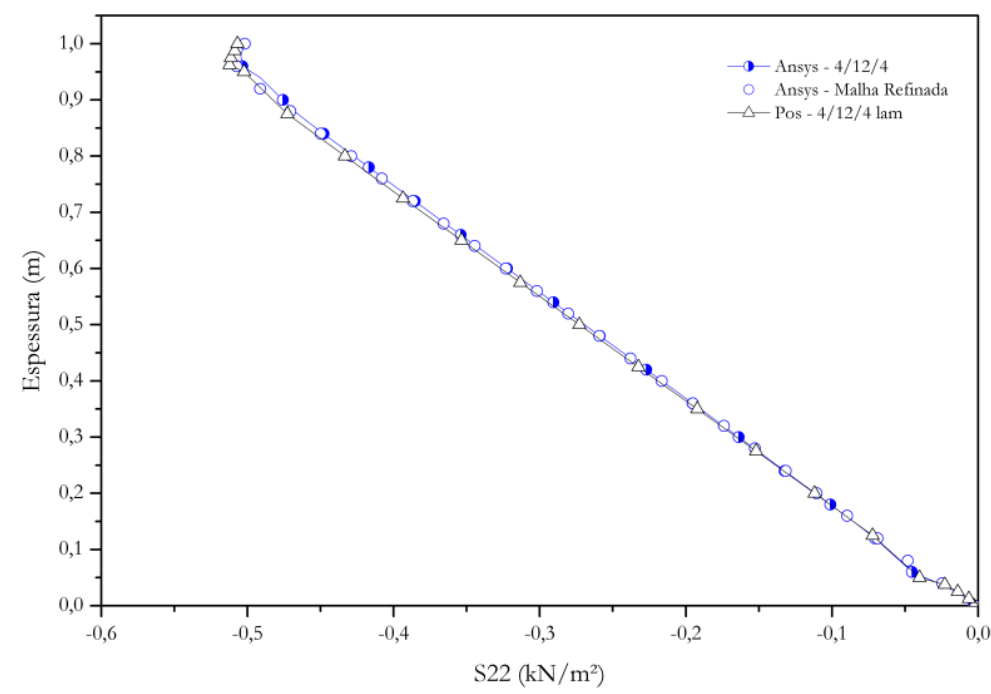

Figura 61 - Resultados do Exemplo 5.2: Tensão axial S22 para seção localizada no meio do vão. 
a) Viga $\operatorname{com} S=2$

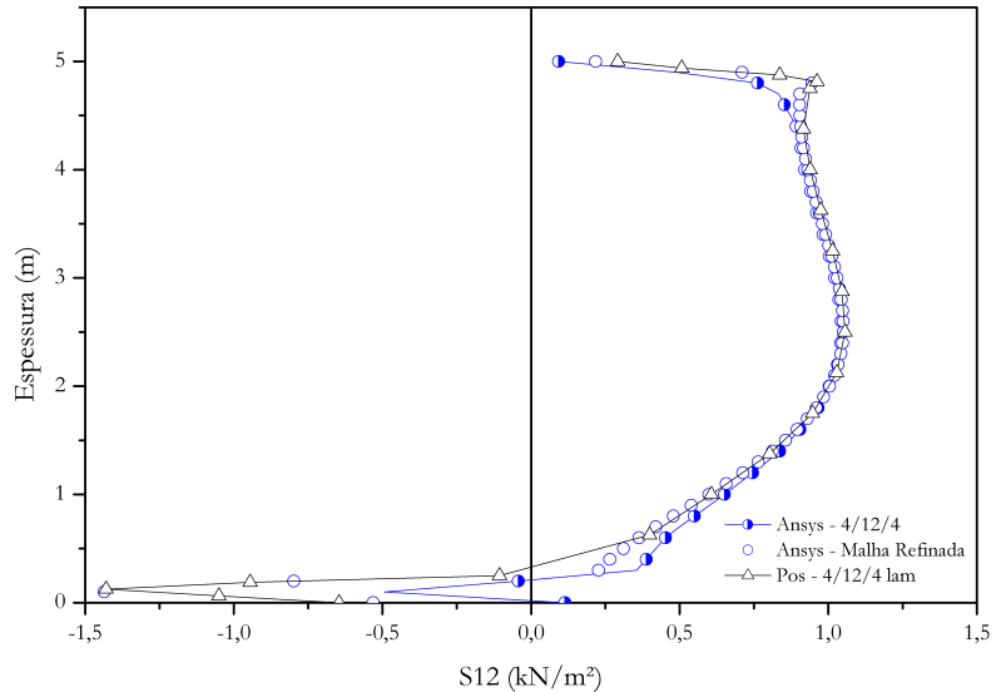

b) Viga $\operatorname{com} S=4$

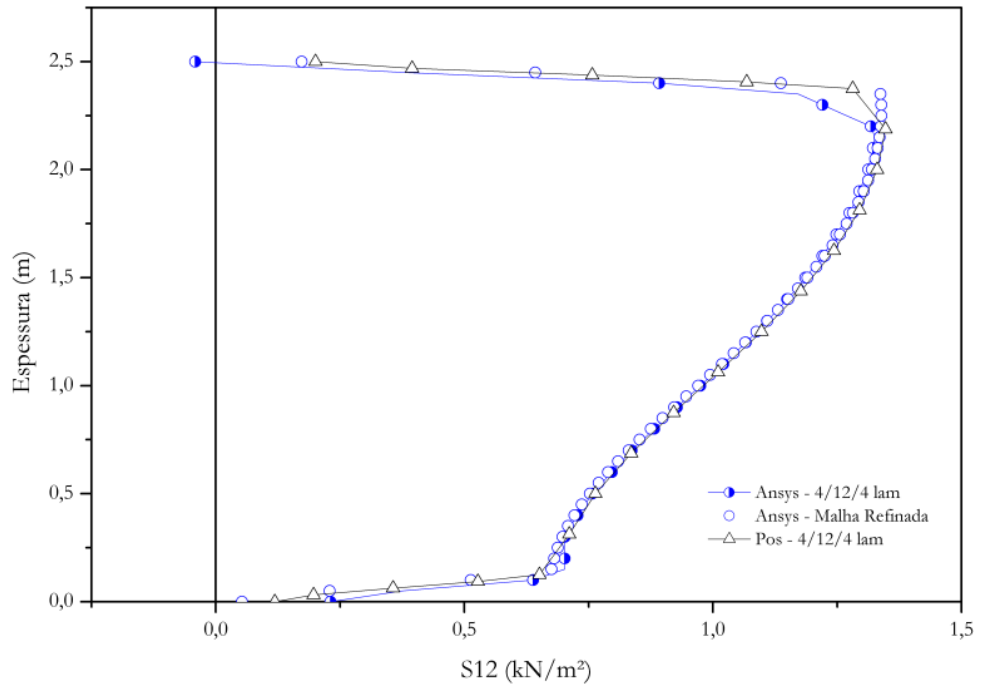

c) Viga $\operatorname{com} S=10$

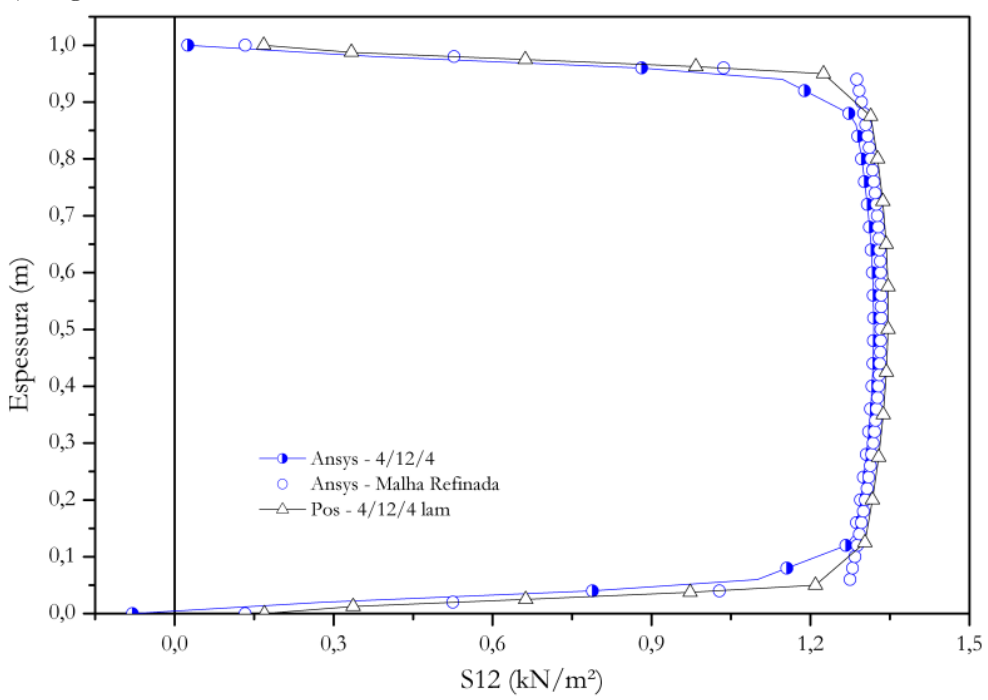

Figura 62 - Resultados do Exemplo 5.2: Tensão de cisalhamento S12 para seção a 2,5 m do apoio esquerdo. 
Para ilustrar os deslocamentos e as tensões obtidos com o elemento de pórtico plano laminado na viga completa, imagens com os mapas de cores dos resultados para a viga alta $(S=2)$ são apresentadas na Figura 63.

a) Deslocamento horizontal $u(\mathrm{~m})$

- Com valores máximos:

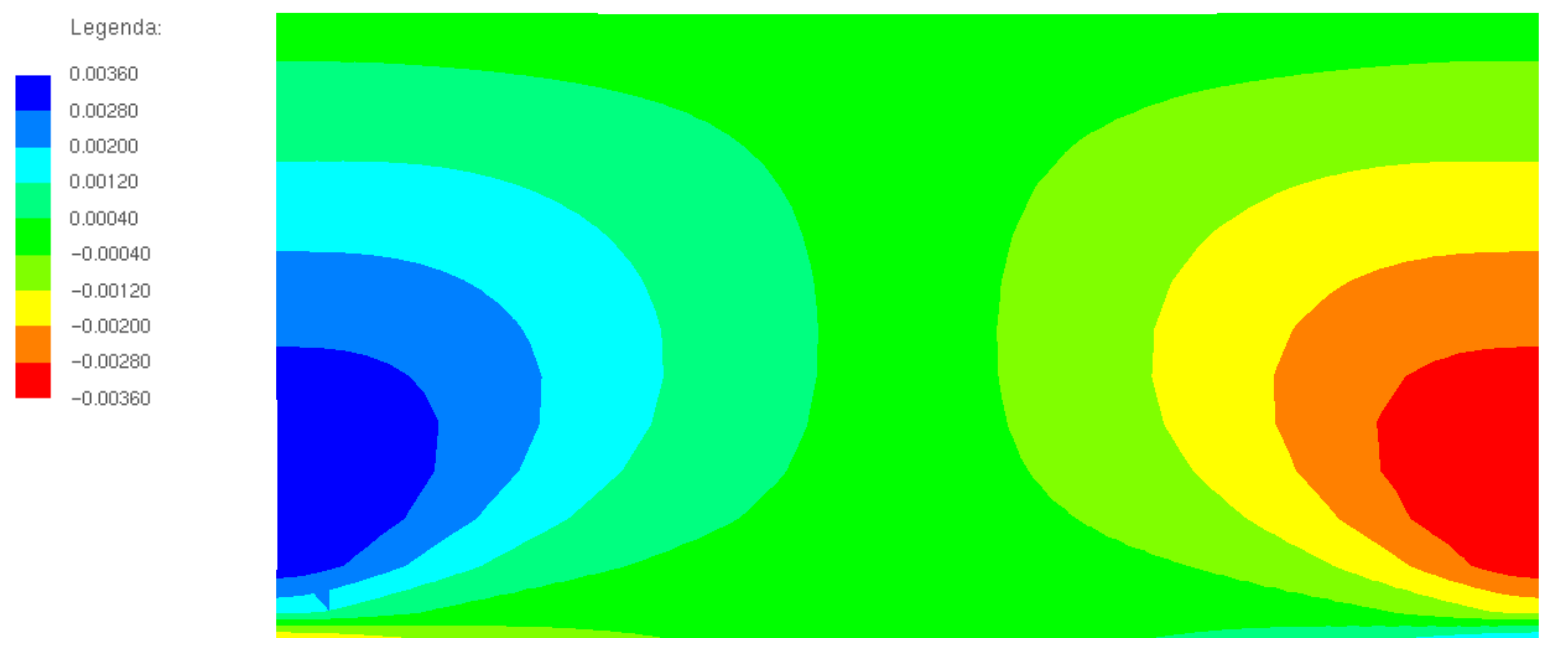

b) Deslocamento vertical $v(\mathrm{~m})$

- Com valores máximos:

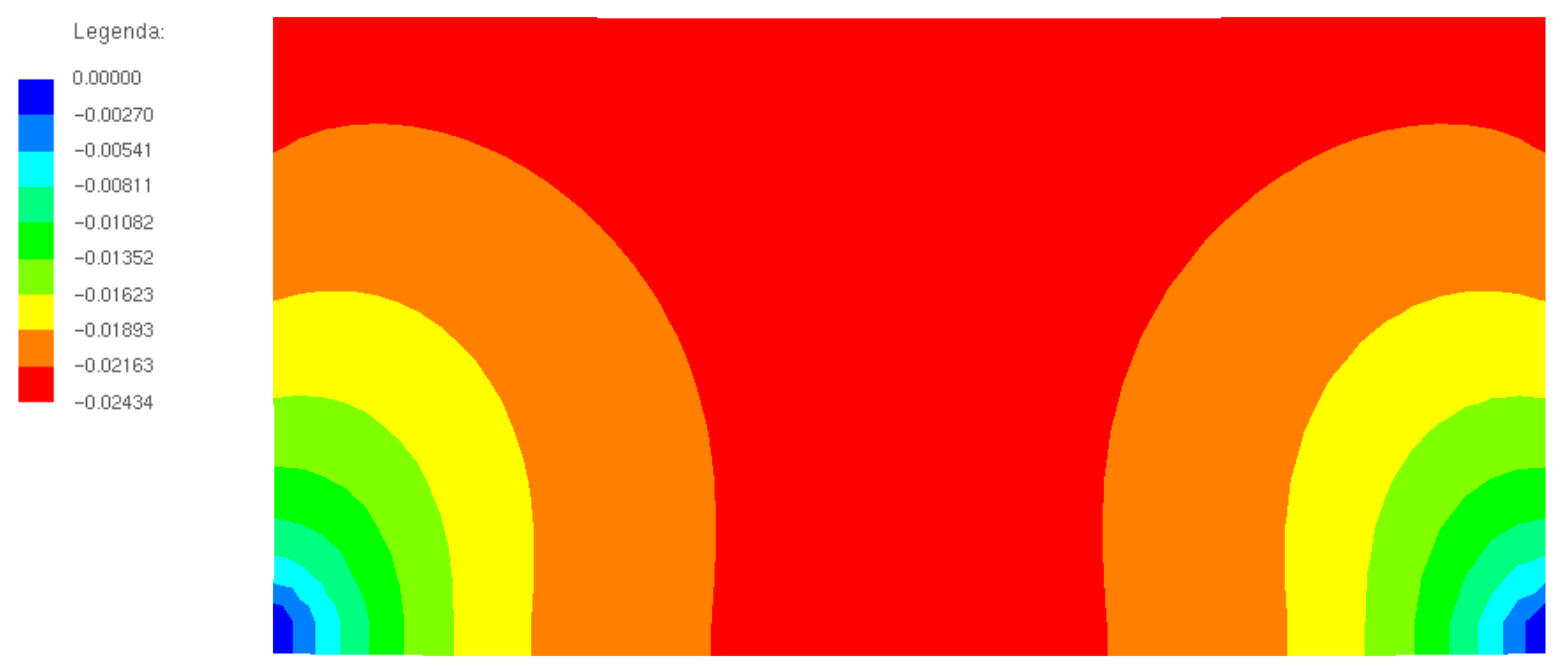


Capítulo 5 - Elemento finito de pórtico plano laminado

c) Tensão axial longitudinal S11 $\left(\mathrm{kN} / \mathrm{m}^{2}\right)$

- Com valores máximos:

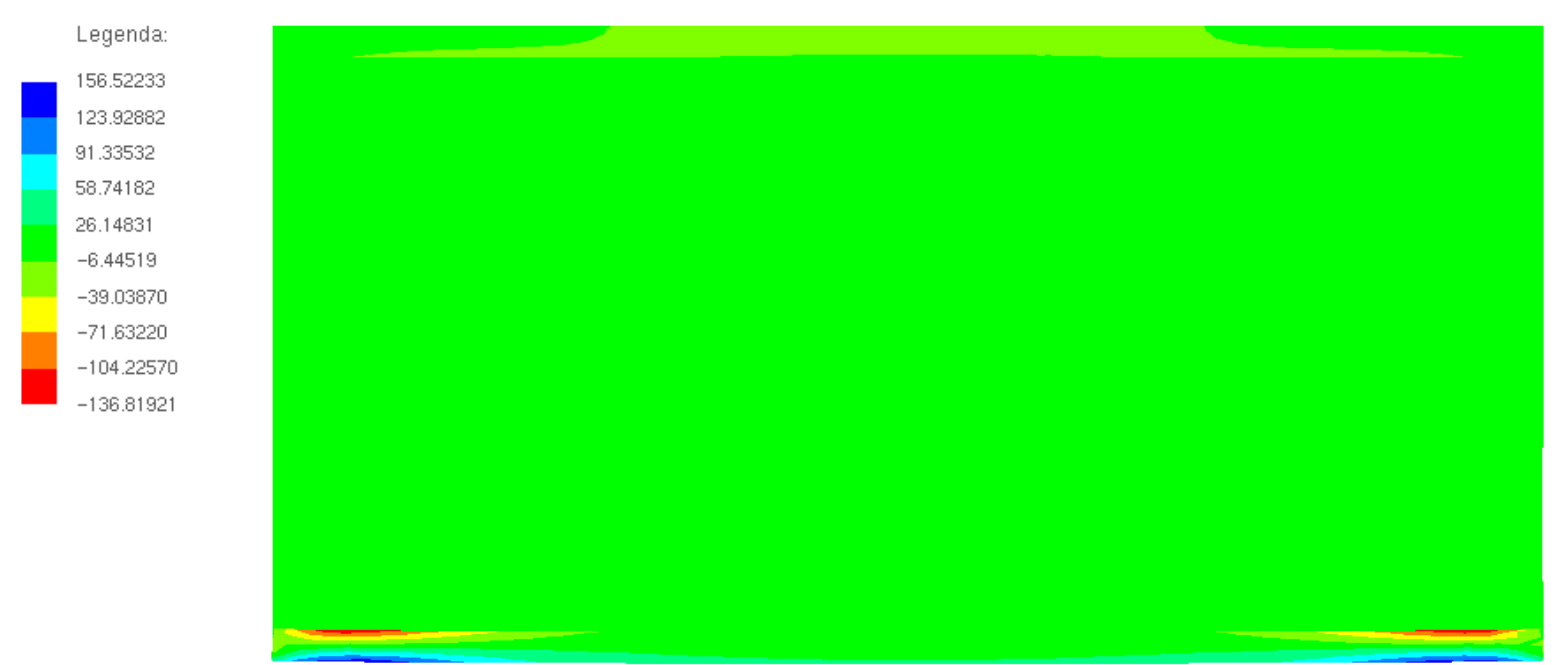

- Com valores em um intervalo selecionado:

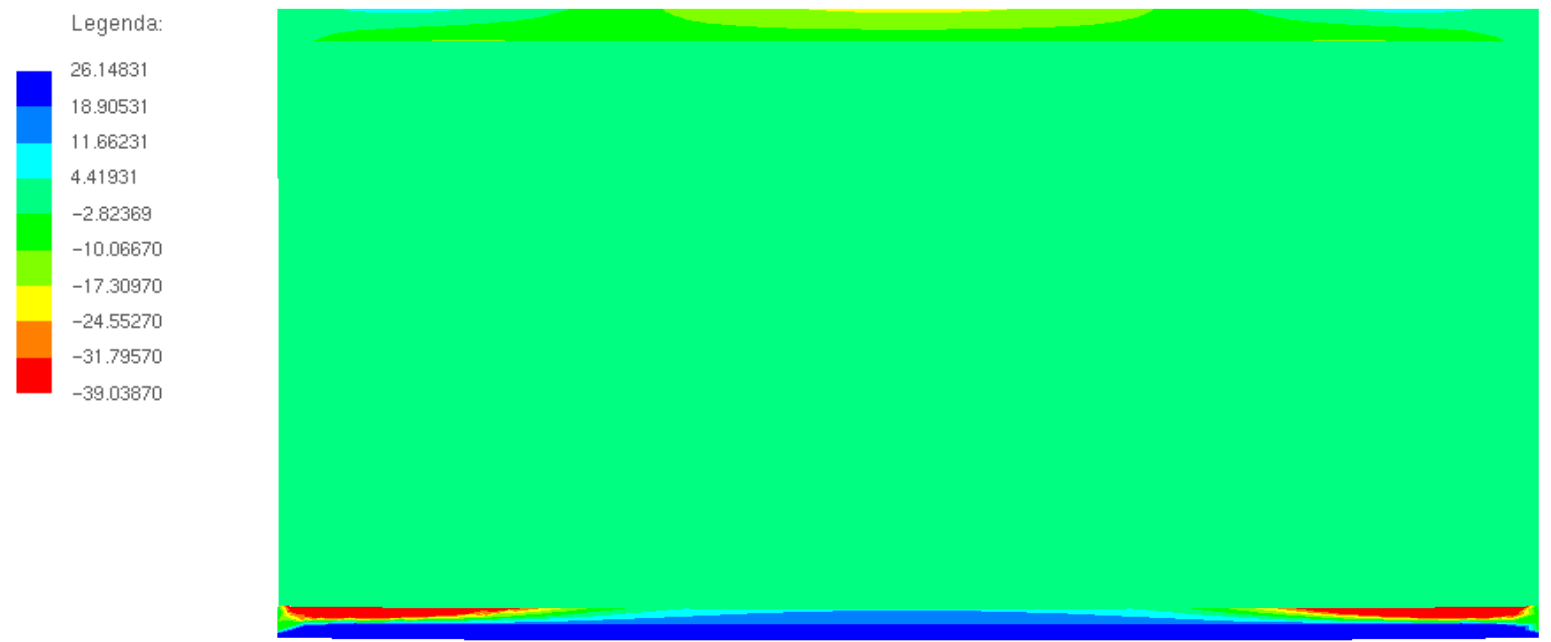

d) Tensão axial transversal S22 $\left(\mathrm{kN} / \mathrm{m}^{2}\right)$

- Com valores máximos:

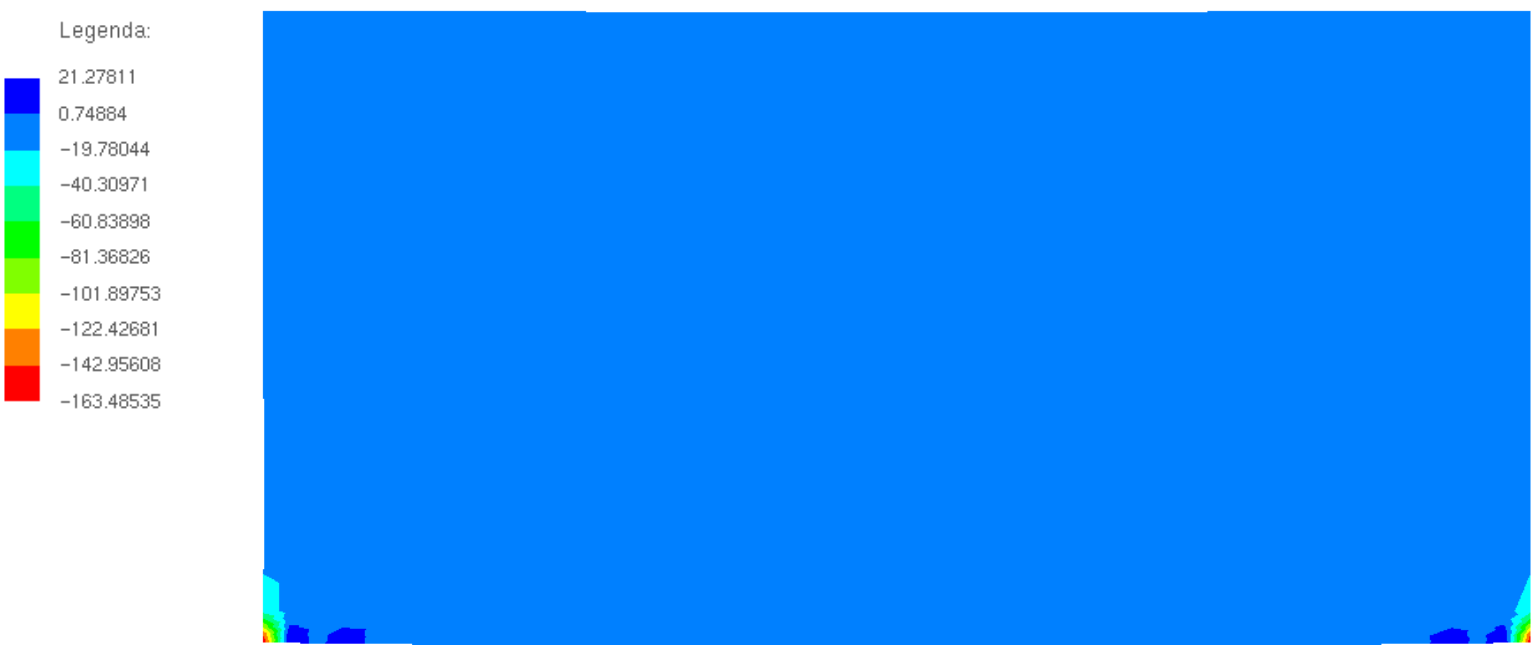


- Com valores em um intervalo selecionado:

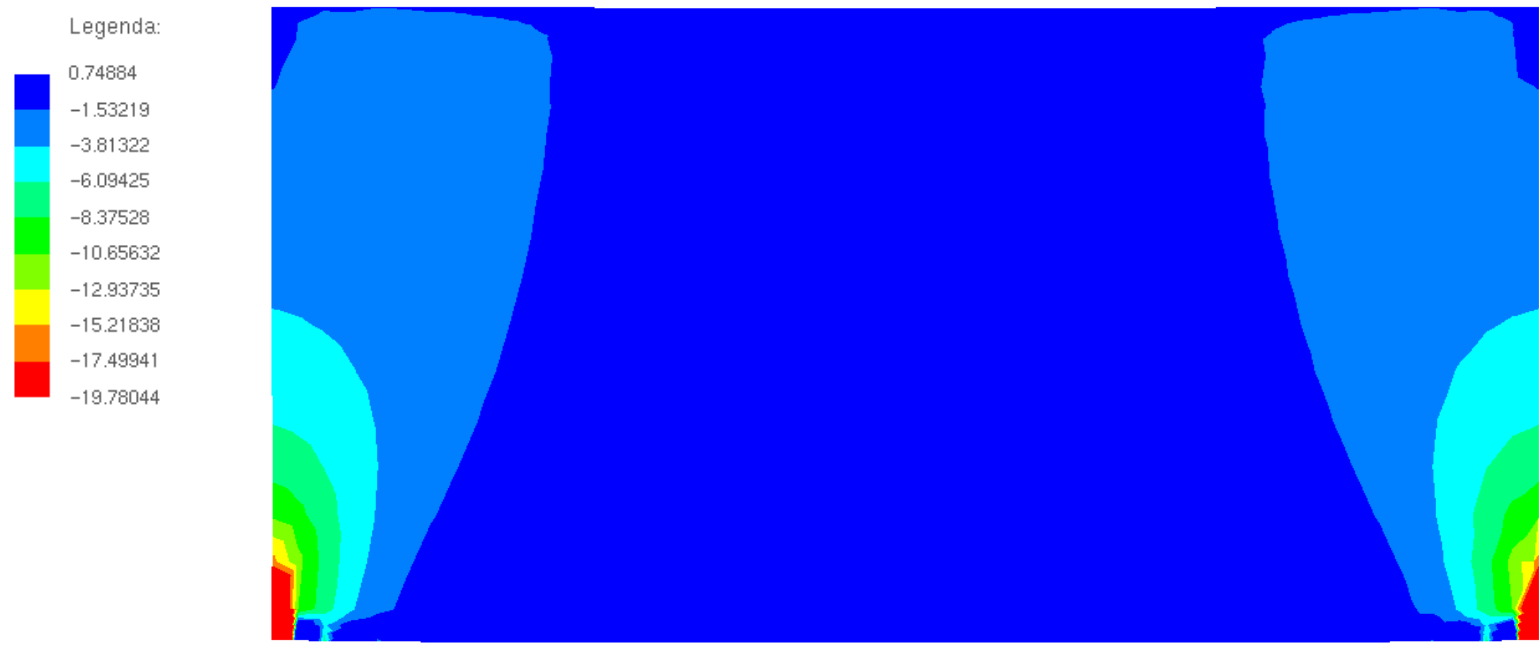

e) Tensão de cisalhamento $\mathrm{S} 12\left(\mathrm{kN} / \mathrm{m}^{2}\right)$

- Com valores máximos:
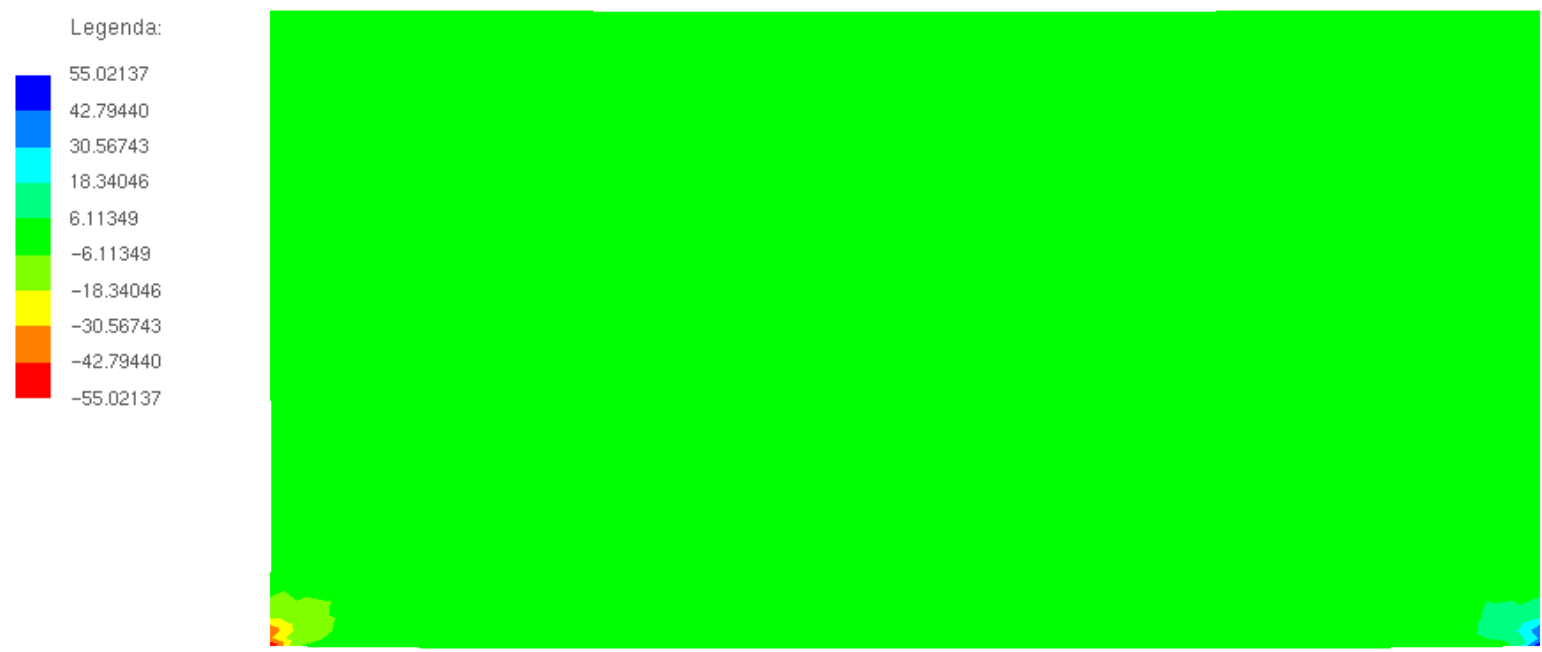

- Com valores em um intervalo selecionado:

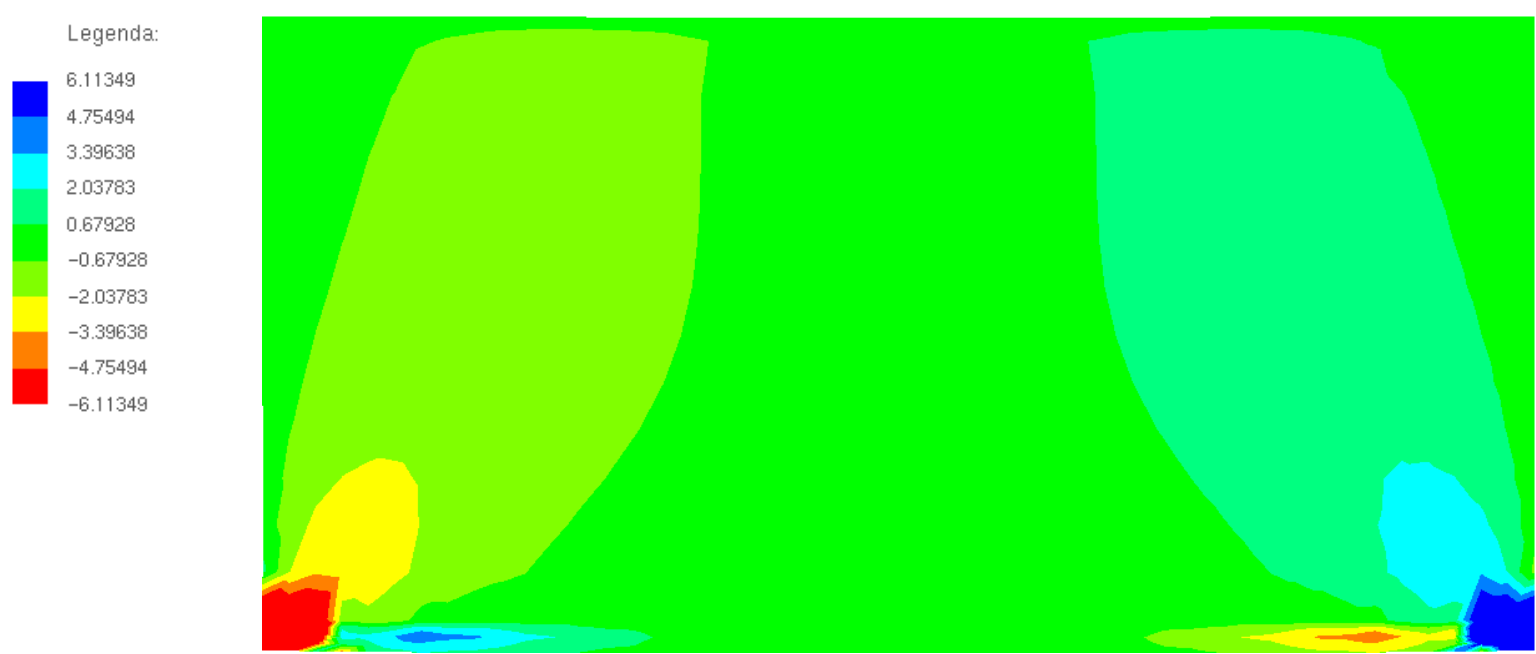

Figura 63 - Resultados do Exemplo 5.2: Mapa de cores para os deslocamentos e tensões na viga com $S=2$. 


\subsubsection{Exemplo 5.3: Viga sanduíche biapoiada com força concentrada}

Neste terceiro exemplo, uma viga sanduíche semelhante a do exemplo anterior submetida à ação de uma força concentrada aplicada no topo da seção localizada no meio do vão e com relação vão e altura $S$ igual a 4 é analisada. São consideradas três situações (AAA, ABA e ACA) nas quais o módulo de elasticidade da lâmina que compõe o núcleo é dividido por 100 começando com um módulo igual ao do material das lâminas localizadas nas faces. As características geométricas da seção transversal e os parâmetros elásticos do material das lâminas estão representados na Figura 64.

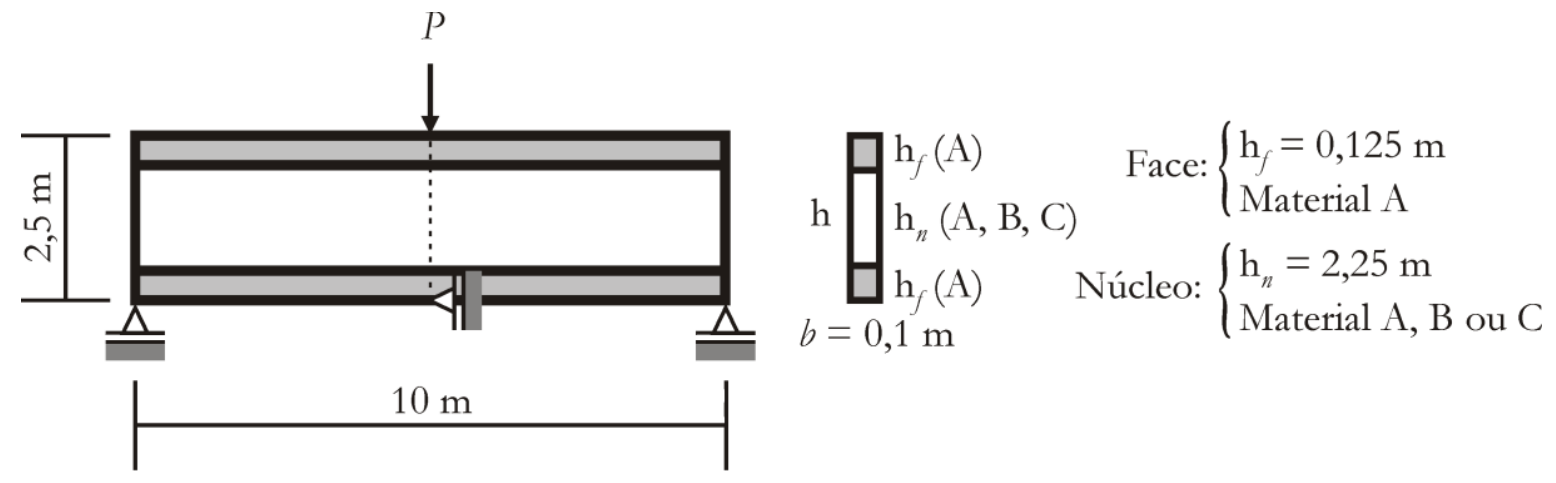

$$
\text { Força: }\left\{\begin{array} { l } 
{ \text { Modelo AAA: } P = 1 0 \mathrm { kN } } \\
{ \text { Modelo ABA: } P = 1 \mathrm { kN } } \\
{ \text { Modelo ACA: } P = 0 , 0 2 \mathrm { kN } }
\end{array} \text { Material: } \left\{\begin{array}{l}
E_{\mathrm{A}}=1,2 \times 10^{5} \mathrm{kN} / \mathrm{m}^{2}, v_{\mathrm{A}}=0 \\
E_{\mathrm{B}}=1,2 \times 10^{3} \mathrm{kN} / \mathrm{m}^{2}, v_{\mathrm{B}}=0 \\
E_{\mathrm{C}}=1,2 \times 10^{1} \mathrm{kN} / \mathrm{m}^{2}, v_{\mathrm{C}}=0
\end{array}\right.\right.
$$

Figura 64 - Geometria, carregamento e parâmetros elásticos do Exemplo 5.3

As análises realizadas nessas três situações permitiram verificar a capacidade da formulação em representar com precisão as distribuições de deslocamentos e tensões em problemas com variações significativas do módulo de elasticidade das lâminas, situação comum principalmente nos compósitos laminados do tipo sanduíche. Isso pode conduzir a problemas de mau condicionamento matricial do modelo discreto de elementos finitos devido à mudança brusca de rigidez entre elementos (lâminas) adjacentes. Os resultados do exemplo anterior já indicaram haver esse problema para as análises realizadas no programa Ansys ${ }^{\circledR}$ utilizando o elemento PLANE42 (com discretização equivalente), pois na região em torno das interfaces entre lâminas os resultados obtidos apresentaram maiores discordâncias.

Além de tudo isso, o problema analisado permitiu avaliar a capacidade da formulação em considerar outro tipo de ação externa: uma força concentrada aplicada em um ponto localizado fora da linha referência do elemento. 
Novamente a viga foi discretizada com 16 elementos finitos e 20 lâminas (Figura 65), estando 4 na face inferior, 12 no núcleo e 4 na face superior (notação: 4/12/4). Essa discretização foi adotada em função dos resultados alcançados nos exemplos anteriores.

a) Malha de elementos finitos posicionais (16 elementos, 20 lâminas e 2058 graus de liberdade)

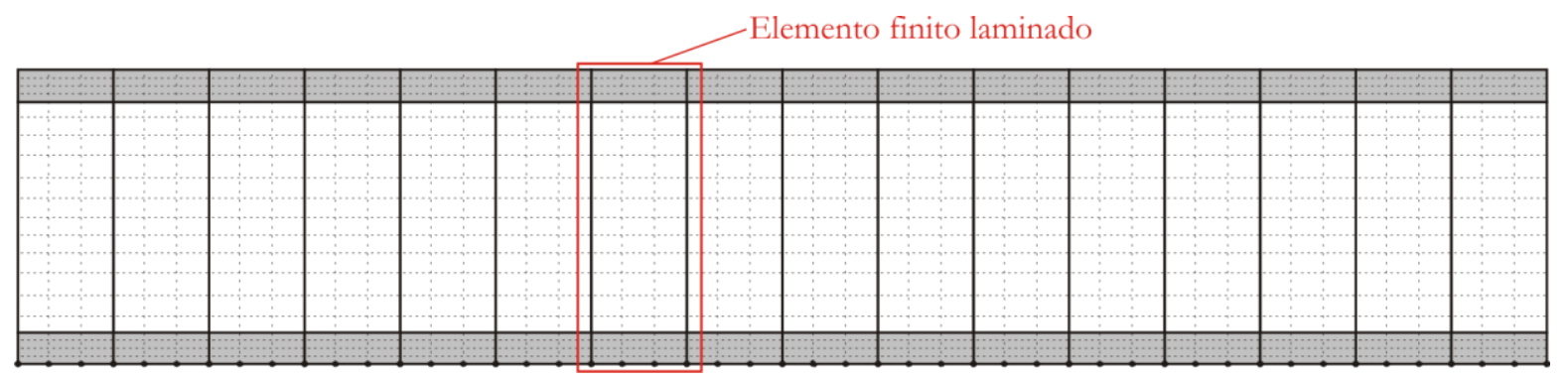

b) Malha equivalente de elementos finitos PLANE42 (960 elementos e 2058 graus de liberdade)

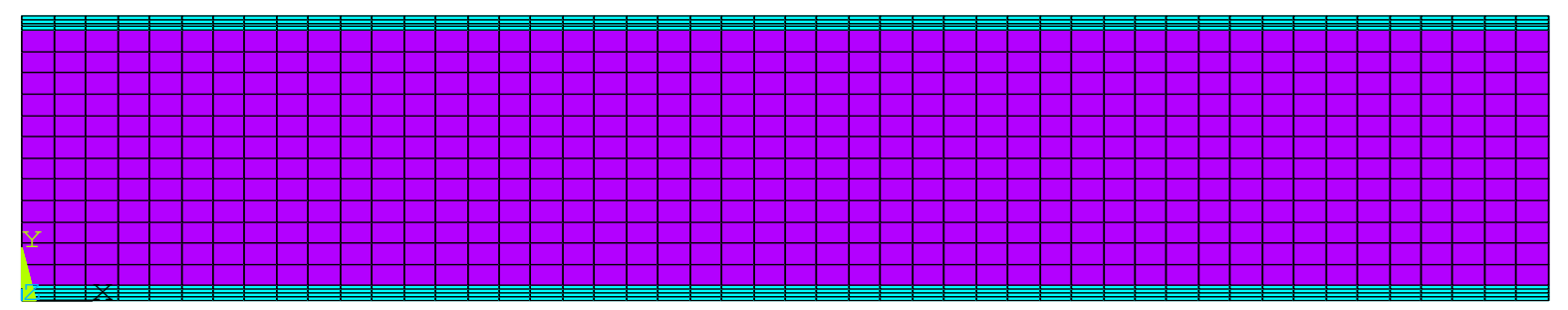

c) Malha refinada de elementos finitos PLANE42 (40000 elementos e 81002 graus de liberdade)

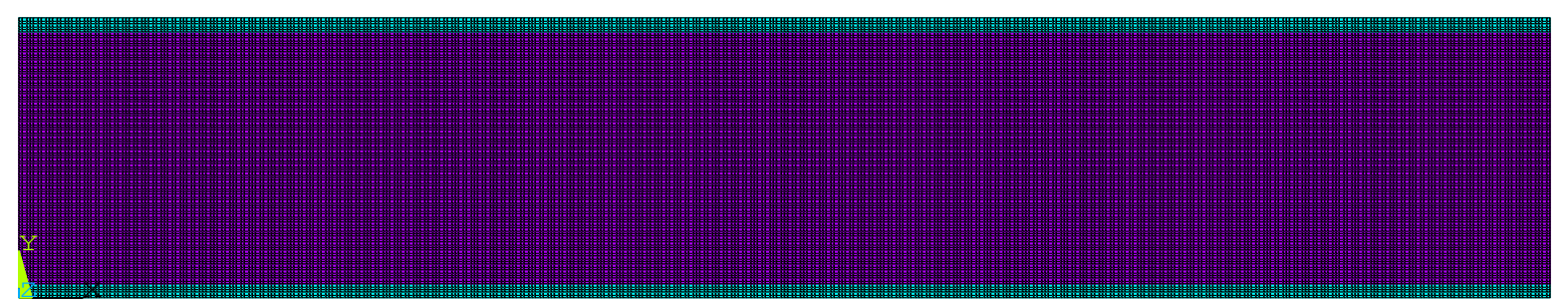

Figura 65 - Malhas de elementos finitos empregadas no Exemplo 5.3 para o Modelo ABA

Em todas as análises, a força concentrada foi aplicada em um único incremento e o processo de solução baseado no método de Newton-Raphson foi controlado por meio dos critérios de convergência em posição e em força com tolerâncias de $10^{-9}$ e $10^{-6}$, respectivamente. A quantidade de pontos de Gauss empregada nas integrações numéricas do vetor de forças internas e da matriz Hessiana foi de 4 x 20 em cada lâmina empregada na discretização.

Os resultados das análises são apresentados através das distribuições de deslocamento horizontal $u$ (Figura 66), de tensão axial longitudinal S11 (Figura 67), de tensão axial transversal S22 (Figura 68) e de tensão de cisalhamento S12 (Figura 69). Todos os resultados são referentes à seção localizada a 2,5 $\mathrm{m}$ do apoio à esquerda. Da mesma forma como no Exemplo 5.2, as tensões representadas são médias entre elementos e a continuidade interlaminar da tensão axial S11 entre lâminas de mesmo material e das tensões transversais S12 e S22 entre 
quaisquer lâminas foi representada calculando a média dos valores obtidos nas interfaces das lâminas adjacentes. Nessas figuras, também constam os resultados médios obtidos a partir de análises numéricas realizadas no Ansys ${ }^{\circledR}$ com emprego do elemento finito bidimensional PLANE42. A mesma equivalência entre as malhas do elemento finito posicional e do elemento PLANE42 foi empregada (Figura 65). Os resultados obtidos a partir de análises numéricas realizadas no Ansys ${ }^{\circledR}$ utilizando uma discretização bastante refinada são novamente apresentados e adotados como referência.

Os resultados fornecidos pelo elemento de pórtico plano laminado são considerados satisfatórios, pois as diferenças observadas são pequenas mesmo para o caso ACA com maior variação dos módulos de elasticidade entre face e núcleo. Essas diferenças foram bem menores do que às observadas para os resultados obtidos no Ansys ${ }^{\circledR}$ com emprego do elemento finito bidimensional PLANE42 através de uma malha equivalente. A influência do mau condicionamento matricial ocasionado pela mudança brusca no módulo de elasticidade entre a lâmina das faces e a lâmina do núcleo foi perceptível com o aumento das discordâncias nos resultados obtidos em ordem crescente para os modelos AAA, ABA e ACA.

O desempenho verificado nos resultados obtidos com o elemento proposto é um indicativo de sua eficiência para analisar estruturas constituídas por compósitos laminados, pois não foram identificados problemas de mau condicionamento matricial mesmo em casos mais extremos com grande variação de módulo de elasticidade entre as lâminas, comum em laminados do tipo sanduíche.

A possibilidade de aplicar uma força concentrada fora da linha de referência do elemento também se mostrou consistente.

Vale ressaltar que os resultados satisfatórios alcançados com o elemento de pórtico plano laminado empregaram uma quantidade bem menor de elementos finitos e graus de liberdade do que os empregados nas análises realizadas no Ansys ${ }^{\circledR}$ com uma malha refinada, conforme se constata quando se comparam as malhas ilustradas na Figura 65. 
a) Modelo AAA

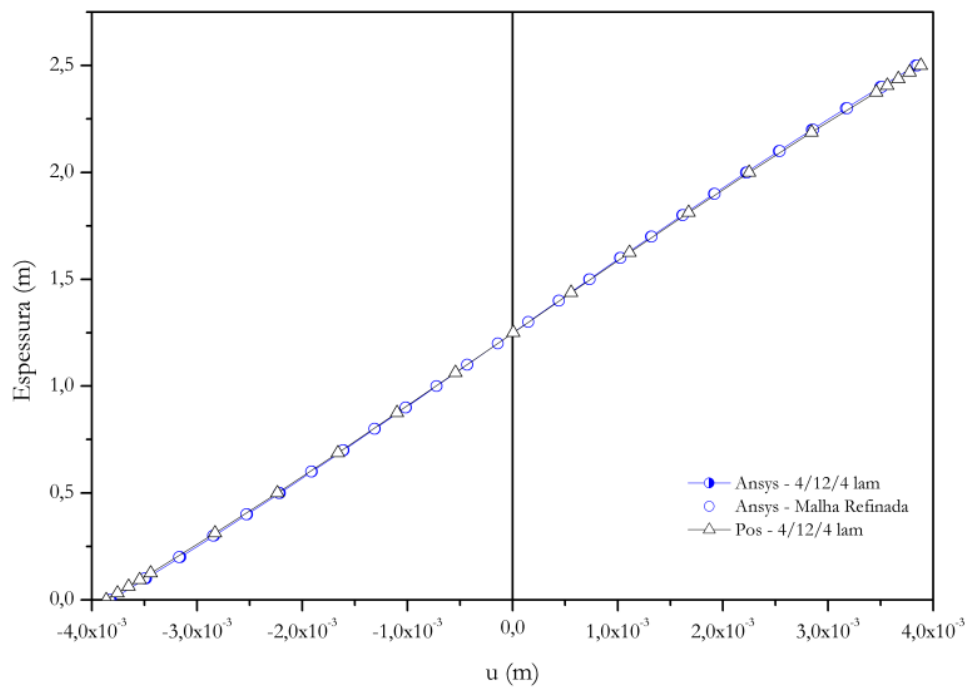

b) Modelo ABA

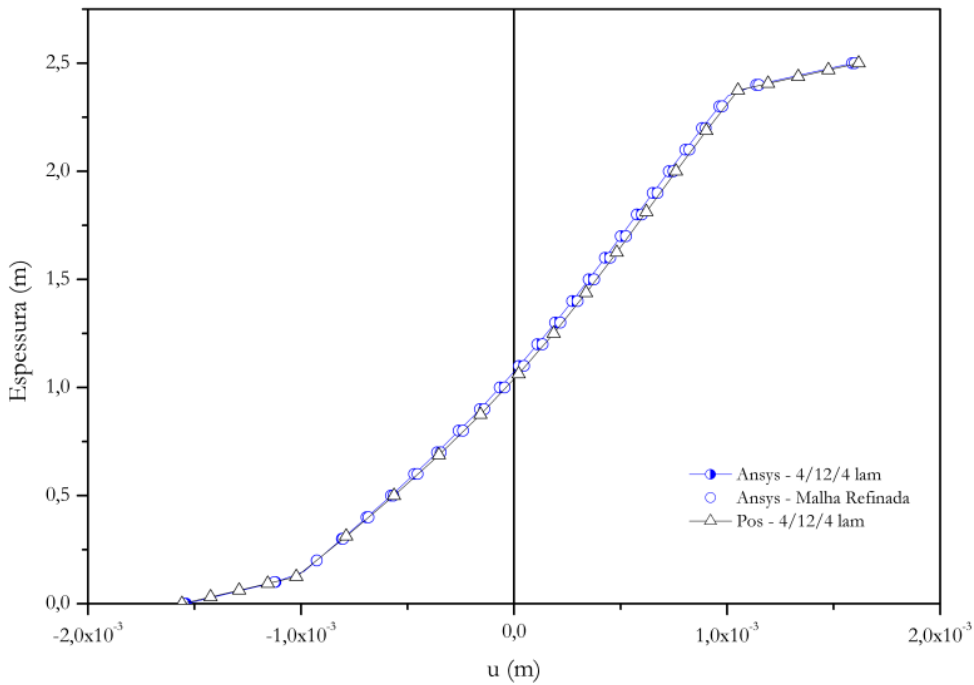

c) Modelo ACA

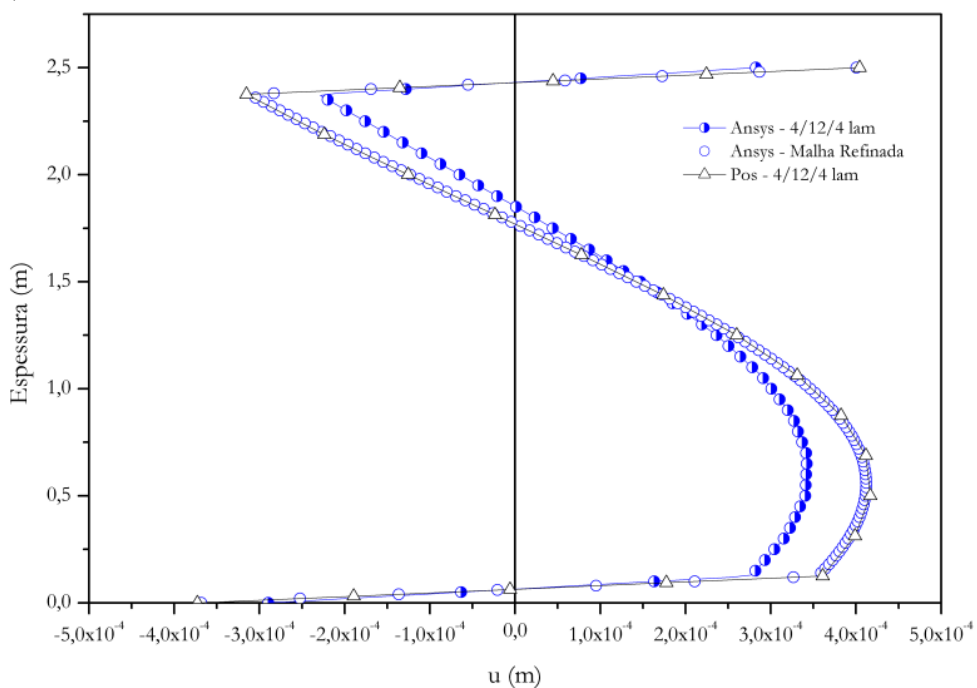

Figura 66 - Resultados do Exemplo 5.3: Deslocamento na direção 1 (u) para seção a 2,5 m do apoio esquerdo. 
a) Modelo AAA

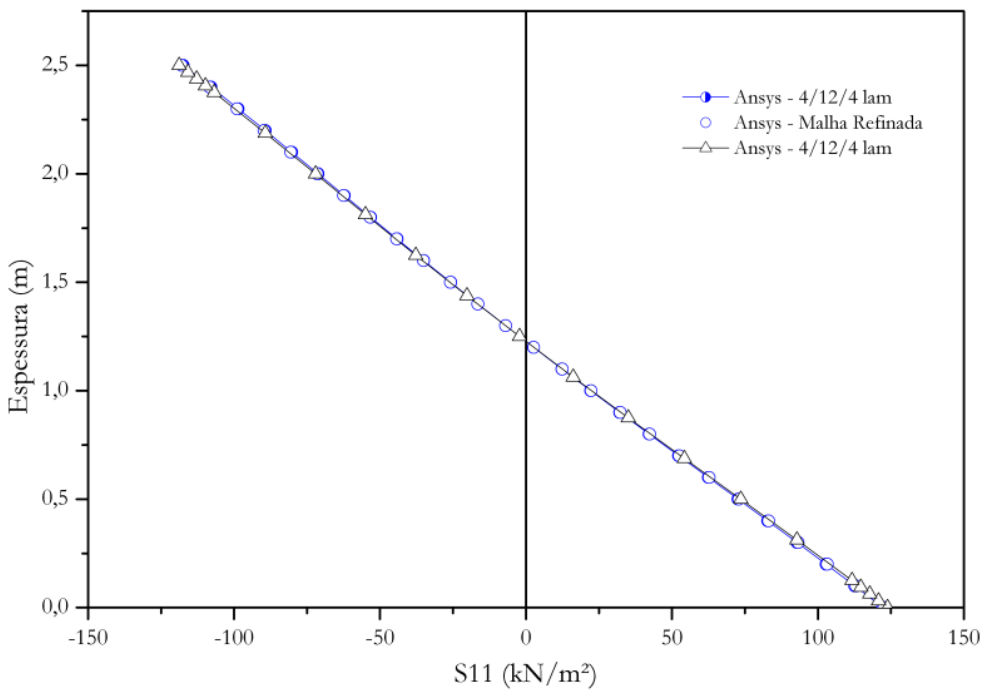

b) Modelo ABA

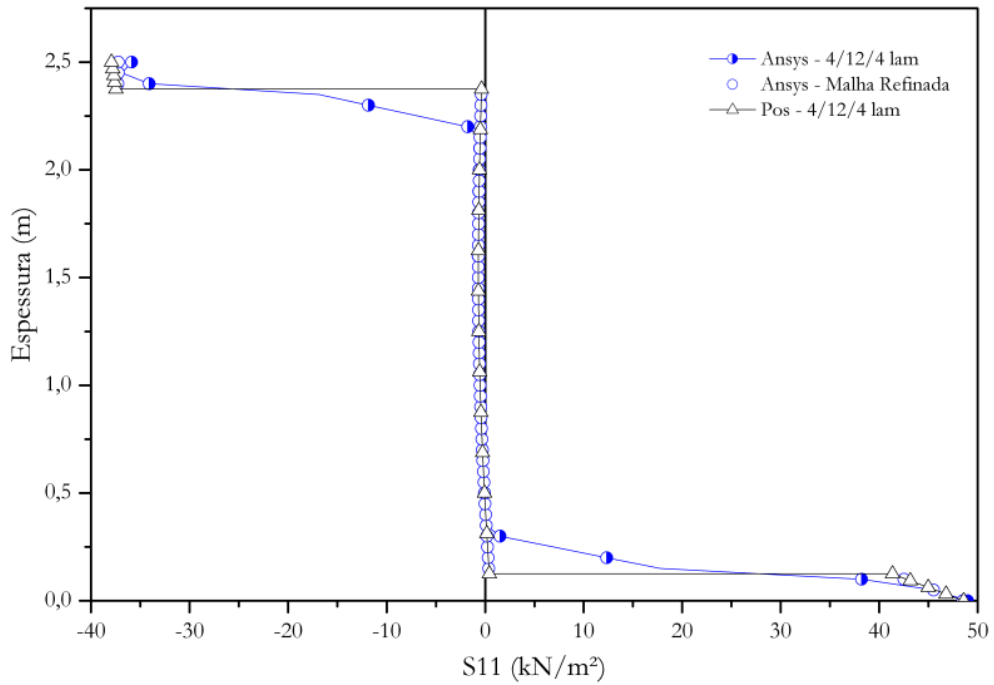

c) Modelo ACA

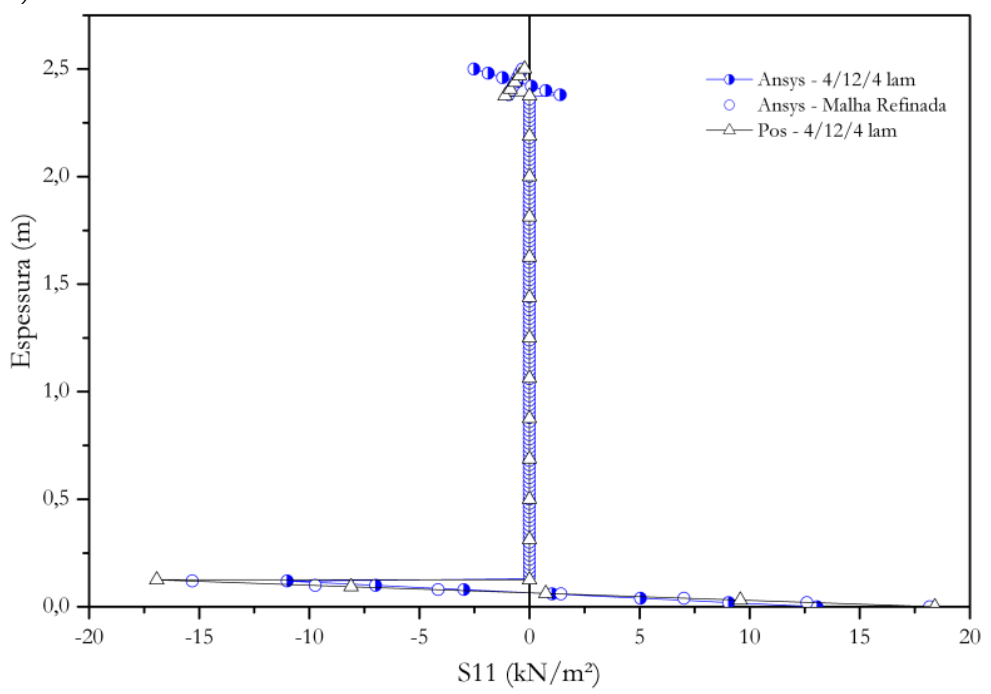

Figura 67 - Resultados do Exemplo 5.3: Tensão axial S11 para seção a 2,5 m do apoio esquerdo. 
a) Modelo AAA

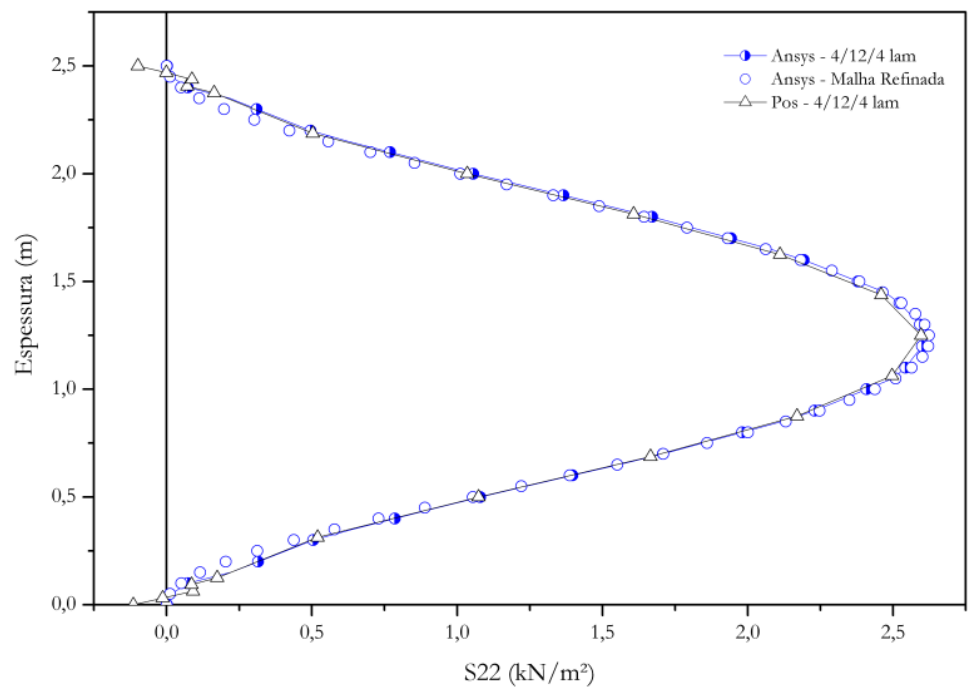

b) Modelo ABA

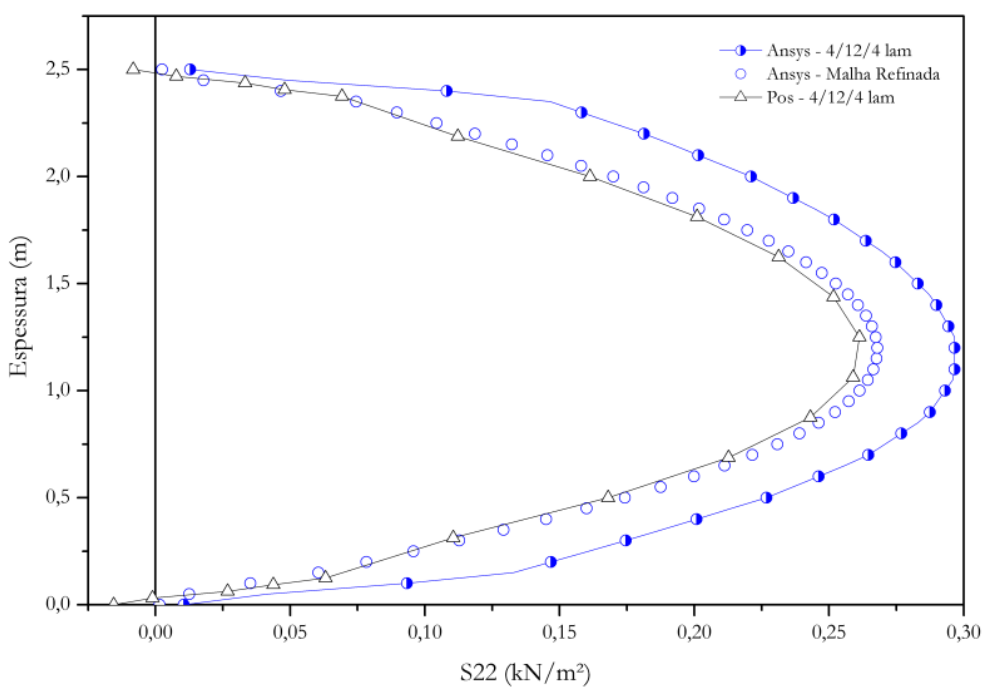

c) Modelo ACA

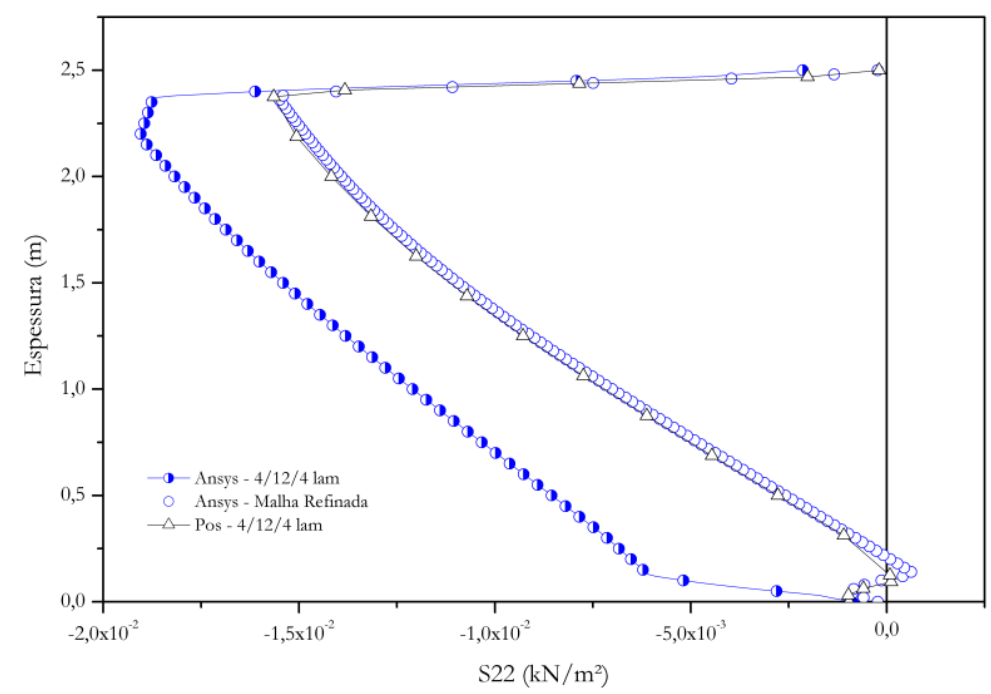

Figura 68 - Resultados do Exemplo 5.3: Tensão axial S22 para seção a 2,5 m do apoio esquerdo. 
a) Modelo AAA

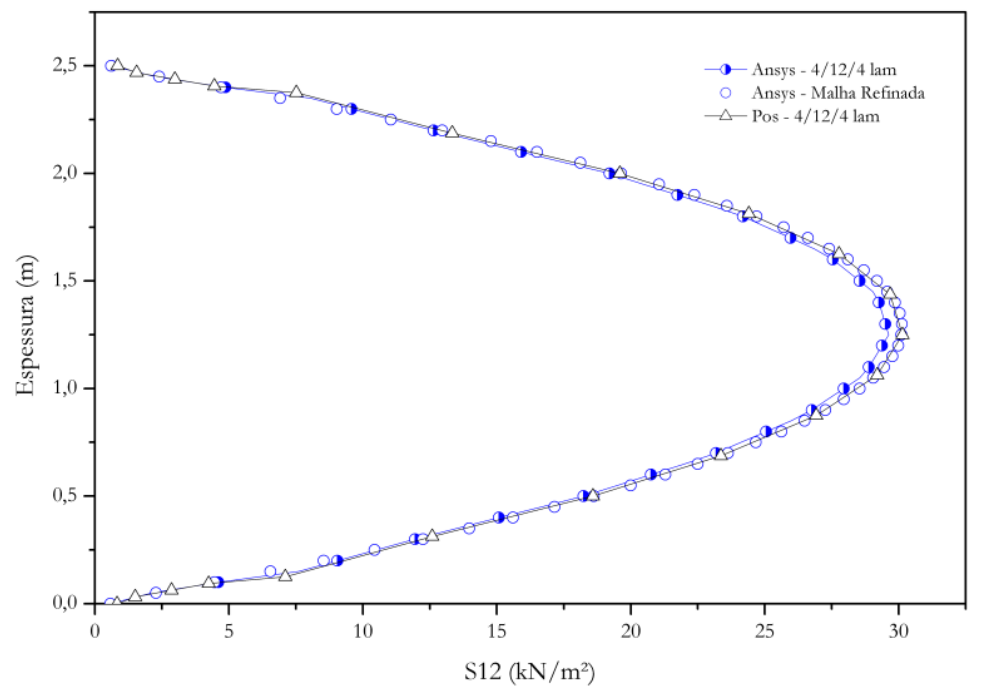

b) Modelo ABA

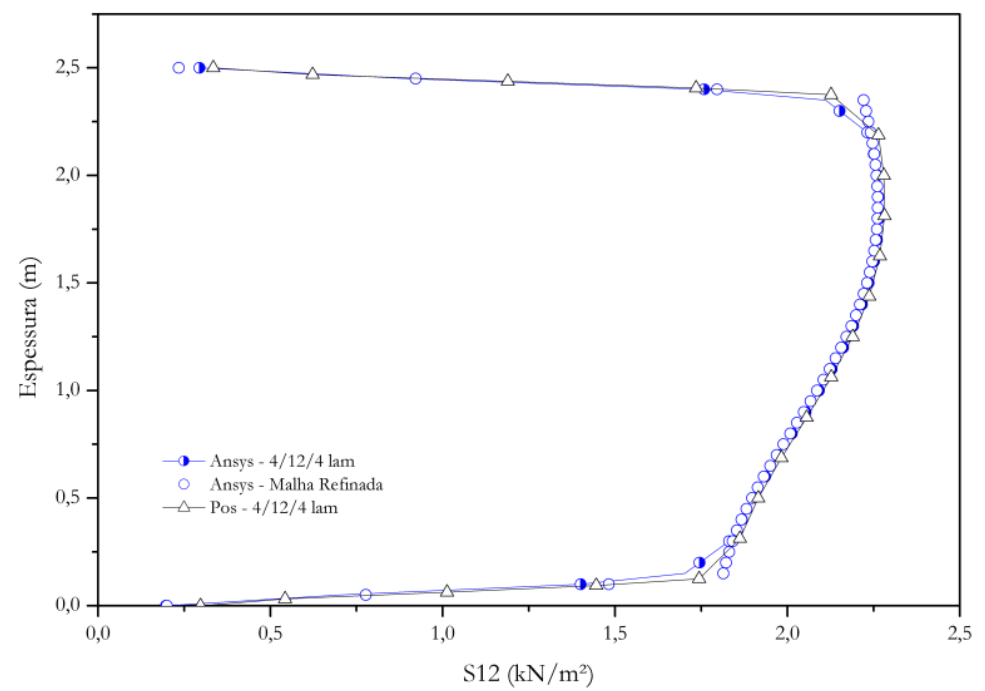

c) Modelo ACA

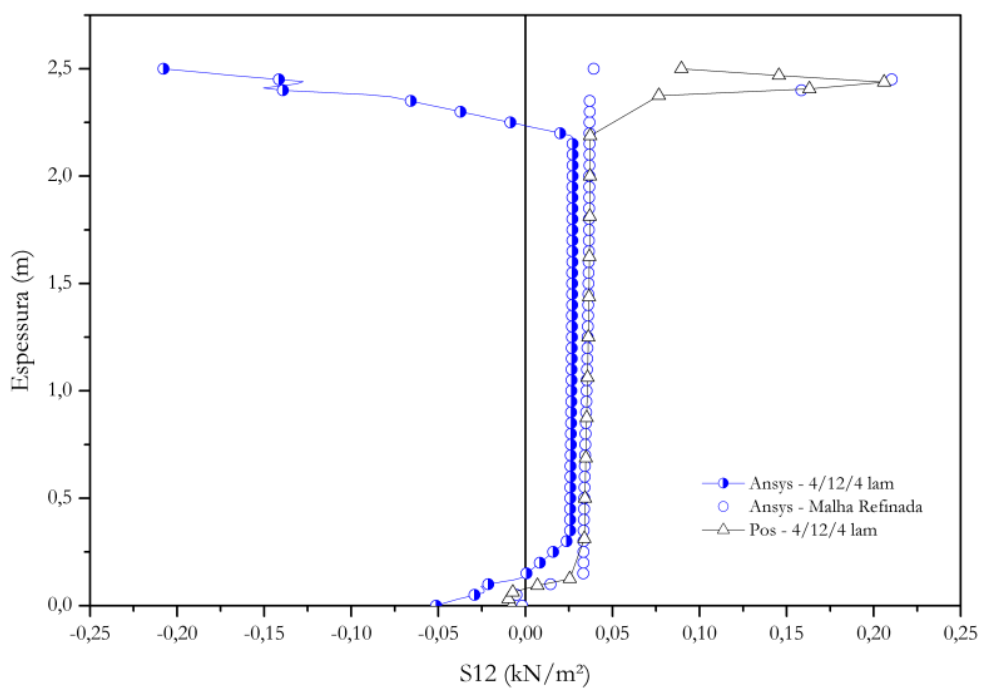

Figura 69 - Resultados do Exemplo 5.3: Tensão de cisalhamento S12 para seção a 2,5 m do apoio esquerdo. 
Para ilustrar os deslocamentos e as tensões obtidos com o elemento de pórtico plano laminado na viga completa, imagens com os mapas de cores dos resultados para a viga com maior variação no módulo de elasticidade das lâminas (modelo ACA) são apresentadas na Figura 70.

a) Deslocamento horizontal $u(\mathrm{~m})$

- Com valores máximos:

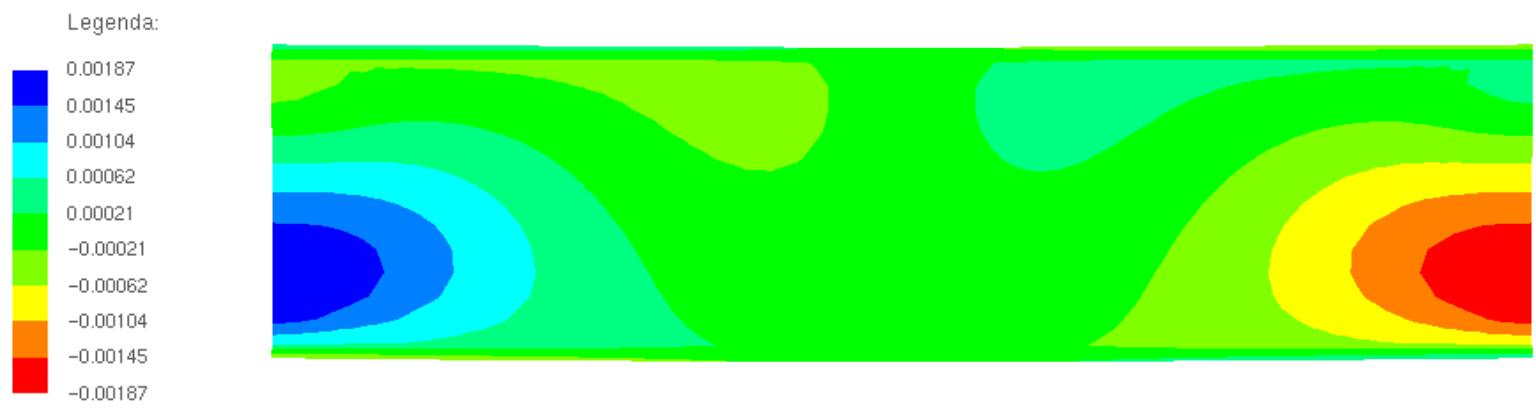

b) Deslocamento vertical $v(\mathrm{~m})$

- Com valores máximos:

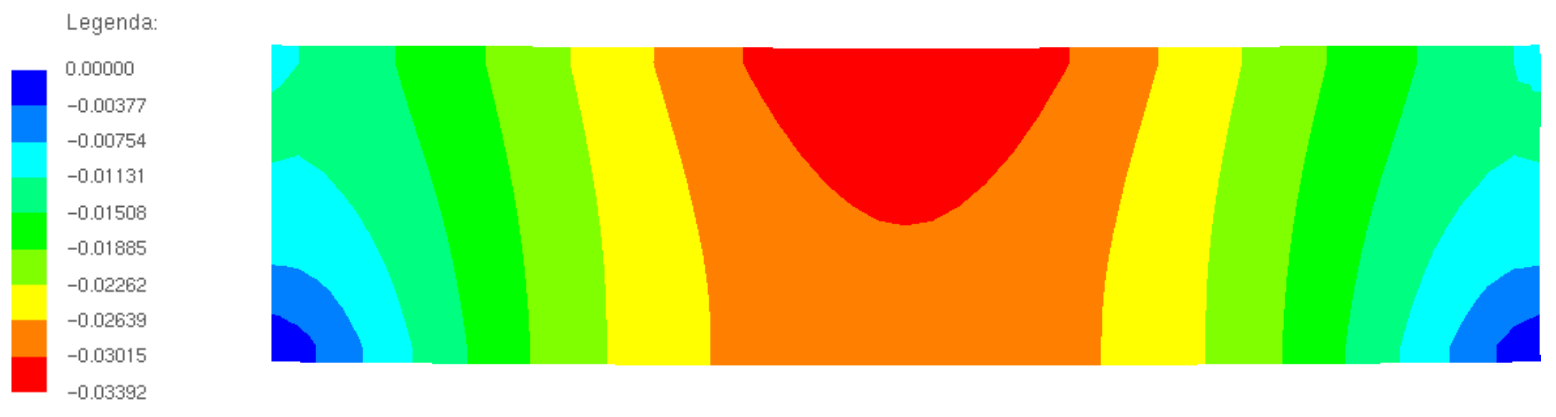

c) Tensão axial longitudinal S11 $\left(\mathrm{kN} / \mathrm{m}^{2}\right)$

- Com valores máximos:

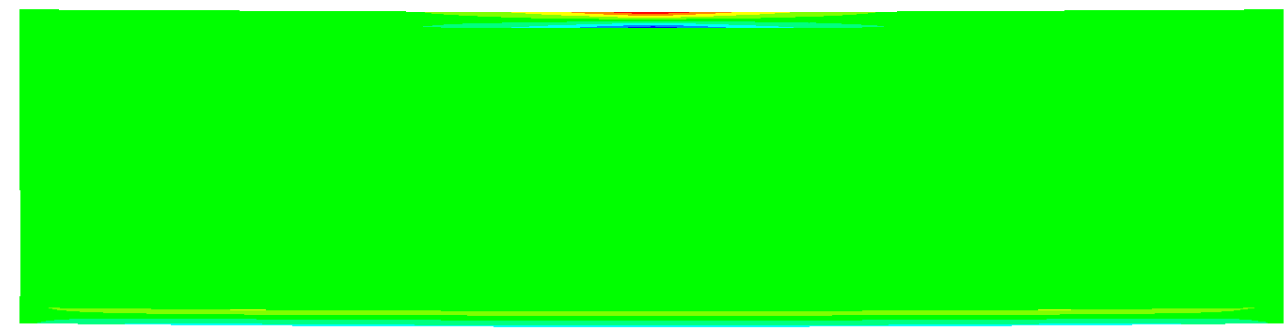

- Com valores em um intervalo selecionado:

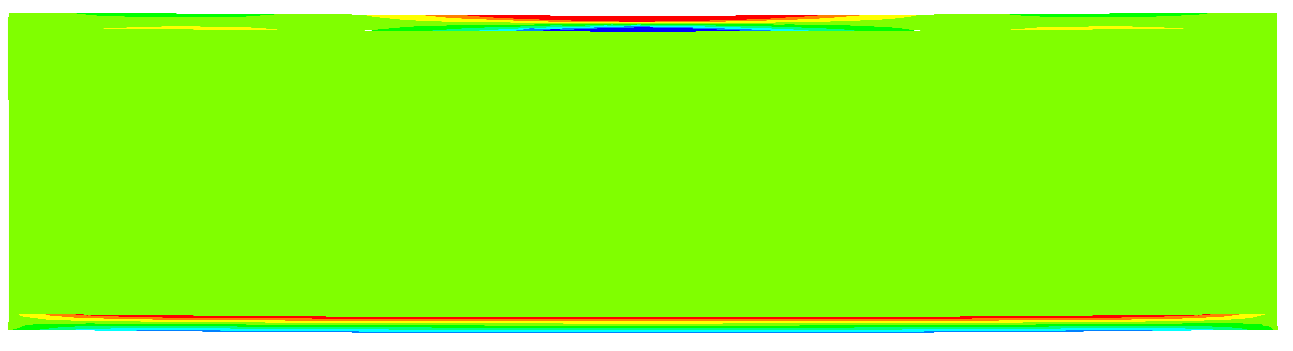


Capítulo 5 - Elemento finito de pórtico plano laminado

d) Tensão axial transversal S22 $\left(\mathrm{kN} / \mathrm{m}^{2}\right)$

- Com valores máximos:

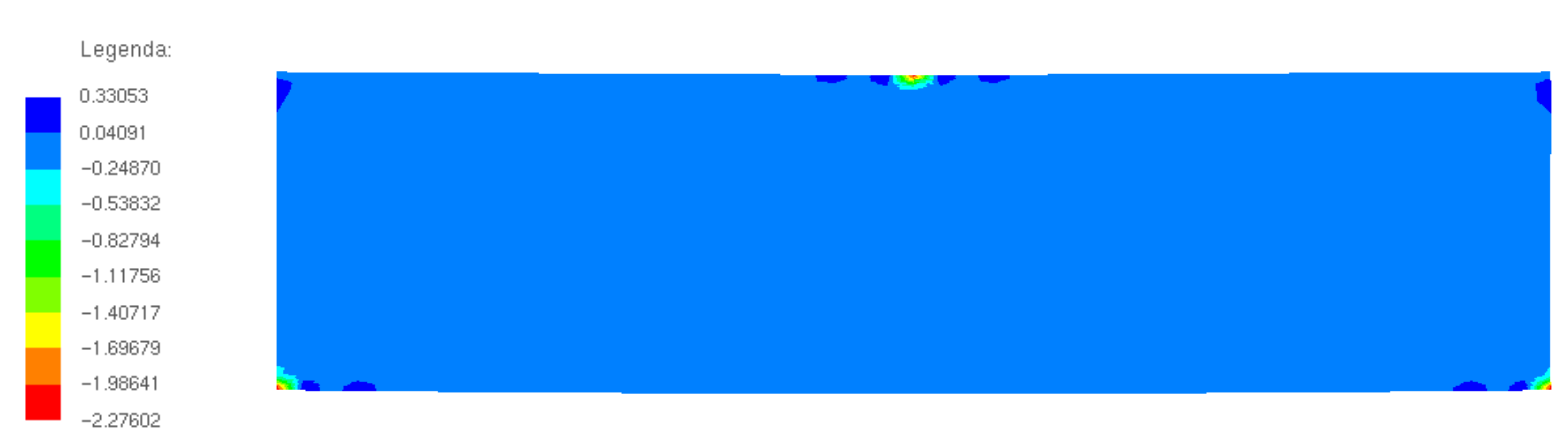

- Com valores em um intervalo selecionado:

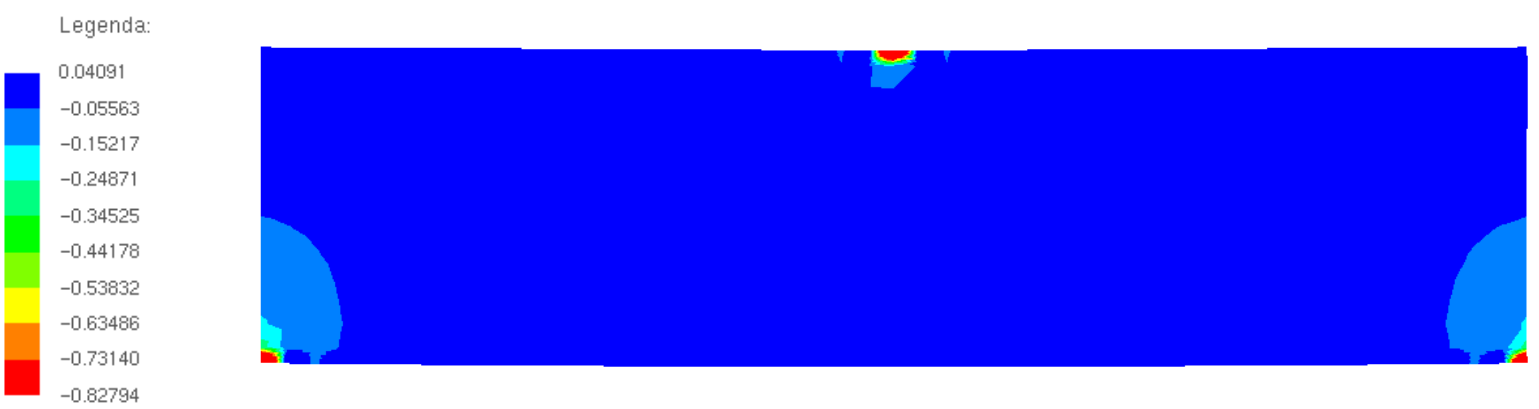

e) Tensão de cisalhamento $\mathrm{S} 12\left(\mathrm{kN} / \mathrm{m}^{2}\right)$

- Com valores máximos:

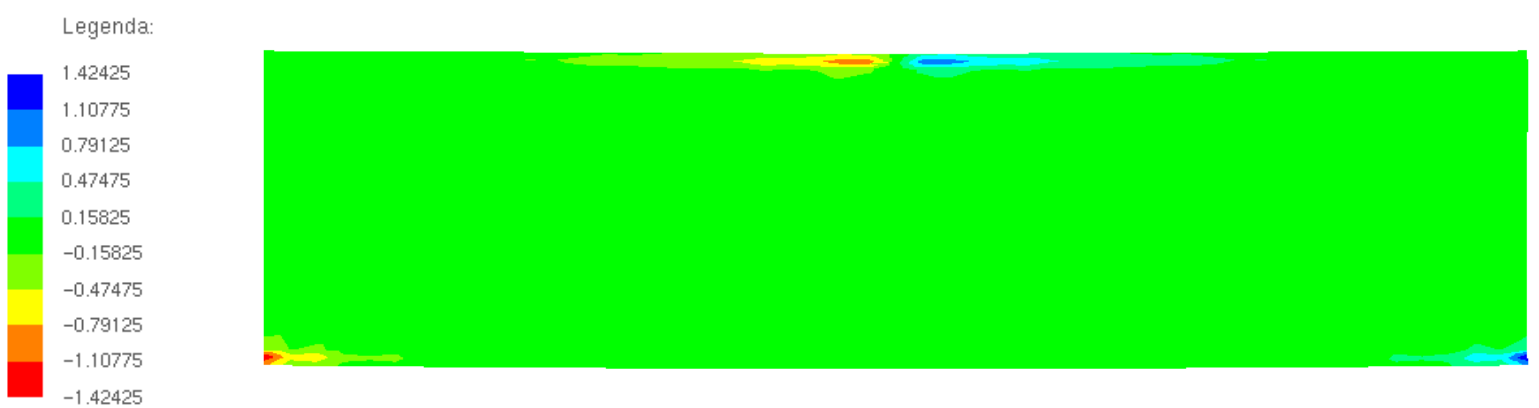

- Com valores em um intervalo selecionado:

\begin{tabular}{|l|l|}
\hline Legenda: \\
\hline 0.47475 \\
0.36925 \\
0.26375 \\
0.15825 \\
0.05275 \\
-0.05275 \\
-0.15825 \\
-0.26375 \\
-0.36925 \\
-0.47475
\end{tabular}

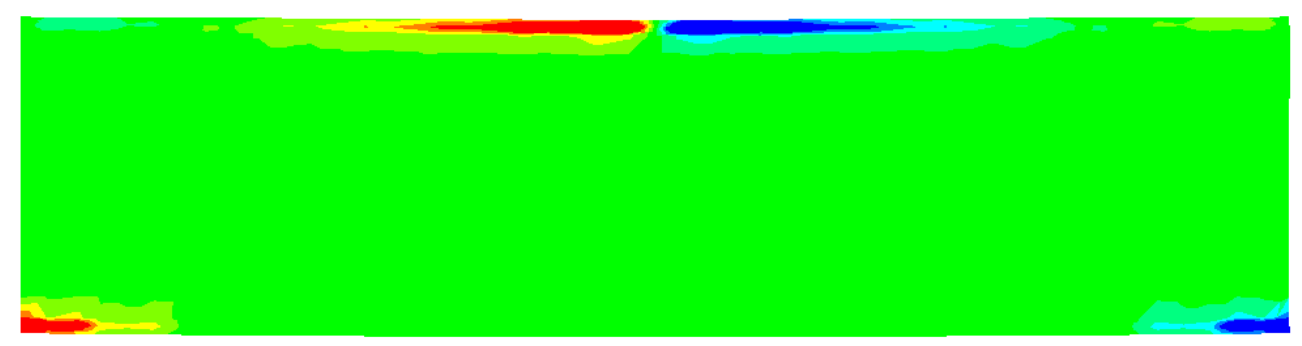

Figura 70 - Resultados do Exemplo 5.3: Mapa de cores para os deslocamentos e tensões do modelo ACA. 


\subsubsection{Exemplo 5.4: Pórtico homogêneo com ligações semirrígidas}

Até este ponto, os exemplos analisados não exigiram o emprego da técnica de penalização apresentada no Item 5.3.6 para o acoplamento entre elementos. Dessa forma, neste exemplo, retoma-se o problema do pórtico com ligações semirrígidas analisado no Item 4.4.3. Na ocasião, a técnica de acoplamento mostrou ser eficiente para o caso do elemento de pórtico plano homogêneo.

A fim de avaliar a técnica para o caso laminado, o pórtico com apoios elásticos à rotação foi novamente analisado. No entanto, a seção é considerada constituída por 5 lâminas de igual espessura, mas com o mesmo material, pois a seção é homogênea. A mesma discretização empregada nas análises realizadas com emprego do elemento de pórtico plano homogêneo foi adotada, ou seja: 4 elementos finitos por trecho de pilar e 6 elemento finitos em cada viga, totalizando 28 elementos. No caso do elemento laminado, uma discretização com 4 elementos finitos por barra também é suficiente para a obtenção de uma resposta adequada em deslocamentos conforme se observou nas análises de convergência apresentadas no Exemplo 5.1.

A geometria, o carregamento e os parâmetros elásticos dos materiais empregados estão representados na Figura 71. A rigidez à rotação do apoio é de 1990,7kNm que corresponde a $0,1(\mathrm{EI} / \mathrm{L})_{\text {pilar }}$. Quatro análises são realizadas: uma considerando as ligações rígidas e as outras três considerando as ligações semirrígidas com rigidez à rotação de $4491 \mathrm{kNm}, 9730 \mathrm{kNm}$ e $30705 \mathrm{kNm}$, respectivamente. Para definir a rigidez da ligação associada a cada lâmina, a rigidez total da ligação foi ponderada pela razão entre a espessura da lâmina e a espessura total da seção.

Os resultados apresentados no Item 4.4.3 (Figura 42) obtidos por Liu e Chen (1988) e a partir de análises numéricas realizadas no Ansys ${ }^{\circledR}$ com emprego do elemento BEAM188, para modelagem das barras, e do elemento de acoplamento COMBIN40, para modelagem das ligações semirrígidas, são novamente utilizados como referência para avaliação dos resultados obtidos com o elemento de pórtico plano laminado. Além disso, os resultados obtidos com o elemento de pórtico plano homogêneo são também apresentados, permitindo avaliar o efeito gerado pelo aumento do número de graus de liberdade associados à seção transversal (giros independentes e variação na espessura de cada lâmina).

Da mesma forma como no Item 4.4.3, o carregamento foi incrementado (passos de $50 \mathrm{kN}$ ) até a desestabilização dos pórticos que foi identificada pela formação de trechos com rigidez muito baixa nas trajetórias de equilíbrio referentes ao deslocamento horizontal do nó superior esquerdo. Essas trajetórias estão ilustradas na Figura 72 e foram representadas até um deslocamento de $0,30 \mathrm{~m}$. 


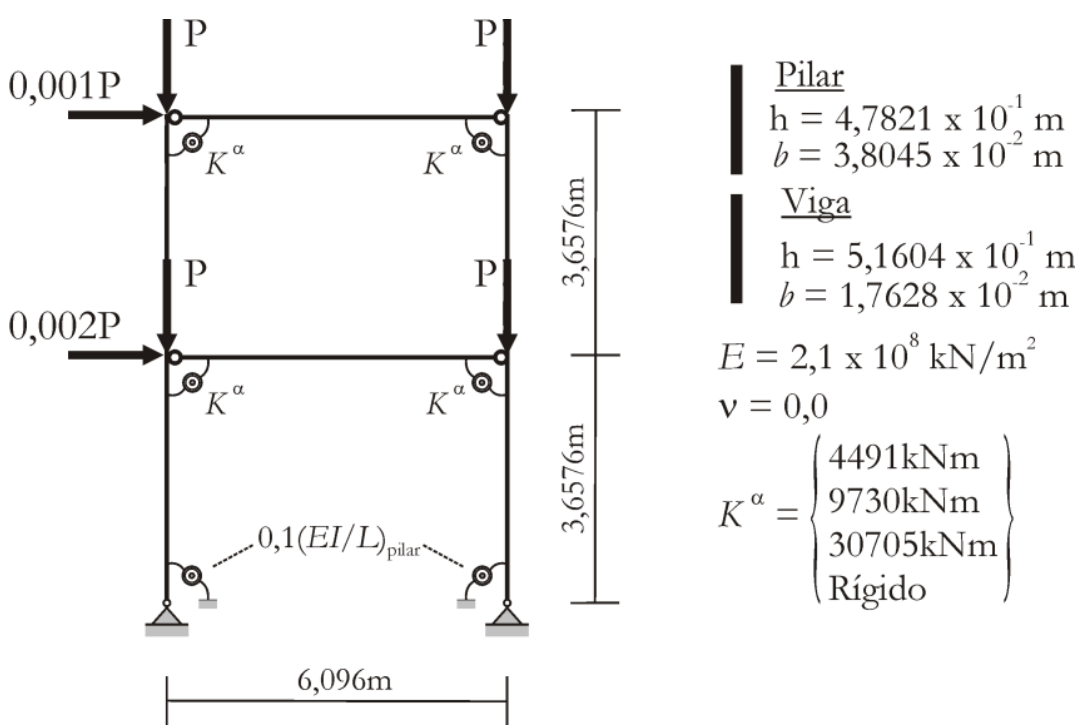

Figura 71 - Geometria, carregamento e parâmetros elásticos do Exemplo 5.4

O processo de solução baseado no método de Newton-Raphson é empregado em todas as análises e os critérios de convergência adotados são em posição e em força com tolerâncias de $10^{-9}$ e $10^{-6}$, respectivamente. Todas as integrações numéricas foram realizadas com emprego de 4 x 20 pontos de Gauss em cada lâmina da discretização.

As trajetórias de equilíbrio obtidas com o elemento de pórtico plano laminado representaram o comportamento da estrutura de forma coerente com os resultados utilizados como referência. Assim, a técnica proposta para o acoplamento entre elementos laminados é verificada e considerada consistente.

O comportamento foi apenas um pouco mais flexível do que o apresentado para o elemento homogêneo em virtude do maior número de graus de liberdade presentes na discretização da seção transversal do elemento laminado. A influência disso é identificada no aumento das diferenças à medida que a rigidez da ligação cresce.

Nos casos com rigidezes de $4491 \mathrm{kNm}$ e $9730 \mathrm{kNm}$, a flexibilidade gerada pelas ligações parece ser predominante sobre a flexibilidade gerada pelo aumento do número de graus de liberdade e as trajetórias de equilíbrio dos elementos homogêneo e laminado praticamente coincidem.

Já nos casos com rigidez de 30705kNm e ligação rígida, a flexibilidade causada pela ligação foi menor e o efeito do aumento do número de graus de liberdade foi mais significativo sobre o comportamento do pórtico. Assim, uma diferença maior é identificada em relação às trajetórias de equilíbrio obtidas com o elemento homogêneo. Apesar disso, os resultados são bastante satisfatórios, pois as diferenças somente refletem uma coerência com a cinemática de ambos os elementos. 

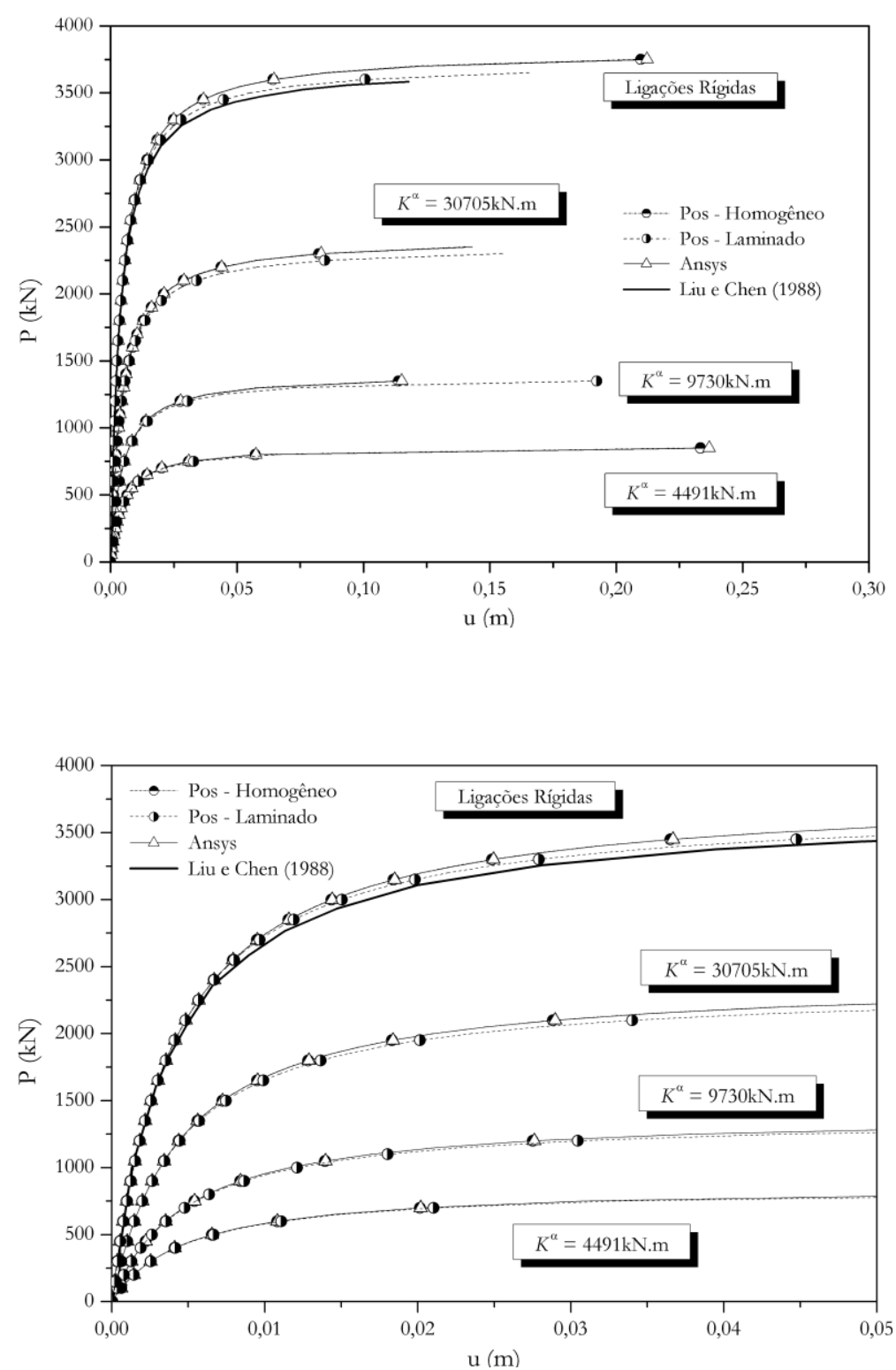

Figura 72 - Trajetórias de equilíbrio para o pórtico com ligações semirrígidas analisado com o elemento laminado (superior). Trecho inicial (inferior)

Para ilustrar a coerência no comportamento obtido, as formas dos pórticos na configuração deformada referentes ao último incremento de força aplicada são apresentadas na Figura 73. As legendas e o mapa de cores se referem ao deslocamento horizontal $u(\mathrm{~m})$. 
a) Pórtico com $K^{\alpha}=4491 \mathrm{kNm}$
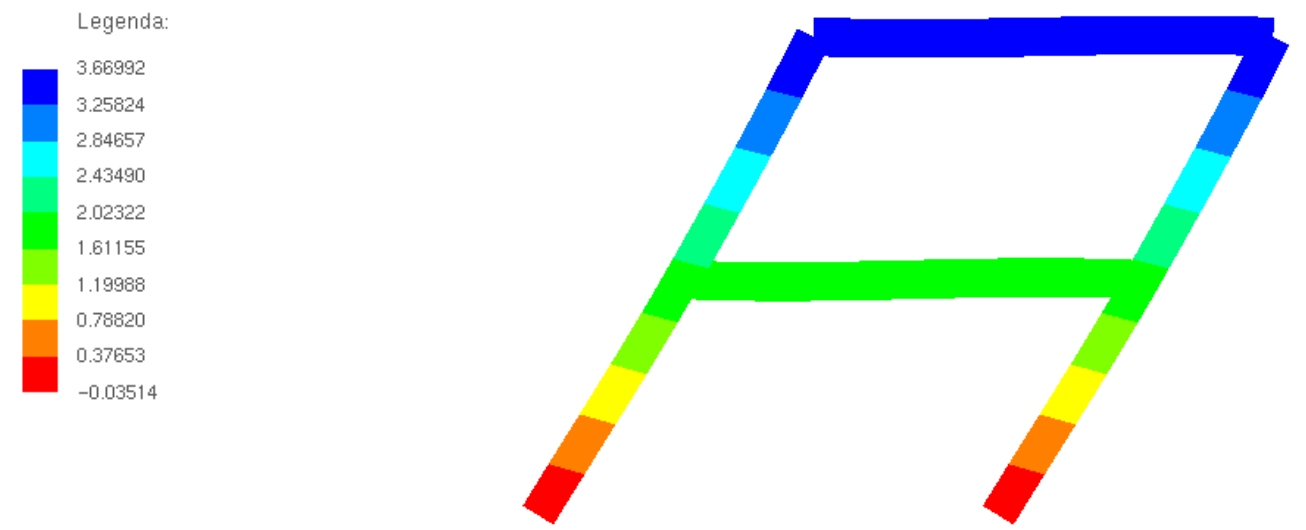

b) Pórtico com $K^{\alpha}=9730 \mathrm{kNm}$

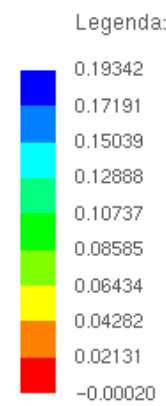

c) Pórtico com $K^{\alpha}=30705 \mathrm{kNm}$
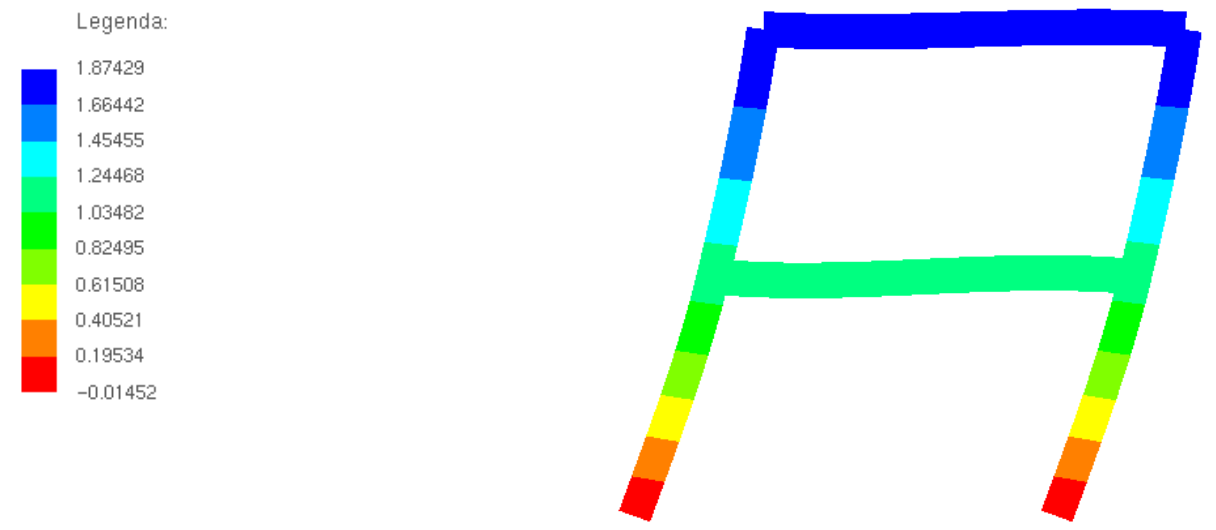
d) Pórtico com ligações rígidas
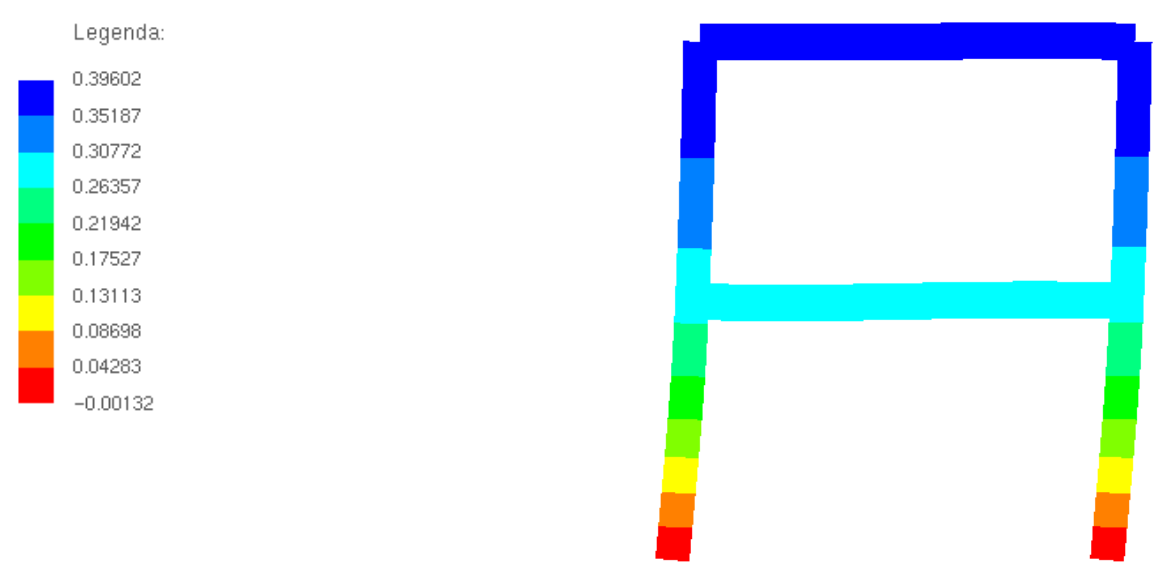

Figura 73 - Resultados do Exemplo 5.4: Configurações atuais no último passo de carga.

\subsubsection{Exemplo 5.5: Pórticos laminados}

Diante dos resultados satisfatórios obtidos nas análises realizadas nos problemas dos quatro exemplos anteriores, tanto a formulação do elemento de pórtico plano laminado quanto sua implementação computacional estão verificadas. Assim, neste último exemplo, dois pórticos laminados foram analisados e os resultados são apresentados na forma de distribuições de deslocamentos ao longo de seções transversais localizadas em alguns pontos específicos dos pórticos.

Como dito anteriormente, os exemplos ilustrativos apresentados aqui irão contribuir com resultados que possam ser utilizados como referência para a verificação de formulações futuras. Dos trabalhos consultados na revisão bibliográfica, a grande parte deles continha exemplos de placas ou cascas laminadas e somente alguns poucos continham exemplos de vigas laminadas. Problemas de pórticos planos laminados não foram encontrados. Além disso, os exemplos disponíveis se restringiam ao regime de linearidade geométrica.

Dito isso, os dois problemas propostos são o pórtico com cinco pavimentos e o pórtico simples com um pavimento, ambos com apoios engastados, ligações rígidas e submetidos à ação de forças concentradas e distribuídas. Os pórticos apresentam seções transversais laminadas constituídas por cinco lâminas. A geometria, propriedades elásticas dos materiais e carregamento estão descritos na Figura 74.

Para o exemplo do pórtico com cinco pavimentos, todas as barras foram discretizadas com 4 elementos e 20 lâminas distribuídas em 2/2/12/2/2. Somente 4 elementos foram utilizados porque são apresentadas apenas as distribuições de deslocamentos nas seções transversais S1, S2, S3, S4, S5 e S6. Já no exemplo do pórtico com um pavimento, os pilares 
Capítulo 5 - Elemento finito de pórtico plano laminado

foram discretizados com 6 elementos e a viga com 10. A seção foi discretizada também com 20 lâminas distribuídas em 2/2/12/2/2. Distribuições de deslocamentos são apresentadas para as seções transversais S1 e S2.

As trajetórias de equilíbrio referentes ao deslocamento horizontal do nó superior esquerdo são também ilustradas para ambos os pórticos.

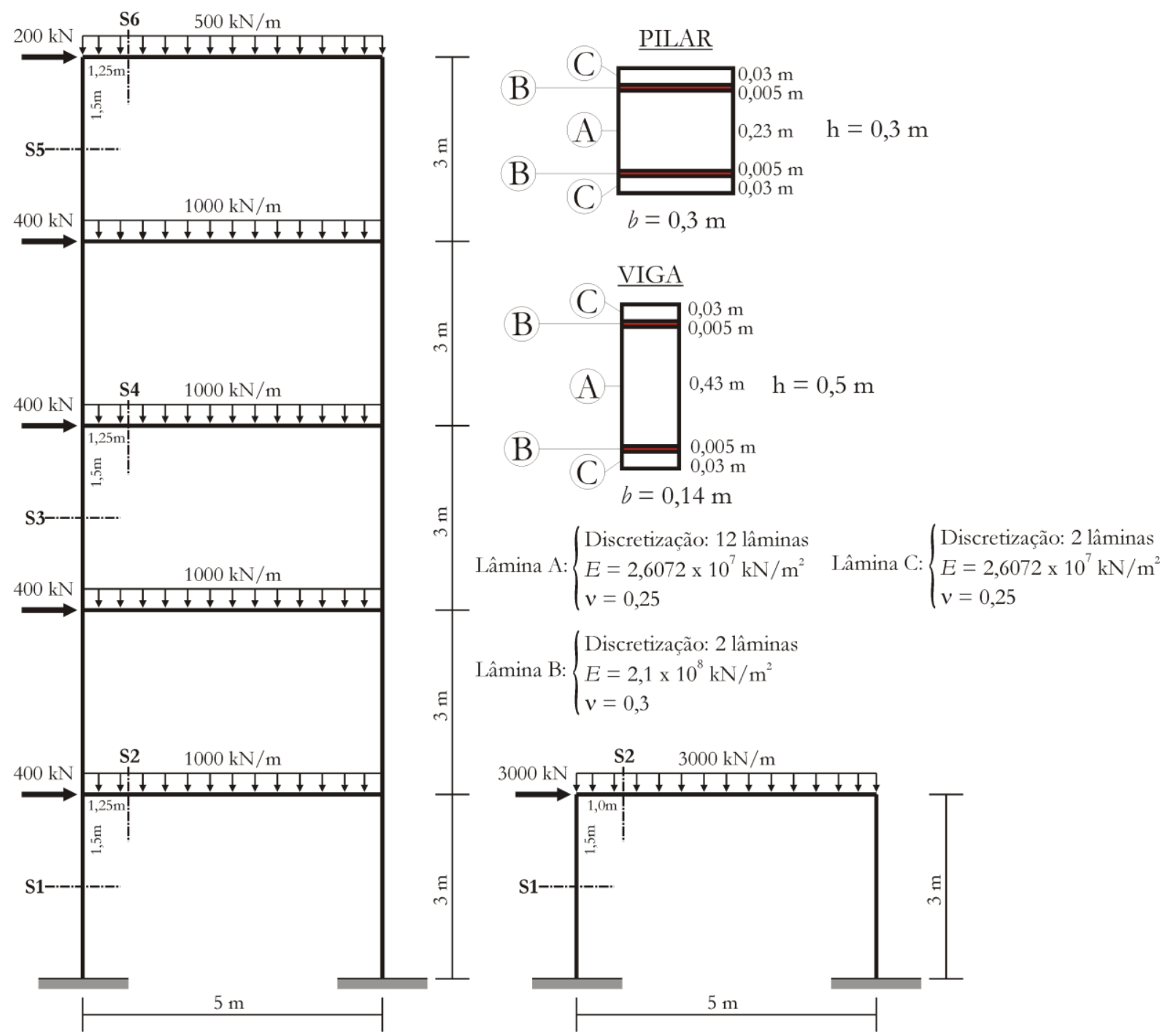

Figura 74 - Geometria, carregamento e parâmetros elásticos dos pórticos laminados.

O carregamento foi incrementado em 4 passos iguais e o processo de solução baseado no método de Newton-Raphson foi empregado em todas as análises com critérios de convergência em posição (tolerância de $10^{-9}$ ) e em força (tolerância de $10^{-6}$ ). Todas as integrações numéricas foram realizadas com emprego de 4 × 20 pontos de Gauss em cada lâmina da discretização. 
Os resultados obtidos para os dois exemplos são apresentados nas Figura 75, Figura 76, Figura 77, Figura 78 e Figura 79.

a) Seção S1

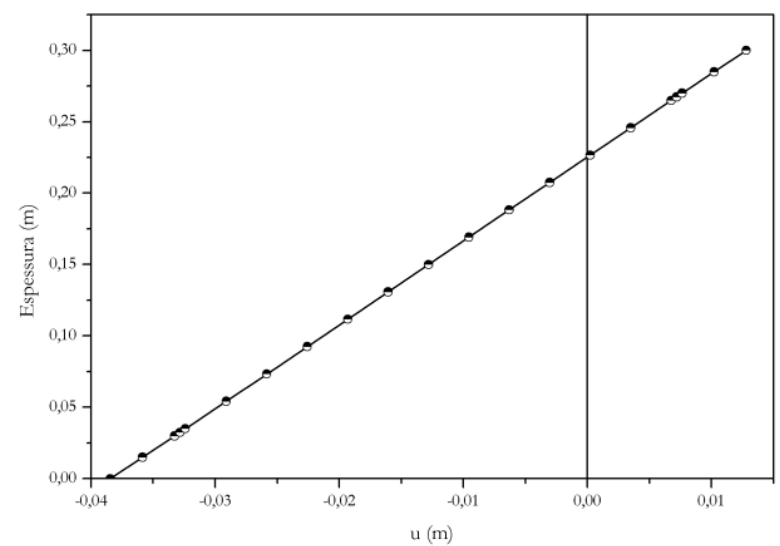

c) Seção S3

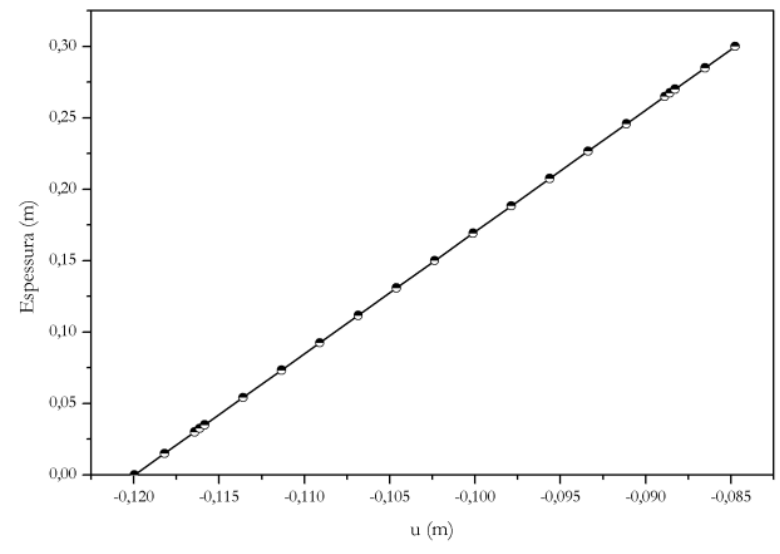

e) Seção S5

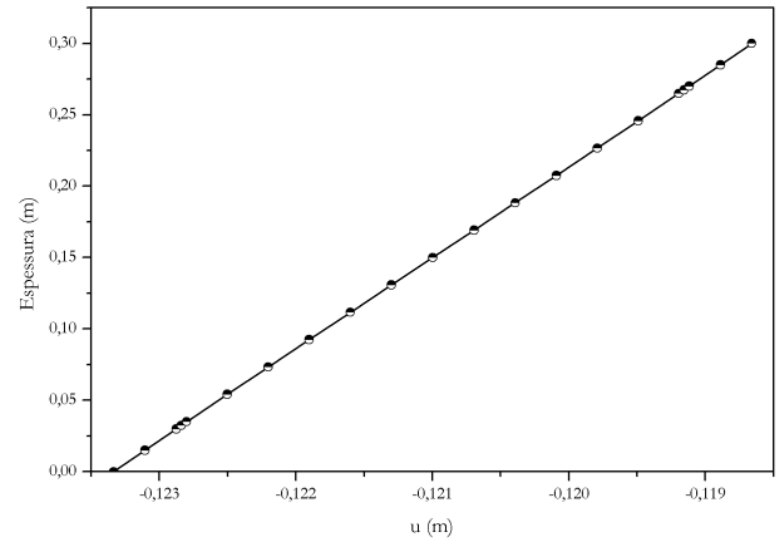

b) Seção S2

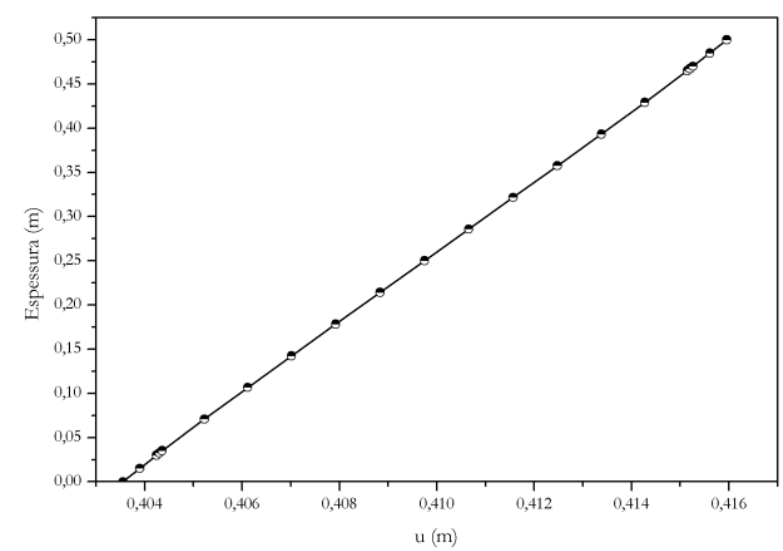

d) Seção S4

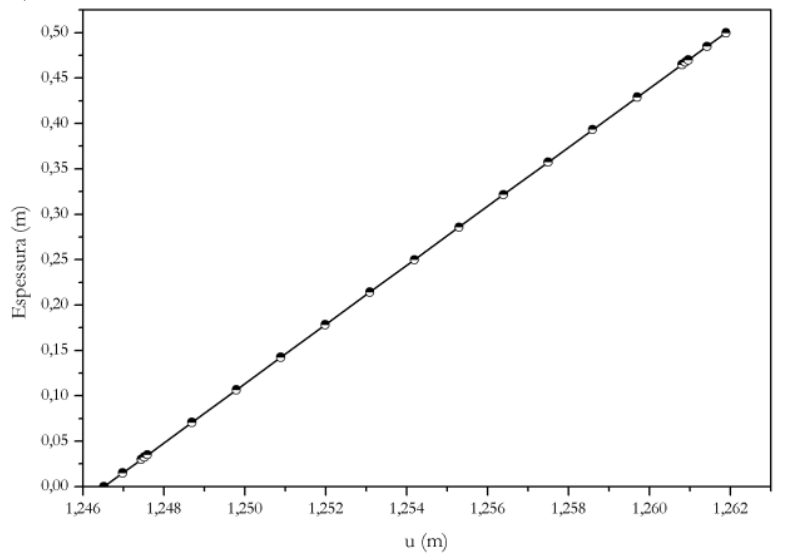

f) Seção S6

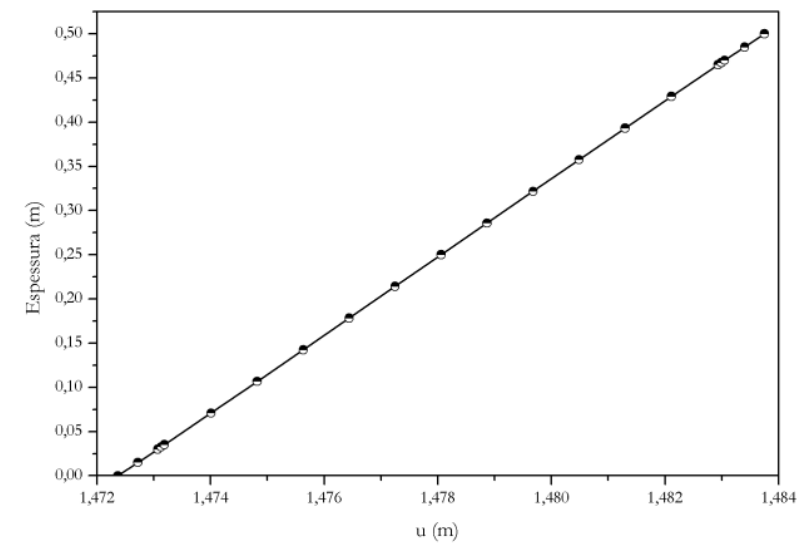

Figura 75 - Distribuição de deslocamentos longitudinais $u(\mathrm{~m})$ para algumas seções transversais do pórtico com cinco pavimentos. Resultados para o último incremento de carga. 
a) Deslocamento horizontal $u(\mathrm{~m})$
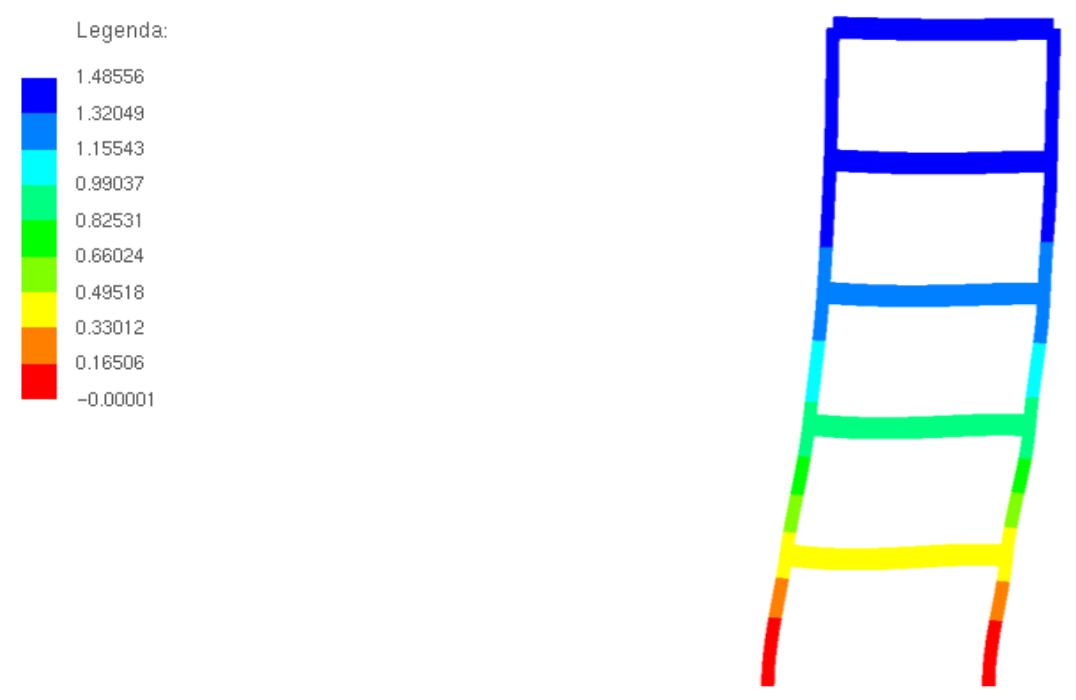

b) Deslocamento vertical $v(\mathrm{~m})$
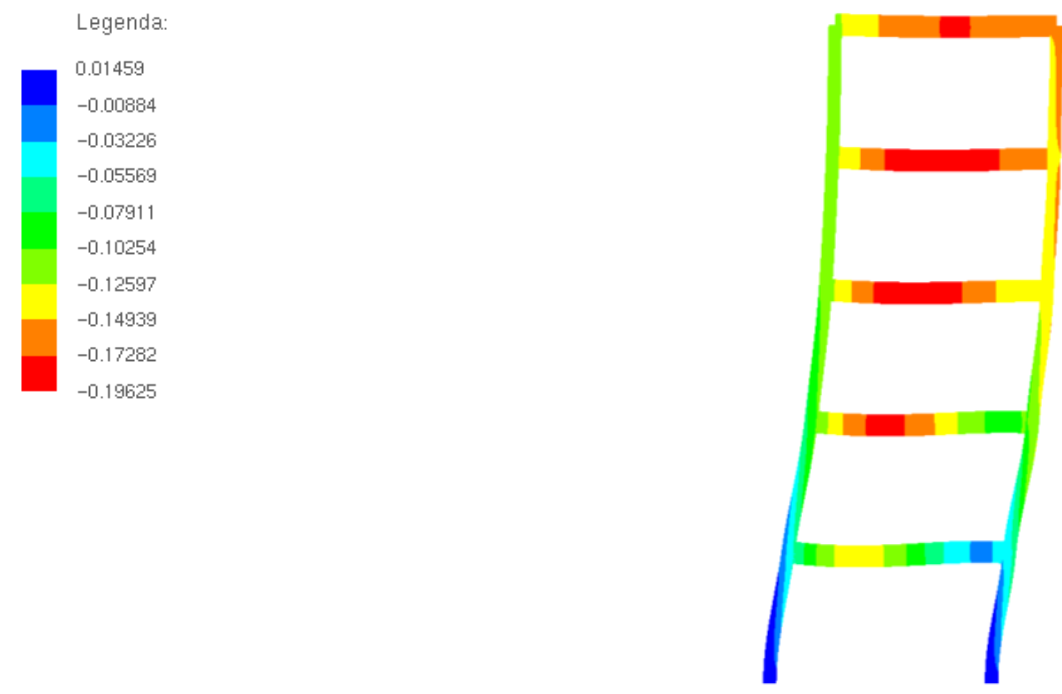

Figura 76 - Deslocamentos globais do pórtico com cinco pavimentos. Resultados para o último incremento de carga.

a) Seção S1

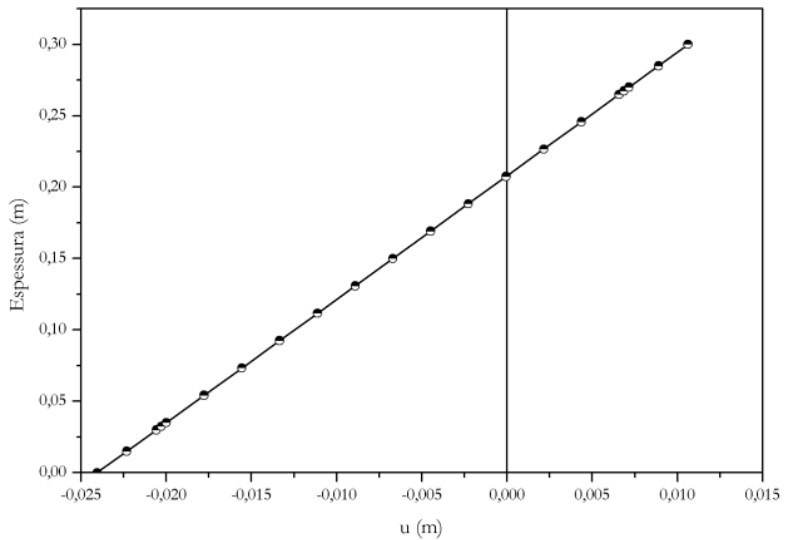

b) Seção S2

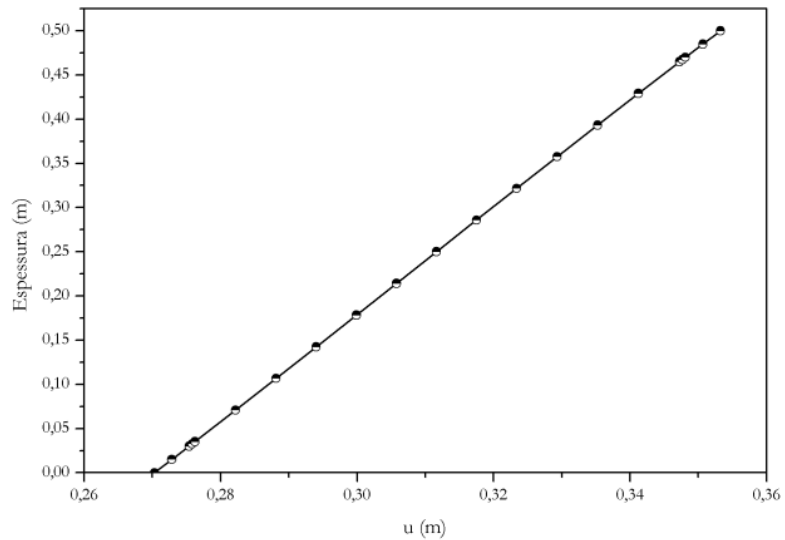

Figura 77 - Distribuição de deslocamentos longitudinais $u(\mathrm{~m})$ para algumas seções transversais do pórtico com um pavimento. Resultados para o último incremento de carga. 
a) Deslocamento horizontal $u(\mathrm{~m})$

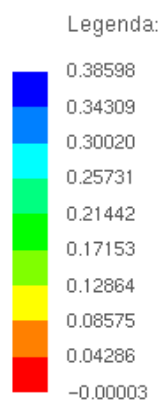

b) Deslocamento vertical $v(\mathrm{~m})$
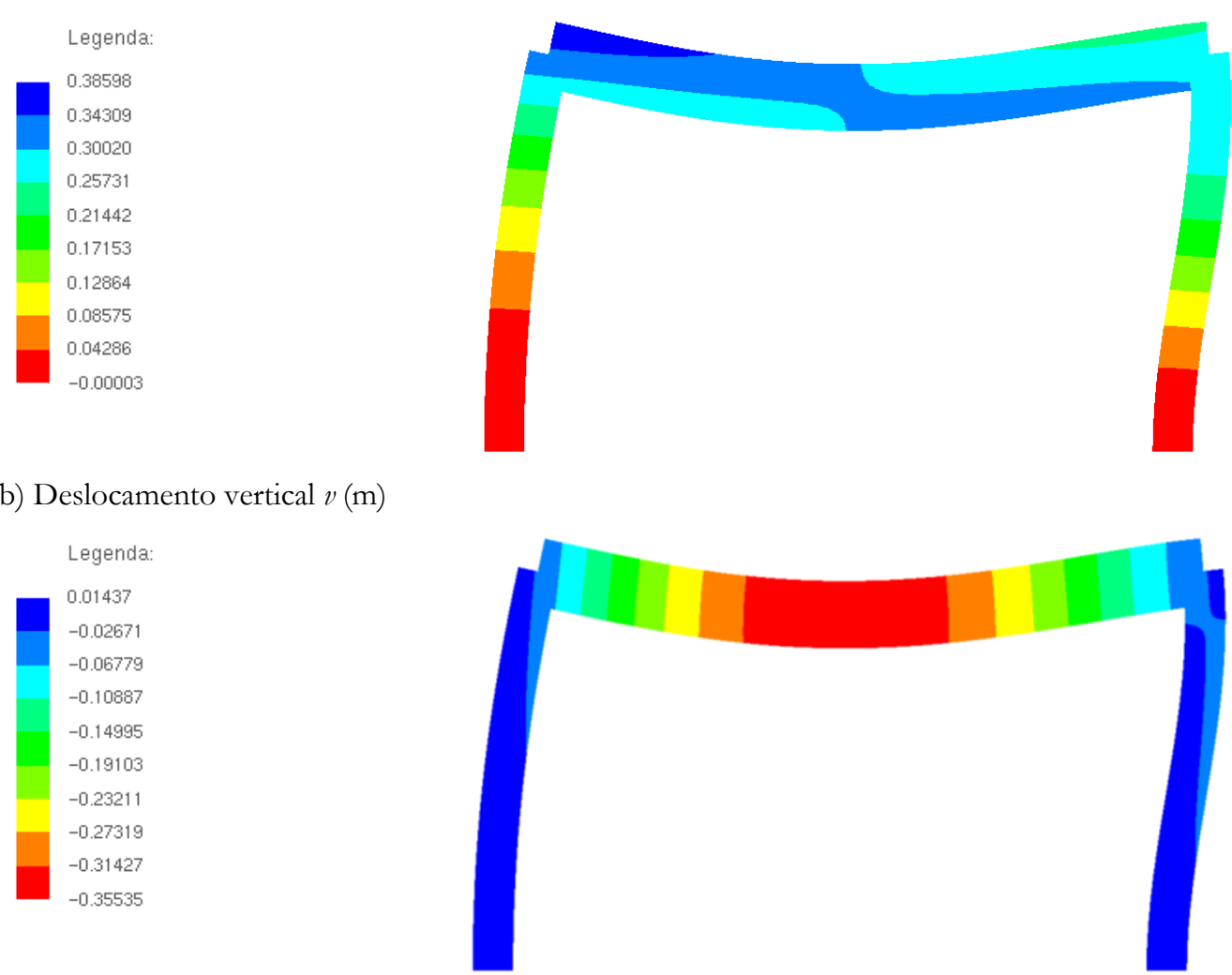

Figura 78 - Deslocamentos globais do pórtico com um pavimento. Resultados para o último incremento de carga.

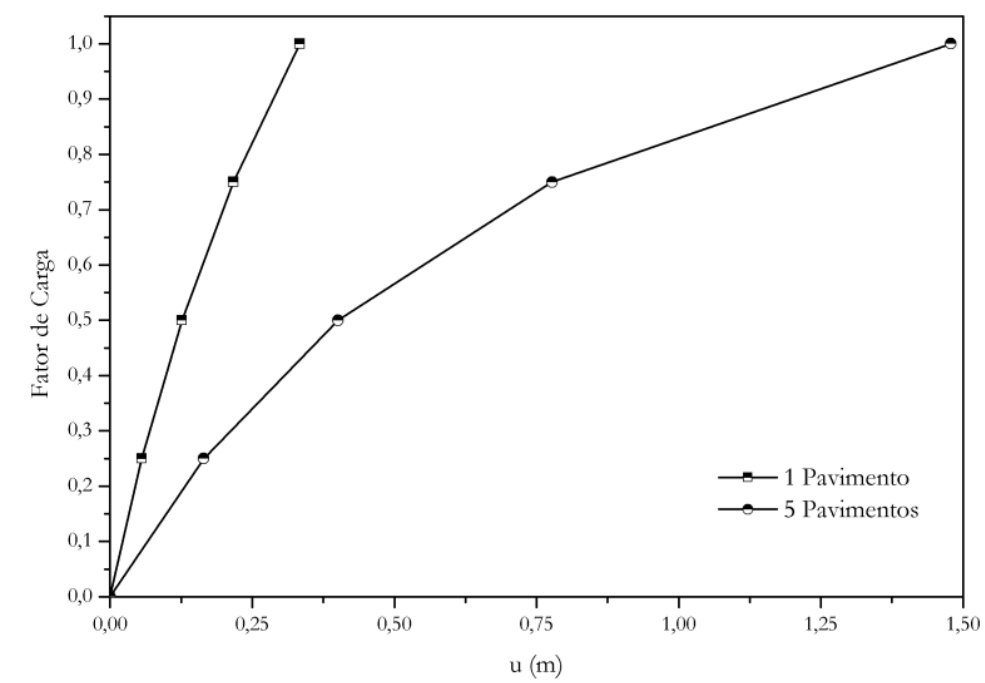

Figura 79 - Trajetórias de equilíbrio referente ao deslocamento horizontal $u$ (m) do nó superior esquerdo.

Nesses exemplos propostos, resultados em tensão não são apresentados porque já foram exaustivamente verificados e apresentados nos exemplos anteriores. 


\subsection{Considerações}

A análise dos cinco exemplos permitiu avaliar diversas características da formulação do elemento de pórtico plano laminado. Os resultados obtidos foram satisfatórios e tanto a formulação do elemento como sua implementação computacional realizada em linguagem de programação FORTRAN foram verificadas.

Dos resultados obtidos no Exemplo 5.1, verificou-se que uma malha de elementos finitos mais refinada é necessária para a obtenção de uma representação adequada das distribuições de tensões ao longo da seção transversal, particularmente as tensões de cisalhamento. Com relação aos deslocamentos, uma discretização bem menor já converge para os valores adotados como referência. Outra observação importante é que um número crescente de pontos de Gauss distribuídos ao longo da espessura das lâminas é necessário à medida que se aumenta a quantidade de lâminas utilizadas na discretização da seção.

Nos Exemplos 5.2 e 5.3, a possibilidade de aplicação de forças distribuídas e forças concentradas fora da linha de referência do elemento foi avaliada, sendo considerada consistente, uma vez que resultados satisfatórios foram obtidos para as distribuições de deslocamentos e tensões nas seções transversais. Nesses exemplos, também se verificou que o emprego, no programa Ansys ${ }^{\circledR}$, do elemento bidimensional PLANE42 apresenta problemas de mau condicionamento matricial causados pela distorção dos elementos e pela variação brusca nas propriedades elásticas do material de uma lâmina para outra. Esse fato não é observado no elemento de pórtico plano laminado, demostrando sua eficiência para analisar problemas planos (esbeltos ou não) constituídos por compósitos laminados.

A técnica de penalização empregada para realizar o acoplamento de elementos também se mostrou eficiente, conforme resultados do Exemplo 5.4. Verificou-se sua versatilidade diante da possibilidade de representar ligações com qualquer rigidez.

Por fim, resultados das distribuições de deslocamentos ao longo da seção transversal foram apresentados para dois exemplos de pórtico propostos. Dessa forma, uma contribuição é dada para reduzir a dificuldade em encontrar resultados de análises não lineares geométricas em exemplos de pórticos planos laminados, vislumbrando aplicações de trabalhos futuros. 



\section{CAPÍTULO 6}

\section{CONCLUSÃO}

As formulações de dois elementos finitos posicionais foram desenvolvidas, implementadas computacionalmente e verificadas através da análise de problemas com soluções analíticas e numéricas disponíveis na literatura ou encontradas a partir de análises numéricas realizadas no software Ansys ${ }^{\circledR}$.

O primeiro elemento desenvolvido foi o de pórtico plano homogêneo com graus de liberdade compostos por posições nodais e por vetores generalizados que representam o giro e a variação na altura da seção transversal. Problemas com características variadas de geometria, carregamento, contorno e rigidez das ligações entre barras foram analisados. Os resultados obtidos confirmaram a consistência, eficiência e robustez da formulação do elemento, pois uma excelente concordância com resultados de referência foi verificada.

Assim, o elemento é adequado para realizar análises não lineares geométricas em modelos estruturais de pórticos planos cujas configurações atuais podem apresentar grandes deslocamentos e rotações, mas com comportamento elástico linear para o material que deve exibir deformações moderadas.

Como propostas de trabalhos futuros relacionados a esse elemento, podem ser apontadas:

- inclusão da não linearidade física por meio da consideração de modelos constitutivos elastoplásticos tanto para o elemento como para as ligações;

- implementação do método de solução baseado na estratégia do comprimento de arco, cuja formulação matemática já foi desenvolvida, restando apenas sua implementação computacional e verificação através de exemplos numéricos;

- expansão da formulação para modelos tridimensionais com desenvolvimento de uma estratégia para representar seções transversais quaisquer.

Diante do bom desempenho apresentado pelo elemento de pórtico plano homogêneo, uma expansão natural de sua cinemática foi utilizada para o desenvolvimento do elemento de pórtico plano laminado.

A eficiência do elemento laminado foi comparada em relação ao elemento finito bidimensional com uma discretização equivalente e mesmo número de graus de liberdade. Foram identificados nos elementos bidimensionais, problemas de mau condicionamento matricial pro- 
vocados por distorções nos elementos e por variações elevadas e bruscas nas propriedades elásticas das lâminas. Por conta disso, um refinamento da malha foi necessário.

Esses problemas não foram verificados no elemento laminado e, portanto, reduções do custo computacional são possíveis, pois resultados satisfatórios são alcançados com considerável menor número de elementos e graus de liberdade se comparado a uma malha refinada de elementos bidimensionais.

Uma vez que não foram encontradas na literatura aplicações dos elementos laminados para análise não linear geométrica de pórticos planos, atrelando a este fato ainda a possibilidade da presente formulação de considerar o carregamento aplicado fora da linha de referência dos elementos, pode-se considerar que os desenvolvimentos aqui apresentados para o elemento de pórtico plano laminado são contribuições alcançadas no presente trabalho.

A formulação posicional proposta para o elemento permite considerar uma seção transversal composta por várias lâminas de materiais diferentes, com independência de giro e variação de espessura. Com essa cinemática, a heterogeneidade transversal e o efeito Zig-Zag presente nos laminados são representados. Além disso, é importante ressaltar que a compatibilidade de posição nas interfaces é atendida de forma intrínseca pelas funções de mapeamento posicional empregadas.

Os resultados obtidos para os exemplos considerados demostraram a capacidade do elemento em realizar análises não lineares geométricas em estruturas de pórticos planos constituídos por materiais compósitos laminados com seção transversal fina ou espessa. Distribuições de tensão axial na direção longitudinal e principalmente de tensão axial e de cisalhamento na direção transversal foram representadas com excelente precisão.

Portanto, a cinemática e o elemento propostos são considerados consistentes e eficientes, viabilizando futuras expansões para modelos estruturais de casca e modelagens do processo de falha de laminados por delaminação ou deslizamento.

Algumas propostas de trabalhos futuros para a otimização do código computacional implementado e para o desenvolvimento do elemento e da formulação posicional aplicada à solução de problemas constituídos por compósitos laminados são os seguintes:

- Modificação do código para calcular as matrizes $\mathbf{A}^{0}\left(\xi_{1}, \xi_{2}\right)$ e $\frac{\partial^{k} \mathbf{A}^{1}}{\partial y_{\alpha}^{\beta}}$ sempre que necessário e não armazená-las no início do processamento;

- Modificação do código computacional implementado no sentido de permitir um número independente de lâminas em cada elemento e uma quantidade diferente de pontos de Gauss utilizados para integração numérica de cada lâmina; 
- Emprego de técnicas baseadas em matriz esparsa para solução do sistema de equações responsável por determinar correções sobre as posições-tentativa;

- Paralelização do código;

- Consideração de ações dinâmicos, comuns nas estruturas construídas com compósitos laminados;

- Expansão da formulação para modelos tridimensionais de pórtico e casca;

- Adequação da formulação para permitir a consideração de materiais ortotrópicos;

- Inclusão da não linearidade física por meio de modelos constitutivos elastoplásticos tanto nas lâminas como nas ligações;

- Desenvolvimento da modelagem do processo de falha por delaminação ou deslizamento. 



\section{REFERÊNCIAS BIBLIOGRÁFICAS}

ACADVIEW: software para pós-processamento em elementos finitos 2D e 3D. Versão 1.0. São Carlos: Departamento de Engenharia de Estruturas, Escola de Engenharia de São Carlos, Universidade de São Paulo, 2005. Disponível em: < http://www.set.eesc.usp.br/>

ANSYS® Multiphysics, Version 12.0.1. [S.1]: ANSYS, Inc, 2009.

ABMACO - ASSOCIAÇÃO BRASILEIRA DE MATERIAIS COMPÓSITOS. Compósitos I: materiais, processos, aplicações, desempenhos e tendências.

ANDRADE, L. G.; AWRUCH, A. M.; MORSCH, I. B. Geometrically nonlinear analysis of laminate composite plates and shells using the eight-node hexahedral element with one-point integration. Composite Structures, v. 79, p. 571-580, 2007.

BARBERO, E. J.; REDDY, J. N. Modeling of delamination in composite laminates using a layerwise plate theory. International Journal Solids Structures, v. 28, p. 373-388, 1991.

BARBERO, E. J.; REDDY, J. N.; TEPLY, J. An accurate determination of stresses in thick laminates using a generalized plate theory. International Journal for Numerical Methods in Engineering, v. 29, p. 1-14, 1990.

BATTINI, J. M. Co-rotational beams elements in instability problems. 2002. Phd thesis, Royal Institute of Technology, Sweden, 2002.

BATHE, K. J. Finite element procedures. New Jersey: Prentice Hall, 1996.

BELO, I. M. Análise eficiente de compósitos laminados planos utilizando-se a formulação de elementos finitos corrigida a-priori sem os efeitos do travamento. 2006. $162 \mathrm{f}$. Dissertação (Mestrado em Engenharia Mecânica) - Departamento de Ciências Exatas e de Tecnologia, Pontifícia Universidade Católica do Paraná, Curitiba, 2006.

BISSHOPP, K. E.; DRUCKER, D. C. On the deflection of a cantilever beam. Quarterly of Applied Mathematics, v. 3, p. 272-275, 1945.

BOTELLO, S.; OÑATE, E.; CANET, J. M. A layerwise triangle for analysis of laminated composite plates and shells. Computers \& Structures, v. 70, p. 635-646, 1999.

BONET, J.; WOOD, R. D.; MAHANEY, J.; HEYWOOD, P. Finite element analysis of air supported membrane structures. Computer Methods in Applied Mechanics and Engineering, v. 190, p. 579-595, 2000.

BONET, J.; WOOD, R. D. Nonlinear continuum mechanics for finite element analysis. 2 ed. Cambridge: Cambridge University Press, 2008.

BRANCO, A. L. L. V. Análise não linear de pórticos planos, considerando os efeitos do cisalhamento no cálculo de esforços e deslocamentos. 2002. 107 f. Dissertação (Mestrado em Engenharia de Estruturas) - Departamento de Engenharia de Estruturas, Escola de Engenharia de São Carlos, Universidade de São Paulo, São Carlos, 2002. 
CARRAZEDO, R.; CODA, H. B. Estudo e desenvolvimento de código computacional para análise de impacto entre estruturas tridimensionais levando em consideração efeitos térmicos. Cadernos de Engenharia de Estruturas (USP), v. 8, p. 161-164, 2006.

CARRAZEDO, R. Estudo e desenvolvimento de código computacional para análise de impacto entre estruturas levando em consideração efeitos térmicos. 2009. $128 \mathrm{f}$. Dissertação (Mestrado em Engenharia de Estruturas) - Departamento de Engenharia de Estruturas, Escola de Engenharia de São Carlos, Universidade de São Paulo, São Carlos, 2009.

CARRAZEDO, R.; CODA, H. B. Alternative positional FEM applied to thermomechanical impact of truss structures. Finite Elements in Analysis and Design, v. 46, p. 1008-1016, 2010.

CARRERA, E. Theories and Finite Elements for Multilayered Anisotropic, Composite Plates and Shells. Archives of Computational Methods in Engineering: State of the art reviews, Barcelona, v. 9, n. 2, p. 87-140, 2002.

ĆETKOVIĆ, M.; VUKSANOVIĆ, Dj. Geometrically nonlinear analysis of laminated composite plates using a layerwise displacement model. Journal of the Serbian Society for Computational Mechanics, v. 5, p. 50-68, 2011.

CHAN, S. L.; CHUI, P. P. T. Nonlinear Static and Cyclic Analysis of Steel Frames with Semi-Rigid Connections. Elsevier, Oxford, 2000.

CHO, K. N.; BERT, C. W.; STRIZ, A. G. Bending analysis of thick bimodular laminates by higher-order individual-layer theory. Composite Structures, v. 15, p. 1-24, 1990.

CHO, K. N.; STRIZ, A. G.; BERT, C. W. Free vibrations of laminated rectangular plates analyzed by higher order individual layer theory. Journal of Sound and Vibration, v. 145, p. 429-442, 1991.

CHO, M.; PARMERTER, R. R. An efficient higher-order plate theory for laminated composites. Composite Structures, v. 20, p. 113-123, 1992.

CHOU, P. C.; PAGANO, N. J. Elasticity: Tensor, dyadic and engineering approaches. 1 ed. New York: Dover, 1992.

CHAUDHURI, R. A.; HSIA, R. L. Effect of thickness on the large elastic deformation laminated shells. Composite Structures, v. 43, p. 117-128, 1998.

CHOUDHARY, S. S.; TUNGIKAR, V. B. A simple finite element for non-linear analysis of composite plates. v. 3, p. 4897-4907, 2011.

CODA, H. B. Dinâmica não linear - MEF. São Carlos, SP, Departamento de Engenharia de Estruturas, EESC-USP: 2006. (Notas de Aula).

CODA, H. B. A solid-like FEM for geometrically non-linear 3D frames. Computer Methods in Applied Mechanics and Engineering, v. 198, p. 3712-3722, 2009.

CODA, H. B.; GRECO, M. A simple FEM formulation for large deflection 2D frame analysis based on position description. Computer Methods Applied Mechanics and Engineering, v. 193, p. 3541-3557, 2004. 
CODA, H. B.; PACCOLA, R. R. An alternative positional FEM formulation for geometrically non-linear analysis of shells: curved triangular isoparametric elements. Computational Mechanics, v. 40, p. 185-200, 2007.

CODA, H. B.; PACCOLA, R. R. A positional FEM Formulation for geometrical nonlinear analysis of shells. Latin American Journal of Solids and Structures, v. 5, p. 205-223, 2008.

CODA, H. B.; PACCOLA, R. R. Improved finite element for 3D laminate frame analysis including warping for any cross-section. Applied Mathematical Modelling, v. 34, p. 1107-1137, 2010.

CODA, H. B.; PACCOLA, R. R. A FEM procedure based on positions and unconstrained vectors applied to non-linear dynamic of 3D frames. Finite Elements in Analysis and Design, v. 47, p. 319-333, 2011.

CODA, H. B.; PACCOLA, R. R. A total-Lagrangian position-based FEM applied to physical and geometrical nonlinear dynamics of plane frames including semi-rigid connections and progressive collapse. Finite Elements in Analysis and Design, v. 91, p. 1-15, 2014.

CODA, H. B.; PACCOLA, R. R.; SAMPAIO, M. S. M.. Positional description applied to the solution of geometrically non-linear plates and shells. Finite Elements in Analysis and Design, v. 67, p. 66-75, 2013.

COOK, R. D.; MALKUS, D. S.; PLESHA, M. E.; WITT, R. J. Concepts and Applications of Finite Element Analysis. 4th ed. New York: John Wiley \& Sons, 2002.

CRISFIELD, M. A. A consistent co-rotational formulation for non-linear three-dimensional beam-elements. Computer Methods in Applied Mechanics and Engineering, v. 81, p. 131$150,1990$.

CRISFIELD, M. A. Non-linear Finite Element Analysis of Solids and Structures: essentials. New York: John Wiley \& Sons, 1991.

DANIEL, I. M.; ISHAI, O. Engineering mechanics of composite materials. 2 ed. New York: Oxford University Press, 2006.

DEMARCO, D.; DVORKIN, E. N. An Eulerian finite element formulation for modelling stationary finite strain elastic deformation processes. International Journal for Numerical Methods in Engineering, v. 62, p. 1038-1063, 2005.

DONEA, J.; HUERTA, A.; PONTHOT, J.-Ph.; FERRAN, A. R. Arbitrary Lagrangian-Eulerian Methods. In: STEIN, E.; BORST, R. de; HUGHES, T. J. R. Encyclopedia of Computational Mechanics: Fundamentals. John Wiley \& Sons, 2004. v. 1, cap. 14, p. 413-437.

EIJO, A.; OÑATE, E.; OLLER, S. Delamination in laminated plates using the 4-noded quadrilateral QLRZ plate element based on the refined zigzag theory. Composite Structures, v. 108, p. 456-471, 2014.

EPSTEIN, M.; GLOCKNER, P. G. Nonlinear analysis of multilayered shells. International Journal Solids Structures, v. 13, p. 1081-1089, 1977. 
EPSTEIN, M.; HUTTELMAIER, H. P. A finite element formulation for multilayered and thick plates. Computers \& Structures, v. 16, p. 645-650, 1983.

EPSTEIN, M.; MURRAY, D. W. Large deformation in-plane analysis of elastic beams. Computers \& Structures, v. 6, p. 1-9, 1976.

FELIPPA, C. A.; HAUGEN, B. A unified formulation of small-strain corotational finite elements: I. Theory. Computer Methods in Applied Mechanics and Engineering, v. 194, p. 2285-2335, 2005.

FELIPPA, C. A. Nonlinear Finite Element Methods. University of Colorado at Boulder, 2014. (Lectures). Disponível em: http:/ /www.colorado.edu/engineering/cas/courses.d/NFEM.d /Home.html. Acesso em: 08 Jan. de 2015.

FOUCARD, L.; ARYAL, A.; DUDDU, R.; VERNEREY, F. A coupled Eulerian-Lagrangian extended finite element formulation for simulating large deformations in hyperelastic media with moving free boundaries. Computer Methods in Applied Mechanics and Engineering, v. 283, p. 280-302, 2015.

GADALA, M. S.; ORAVAS, G. A.; DOKAINISH, M. A. A consistent Eulerian formulation of large deformation problems in statics and dynamics. International Journal Non-Linear Mechanics, v. 18, p. 21-35, 1983.

GADALA, M. S.; ORAVAS, G. A. Numerical solutions of nonlinear problems of continua - I. Computers \& Structures, v.19, p.865-877, 1984.

GADALA, M. S.; DOKAINISH, M. A.; ORAVAS, G. A. Formulation methods of geometric and material nonlinearity problems. International Journal for Numerical Methods in Engineering, v. 20, p. 887-914, 1984.

GATTASS, M.; ABEL, J. F. Equilibrium considerations of the updated Lagrangian formulation of beam-columns with natural concepts. International Journal for Numerical Methods in Engineering, v. 24, p. 2119-2141, 1987.

GAUDENZI, P. A general formulation of higher-order theories for the analysis of laminated plates. Composite Structures, v. 20, p. 103-112, 1992.

GAUDENZI, P.; BARBONI, R.; MANNINI, A. A finite element evaluation of single layer and multi-layer theories for the analysis of laminated plates. Composite Structures, v. 30, p. 427440, 1995.

GHUGAL, Y. M.; SHIMPI, R. P. A Review of Refined Shear Deformation Theories for Isotropic and Anisotropic Laminated Beams. Journal of Reinforced Plastics and Composites, v. 20, p. 255-272, 2001.

GHUGAL, Y. M.; SHIMPI, R. P. A Review of Refined Shear Deformation Theories of Isotropic and Anisotropic Laminated Plates. Journal of Reinforced Plastics and Composites, v. 21, p. 775-813, 2002. 
GRECO, M. Análise de problemas de contato/impacto em estruturas de comportamento não linear pelo Método dos Elementos Finitos. 2004. 163 f. Tese (Doutorado em Engenharia de Estruturas) - Departamento de Engenharia de Estruturas, Escola de Engenharia de São Carlos, Universidade de São Paulo, São Carlos, 2004.

GRECO, M.; GESUALDO, F. A. R.; VENTURINI, W. S.; CODA, H. B. Nonlinear positional formulation for space truss analysis. Finite Elements in Analysis and Design, v. 42, p. 10791086, 2006.

GRUTTMANN, F.; WAGNER, W.; MEYER, L.; WRIGGERS, P. A nonlinear composite shell element with continuous interlaminar shear stresses. Computational Mechanics, v. 13, p. 175188, 1993.

HE, J. F.; CHOU, M.; ZHANG, X. Bending analysis of laminated plates using a refined shear deformation theory. Composite Structures, v. 24, p. 125-138, 1993.

HE, J. F.; ZHANG, S. W. Antisymmetric bending analysis of symmetric laminated plates including transverse shear and normal effects. Composite Structures, v. 37, p. 393-417, 1997.

HE, J. F.; ZHANG, S. W. Symmetric deformation analysis of symmetric laminated plates including transverse shear and normal effects. Composite Structures, v. 45, p. 205-226, 1999.

HOLZAPFEL, G. A. Nonlinear solid mechanics: a continuum approach for engineering. Chichester: John Wiley \& Sons, 2004.

HSIAO, K. M. Nonlinear analysis of general shell structures by flat triangular shell element. Computers \& Structures, v. 25, p. 665-675, 1987.

HUGHES, T. J. R.; LIU, W. K.; ZIMMERMANN, T. K. Lagrangian-Eulerian finite element formulation for incompressible viscous flows. Computer Methods in Applied Mechanics and Engineering, v. 29, p. 329-349, 1981.

HULL, D.; CLYNE, T. W. An introduction to composite materials. 2nd ed. Cambridge: Cambridge University Press, 1996.

HUTTELMAIER, H. P.; EPSTEIN, M. A finite element formulation for multilayered and thick shells. Computers \& Structures, v. 21, p. 1181-1185, 1985.

IBRAHIMBEGOVIĆ, A. On finite element implementation of geometrically nonlinear Reissner's beam theory: three dimensional curved beam elements. Computer Methods in Applied Mechanics and Engineering, v. 122, p. 11-26, 1995.

ICARDI, U. The nonlinear response of unsymmetric multilayered plates using smeared laminate and layerwise models. Composite Structures, v. 29, p. 349-364, 1994.

ICARDI, U. Eight-noded zig-zag element for deflection and stress analysis of plates with general lay-up. Composites, v. 29B, p. 425-441, 1998.

ICARDI, U. Layerwise mixed element with sublaminates approximation and 3D zig-zag field, for analysis of local effects in laminated and sandwich composites. International Journal for Numerical Methods in Engineering, v. 70, p. 94-125, 2007. 
ISOLDI, L. A.; AWRUCH, A. M.; TEIXEIRA, P. R. de F.; MORSCH, I. B. Geometrically nonlinear static and dynamic analysis of composite laminates shells with a triangular finite element. J. of the Braz. Soc. of Mech. Sci. \& Eng., v. 30, p. 84-93, 2008.

JONES, R. M. Mechanics of composite materials. 2nd ed. New York: Taylor \& Francis, 1999.

KAM, T. Y.; SHER, H. F.; CHAO, T. N. Predictions of deflection and first-ply failure load of thin laminated composite plates via the finite element approach. International Journal Solids Structures, v. 33, p.375-398, 1996.

KAPOOR, H.; KAPANIA, R. K. Geometrically nonlinear NURBS isogeometric finite element analysis of laminated composite plates. Composite Structures, v. 94, p. 3434-3447, 2012.

KARAMA, M.; HARB, B. A.; MISTOU, S.; CAPERAA, S. Bending, buckling and free vibration of laminated composite with a transverse shear stress continuity model. Composites, v. 29B, p. 223-234, 1998.

KIM, D.; CHAUDHURI, R. A. Influence of localized imperfection on the instability of isotropic/cross-ply cylindrical shells/rings under external pressure. Composite Structures, v. 67, p. 57-70, 2005.

KISHORE, M. D. V. H.; SINGH, B. N.; PANDIT, M. K. Nonlinear static analysis of smart laminated composite plate. Aerospace Science and Technology, v. 15, p. 224-235, 2011.

KO, F. K. 3-D textile reinforcements in composite materials. Woodhead Publishing Series in Composites Science and Engineering, n. 10, p. 9-42, 1999.

KREJA, I. A literature review on computational models for laminated composite and sandwich panels. Central European Journal of Engineering, v. 1, p. 59-80, 2011.

LEE, C. Y.; LIU, D. An interlaminar stress continuity theory for laminated composite analysis. Computer \& Structures, v. 42, p. 69-78, 1992.

LEE, K. H.; LIN, W. Z.; CHOW, S. T. Bidirectional bending of laminated composite plates using an improved Zig-Zag model. Composite Structures, v. 28, p. 283-294, 1994.

LEE, K. H.; SENTHILNATHAN, N. R.; LIM, S. P.; CHOW, S. T. An improved Zig-Zag model for the bending of laminated composite plates. Composite structures, v. 15, p. 137-148, 1990.

LEVY NETO, F.; PARDINI, L. C. Compósitos estruturais: ciência e tecnologia. São Paulo: Edgard Blücher, 2006.

LIU, E. M.; CHEN, W. F. Behavior of braced and unbraced semi-rigid frames. International Journal Solids Structures, v. 24, p. 893-913, 1988.

LO, S. H.; ZHEN, W.; SZE, K. Y.; WANJI, C. An improved in-plane displacement model for the stability analysis of laminated composites with general lamination configurations. Composite Structures, v. 93, p. 1584-1594, 2011. 
MACIEL, D. N. Análise de problemas elásticos não lineares geométricos empregando o Método dos Elementos Finitos posicional. 2008. 180 f. Tese (Doutorado em Engenharia de Estruturas) - Departamento de Engenharia de Estruturas, Escola de Engenharia de São Carlos, Universidade de São Paulo, São Carlos, 2008.

MACIEL, D. N.; CODA, H. B. Dynamic Positional Finite Element Method Applied to Nonlinear Geometric 3D Solids. Mecánica Computacional, v. XXIX, p. 4377-4387, 2010.

MARTHA, L. F. Análise de estruturas: Conceitos e métodos básicos. 1 ed. Rio de Janeiro: Elsevier, 2010.

MATTIASSON, K. Numerical results from large deflection beam and frame problems analysed by means of elliptic integrals. International Journal for Numerical Methods in Engineering, v. 17, p. 145-153, 1981.

MEEK, J. L.; TAN, H. S. Geometrically nonlinear analysis of space frames by an incremental iterative technique. Computer Methods in Applied Mechanics and Engineering, v. 47, p. 261-282, 1984.

MENDONÇA, P. R. T. Materiais compostos e estruturas-sanduíche: projeto e análise. Barueri: Manole, 2005.

MOAZZAMI, M.; SANDHU, R. S. A higher order discrete theory for laminated plates. Composite Structures, v. 23, p. 205-220, 1993.

MONDKAR, D. P.; POWELL, G. H. Finite element analysis of non-linear static and dynamic response. International Journal for Numerical Methods in Engineering, v. 11, p. 499-520, 1977.

MONTEIRO, F. A. C. Uma formulação co-rotacional geral - Aplicação a pórticos espaciais. 2004. Dissertação (Mestrado em ciência na área de mecânica dos sólidos e estruturas) - Instituto Tecnológico de Aeronáutica, São José dos Campos, 2004.

MOREIRA, R. A. S.; SOUSA, R. J. A. de; VALENTE, R. A. F. A solid-shell layerwise finite element for non-linear geometric and material analysis. Composite Structures, v. 92, p. 1517$1523,2010$.

NEGISHI, Y.; HIRASHIMA, K. General higher order theory for laminated composite structures with interlayer slip. JSME International Journal, v. 40, p. 75-83, 1997.

NOOR, A. K. Mixed finite-difference scheme for analysis of simply supported thick plates. Computer \& Structures, v. 3, p. 967-982, 1973.

OGDEN, R. W. Non-linear Elastic Deformation. England: Ellis Horwood, 1984.

OWEN, D. R. J.; LI, Z. H. A refined analysis of laminated plates by finite element displacement methods - I. fundamentals and static analysis. Computers \& Structures, v. 26, p. 907-914, $1987 \mathrm{a}$

OWEN, D. R. J.; LI, Z. H. A refined analysis of laminated plates by finite element displacement methods - II. vibration and stability. Computers \& Structures, v. 26, p. 915-923, 1987 b. 
PACCOLA, R. R. Análise não linear física de placas e cascas anisotrópicas laminadas acopladas ou não com meio contínuo tridimensional viscoelástico através da combinação entre o MEC e o MEF. 2004. 190 f. Tese (Doutorado em Engenharia de Estruturas) Departamento de Engenharia de Estruturas, Escola de Engenharia de São Carlos, Universidade de São Paulo, São Carlos, 2004.

PAGANO, N. J. Exact solutions for composite laminates in cylindrical bending. Journal of Composite Materials, v. 3, p. 398-411, 1969.

PAGANO, N. J. Exact solutions for rectangular bidirectional composites and sandwich plates. Journal of Composite Materials, v. 4, p. 20-34, 1970.

PAGANO, N. J.; HATFIELD, S. J. Elastic behavior of multilayered bidirectional composites. AIAA Journal, v. 10, p. 931-933, 1972.

PARDINI, L. C. Preformas para compósitos estruturais. Polímeros: Ciência e Tecnologia, v. 10, n. 2, p. 100-109, 2000.

PARENTE JR, E. Análise não linear de estruturas. Fortaleza, CE, Departamento de Engenharia Estrutural e Construção Civil, UFC: 2012. (Notas de Aula).

PARENTE JR., E.; NOGUEIRA, G. V. ; MEIRELES, M. N. ; MOREIRA, L. S. . Material and geometric nonlinear analysis of reinforced concrete frames. Revista IBRACON de Estruturas e Materiais, v. 7, p. 879-904, 2014.

PASCON, J. P. Sobre modelos constitutivos não lineares para materiais com gradação funcional exibindo grandes deformações: implementação numérica em formulação não linear geométrica. 2012. 480 f. Tese (Doutorado em Engenharia de Estruturas) - Departamento de Engenharia de Estruturas, Escola de Engenharia de São Carlos, Universidade de São Paulo, São Carlos, 2012.

PASCON, J. P.; CODA, H. B. Large deformation analysis of elastoplastic homogeneous materials via high order tetrahedral finite elements. Finite Elements in Analysis and Design, v. 76, p. 21-38, 2013.

PETERSON A.; PETERSSON H. On finite-element analysis of geometrically nonlinear problems. Computer Methods in Applied Mechanics and Engineering, v. 51, p. 277-286, 1985.

PINHEIRO, L. SILVEIRA, R. A. M. Computational procedures for nonlinear analysis of frames with semi-rigid connections. Latin American Journal of Solids and Structures, v. 2, p. 339367, 2005.

PISKUNOV, V. G.; SIPETOV, V. S.; TUIMETOV, SH. Solution of a static problem for laminated orthotropic plates in a three-dimensional formulation. Kiev Highway Institute, translated from Prikladnaya Mekhanika, v. 26, p. 41-49, 1990.

RATH, B. K.; DAS, Y. C. Vibration of layered shells. Journal of Sound and Vibration, v. 28, p. 737-757, 1973. 
REDDY, J. N. An evaluation of equivalent-single-layer and layerwise theories of composite laminates. Composite Structures, v. 25, p. 21-35, 1993.

REDDY, J. N. Mechanics of laminated composite plates and shells: theory and analysis. 2nd ed. New York: CRC Press, 2004a.

REDDY, J. N. An Introduction to Nonlinear Finite Element Analysis. New York: Oxford University Press, 2004b.

REDDY, J. N.; PHAN, N. D. Stability and Vibration of Isotropic, Orthotropic and Laminated Plates According to a Higher order Shear Deformation Theory. Journal of Sound and Vibration, v. 98, n. 2, p. 157-170, 1985.

REDDY, Y. S. N.; MOORTHY, C. M. D.; REDDY, J. N. Non-linear progressive failure analysis of laminated composite plates. International Journal Non-Linear Mechanics, v. 30, p. 629649, 1995.

REDDY, Y. S. N.; REDDY, J. N. Linear and non-linear failure analysis of composite laminates with transverse shear. Composites Science and Technology, v. 44, p. 227-255, 1992.

REIS, M. C. J.; CODA, H. B. Physical and geometrical non-linear analysis of plane frames considering elastoplastic semi-rigid connections by the positional FEM. Latin American Journal of Solids and Structures, v. 11, p. 1163-1189, 2014.

REN, J. G. A new theory of laminated plate. Composites Science and Technology, v. 26, p. 225-239, 1986a.

REN, J. G. Bending theory of laminated plate. Composites Science and Technology, v. 27, p. 225-248, $1986 b$.

REN, J. G. Bending of simply supported, antisymmetrically laminated rectangular plate under transverse loading. Composites Science and Technology, v. 28, p. 231-243, 1987 a.

REN, J. G. Exact solutions for laminated cylindrical shells in cylindrical bending. Composites Science and Technology, v. 29, p. 169-187, 1987b.

RICHTER, T. A Fully Eulerian formulation for fluid-structure-interaction problems. Journal of Computational Physics, v. 233, p. 227-240, 2013.

SAMPAIO, M. S. M. Análise não linear geométrica de cascas laminadas reforçadas com fibras. 2014. 190 f. Tese (Doutorado em Engenharia de Estruturas) - Departamento de Engenharia de Estruturas, Escola de Engenharia de São Carlos, Universidade de São Paulo, São Carlos, 2014.

SAMPAIO, M. S. M.; PACCOLA, R. R.; CODA, H. B. A geometrically nonlinear FEM formulation for the analysis of fiber reinforced laminated plates and shells. Composite Structures, v. 119, p. 799-814, 2015. 
SANCHES, R. A. K. Sobre o acoplamento fluido-casca utilizando o Método dos Elementos Finitos. 2011. 228 f. Tese (Doutorado em Engenharia de Estruturas) Departamento de Engenharia de Estruturas, Escola de Engenharia de São Carlos, Universidade de São Paulo, São Carlos, 2011.

SANCHES, R. A. K.; CODA, H. B. On fluid-shell coupling using an arbitrary LagrangianEulerian fluid solver coupled to a positional Lagrangian shell solver. Applied Mathematical Modelling, v. 38, p. 3401-3418, 2014.

SCHMIDT, R.; LIBRESCU, L. Further results concerning the refined theory of anisotropic laminated composite plates. Journal of Engineering Mathematics, v. 28, p. 407-425, 1994.

SCHULZ, M.; FILIPPOU, F. C. Non-linear spatial Timoshenko beam element with curvature interpolation. International Journal for Numerical Methods in Engineering, v. 50, p. 761 785, 2001.

SCIUVA, M. D. Bending, vibration and buckling of simply supported thick multilayered orthotropic plates: an evaluation of a new displacement model. Journal of Sound and Vibration, v. 105, p. 425-442, 1986.

SCIUVA, M. D. Multilayered anisotropic plate models with continuous interlaminar stresses. Composite Structures, v. 22, p. 149-167, 1992.

SCIUVA, M. D.; ICARDI, U.; VILLANI, M. Failure analysis of composite laminates under large deflection. Composite Structures, v. 40, p. 239-255, 1998.

SILVA, W. Q. Sobre análise não linear geométrica de edifícios considerando o empenamento dos núcleos estruturais e a interação solo-estrutura. 2014. 186 f. Tese (Doutorado em Engenharia de Estruturas) - Departamento de Engenharia de Estruturas, Escola de Engenharia de São Carlos, Universidade de São Paulo, São Carlos, 2014.

SINGH, J.; SHUKLA, K. K. Nonlinear flexural analysis of laminated composite plates using RBF based meshless method. Composite Structures, v. 94, p. 1714-1720, 2012.

SKINNER, J. M. A critical analysis of the Aberfeldy footbridge, Scotland. In: BRIDGE ENGINEERING CONFERENCE, 2., 2009, Bath. Proceedings...,Bath: University of Bath, 2009.

SOLDATOS, K. P. A general laminated plate theory accounting for continuity of displacements and transverse shear stresses at material interfaces. Composite Structures, v. 20, p. 195-211, 1992.

SOUSA, S. R. M. de; PINA FILHO, A. C. de; DUTRA, M. S. Produção de riser em material compósito, seu desenvolvimento e testes. In: CONGRESSO BRASILEIRO DE ENGENHARIA DE FABRICAÇÃO, 4., 2007, Estância de São Pedro. Anais... Estância de São Pedro: 2007.

SPILKER, R. L. A hybrid stress finite element formulation for thick multilayer laminates.

Computer \& Structures, v. 11, p. 507-514, 1980. 
SRINIVAS, S. A refined analysis of composite laminates. Journal of Sound and Vibration, v. 30, p. 495-507, 1973.

SURANA, K. S. Geometrically non-linear formulation for bidimensional curved beam elements. Computer \& Structures, v. 17, p. 105-114, 1983.

TEÓFILO, F. A. F.; PARENTE JUNIOR, E.; HOLANDA, A. S.; MELO, A. M. C. Análise de estabilidade de placas laminadas. In: IBERIAN LATIN AMERICAN CONGRESS ON COMPUTATIONAL METHODS IN ENGINEERING, 29, 2008, Maceió. Proceedings..., Maceió: CILAMCE, p. 1-18, 2008.

TO, C. W. S; LIU, M. L. Geometrically nonlinear analysis of layerwise anisotropic shell structures by hybrid strain based lower order elements. Finite Elements in Analysis and Design, v. 37, p. 1-34, 2001.

TOLEDANO, A.; MURAKAMI, H. A high order laminated plate theory with improved in plane responses. International Journal Solids Structures, v. 23, p. 111-131, 1987.

TOUDESHKY, H. H.; HOSSEINI, S.; MOHAMMADI, B. Buckling and delamination growth analysis of composite laminates containing embedded delaminations. Applied Composite Materials, v. 17, p. 95-109, 2010.

VANALLI, L. O MEC e o MEF aplicados à análise de problemas viscoplásticos em meios anisotrópicos e compostos. 2004. 194 f. Tese (Doutorado em Engenharia de Estruturas) Departamento de Engenharia de Estruturas, Escola de Engenharia de São Carlos, Universidade de São Paulo, São Carlos, 2004.

VARADAN, T. K.; BHASKAR, K. Bending of laminated orthotropic cylindrical shells - An elasticity approach. Composite Structures, v. 17, p. 141-156, 1991.

VINSON, J. R.; SIERAKOWSKI, R. L. The behavior of structures composed of composite materials. 2nd ed. New York: Kluwer Academic Publishers, 2004.

VO, T. P.; LEE, J. Geometrically nonlinear analysis of thin-walled open-section composite beams. Computers and Structures, v. 88, p. 347-356, 2010.

WANG, T. M.; LEE, S. L.; ZIENKIEWICZ, O. C. A numerical analysis of large deflections of beams. International Journal of Mechanical Sciences, v. 3, p. 219-228, 1961.

WONG, M. B.; TIN-LOI, F. Geometrically nonlinear analysis of elastic framed structures. Computers \& Structures, v. 34, p. 633-640, 1990.

WU, C. P.; HSU, C. S. A new local high-order laminate theory. Composite Structures, v. 25, p. 439-448, 1993.

WU, C. P.; KUO, H. C. Interlaminar stresses analysis for laminated composite plates based on a local high order lamination theory. Composite Structures, v. 20, p. 237-247, 1992.

XAVIER, P. B.; CHEW, C. H.; LEE, K. H. Buckling and vibration of multilayer orthotropic composite shells using a simple higher order layerwise theory. International Journal Solids Structures, v. 32, p. 3479-3497, 1995. 
XAVIER, P. B.; LEE, K. H.; CHEW, C. H. An improved Zig-Zag model for the bending of laminated composite shells. Composite Structures, v. 26, p. 123-138, 1993.

YANG, T. Y. Matrix displacement solution to elastic problems of beams and frames. International Journal Solids Structures, v. 9, p. 829-842, 1973.

YAZDANI, S.; RIBEIRO, P.; RODRIGUES, J. D. A p-version layerwise model for large deflection of composite plates with curvilinear fibres. Composite Structures, v. 108, p. 181-190, 2014.

YSHII, Y. Formulação co-rotacional para pórticos planos. 2002. Dissertação (Mestrado em Ciência na área de infra-estrutura de transportes) - Instituto Tecnológico de Aeronáutica, São José dos Campos, 2002.

ZHU, C.; LAM, Y. C. A Rayleigh Ritz solution for local stresses in composite laminates. Composites Science and Technology, v. 58, p. 447-461, 1998.

ZINNO, R.; BARBERO, E. J. Total Lagrangian formulation for laminated composite plates analysed by three-dimensional finite elements with two-dimensional kinematic constraints. Computers \& Structures, v. 57, p. 455-466, 1995. 